\title{
UNIVERSITY OF SOUTHAMPTON
}

FACULTY OF NATURAL \& ENVIRONMENTAL SCIENCES

School of Biological Science

Trophectoderm stem cells to model the effect of altered periconceptional diet on embryos

by

Yi-Lung Chang

Thesis for the degree of Doctor of Philosophy

September 2017 



\title{
UNIVERSITY OF SOUTHAMPTON
}

\section{ABSTRACT}

FACULTY OF NATURAL \& ENVIRONMENTAL SCIENCES

School of Biological Science

Doctor of Philosophy

\section{TROPHECTODERM STEM CELLS TO MODEL THE EFFECT OF ALTERED PERICONCEPTIONAL DIET ON EMBRYOS}

\author{
Yi-Lung Chang
}

The developmental origin of adult disease hypothesis was presented by David Barker in the late 1980s. He and his colleagues found babies with low birth weight are at a higher risk of cardiovascular disease (Barker and Osmond, 1986) and type II diabetes (Hales et al., 1991) in their adult life. He hypothesized that the gestation environment would affect the offspring in the long term. Animal models also demonstrate the effect of maternal diet on the risk of hypertension, cardiovascular and metabolic disease in the offspring, and on the function of extraembryonic tissue; for example, a maternal low protein diet increased the endocytic capacity of the visceral yolk sac (VYSE) (Watkins et al., 2008). Previous studies show that changing the maternal diet during the pre-implantation period (Day 0 to 3.5 ) also has long term effects on murine offspring, such as lung and serum angiotensin-converting enzyme (ACE) activity changes (Watkins et al., 2010). During pregnancy, the placenta plays the main role of exchanging nutrients and metabolic products between the foetus and mother, and directly affects the development of the foetus.

In this study, a number of parameters changing the ability to isolate TS cell lines were first examined, and we produced recombinant protein FGF4 for TS cell culture. In order to establish an in vitro model to understand how the maternal diet altered inheritable characteristics.

TS cell lines were established from low protein (LPD) and normal protein diet (NPD) embryos. These lines were analysed for the expression of TE markers and were characterised for sex and chromosomal stability. Comparing their expression of specific markers of TE 
differentiation showed that the lines showed great variability in their differentiation pathways. However, despite this the proliferation rate and metabolism as measured by MTT conversion is significantly higher in LPD group. This finding correlated with pervious study, that LPD embryos show a greater number TE cells in the late blastocyst (Eckert et al., 2012). The cell endocytosis activity shown by uptake and conversion of the late endosome marker pHrodo was also increased in our LPD models. 


\section{Table of Contents}

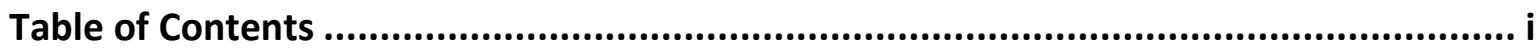

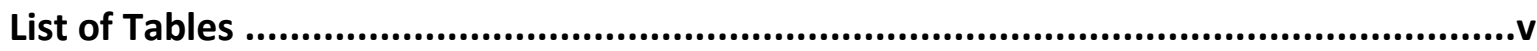

List of Figures ...................................................................................................................

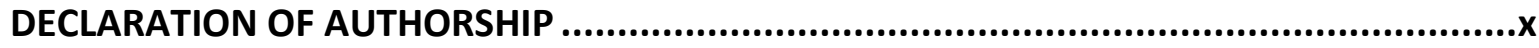

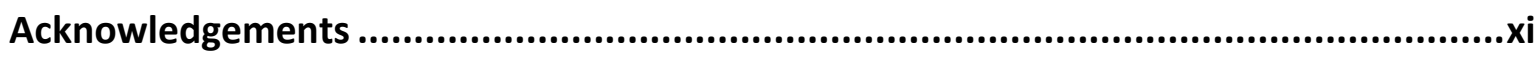

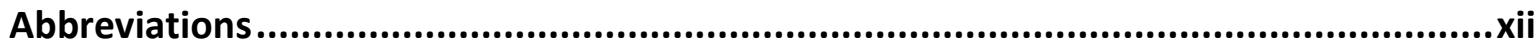

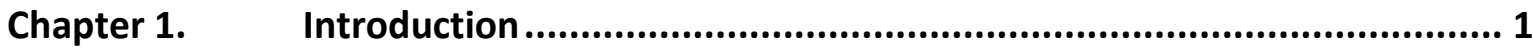

1.1 Developmental Origins of Health and Disease Hypothesis (DOHaD) .....................1

1.1.1 Evidence of DOHaD from Human populations ....................................2

1.1.2 Manipulative animal experiments modifying maternal diet...................9

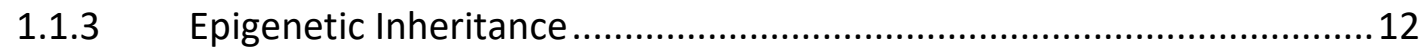

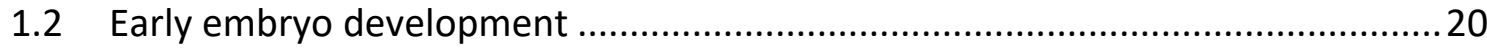

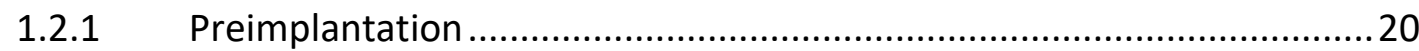

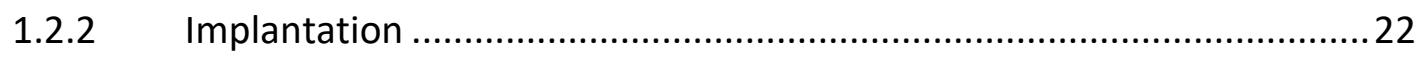

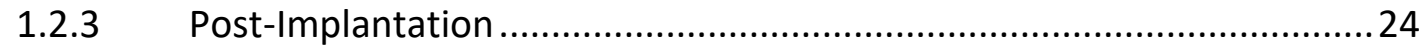

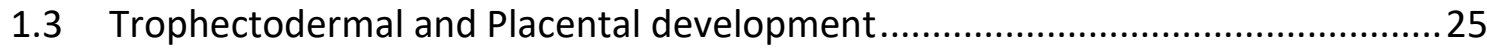

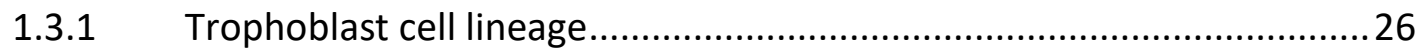

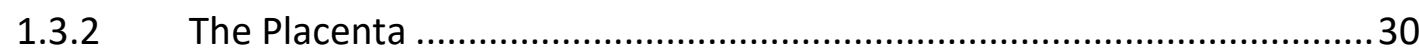

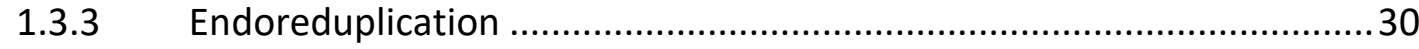

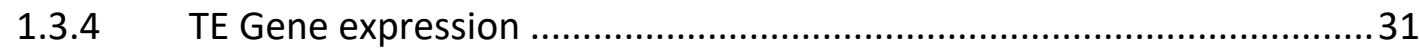

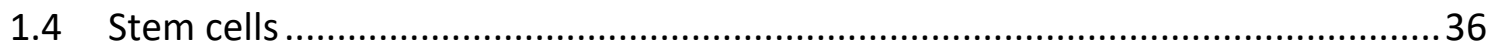

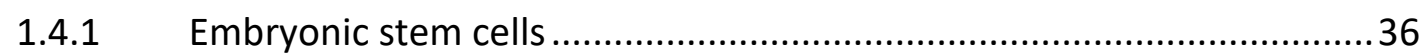

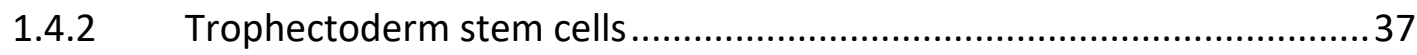

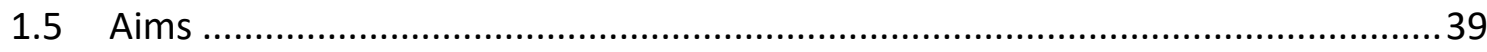

Chapter 2. General Material and Methods................................................40

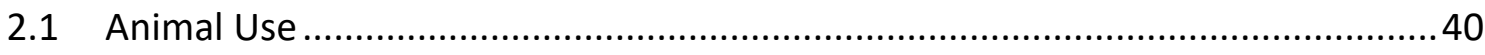

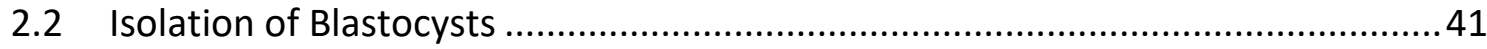

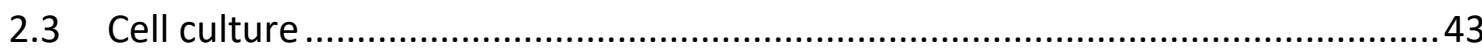


2.3.1 Production of Embryonic Fibroblasts ..................................................... 43

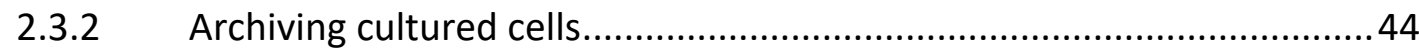

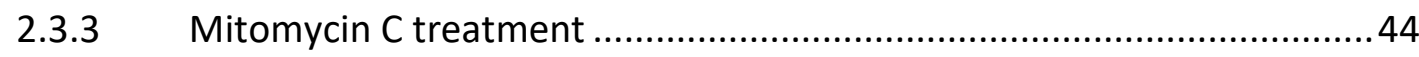

2.3.4 Cell counting and viability assays ..................................................... 45

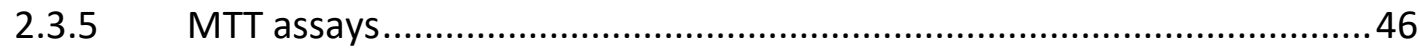

2.4 Immunofluorescent Staining of Cultured Cells............................................... 46

2.5 SDS Page electrophoresis and Immunoblotting ................................................. 47

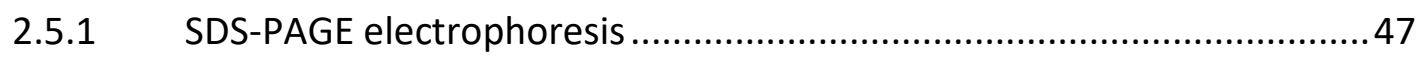

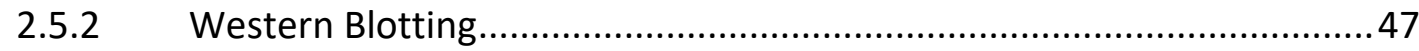

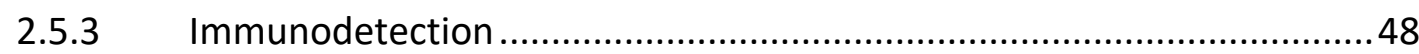

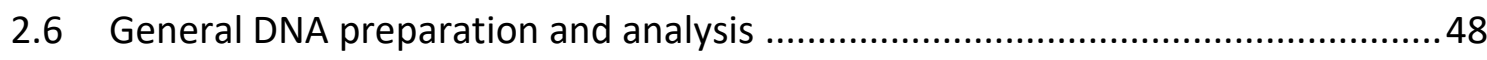

2.6.1 Genomic DNA extraction and analysis ............................................ 48

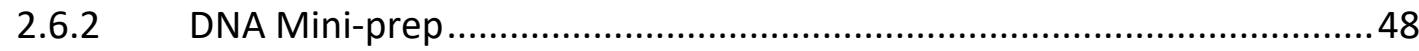

2.6.3 Vector ligation and sub cloning ....................................................... 49

2.6.4 Competent cells and vector Transformation.......................................49

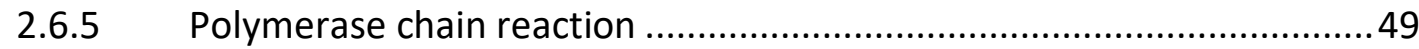

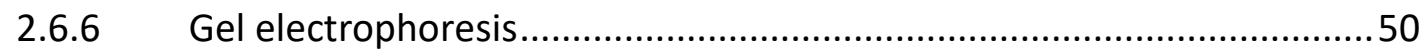

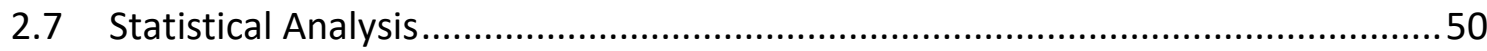

Chapter 3. Production of recombinant murine FGF4 …..................................51

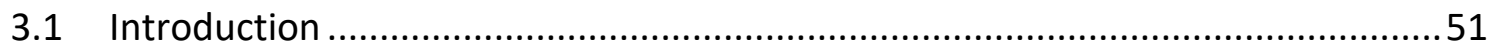

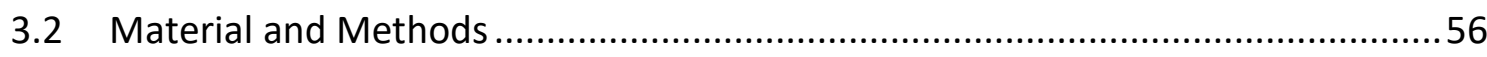

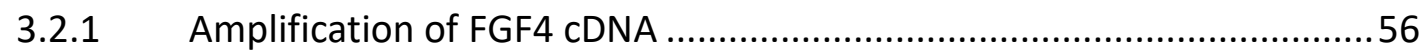

3.2.2 Ligation and cloning into sequencing and expression vectors ...............59

3.2.3 Transfection into mammalian cells ......................................................6 60

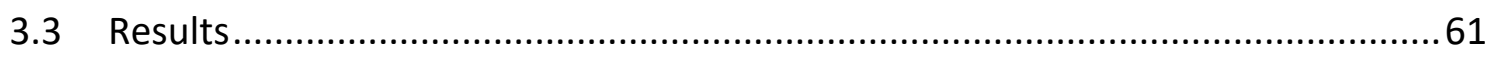

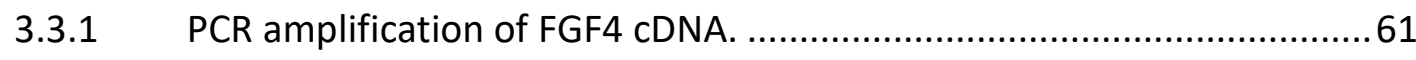

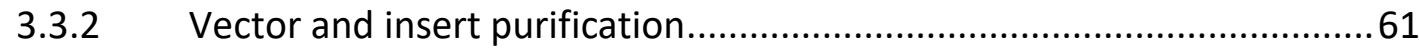

3.3.3 Transfection of HEK-293 cells and Analysis of FGF4 Expression .............63

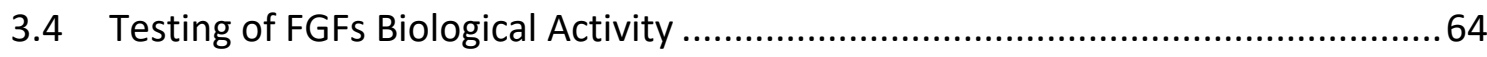

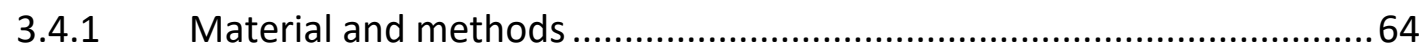

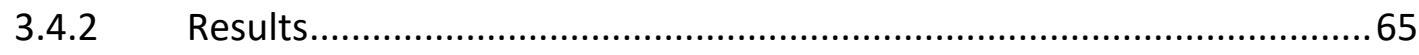


Chapter 4. Optimization of Methods to Establish TS Cell Lines ..........................71

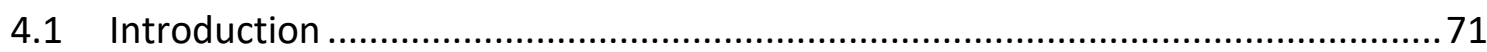

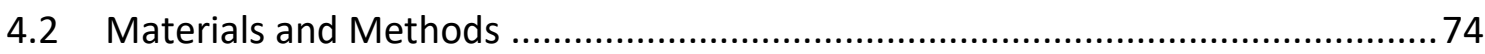

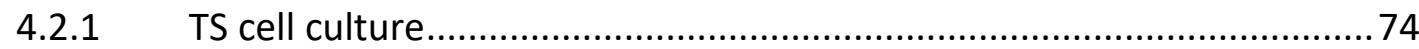

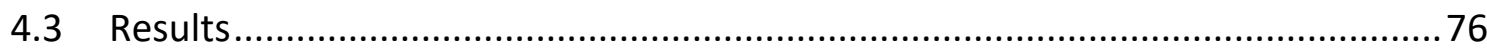

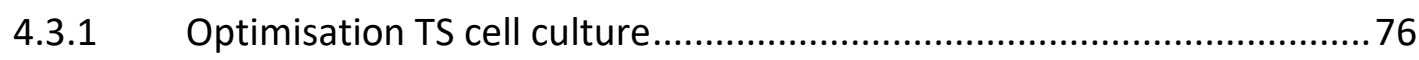

4.3.2 Isolation of TS cells from MF1 mothers.............................................. 78

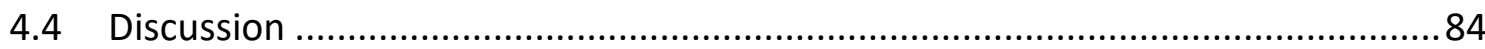

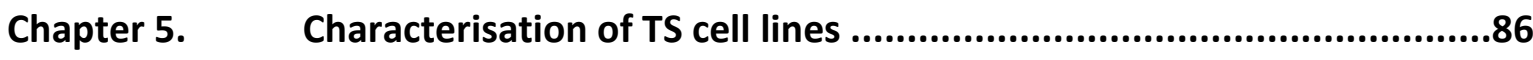

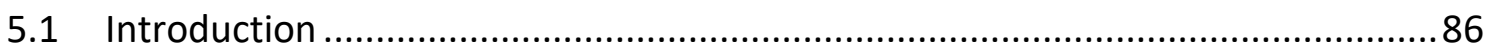

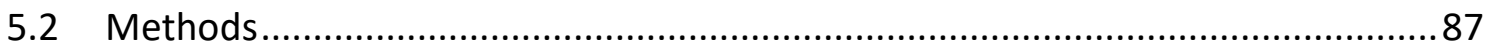

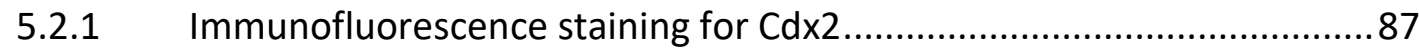

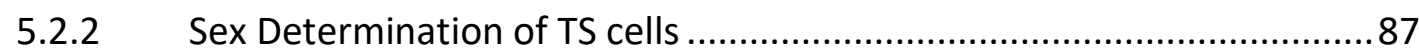

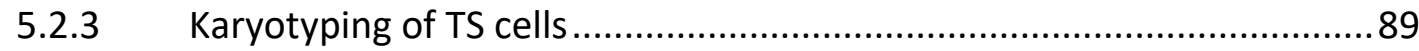

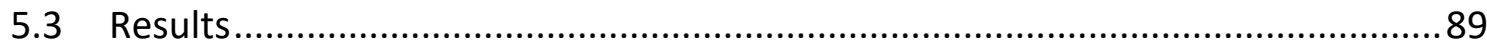

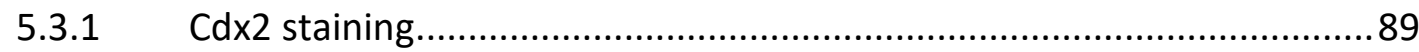

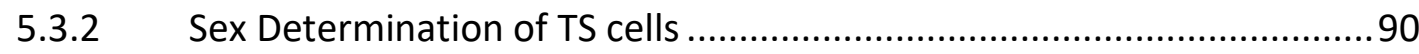

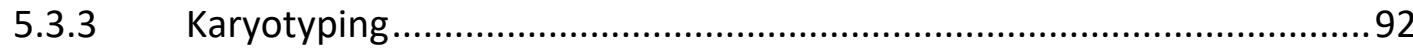

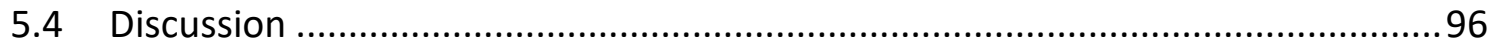

Chapter 6. Analysis of the functional characteristics of TS cell lines....................99

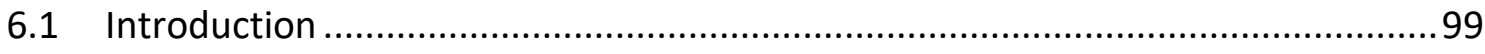

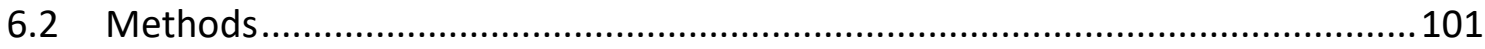

6.2.1 Reverse Transcription Quantitative PCR (RT-qPCR) analysis................101

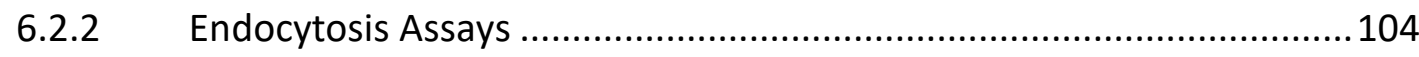

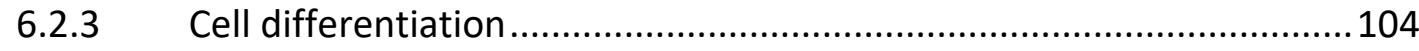

6.2.4 Trophoblast Invasion/Migration Assay..................................................105

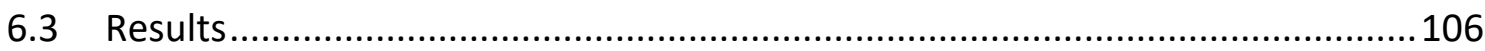

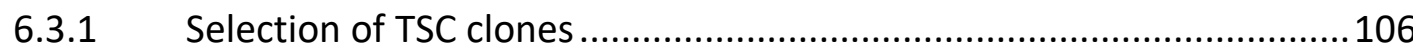




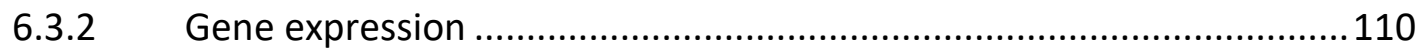

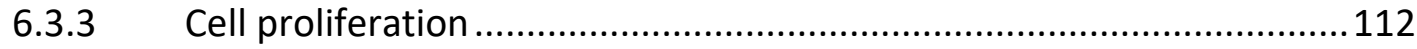

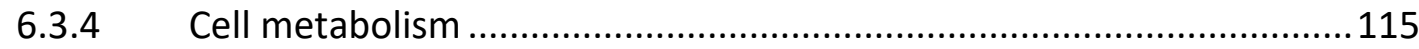

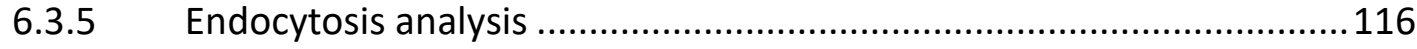

6.3.6 Cell differentiation assays...............................................................120

6.3.7 Cell proliferation during differentiation ..............................................124

6.3.8 Metabolic Activity of Differentiating Cells...........................................124

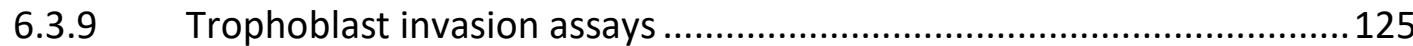

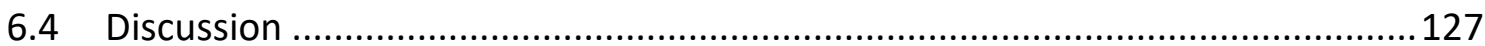

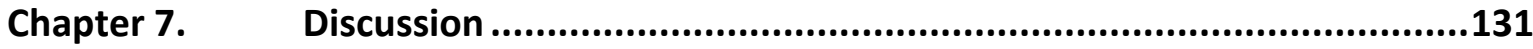

Appendix A

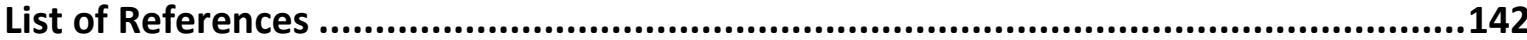




\section{List of Tables}

Table 1-1: Effects of various histone modifications on gene transcription

Table 1-2: Parental exposures and intergenerational epigenetic alterations in models of programming of adult metabolic disease.

Table 1-3: The mouse trophectoderm giant cells, location, appearance time, gene expression and suggested function

Table 1-4: Gene expression and cell marker 31

Table 2-1: Nutrient composition of diets used in these studies .40

Table 2-2: Composition of stocks used for embryo handling media in these studies .41

Table 2-3: Final Composition of KSOM media

Table 3-1: The effect of FGF4 on the formation and maintenance of early embryo stem cells.. 53

Table 3-2: Conditions to produce random primed total cDNA. .58

Table 3-3: PCR conditions to amplify FGF4 mRNA 59

Table 3-4: Conditions to digest the expression vector by the restriction enzymes Nhe1 and Not1 59

Table 3-5: cDNA Ligation conditions. 60

Table 3-6: The medium used in bio-activity test .65

Table 4-1: TS cell lines established to date .73

Table 4-2: TS cell lines establishment from different backgrounds .80

Table 4-3: TS cell lines established and frozen in liquid nitrogen, all were frozen at passage 3 or 4 .81

Table 5-1: Details of Sex specific primers. .88

Table 5-2 Sex of TSC lines .92

Table 5-4: Spread of Chromosomes in TSC lines ... .96

Table 6-1: Primers used in RT-qPCR 103 
Table 6-2: The differentiation media 105

Table 6-3: Proliferation of TS cells 112 


\section{List of Figures}

Figure 1-1: Comparison of birth weights of babies born after foetal culture in different media ..7

Figure 1-2: Modification of Cytosine to 5-methylcytosine .13

Figure 1-3: Changes in DNA methylation. .14

Figure 1-4: Development of early embryo in Mice. .20

Figure 1-5: Three cell fate models to explain TE development. .21

Figure 1-6: A diagram of the cell lineage relationships in the early mouse embryo showing the origins of the embryonic and extra-embryonic tissues. .24

Figure 1-7: Blastocyst: trophectoderm, primitive endoderm and inner cell mass..... 25

Figure 1-8: Summary of the trophoblast cell lineage and origins of different TGC subtypes. .....26

Figure 1-9: Polyploid cytotrophoblast (short arrow) and mitotic division (long arrows) in implantation site Giant cells show incomplete cell division and increase their chromosomal numbers greatly

Figure 1-10: Day 7.5 and 12.5, the components of the yolk sac and mature placenta and different subtypes of TGCs. .29

Figure 1-11: The transcription factors regulate between TE and ICM. .32

Figure 1-12: The ternary complex of FGF-FGFR-HS .35

Figure 1-13: Stem cells derived from embryos at different stages with different markers .36

Figure 2-1: The DNA sequence and chemical form of the interstrand cross-links caused by Mitomycin $C$ between guanine residues .45

Figure 3-1: Main signalling paths induced through FGF signalling .52

Figure 3-2: Linkage between the main early stem cell types and the role of FGF4 and Lif .........54

Figure 3-3: The Mus musculus FGF4 sequence from NCBI (BC104312) ...................................56

Figure 3-4: The structure of $p C E P-P u$ .57

Figure 3-5: The amplification of the FGF4 CDNA from mouse ES cells. .61 
Figure 3-6: Extracted plasmids following ligation of the FGF4 DNA fragment into the pDrive vector.

Figure 3-7: The insert cut after cloning FGF CDNA into the pDrive vector.

Figure 3-8: Analysis of the pCep-Pu vector containing FGF4-Mu, from the pDRIVE 63

Figure 3-9: HEK-293 cells were selected by puromycin 63

Figure 3-10: The Western blotting result indicated FGF4 present in lanes 1 and 3 with a band of molecular weight of approximately $20 \mathrm{kDa}$ 64

Figure 3-11: Effects on 3T3 cell numbers upon culture in FGF4 and dilutions of conditioned media (CM).

Figure 3-12: MTT conversion assay upon culture of 3T3 fibroblasts in FGF4 and dilutions of conditioned media (CM) .66

Figure 3-13: Effects on $3 T 3$ cell numbers upon culture in FGF4 and dilutions of conditioned media (CM) 67

Figure 3-14: MTT conversion assay upon culture of 3T3 fibroblasts in FGF4 and dilutions of conditioned media (CM)

Figure 3-15: Effects on 3T3 cell numbers upon culture in FGF4 and dilutions of conditioned media (CM) 68

Figure 4-1: Embryonic outgrowth on MEF cells at day 5. 74

Figure 4-2: Diagram of the steps used in the establishment of TS cell lines..... 75

Figure 4-3: Parietal Cells (P) appearing from the ICM in a differentiating embryonic outgrowth.76 Figure 4-4: MF1 TS cells 79

Figure 4-5: TS cell lines 4 days after passage; photomicrographs of TS cells after passage 3 or 4.83

Figure 5-1: Immunostaining of TS cells for Cdx2. .90

Figure 5-2: Example of PCR analysis of sex of TSC clones. 91

Figure 5-3: Chromosomal spreads of TSC lines .93

Figure 5-4:(following page) Analysis of karyotype of TS cell lines. 94

Figure 6-1: Expression of pluripotency markers in TSC clones (overleaf)........ 107 
Figure 6-2: Cdx2 expression in TS cell lines

Figure 6-3: Electrophoresis of TS cell line's total RNA -Tested to confirm RNA integrity.

Figure 6-4: RT-qPCR of Trophectodermal markers in undifferentiated TS cells

Figure 6-5: TS cell proliferation

Figure 6-6: Representative photomicrographs of proliferating TS cells

Figure 6-7: MTT assay to compare metabolism of the different diet groups 115

Figure 6-8: Time points after pHrodo was added 116

Figure 6-9: pHrodo signal over time after initial incubation of TS cells from clone LF5

Figure 6-10: TSC endocytosis

Figure 6-11: Analysis of TSC pHrodo staining

Figure 6-12: Expression of megalin in TS cells 120

Figure 6-13: TS cells cultured with various media

Figure 6-14: TS cells with FGF4 and heparin withdrawn (medium C) showing emergence of numerous large flat cells by day 3

Figure 6-15: Cdx2 and Eomes expression in differentiating TS cells (following page)..... 123

Figure 6-16: Cell numbers after culture in differentiation medium. 124

Figure 6-17: MTT conversion by differentiating TSCS 125

Figure 6-18: Matrigel invasion assay 126

Figure 6-19: Differentiating TS cell matrigel invasion assay.....

Figure 7-1: Formation of trophospheres by TSC aggregates (A) using clone LE5 and (B) section taken from Rai and Cross, 2015. 135 


\section{DECLARATION OF AUTHORSHIP}

I,Yi-Lung Chang

declare that this thesis and the work presented in it are my own and has been generated by me as the result of my own original research.

Trophectoderm stem cells to model the effect of altered periconceptional diet on embryos.

I confirm that:

1. This work was done wholly or mainly while in candidature for a research degree at this University;

2. Where any part of this thesis has previously been submitted for a degree or any other qualification at this University or any other institution, this has been clearly stated;

3. Where I have consulted the published work of others, this is always clearly attributed;

4. Where I have quoted from the work of others, the source is always given. With the exception of such quotations, this thesis is entirely my own work;

5. I have acknowledged all main sources of help;

6. Where the thesis is based on work done by myself jointly with others, I have made clear exactly what was done by others and what I have contributed myself;

7. None of this work has been published before submission

Signed:

Date: 


\section{Acknowledgements}

I would like to thank both of my supervisors, Dr. Neil Smyth and Prof. Tom Fleming. Special thanks are due to Neil, who guided and enlightened me with regards to performing academic research, which has been the most rewarding part of my PhD.

Thank you to Dr. Bhavwanti Sheth for all your advice and company over lunch time.

Thank you for Dr. David Johnston in the Biomedical Imaging Unit for helping me to set up the confocal microscope.

Thank you to the staff in the animal unit for looking after the experimental animals.

Thank you to both of my examiners, Dr. Judith Eckert and Prof. Christine Wrenzycki. Also, I would like to thank my partner Alex, for all his support.

This work is dedicated to my parents, Dr. Chang Tsang-Chuan and Dr. Huang Chun-Lan. 


\section{Abbreviations}

\begin{tabular}{|c|c|}
\hline AAR & Amino acid response pathway \\
\hline ACE & Angiotensin-converting enzyme \\
\hline ADAMs & A Disintegrin and Metalloproteinase Domain \\
\hline Aldh1a3 & Aldehyde Dehydrogenase 1 Family, Member A3 \\
\hline ART & Assisted reproductive technologies \\
\hline ATF4 & Activating transcription factor 4 \\
\hline ATP & Adenosine triphosphate \\
\hline BCOR & BCL-6 corepressor \\
\hline BMP4 & Bone morphogenetic protein 4 \\
\hline BMPs & Bone morphogenetic proteins \\
\hline bp & base pairs \\
\hline BWS & Beckwith-Wiedemann syndrome \\
\hline Cdk & Cyclin-dependent kinase \\
\hline $\mathrm{Cdx} 2$ & Caudal type homeobox 2 \\
\hline Cebpa & CCAAT/enhancer-binding protein alpha \\
\hline C-TGC & Canal-associated TGCs \\
\hline Ctsq & Cathepsin Q \\
\hline DAPI & 4',6-diamidino-2-phenylindole \\
\hline DMEM & Dulbecco's Modified Eagle Medium \\
\hline DMSO & Dimethyl sulphoxide \\
\hline DNA & Deoxyribonucleic acid \\
\hline DNMTs & DNA methyltransferase \\
\hline $\mathrm{DOHaD}$ & Developmental Origins of Health and Disease \\
\hline dpc & days post coitum \\
\hline ECM & Extracellular matrix \\
\hline EDTA & Ethylenediaminetetraacetic acid \\
\hline Elf5 & E74-like factor 5 \\
\hline Emb-LPD & Embryo low protein diet \\
\hline EMFI & Embryonic murine fibroblasts \\
\hline
\end{tabular}




\begin{tabular}{|c|c|}
\hline Eomes & Eomesodermin \\
\hline EPC & Ectoplacental cone \\
\hline Epi-SC & Epiblast stem cell \\
\hline ESCS & Embryonic stem cells \\
\hline Esrrb & Estrogen-Related Receptor Beta \\
\hline ExE & Extraembryonic endoderm \\
\hline $\mathrm{fb}-\mathrm{hCG}$ & foetal- human chorionic gonadotrophin \\
\hline FBS & Fetal bovine serum \\
\hline FCM & Fibroblast condition media \\
\hline FGF & Fibroblast growth factor \\
\hline FGF4 & Fibroblast growth factor 4 \\
\hline FGFR & Fibroblast growth factor receptors \\
\hline GA & Gestational age \\
\hline GFP & Green fluorescent protein \\
\hline hCG & human chorionic gonadotropin \\
\hline HP1 & Heterochromatin Protein 1 \\
\hline HS & Heparan sulphate \\
\hline ICM & Inner cell mass \\
\hline ICSI & Intra-cytoplasmic sperm injection \\
\hline IUGR & Intrauterine growth restriction \\
\hline IVF & In vitro fertilization \\
\hline KSOM & Potassium simplex optimization medium \\
\hline LIF & Leukemia inhibitory factor \\
\hline LIFR & Leukemia inhibitory factor receptor \\
\hline LNF-1 & Lacto-N-fucopentaose-1 \\
\hline LPD & Low protein diet \\
\hline Mash2 & Mammalian achaete scute-like homologue 2 \\
\hline MFF & Mouse embryonic fibroblast \\
\hline MMPs & Matrix metalloproteinases \\
\hline mTOR & mechanistic target of rapamycin \\
\hline mTORC1 & mammalian target of rapamycin complex 1 \\
\hline MTT & 3-(4,5-dimethylthiazol-2-yl)-2,5-diphenyltetr \\
\hline
\end{tabular}




\begin{tabular}{|c|c|}
\hline MUC-1 & Mucin1 \\
\hline NK & Natural killer \\
\hline NPD & Normal protein diet \\
\hline NSET & Non surgical embryo transfer \\
\hline Oct4 & Octamer-binding transcription factor 4 \\
\hline PAGE & Polyacrylamide gel electrophoresis \\
\hline PBS & Phosphate-buffered saline \\
\hline PBS-T & PBS-Tween 20 \\
\hline PCR & Polymerase chain reaction \\
\hline $\mathrm{PE}$ & Primitive endoderm \\
\hline PFA & Paraformaldehyde \\
\hline PL & Placental lactogen \\
\hline PLF & Proliferin \\
\hline PLP & Prolactin-like protein \\
\hline PLP & Prolactin-like proteins \\
\hline PR & Proliferin-related protein \\
\hline P-TGC & Parietal TGCs \\
\hline PVDF & Polyvinylidene fluoride \\
\hline qPCR & Quantitative PCR \\
\hline RNA & Ribonucleic acid \\
\hline RT-qPCR & Reverse transcription quantitative PCR \\
\hline S.E.M & Standard error of mean \\
\hline Sall4 & Spalt-Like Transcription Factor 4 \\
\hline SDS & Sodium dodecyl sulphate \\
\hline SGA & Small gestational age \\
\hline Socs3 & Suppressor of cytokine signalling 3 \\
\hline Sox 2 & SRY (sex determining region Y)-box 2 \\
\hline SpA-TGC & Spiral artery-associated TGC \\
\hline STAT & Signal Transducer and Activator of Transcription \\
\hline STAT3 & Signal transducer and activator of transcription 3 , \\
\hline S-TGC & Sinusoidal TGCs \\
\hline
\end{tabular}




$\begin{array}{ll}\text { TE } & \text { Trophectoderm } \\ \text { Tead4 } & \text { TEA domain family member } 4 \\ \text { TGC } & \text { Trophoblast giant cell } \\ \text { TIMPs } & \text { Tissue inhibitors of metalloproteinase } \\ \text { TIMPs } & \text { Tissue inhibitors of metalloproteinase } \\ \text { Tpbpa } & \text { Trophoblast specific protein alpha } \\ \text { TSCs } & \text { Trophoblast stem cells } \\ \text { TSSC3 } & \text { Tumour-suppressing STF cDNA 3 } \\ \text { VEGF } & \text { Vascular endothelial growth factor } \\ \text { VYSE } & \text { Visceral yolk sac endoderm } \\ \text { XEN } & \text { Extraembryonic endoderm stem } \\ \text { YAP } & \text { Yes-associated protein }\end{array}$





\section{Chapter 1. Introduction}

A suboptimal maternal environment occurring during specific developmental windows has been demonstrated to alter the subsequent development of the foetus and the health of the offspring in later postnatal life. For example, many epidemiological studies have indicated that changes during pregnancy resulting in low birth weight babies are strongly correlated with higher risk of cardiovascular and associated disease in the adult (Barker et al., 1989).

In rodents, highly controlled experimental studies have shown that the periconceptional period is a critical window of exposure that can influence growth and development, and that changing the maternal diet to ones which are isocaloric but with reduced percentages of protein only for the first three days following fertilisation, causes abnormal behaviour and high blood pressure in the offspring (Watkins et al., 2008a). This indicates that at the earliest time in gestation, the embryo is highly sensitive to external conditions: studies looking at the murine yolk sac (the early extraembryonic tissue involved in nutrient transfer to the embryo) have demonstrated that it is directly affected by the condition of the uterus, which subsequently affects the foetus (Watkins et al., 2008a). My research is focused on studying the trophectoderm stem cells whose derivatives are crucial for nutrient transfer through pregnancy as they differentiate to form the foetal placenta.

\subsection{Developmental Origins of Health and Disease Hypothesis (DOHaD)}

In early 1990s, David Baker (an epidemiologist based at the University of Southampton) published the Barker or thrifty phenotype hypothesis. This was based upon evidence which correlated a lower birth weight with a higher risk of adult cardiovascular disease, hypertension and type 2 diabetes (Barker, 1995) - together considered as metabolic syndromes. Interestingly, in his initial studies, the highest birth weight groups had the lowest death rates (Barker et al., 1989). This former association has been replicated in many other studies in Europe, the USA and India (Barker, 2004). Further studies following children through maturation indicate that low birth weight group babies gain weight rapidly during infancy, resulting in a greater risk of coronary heart disease than babies which gain weight more gradually (Eriksson et al., 2001). 


\section{Chapter 1}

The DOHaD (Barker) hypothesis suggests that the foetus has developmental "plasticity", meaning that it can sense the maternal environment and can respond by regulating its metabolism, hormones or the number of cells in key organs so as to maintain its growth and survival. These "predictive adaptive responses" have been widely reported in many species. For example, the meadow vole can predict the birth season and this results in changes in the coat thickness in offspring before birth (Gluckman et al., 2005), and nutritional changes during pregnancy can change the timing of sexual maturity in rodents (Sloboda et al., 2009). The hypothesis expands these findings to suggest that where the predicted environment fails to occur, a "mismatch" in metabolism and environment may result and that in some cases the metabolic adaption may be lifelong or have lifelong consequences. Hence it is believed that this predictive failure can cause a later increase in disease risk. So, an undernourished foetus may react in a "thrifty" way to store or more efficiently utilise nutrients in anticipation of a poor postnatal diet. However, when the environment does not produce the expected shortage, this inappropriate metabolic behaviour may increase the risk of metabolic diseases (Barker, 2004). A more detailed discussion of the evidence and possible mechanisms for this hypothesis is given below.

\subsubsection{Evidence of DOHaD from Human populations}

\section{A. Epidemiological Studies}

\section{Dutch Hunger Winter}

In 1944-45, during the Second World War, the Dutch "Hunger Winter" affected 4.5 million citizens of the Netherlands for five months. The population received on average between 400 and 800 calories a day, whereas the normal recommended intake would be $\sim 2000$ calories for a woman and $\sim 2700$ for a man. Studies on individuals born after this event indicated that when women were exposed to famine in the earlier stages of pregnancy, their offspring showed many of the changes expected of metabolic syndrome. These included greater glucose intolerance, a higher risk of an atherogenic lipid profile, and increased coronary heart disease. They also demonstrated altered blood coagulation and a greater incidence of breast cancer (Roseboom et al., 2006). All women who were exposed to the famine had smaller placental areas, but the birth weight of the baby depended on the gestational stage in which they were exposed to the famine: those exposed in the early stages had heavier than average babies, whilst those who were exposed in the middle to late stages of pregnancy had lighter babies (Roseboom et al., 2011b). This is in 
agreement with more general findings discussed in a systematic review in 2003, which showed that most published papers reported an inverse relationship between birth weight and insulin metabolism dysfunction (Newsome et al., 2003). Hence, although reduced birth weight is a marker of intrauterine deprivation, it is not itself the cause of later adult disease. Indeed, the most important finding from the Dutch Hunger Winter study was that intrauterine changes do not have to result in altered birth weight to cause an increase in later disease. Exposure to famine at later gestation resulted in babies with significantly reduced birth weights, while babies whose mothers were exposed only during early gestation had normal birth weights. However, it was only the latter which have higher rates of obesity (Roseboom et al., 2006), while those exposed to famine only in late gestation were born, and continued to be, small throughout their lives. This suggests that dysregulated or mismatched "catch-up" growth was occurring in utero and postnatally after the embryo had undergone a period of nutrient restriction and then entered an environment of normal nutrition, and that this event was predictive and possibly causative of later metabolic syndrome.

\section{Other Natural Birth Studies}

While the Dutch Hunger study has the advantage that mothers from across the social spectrum were relatively equally affected, and that the timing of the nutritional deficit could be recorded, similar findings had been observed in other work. Furthermore, more specific retrospective longitudinal studies could then be carried out using well documented populations with careful measurements made from birth. The first of these was based upon a population from Hertfordshire UK (Barker et al., 1989) and since then, further studies in South India (Stein et al., 1996), USA, (Rich-Edwards et al., 1997) and China (Fan et al., 2010) have all indicated that lower birth weight babies had higher risk of coronary heart disease. In a meta study, including these and other publications, prevalence of cardiovascular disease was $11 \%$ in people whose birthweights were less than $2.5 \mathrm{~kg}$, and only $3 \%$ with birthweights greater than $3.1 \mathrm{~kg}$.

In Sweden, a large cohort $(>15,000)$ of people have been followed for over 80 years, and many birth and growth parameters have been intensely studied. Here, while both birth weight, and birth weight for gestational age, were highly significant in being inversely related to the likelihood of death due to cardiovascular disease, the authors claimed that these could be statistically separated and suggested that it is the rate of foetal growth that underlies the association with 


\section{Chapter 1}

mortality from ischaemic heart disease (Leon et al., 1998). From the same study group, the highest blood pressures were observed in men who had not reached their full growth potential prior to birth, in that they showed a lower birth weight. However, they went on to become tall adults, and this linkage was greater than that caused by other widely recognised contributors to high blood pressure such as obesity or smoking (Leon et al., 1996).

While all these epidemiological studies give good evidence for programming during pregnancy, the work on such cohorts cannot suggest which developmental period may be most susceptible to environmental challenge. The Dutch winter famine and similar studies such as the Chinese famine of 1959-62, (Li et al., 2010, de Rooij et al., 2014) strongly link the changes to the earlier periods of gestation, albeit in extreme conditions.

Further, the above studies have shown that particular dietary challenges to the mother during pregnancy alter the postnatal phenotype of the offspring in other ways. These changes include altered immunological responses and behaviour as well as the metabolic profile. However, though they suggest that earlier pregnancy may be of especial importance due to the form of the study and length of challenge, they fail to give evidence of which developmental windows during this period are significant. Research on the periconceptional embryo has demonstrated that this point in gestation is one which is especially sensitive to environmental changes, and this work will be discussed below.

\section{B. Evidence from Assisted Reproductive Technologies}

Infertility or subfertility is seen in $16 \%$ of couples worldwide, and since the first IVF baby Louise Brown was born in 1978, assisted reproduction technology (ART) has been estimated to play a role in the birth of over 5 million people, with approximately 350,000 babies born annually ${ }^{1}$. While large collections of data have been obtained concerning the efficiency of the procedures used in producing live offspring, there is relatively little work following the long term health of

${ }^{1}$ http://www.eshre.eu/Guidelines-and-Legal/ART-fact-sheet.aspx. 
these babies as children or adults. In part, this may be because studies after ART can be difficult to fully interpret (as the term ART includes a spectrum of procedures), and also as ART is generally called for due to a failure in normal fertility, which may be may only be one symptom of a wider disease syndrome with maternal, paternal and offspring epidemiology. The reasons for infertility can include hormonal irregularities and aging, as well as genetic causes in either of the parents, or possibly immunological or genetic incompatibility between the parents - all of which can confound $\mathrm{DOHaD}$ induced changes as they may be hereditable (Guerrero-Bosagna and Skinner, 2014).

ART treatments are multiple and can involve many manipulations, including hormonal treatments to induce superovulation, in vitro culture and maturation of gametes and/or early embryos which may be for long or short periods, artificial insemination, in vitro and in vivo fertilisation, intracytoplasmic sperm injection (ICSI), and possibly mitochondrial replacement therapies. Further, embryos or gametes are often cryopreserved either by vitrification or slow freezing. Also, despite the attempts to induce best practice throughout the field, these methods vary between fertility laboratories.

Hence many of the studies from IVF cohorts give conflicting results; for instance (Wang et al., 2005) reported that infants born after IVF showed a lower birth weight, had a higher incidence of preterm births, and were small for gestational age (SGA). However, while this study was using a very large cohort, it only took partial allowance for parental effects or ART procedure. When comparing singleton babies born after IVF with their naturally produced siblings (a far smaller study but with more appropriate controls), these parameters were not statistically different (Romundstad et al., 2008).

An ongoing study in Sweden has shown an increase in the incidence of a number of congenital defects in IVF born babies; defects in the central nervous system, cardiovascular defects, kidney agenesis and limb reduction defects being approximately $50 \%$ more common in children born alter various forms of IVF. However, despite a cohort of 15,570 IVF children, there was no evidence of a difference between the different forms of gamete or embryo manipulation used (Källén et al., 2010). 


\section{Chapter 1}

Disorders associated with alterations in imprinting are increased in animals born with ART; however, due to the low incidence of such diseases in man, it is not possible to meaningfully ascertain the level of increased risk. However, in children born with either Beckwith-Wiedemann or Angelman syndromes, the proportion having imprinting defects is far higher ( $90 \%$ ) after ART when compared to those conceived naturally ( $50 \%)$, suggesting that ART might cause imprinting changes (Manipalviratn et al., 2009, Vermeiden and Bernardus, 2013).

The effect of culture per se on babies born after IVF is controversial and appears to depend upon the culture media being compared. While certain studies (Eaton et al., 2012, Vergouw et al., 2012, Lin et al., 2013) failed to find differences between different culture regimes, a number of well controlled studies have demonstrated that formulation of embryo culture media alters placental and birth weight as well as the placenta to birth weight ratio, and this may have effects in later life (Dumoulin et al., 2010, Eskild et al., 2013), Figure 1-1. These studies on singleton births compared $2 / 3$ commercial media and suggested that the in vitro culture period - typically 5-6 days - appears crucial, as changes persisted after allowance for gestational age (GA) at delivery, gender, number of transferred embryos, fertilization method (IVF or ICSI), parity, cause of infertility, and life-style factors. In follow-up studies, these authors showed that differences in foetal growth could be observed by 20 weeks of gestation, with one group (Vitrolife cultured) showing a more advanced gestational age, head circumference $(\mathrm{HC})$ and trans-cerebellar diameter, all reflecting increases in foetal growth. While there were no changes observed in the foetus at 8 weeks, evidence for other differences are present, with increased fb-hCG (foetalhuman chorionic gonadotrophin) in the serum of mothers carrying babies cultured in Vitrolife media as embryos. This is produced by the foetal placenta and is consistent with an increase in both foetal and placental growth. Interestingly, measuring serum hCG as early as 18 days of gestation also showed a similar increase (Orasanu et al., 2006). Interestingly for this thesis, the level of fb-hCG in early pregnancy appears dependent upon syncytial trophoblasts; hence it is possible that the number of trophoblast cells alters with culturing of embryos and with different culture media (see below).

This work has been extended to study changes in the gene expression profiles after culture: the mothers were randomly assigned to two culture medium groups and similar morphological quality embryos were cultured until day 6. Approximately 950 transcripts showed a significant difference in expression between the media, with 18 pathways demonstrating modifications in 
particular gene groups involved in apoptosis, metabolism, protein processing and cycle regulation being significantly overrepresented. Further these findings were in agreement with an increased cell number in the embryos cultured in one media (G5) which correlated with a higher implantation rate (Kleijkers et al., 2015).

Not only does the media type have bearing on the offspring, but also period of time in culture has been shown to be significant: longer periods in culture have been linked with increased numbers of large for gestational age and overall greater birthweight of babies born after IVF, with those cultured for $5 / 6$ days having almost twice the incidence of the former than either those cultured $2 / 3$ days or the naturally conceived population (there are also fewer small for gestational age babies in the 5/6 day culture group) (Mäkinen et al., 2013). Interestingly, work in our laboratory has shown similar effects in the mouse embryo (Anan Aljahdali and Ili Raja Khalif, unpublished).

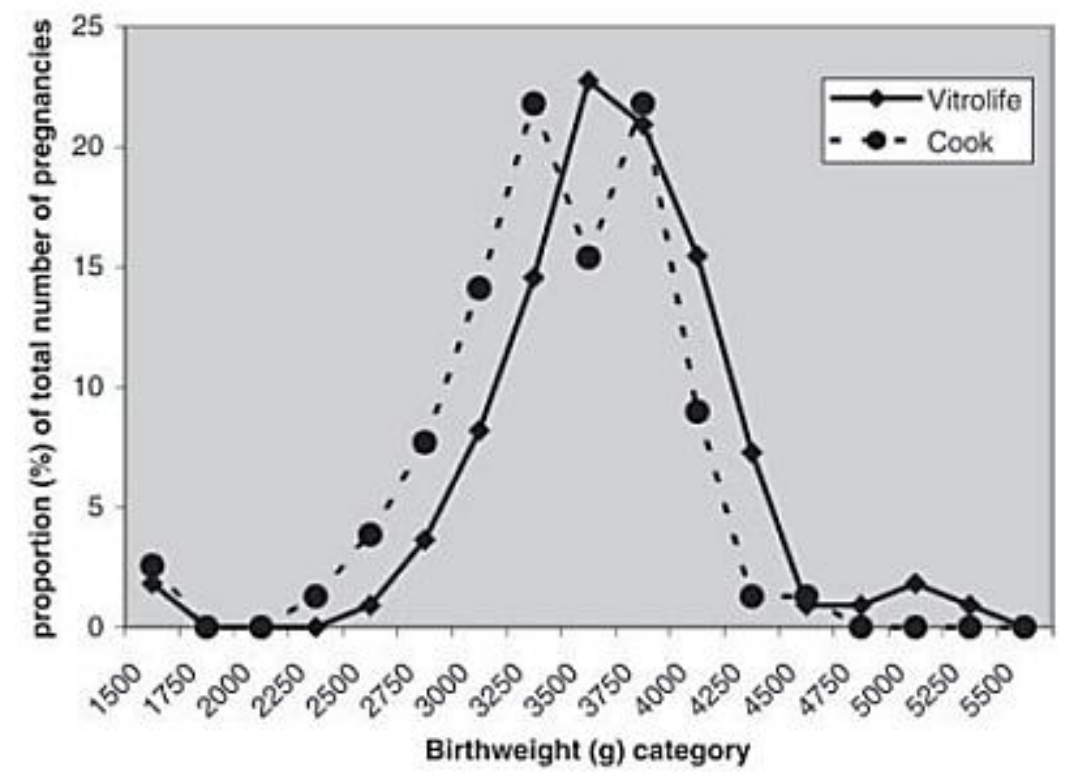

Figure 1-1: Comparison of birth weights of babies born after foetal culture in different media (Dumoulin et al., 2010).

Following individuals born after IVF into adulthood has also shown that growth changes follow on into later life; for example, older IVF children have more peripheral body fat (Ceelen et al., 2007, Belva et al., 2012). Further, IVF often produces children with accelerated early childhood weight gain, which is associated with higher blood pressure in late childhood (Ceelen et al., 2009), so that 


\section{Chapter 1}

by 12 years of age, IVF children have higher blood pressures and higher fasting serum glucose concentrations than the controls (Sakka et al., 2010, Ceelen et al., 2008b).

Animal models of ART have the advantage that the subfertility effects occurring in man usually play no part, permitting analysis without that variable. However, the requirements for fertilization and preimplantation development vary with the species. For instance, rodents carry large litters for short gestations, and the maturity of metabolic tissues and hormonal regulatory networks occurs at different times compared to humans (Rinaudo and Wang, 2012).

Many components of the culture environment influence embryo development (Schwarzer et al., 2012); different culture media altered rates of development of rodent blastocysts and foetuses, as well as changing litter sizes and gene expression. Further, ICSI-produced murine embryos have both fewer inner cell mass (ICM) and trophectoderm (TE) cells (Giritharan et al., 2012) than their naturally produced counterparts. Interestingly, this is different to classic IVF, which produces blastocysts with an increased ICM:TE cell ratio (Giritharan et al., 2007, Giritharan et al., 2012). However, following implantation, the placental tissue shows increased growth, and murine IVF placentae are 30\% larger than controls at E18.5. This change in placenta size may impact on the foetus, as IVF foetuses are slow-growing in early gestation but display catch-up growth (Bloise et al., 2012). In other species, this overgrowth caused by embryo culture has also been shown; for instance, an increase the incidence of bovine large offspring is well known to occur (Sinclair et al., 2000). In vitro culture may also affect organ growth in the mouse (Fernández-Gonzalez et al., 2004). Finally, considering postnatal and long term metabolic changes, embryo culture increases systolic blood pressure in adult mice (Watkins et al., 2007) and modifies long-term growth (Watkins et al., 2007) and glucose homeostasis into adulthood (Scott et al., 2010).

In summary, both the animal and human studies with offspring produced by IVF suggest that in vitro culture of embryos results in an increased risk of an altered growth profile, a changed metabolism and increased blood pressure in adolescence. Further, individuals exposed to adverse prenatal conditions are susceptible to cardiovascular disease and type 2 diabetes (Ekelund et al., 2006). 


\subsubsection{Manipulative animal experiments modifying maternal diet}

The above sections give evidence that altering the maternal or embryonic environment can have major effects on the developmental pathway, and can result in changes observable in the adult. To understand these findings mechanistically, a number of animal models have been produced and, in particular, offspring subjected to different maternal protein diets during pregnancy have been widely studied.

\section{Molecular effects of a low protein diet in different species}

A number of studies have subjected animals to lower nutrition throughout pregnancy; for instance, pregnant rats given a low protein diet (LPD) containing $9 \%$ casein in contrast to a normal protein diet (NPD) (18\% casein) - i.e. protein levels that do not affect the birth rate - produced offspring with low birth weight and lifelong raised systolic blood pressure (Langley and Jackson, 1994). These animals demonstrated higher expression of the glucocorticoid receptor and $11 \beta$ hydroxysteroid dehydrogenase, the enzyme which destroys both mineralo- and glucocorticoids (Bertram et al., 2001). The same rat model also shows reduced $\beta$-adrenergic and insulin signalling, with lower levels of the $\beta$-adrenergic receptor- 1 in the heart - a finding common in humans with heart failure (Fernandez-Twinn et al., 2006). Similar changes have been observed in other protein restriction models: in pigs, a low protein diet increased maternal cortisol concentration (Kanitz et al., 2012), as well as inducing long term changes in their hypothalamic-pituitary-adrenal and sympatho-adrenomedullary systems (Otten et al., 2013).

A number of studies have shown changes in the renin/ angiotensin/ aldosterone pathway, which is one of the key regulatory paths for blood pressure maintenance. Angiotensin-converting enzyme (ACE) is secreted from the lungs and kidneys, and through catalysing the conversion of angiotensin I to angiotensin II, causes a rise in blood pressure through both renal and vascular effects. This pathway has been extensively studied, and has been shown to be modified by maternal LPD. The angiotensin receptor is over-expressed in both mice (Goyal et al., 2009) and rats, and in the latter, its promotor has shown to have a reduction in $\mathrm{CpG}$ methylation (see below) (Bogdarina et al., 2007). Interestingly, the level of angiotensinogen in the serum of these animals was reduced, and this may be related to the finding that offspring of mice which were fed an LPD 


\section{Chapter 1}

during pregnancy have increased ACE activity in the lungs (Watkins et al., 2010), and have an increase in angiotensin 2 production (Gao et al., 2012a).

The testosterone-inactivating enzyme hydroxysteroid (17- $\beta$ ) dehydrogenase 2 (Hsd17b2) has been shown to be reduced in the labyrinth zone in the placenta of rats fed a maternal LPD (Gao et al., 2012b). This may result in more testosterone reaching the foetus, an excess of androgen having been implicated in both a loss in endothelial relaxation (Chinnathambi et al., 2013) and altered metabolic responses with glucose intolerance and insulin resistance (Nohara et al., 2013).

The amino acid response pathway (AAR) is activated upon reduced protein intake when an accumulation of "uncharged" tRNAs is sensed. The translation initiation factor $2 \alpha$ (elF2 $\alpha$ ) becomes phosphorylated, which leads to a general down-regulation of protein synthesis - though certain transcription factors important in driving stress-related responses are induced (for instance the activating transcription factor 4 - ATF4), so stress-related proteins are produced. Rats on a low protein maternal diet (9\% casein) upregulate the AAR pathway in the placenta (Strakovsky et al., 2010) and, interestingly, levels of ATF4 remain upregulated long term and are found increased in the liver of the adult rat (Zhou and Pan, 2011).

A low protein diet affects the function of the placenta and yolk sac in several animal models. It might be expected to induce a more effective transport system in placenta and in better amino acid retrieval in the kidney. However, very low protein diets (4\%) shows LPD downregulates the placental activity of the system A transport of amino acids (Jansson et al., 2006). This severe 4\% LPD in rats also inhibits placental insulin, mTOR and STAT3 signalling (Rosario et al., 2011).

Less severe protein reduction has different effects in different species. In cattle, switching between different protein levels during gestation (low to high or high to low) increases trophectoderm volume density (Perry et al., 1999). In mice, a reduction in length of the placental labyrinthine vessels (Rutland et al., 2007), and the downregulation of the adhesion molecules (Rutland et al., 2007), along with an altered organisation of the placental ultrastructure structure (Rebelato et al., 2013) has been observed in LPD placenta. 
Functionally, in mild LPD ( $8 \%$ protein), there is evidence that the fluid-phase endocytosis in visceral yolk sac endoderm (VYSE) is increased (Watkins et al., 2008). The major receptor for receptor-mediated endocytosis megalin (which regulates uptake of many macromolecules into cytoplasmic vesicles) is increased in its expression. This may result in a more efficient uptake of nutrients when in a starvation environment.

\section{Embryonic low protein diet (Emb-LPD)}

The suggestion is that challenges at different times during pregnancy may affect the plasticity of the offspring. Much investigation has been made of the periconceptional period, as this coincides with the initiation of epigenetic remoulding occurring with remethylation of the chromatin (see below). Hence a series of studies of both blastocysts taken from LPD mothers, and follow-up work on embryos and foetuses only receiving a LPD for days E0.5 to E3.5 have been produced (EmbLPD). Rat embryos in the early blastocyst stage have fewer cells when their mother was fed an Emb-LPD, and this was mainly caused by a reduction in the ICM rather than TE. In the mouse, the same manipulation resulted in an overall increase in the TE cell number by E3.75 (Eckert et al., 2012). Further, offspring showed an increase in systolic blood pressure in both the juvenile and adult in both species (Kwong et al., 2000). The cardiovascular change was related to changes in lung ACE activity, and these mice showed an attenuated vasodilatation to isoprenaline (Watkins et al., 2010). Emb-LPD diet also causes offspring to have abnormal anxiety-related behaviour (Watkins et al., 2008a). The maternal LPD fed to mouse dams exclusively during preimplantation enhanced postnatal growth and adiposity. This increase in postnatal growth was closely correlated to the adult adiposity, cardiovascular and behavioural changes (Watkins et al., 2008b). Further, blastocysts transferred from LPD mothers into recipients receiving a NPD also showed an elevated foetal growth showing that this dietary change induces embryonic programming during preimplantation development (Watkins et al., 2008a).

Emb-LPD depletes the amino acids leucine, isoleucine and valine in maternal serum, uterine fluid and the blastocyst (Eckert et al., 2012). Further, there are decreases in maternal insulin and increased serum and uterine levels of glucose which also control the mTOR pathway, and indeed mTORC1 signalling is altered in the LPD blastocyst. Studying the trophectoderm from these embryos also shows distinct changes; for instance, blastocysts from such dietary changes show enhanced endocytic activity in the trophectoderm in a similar way to the endoderm produced by 


\section{Chapter 1}

differentiating ES cells derived from these embryos (Sun et al., 2014). Further, Emb-LPD treatment induces significant increases in the foetal : placental ratio, through reduced placental and enhanced foetal growth respectively. Despite this, out-growths of the ectoplacental cone, removed from E8.5 Emb-LPD embryos, are more rapid (Watkins et al., 2015).

The trophectoderm is the precursor of most of the embryonic placental tissues; it is also the product of a stem cell group present in the E3.5 embryos. It is these trophectoderm stem (TS) cells which will be investigated during the course of this study.

\subsubsection{Epigenetic Inheritance}

An epigenetic change is defined as a "a stably heritable phenotype resulting from changes in a chromosome without alterations in the DNA sequence" (Berger et al., 2009).

As the phenotypic changes caused by alteration in the early embryonic environment are not genetic, such epigenetic heredity is likely to be the underlying cause of the DOHaD phenomena described earlier. There are several mechanisms causing these changes, including DNA methylation and histone modification. While RNA regulation through non-coding RNAs is often considered an epigenetic regulator (in that induced phenotypic changes may be passed at cell division), it is not caused through changes in the direct chromatin RNA and will not be considered here.

\section{Mechanisms of chromatin modification}

DNA methylation occurs mostly at CpG sites where methyl groups are added to DNA at the carbon-5 position of the cytosine ring - producing 5-methylcytosine (5mC) (Figure 1-2). It should be noted that non-CpG methylation also has been reported (Ramsahoye et al., 2000). Certain areas of the genome show greater methylation than others and these regions often demonstrate gene silencing, despite the fact that $5 \mathrm{mC}$ performs much like a regular cytosine in pairing with a guanine in double-stranded DNA. However, $5-\mathrm{mC}$ may be readily converted to thymidine by deamidation, and so appears to be often mutated in the genome - except at so-called CpG 
islands, where they remain unmethylated (see below). The exact mechanism of silencing is not understood; it may be that the methylated region is less able to directly retain the transcription machinery. However, it is known that non-methylated, $\mathrm{CpG}$-rich regions are bound by CXXC finger protein 1 (CFP1; also known as CXXC1), which recruits histone H3 lysine 4 (H3K4)

methyltransferases, and so these regions are often related to changes in the histone structure as well (see below). This plays an important role in genomic imprinting and $\mathrm{X}$-inactivation.

Mammalian genomes show CpG-under-representation (approximately $20 \%$ of that expected by a random presence), and of these, $60-80 \%$ are generally methylated. Of those that are largely resistant to DNA methylation, $10-50 \%$ of all CpGs occur in CG-dense regions: the CpG islands. These are found predominantly at transcription start sites of developmental regulator genes and housekeeping genes, which results in a second form of $\mathrm{CpG}$ presence where most genomic methylation patterns are static both across tissues and throughout life, changing only in localized contexts as specific cellular processes occur.

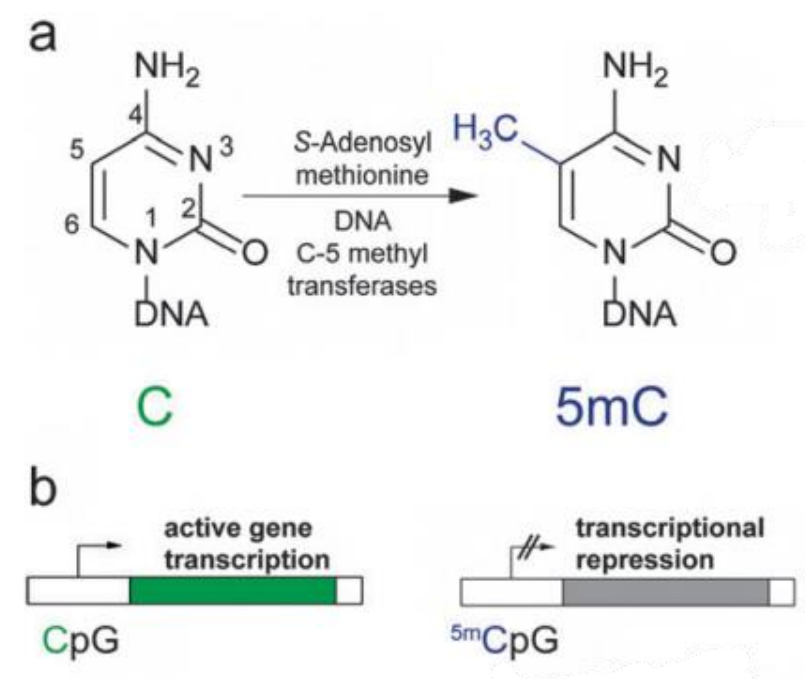

Figure 1-2: Modification of Cytosine to 5-methylcytosine Most biological studies have concentrated at changes around promotor regions, as most other CpG areas are usually methylated. However, these other non-promotor areas of the genome may also have regulatory roles. Figure from Thalhammer et al., 2011

Notable exceptions to this are in the germline, and, in the context of this work, during preimplantation development, where rapid demethylation of the paternal genome at fertilization is followed by a further depletion in both genomes prior to implantation (Figure 1-3). Though much $5 \mathrm{mC}$ marks are lost in non-imprinted genes, this is not absolute, with $5 \%$ being retained at 


\section{Chapter 1}

implantation. Also, remethylation is rapid, reaching about $50 \%$ of that seen in the mature mouse three days later (Kafri et al., 1992). The DNA methylation patterns produced can be heritable in daughter cells but are not permanent, and they may alter in response to environmental changes. Similar changes are associated with cancer, diabetes, and cardiovascular disease. Hence it might be that changes either in the loss of methylation prior to implantation, or in methylation shortly after implanting, could result in long term metabolic alteration and changed developmental and adult phenotype.

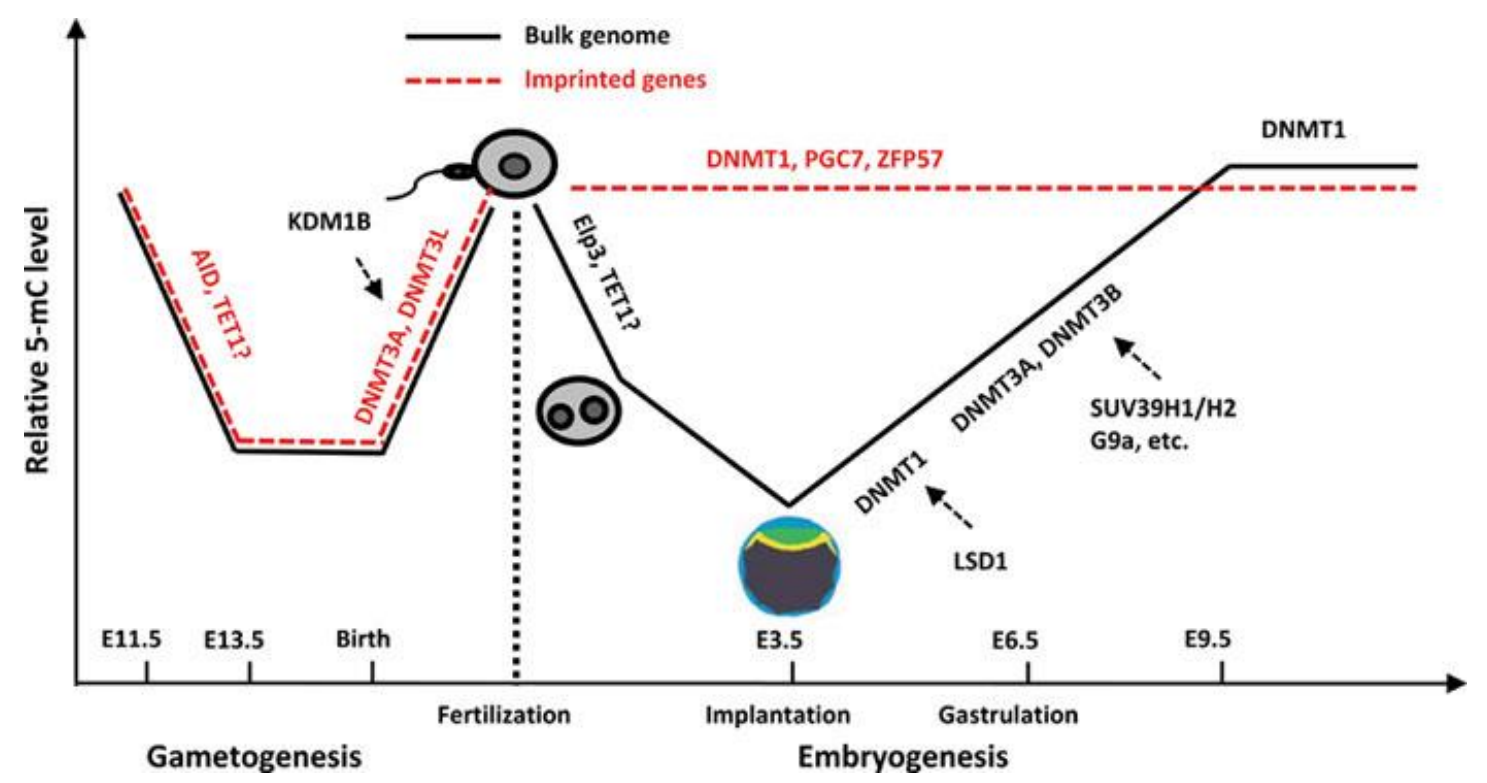

Figure 1-3: Changes in DNA methylation

Shortly following fertilization, the paternal genome is actively demethylated, while the maternal genome becomes passively demethylated during cleavage divisions. At implantation, the embryo undergoes re-methylation that establishes a new methylation pattern. Imprinted genes escape the waves of demethylation and methylation during embryogenesis. During gametogenesis, genomewide demethylation and re-methylation occurs in germ cells, which is critical for the establishment of genomic imprinting. The DNMTs involved in these processes are indicated. Figure from He et al., 2011

Histone modifications are a second group of chromatin modifications which change gene expression. The core histone proteins $\mathrm{H} 2 \mathrm{~A}, \mathrm{H} 2 \mathrm{~B}, \mathrm{H} 3$, and $\mathrm{H} 4$ assemble to form octameric nucleosome cores, with $\mathrm{H} 1$ and $\mathrm{H} 5$ acting as linker histones. The free $\mathrm{N}$-terminal ends of these proteins appear to be very open to modification, including methylation, acetylation, 
phosphorylation, and ubiquitination, ADP-ribosylation, sumoylation, ribosylation and citrullination (Chason et al., 2011). Histone methylation (which may be addition of one of more methyl groups) and acetylation of the side groups of specific and highly species conserved lysine residues are the best understood. These modifications to side chain charges are believed to change the nucleosome structure and result in altered accessibility of the DNA strands to transcription factors.

Table 1-1: Effects of various histone modifications on gene transcription

\begin{tabular}{|c|c|}
\hline Type of modification & Target gene transcription \\
\hline \multicolumn{2}{|l|}{ ACETYLATION } \\
\hline H3 K9 & Activating \\
\hline H3 K14 or K18 or K23 & Activating \\
\hline $\mathrm{H} 3$ and $\mathrm{H} 4$ & Activating \\
\hline \multicolumn{2}{|l|}{ DEACETYLATION } \\
\hline $\mathrm{H} 3 \mathrm{H} 4$ & Activating \\
\hline H3 K9 & Silencing \\
\hline \multicolumn{2}{|l|}{ METHYLATION } \\
\hline H3 K4 & Activating \\
\hline H3K36 & Activating \\
\hline H3К79 & Activating \\
\hline H3К27 & Silencing \\
\hline H4K2O & Silencing \\
\hline
\end{tabular}

In general, acetylation appears associated with "active" transcription and it is assumed that the positively charged amine side chain of the lysine binds phosphates of the DNA backbone.

Acetylation events convert the amine group into a neutral amide, thus loosening the DNA from the histone. This allows transcriptional factors to bind the DNA and allows transcription to occur. Hence changes to the histone tails have a direct effect on the DNA. (Table 1-1) modified from Chandrasekar, 2013

An alternative is that changes to the histone tails act to create a binding site for transcription factors and/or chromatin-modifying enzymes (see above). Histone methylation may also act as a docking site for other molecules; for instance, methylation of $\mathrm{K}$ (lysine) 9 of H3 is associated with transcriptionally-silent chromatin (constitutive heterochromatin), and the transcriptional repressor HP1 has been demonstrated binding to K9 methylated regions (Roh et al., 2006, Bártová et al., 2008). 


\section{Chapter 1}

\section{Evidence that epigenetic changes are induced by early embryonic environment}

The evidence that ART techniques alter the DNA methylation of specific genes in man is controversial, in part because overt disease after ART is rare. However, it is well recognised that there are increased imprinting errors after ART in animals, with large offspring syndrome occurring in ruminants due to reduced methylation at the imprinting control region KvDMR1 (Young et al., 1998, Hori et al., 2010). Children conceived by IVF/ICSI also appear to be at higher risk of certain imprinting disorders compared with those conceived spontaneously (Lazaraviciute et al., 2014) and again, the KvDMR1 gene shows hypomethylation (Gomes et al., 2009). BeckwithWiedemann syndrome (BWS), an overgrowth disorder, has almost double the incidence (Lim et al., 2009) in ART children, and reports suggest an increased incidence of changes in the methylation patterns at IGF2/H19 loci underlie this syndrome in such children (Shi et al., 2011, Chen et al., 2010b). In mice, many of the manipulations used in ART have been shown to be significant in altering imprinting including culture (Rivera et al., 2008) and hormonal superovulation (MarketVelker et al., 2010).

Significant differences in DNA methylation at non-imprinted genes have also been identified in children produced by ART (Katari et al., 2009, Nelissen et al., 2013). While the studies show variation in the degree of these changes, it appears that in general they are associated with the laboratory interventions rather than the diagnosis of infertility itself (Song et al., 2015). In vitro culture alone can cause also cause epigenetic differences, and interestingly, these are often gender related (Bermejo-Alvarez et al., 2008). In mice, IVF increases placental weight and the placental to foetal-to weight ratio, and even non-surgical embryo transfer (NSET) impacts upon development of the placenta. IVF placenta, as well as showing hypomethylation of imprinting control regions, have a general reduction in DNA methylation (Waal et al., 2015, Katari et al., 2009). Both placental tissue and cord blood demonstrated changes in a number of genes, and of particular interest was that 4 of 6 of those showing the greatest differences in both expression and $\mathrm{CpG}$ methylation were related to adipocyte formation and/or the insulin signalling pathway.

Placental tissue shows marked changes in methylation pattern, in part driven by the hormonal state of the mother, so there is a general reduced DNA methylation of the placental genome in offspring born to mothers with gestational diabetes mellitus (Ruchat et al., 2013). Interestingly, there are often more limited epigenetic changes in the embryonic tissues of the offspring. This is 
of particular clinical significance as these children appear more prone to metabolic changes (Keely et al., 2008, Aceti et al., 2012), and is suggestive that the placenta maybe a major site of epigenetic driven regulation.

A large series of experiments have shown that maternal diet drives epigenetic changes in offspring (see Table 1-2). Studies on the Dutch Hunger Winter and Chinese famine have both demonstrated epigenetic changes, with the former showing altered methylation patterns at both the IGF2/DMR and GNASAS imprinted loci (Heijmans et al., 2008, Tobi et al., 2009).

Similarly the study of Gambian children showed that the rainy/hungry and dry/harvest timing of conception had major changes on the DNA methylation status of the offspring (Dominguez-Salas et al., 2014). Here, increased methylation occurred at most of the altering metastable epialleles when conception occurred during the rainy season, when the diet was more limited both in protein and micronutrients such as folate. 


\section{Table 1-2: Parental exposures and intergenerational epigenetic alterations in models of programming of adult metabolic disease}

Modified from Fernandez-Twinn et al., 2015.

\begin{tabular}{|c|c|c|c|c|c|c|}
\hline Parental exposure & $\begin{array}{l}\text { Metabolic } \\
\text { organ/gamete }\end{array}$ & $\begin{array}{l}\text { Nature of } \\
\text { modification }\end{array}$ & $\begin{array}{l}\text { Disease } \\
\text { Association }\end{array}$ & $\begin{array}{l}\text { Physiological } \\
\text { function of gene }\end{array}$ & $\begin{array}{l}\text { Generatio } \\
\text { n affected }\end{array}$ & Reference \\
\hline $\begin{array}{l}\text { Maternal high fat } \\
\text { feeding }\end{array}$ & Liver & $\begin{array}{l}\text { Reduced histone } \\
\text { methylation }\end{array}$ & $\begin{array}{l}\text { Increased } \\
\text { lipogenesis, } \\
\text { steatosis }\end{array}$ & $\begin{array}{l}\text { LXR } \alpha \text { and ERO1- } \alpha \\
\text { gene promoters }\end{array}$ & F1, F2 & (Rakyan et al., 2002) \\
\hline $\begin{array}{l}\text { Maternal protein } \\
\text { restriction }\end{array}$ & Liver & $\begin{array}{l}\text { Hypomethylation of } \\
\text { PPAR alpha } \\
\text { promoters }\end{array}$ & $\begin{array}{l}\text { Impaired glucose } \\
\text { tolerance, } \\
\text { obesity }\end{array}$ & $\begin{array}{l}\text { Increased expression } \\
\text { of GR and PPAR } \alpha\end{array}$ & $\mathrm{F} 1$ & $\begin{array}{l}\text { (Dominguez-Salas et al., } \\
\text { 2014) }\end{array}$ \\
\hline $\begin{array}{l}\text { Global maternal calorie } \\
\text { restriction }\end{array}$ & Liver & $\begin{array}{l}\text { Hypermethylation of } \\
\text { GR and PPAR alpha }\end{array}$ & $\begin{array}{l}\text { Impaired glucose } \\
\text { tolerance,obesity }\end{array}$ & $\begin{array}{l}\text { Altered expression of } \\
\text { GR and PPAR } \alpha\end{array}$ & $\mathrm{F} 1$ & $\begin{array}{l}\text { (Aagaard-Tillery et al., } \\
\text { 2008) }\end{array}$ \\
\hline Uterine artery ligation & $\begin{array}{l}\text { Pancreatic } \\
\text { islets }\end{array}$ & $\begin{array}{l}\text { Deacetylation of } \\
\text { histones } \mathrm{H} 3 \text { and } \mathrm{H} 4 \\
\text { in PDX1 promoter }\end{array}$ & Type-2 diabetes & $\begin{array}{l}\text { Reduced PDX1 } \\
\text { expression }\end{array}$ & $\mathrm{F} 1$ & (Li et al., 2012) \\
\hline $\begin{array}{l}\text { Maternal protein } \\
\text { restriction }\end{array}$ & $\begin{array}{l}\text { Pancreatic } \\
\text { islets }\end{array}$ & $\begin{array}{l}\text { Excess of repressive } \\
\text { H3K9me } 2 \text {; loss of } \\
\text { active H3K4me1 }\end{array}$ & Type-2 diabetes & $\begin{array}{l}\text { Reduced interaction } \\
\text { with P2-enhancer of } \\
\text { HNF4a and its } \\
\text { expression }\end{array}$ & $\mathrm{F} 1$ & (Lillycrop et al., 2008) \\
\hline Gestational diabetes & $\begin{array}{l}\text { Pancreatic } \\
\text { islets }\end{array}$ & $\begin{array}{l}\text { Abnormal } \\
\text { methylation at DMR }\end{array}$ & $\begin{array}{l}\text { Impaired glucose } \\
\text { tolerance }\end{array}$ & $\begin{array}{l}\text { Downregulation of } \\
\text { Igf } 2 \text { and } \mathrm{H} 19\end{array}$ & $\mathrm{~F} 1, \mathrm{~F} 2$ & $\begin{array}{l}\text { (Lillycrop and Burdge, } \\
\text { 2015) }\end{array}$ \\
\hline $50 \%$ calorie restriction & Muscle & $\begin{array}{l}\text { H3K14 de- } \\
\text { acetylation }\end{array}$ & Insulin resistance & Diminished GLUT4 & F1 & (Park et al., 2008) \\
\hline
\end{tabular}




\begin{tabular}{|c|c|c|c|c|c|c|}
\hline Undernourished dams & Liver, sperm & $\begin{array}{l}\text { Hypomethylated } \\
\text { DMRs }\end{array}$ & Metabolic defects & $\begin{array}{l}\text { Increased expression } \\
\text { of genes involved in } \\
\text { lipid oxidation, i.e. } \\
\text { PPAR, Pgc1, and } \\
\text { Pgc1, and a trend } \\
\text { toward down- } \\
\text { regulation of genes } \\
\text { involved in lipid } \\
\text { synthesis, including } \\
\text { Scd1, Srebp1, and } \\
\text { Dgat1 }\end{array}$ & $\mathrm{F} 1, \mathrm{~F} 2$ & (Sandovici et al., 2011) \\
\hline $\begin{array}{l}\text { Maternal protein } \\
\text { restriction }\end{array}$ & Adipose tissue & $\begin{array}{l}\text { Overexpression of } \\
\text { miR483-3p }\end{array}$ & $\begin{array}{l}\text { Impaired glucose } \\
\text { tolerance }\end{array}$ & $\begin{array}{l}\text { Reduced levels of } \\
\text { target protein GDF3 }\end{array}$ & $\mathrm{F} 1$ & $\begin{array}{l}\text { (Raychaudhuri et al., } \\
\text { 2008) }\end{array}$ \\
\hline Maternal obesity & Adipose tissue & $\begin{array}{l}\text { Overexpression of } \\
\text { mir-126-3p }\end{array}$ & $\begin{array}{l}\text { Impaired glucose } \\
\text { tolerance, obesity }\end{array}$ & $\begin{array}{l}\text { Reduced levels of } \\
\text { target protein IRS1 }\end{array}$ & $\mathrm{F} 1$ & (Radford et al., 2014) \\
\hline Twin pregnancies & $\begin{array}{l}\text { Skeletal } \\
\text { muscle }\end{array}$ & $\begin{array}{l}\text { Increased miR-15b, } \\
\text { miR-16 in the } \\
\text { diabetic twin }\end{array}$ & Diabetes & $\begin{array}{l}\text { Reduced levels of } \\
\text { target proteins InsR } \\
\text { and IRS1 }\end{array}$ & $\mathrm{F} 1$ & (Park et al., 2009) \\
\hline Maternal obesity & $\begin{array}{l}\text { Skeletal } \\
\text { muscle }\end{array}$ & $\begin{array}{l}\text { Reduced expression } \\
\text { of let- } 7 g\end{array}$ & Obesity & $\begin{array}{l}\text { Reduced } \\
\text { mesenchymal stem } \\
\text { cell to myoblast } \\
\text { commitment }\end{array}$ & $\mathrm{F} 1$ & $\begin{array}{l}\text { (Fernandez-Twinn et al., } \\
\text { 2014) }\end{array}$ \\
\hline Maternal obesity & Heart & $\begin{array}{l}\text { Overexpression of } \\
\text { miR-133 }\end{array}$ & $\begin{array}{l}\text { Cardiac } \\
\text { hypertrophy }\end{array}$ & $\begin{array}{l}\text { Impaired cardiac } \\
\text { function }\end{array}$ & $\mathrm{F} 1$ & $\begin{array}{l}\text { (Yan et al., 2013, Chen } \\
\text { et al., 2010c) }\end{array}$ \\
\hline $\begin{array}{l}\text { Maternal protein } \\
\text { restriction }\end{array}$ & Embryo bodies & $\begin{array}{l}\text { Reduced } \mathrm{H} 3 \text { and } \mathrm{H} 4 \\
\text { acetylation }\end{array}$ & & $\begin{array}{l}\text { Reduced Gata6 } \\
\text { transcription factor }\end{array}$ & $\mathrm{F} 1$ & (Sun et al., 2015) \\
\hline
\end{tabular}




\subsection{Early embryo development}

As the model we intend to use is studying the changes in TE stem cells isolated from embryos from a mother receiving a periconceptional low protein diet, I will describe the early events in embryonic development and the regulation of trophectoderm formation.

\subsubsection{Preimplantation}

\section{Early embryonic differentiation}

Upon fertilization, the egg becomes a diploid zygote. During an early series of mitotic divisions - a process called "cleavage" - it does not increase in volume; rather the number of cells present is amplified. After three cleavage cycles, the fertilized mouse embryo has reached the 8-blastomere stage. At this stage, compaction occurs; the cells become bound tightly to each other, and the embryo enters the morula stage, with the cell becoming polarized in regard to their distribution of membrane components. The cell adhesion molecule E-cadherin is essential for compaction, and polarized E-cadherin negative embryos fail to differentiate further (Larue et al., 1994). As the morula forms, the embryo starts to travel by ciliary action of the oviduct epithelium and peristaltic contractions to the uterus (Ross et al., 1995), Figure 1-4. The cells of the embryo now proceed to differentiate into two populations: intraembryonic and extraembryonic lineages.

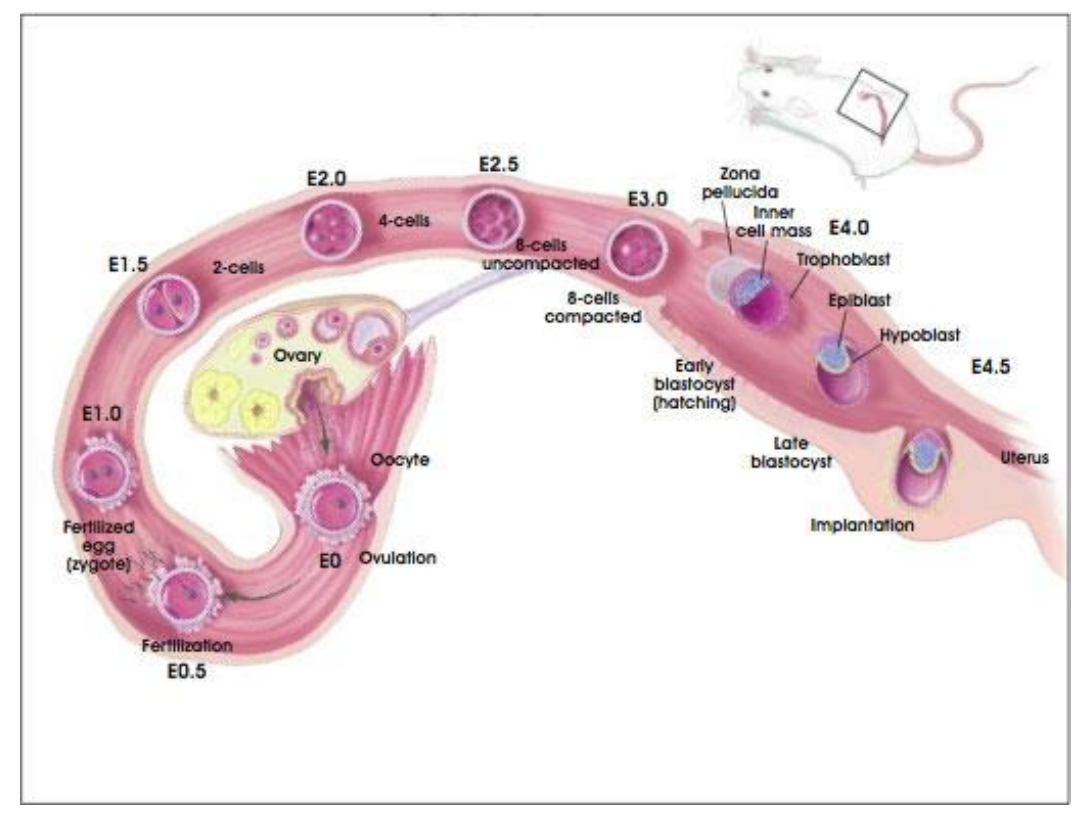

Figure 1-4: Development of early embryo in Mice

From Embryonic Day 0 (EO) Through Day 5 (E5.0)(Winslow, 2001)

The outer extraembryonic cells will differentiate into the trophectoderm, while interior cells become the inner cell mass (ICM) of the blastocyst (Zernicka-Goetz, 2005). In the late morula 
stage, tight junctions begin to form between the cells, and the outer cells of the morula pump fluid from outside into the embryo (Watson, 2004). This is achieved as the Na/K-ATPase becomes polarised to the inner surfaces, which sets up an ion gradient and causes fluid movement into the centre of the morula by aquaporin or water channels (Barcroft et al., 2003, Watson et al., 2004). The accumulation of water causes the formation of a cavity - the blastocoel. The tight junctions between the outer cells allow the developing blastocoel to retain fluid. This "blastocyst" is also the developmental stage that penetrates the uterine epithelium at implantation.

\section{ICM/TE Development and Cell Fate Models}
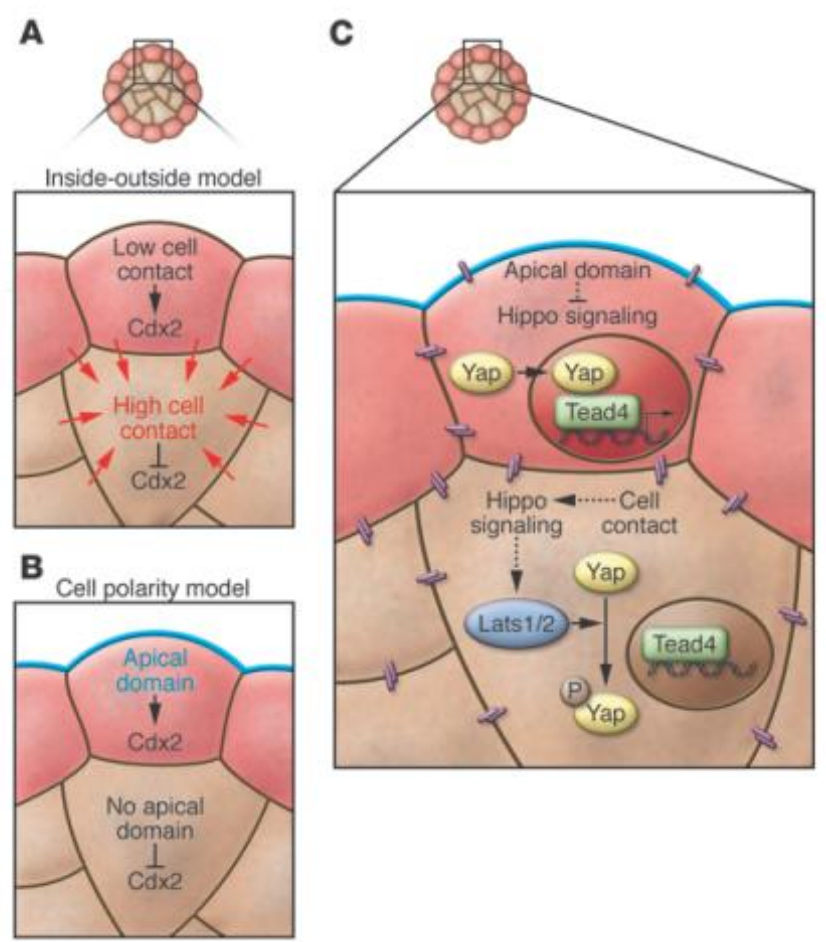

Figure 1-5: Three cell fate models to explain TE development

(A) The 'Inside-outside' model, in which cell fate depends on cell contact. (B) The Cell polarity model, in which cell polarity translates to TE fate. (C) The Complex model, in which cell polarity and contact both regulate cell fate (Cockburn and Rossant, 2010).

The differentiation of the ICM and TE cells is the first lineage specification occurring during development and, as such, has been the focus for much research. Several models have been presented that discuss cell fate with TE specification (see

Figure 1-5). In the 'Inside-outside' model (Figure 1-4A), the cell fate depends on cell location driving the differentiation path, depending on the extent of cell contact in the late morula (Cockburn and Rossant, 2010). Position may determine cell fate in various ways: inside cells make 


\section{Chapter 1}

symmetrical contact with other cells, while outside cells have an asymmetrical cell contact. These different types of contact can drive cell differentiation in different pathways during the 8 and 16cell stage.

In the alternative 'cell polarity' model (Figure 1-5B), blastomere polarization is responsible for cell fate (Johnson and Ziomek, 1981). Subcellular components, including surface microvilli, cytoskeletal elements, endosomes, and microtubule organizing centres, are changed by polarization (Johnson and Ziomek, 1981). Cells then segregate asymmetrically, deciding cell position and fate.

Recent research suggests the two models may interact and affect cell fate together (

Figure 1-5C). The trophectoderm marker $C d x 2$ is expressed in the $T E$, and is also required for TE development (Strumpf et al., 2005). It is believed that in the outer cells, the apical signal inhibits the hippo signalling pathway, which causes an increase in the expression of the transcription factor Tead4 and co-activator protein Yap, which is located in the nucleus. Together, these upregulate the $C d x 2$ expression in these cells (Nishioka et al., 2009).

\subsubsection{Implantation}

The zona pellucida is a glycoprotein membrane surrounding the blastocyst. Prior to the implantation of the embryo, the blastocyst must hatch from the zona pellucida so as to make the attachment to the recipient maternal endometrium possible. The zona pellucida is also believed to prevent implantation happening in the oviduct (Modlinski, 1970). While proteolytic factors from the uterine cavity play a role in this hatching, blastocysts in vitro also show efficient hatching (McLaren, 1970), suggesting that maternal and embryonic enzymes play a role in hatching in vivo.

Implantation can only occur at certain times during the reproductive cycle - the so-called "implantation window". In humans, it occurs between 6 to 10 days after ovulation (Wilcox et al., 1999) and in mice at day 4.5. When implantation starts, the first connection between the blastocyst and the endometrium is called the apposition. This is mediated by transmembrane cellcell receptor proteins such as selectins, galectins, and cadherins (Bazer et al., 2009). Cadherins anchor the blastocyst into the endometrium. In initial apposition, the uterine luminal epithelium 
is required to lose some inhibitory factors, such as the lacto-N-fucopentaose-1 (LNF-1) and Mucin1 (MUC-1) to allow attachment to continue. These strongly inhibit the cell-to-cell and cellto-extracellular matrix (ECM) adhesion: genetic experiments with mice in vivo revealed that a high level of expression of MUC-1 can block embryo attachment (DeSouza et al., 1999), while LNF-1 has been shown to inhibit blastocyst attachment to the epithelium in vitro (Lindenberg et al., 1988).

The second stage of implantation is adhesion, which is induced by the heparan sulphate (HS) proteoglycans present on the uterine epithelium surface. They promote attachment between the apical uterine epithelium and the trophectoderm (Carson et al., 2000). After this initial weak interaction, the trophoblast cells penetrate the epithelium and come into contact with the underlying ECM; $\alpha v \beta 3$ integrin is highly expressed by the embryo during implantation, and binds to many of the matrix components. This is a highly avid interaction so that the trophoblast adheres to the uterine tissue more stably as it invades the deeper uterine tissues. The importance of this interaction can be shown by experiments using $\alpha v \beta 3$ blocking antibodies, which inhibit invasion into the uterine wall and reduce the number of implantation sites in both mice and rabbits (Illera et al., 2000, Illera et al., 2003).

Invasion of the uterine wall is aided by expression of matrix metalloproteinases (MMPs). These zinc-dependent endopeptidases are capable of degrading the extracellular matrix, and in particular collagen fibrils. MMPs and their inhibitors - tissue inhibitors of metalloproteinase (TIMPs) are highly regulated by several cytokines secreted by trophoblast cells and decidua stromal cells (Huang, 1998). In vitro studies shows the MMP9 collagenase is required, metalloproteinase MMP9 inhibition completely inhibiting invasion (Librach et al., 1991).

The blastocysts now having crossed the endometrial epithelium begin to differentiate further, with the trophectoderm producing various cell types with specific functions. In particular, syncytiotrophoblast and cytotrophoblast cells appear early after invasion. Syncytiotrophoblasts secrete enzymes, including MMP and ADAMs, into the endometrium and cause endometrial epithelial cell apoptosis - possibly due to destruction of the ECM, which induces anoikis. 


\subsubsection{Post-Implantation}

At E4.5, the mouse embryo is made up of three cell types: primitive endoderm, primitive ectoderm (epiblast) and trophectoderm (Figure 1-6), the primitive endoderm and primitive ectoderm together forming the inner cell mass. In further development, the primitive endoderm differentiates to become the extraembryonic endodermal layers and also gives rise to the primordial germ cells. The primitive ectoderm forms the foetus itself and the extraembryonic mesoderm, while the trophectoderm makes up all the trophoblast tissues within the placenta (Cockburn and Rossant, 2010, Quinn et al., 2006).

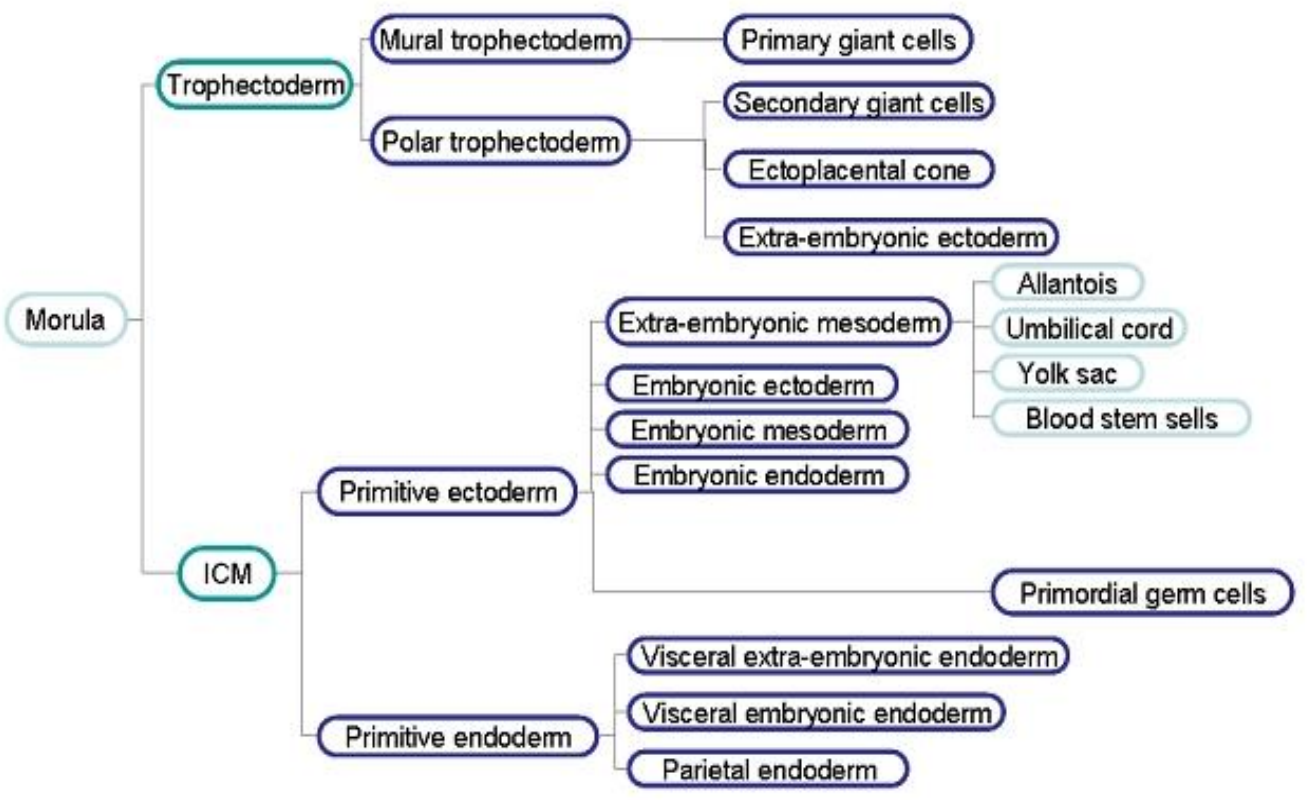

Figure 1-6: A diagram of the cell lineage relationships in the early mouse embryo showing the origins of the embryonic and extra-embryonic tissues.

Primitive ectoderm forms three germ layers of foetus: ectoderm, mesoderm and endoderm, and extraembryonic mesoderm. Endoderm forms the gastrointestinal tract, liver, pancreas, urinary bladder, and the lungs. Mesoderm forms muscle, bone, the circulatory and lymphatic systems, and the notochord. Ectoderm forms the epidermis, nervous system, and tooth enamel. From Bard, 1994 


\subsection{Trophectodermal and Placental development}

TE is the first differentiated cell type to form during early mammalian embryonic development. The outer single epithelial layer appears in mice on day 3.5 after fertilization, while in humans it occurs on day 5.0 (Cockburn and Rossant, 2010). The TE may be also divided into two cell forms, both of which differentiate further into various cell types during embryonic development. The part of TE in direct contact with the ICM is known as the "polar trophectoderm", and the region not contacting with the ICM, but surrounding the blastocoel cavity, is called the "mural trophectoderm" Figure 1-7.

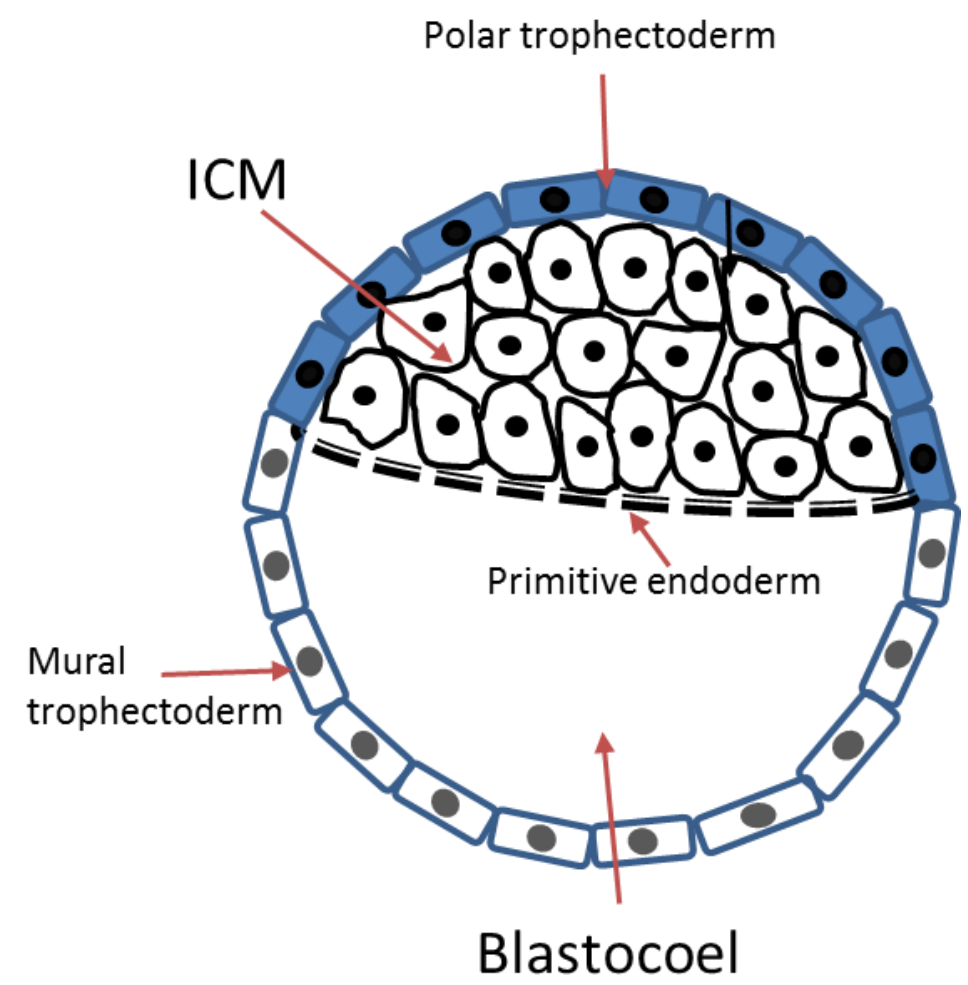

Figure 1-7: Blastocyst: trophectoderm, primitive endoderm and inner cell mass

The trophectoderm around inner cell mass is polar trophectoderm; the mural trophectoderm lacks this contact. This differentiation occurs at day 3.5 in mice and 5.5 in human. 


\subsubsection{Trophoblast cell lineage}

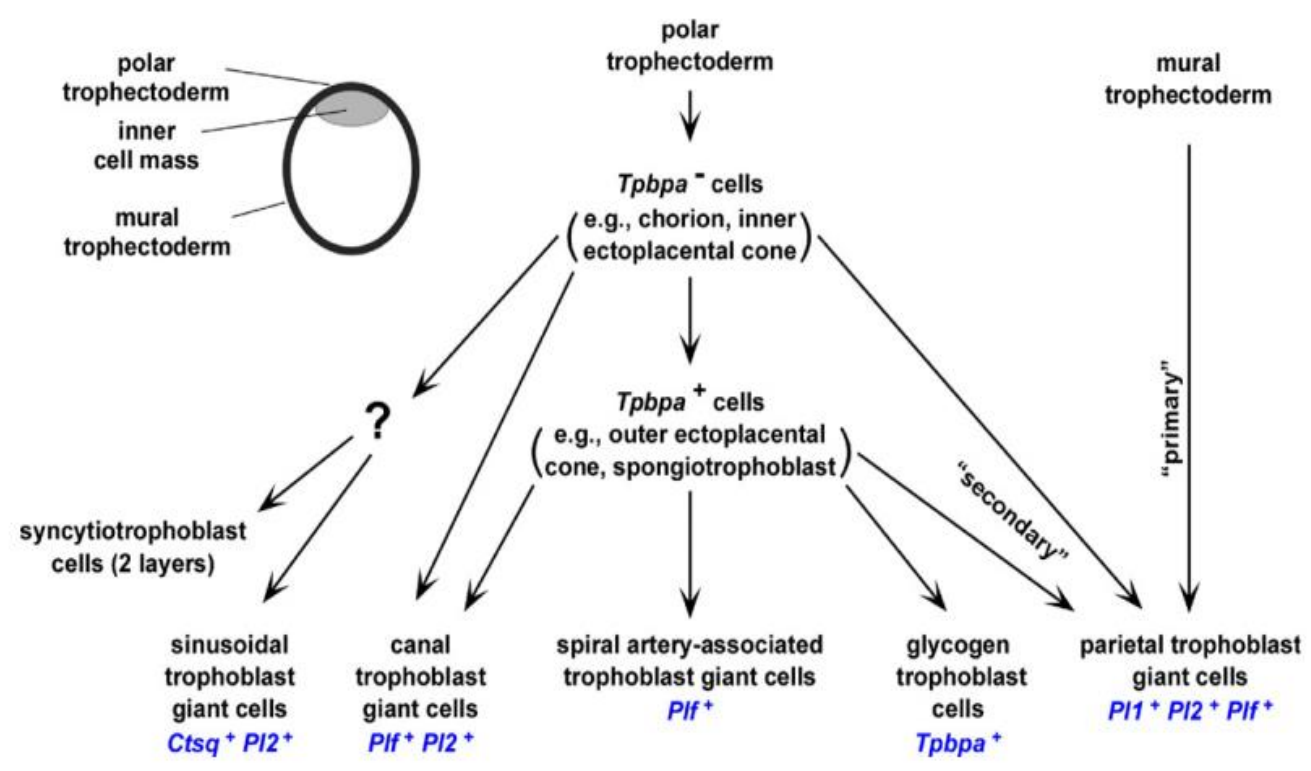

Figure 1-8: Summary of the trophoblast cell lineage and origins of different TGC subtypes

Polar trophectoderm differentiates into ectoplacental cone, then spongiotrophoblast, syncytiotrophoblast, glycogen trophoblast, and other subtype giant cells. Mural trophectoderm differentiates into parietal trophoblast giant cells (Simmons et al., 2007).

After implantation, mural TE cells will differentiate into "primary" trophoblast giant cells (TGCs). These produce several hormones, such as placental lactogen (PL), which have direct effects on the maternal metabolism. For instance, PL reduces the maternal sensitivity to insulin, resulting in higher serum levels of glucose, amino acids and other nutrients - a mechanism initiated by pregnancy to increase the supply of nutrients to the foetus. Further prolactin-like proteins (PLPs), of which there are many subtypes, are also produced by these cells. These have many reported roles, however they appear most important in regulating the maternal immune system modulating of the activity of natural killer (NK) cells, and reducing their activity when they meet the foetal cells of the placenta. The TGCs also release the cytokines proliferin (PLF), and proliferinrelated protein (PR), which control angiogenesis in both the foetal and maternal placenta. Spiral artery-associated TGCS (SPA-TGC), which bind to the outer surface of the maternal spiral arteries, regulate the maternal blood flow at the implantation site and express the potent vasodilator peptide adrenomedullin, and endothelial nitric oxide synthetase (eNos/Nos3) (Linzer and Fisher, 1999, Hu and Cross, 2010), both of which maintain the high blood flow needed by the developing placenta. 
The polar trophectoderm maintains a proliferative capacity and forms the extraembryonic ectoderm (ExE) and the ectoplacental cone (EPC), as well as the trophoblast cell components of the mature chorioallantoic placenta: the spongiotrophoblast, labyrinth and "secondary" giant cell layer (Tanaka et al., 1998) (Figure 1-8). In vitro, cells from the E7.5 ectoplacental cone explant spontaneously differentiate into polyploid giant cells (Carney et al., 1993). However, not all secondary TGCs come from Tpbpa ${ }^{+}$cells (which are derived from the ectoplacental cone or the spongiotrophoblast). This means that the same sub-types of TGCs may be derived from both origins, i.e. Tpbpa or Tpbpa ${ }^{+}$cells (Figure 1-8) (Simmons et al., 2007).

After endoreduplication (see later), the giant cells form large polyploid cells which, while often highly invasive in vitro, appear to have a delimiting role in vivo (Tanaka et al., 1998). In mice, the chromosome level in primary and secondary trophoblast giant cells can accumulate to $64 \sim 512$ DNA ploid (Zybina and Zybina, 1996). See Figure 1-9

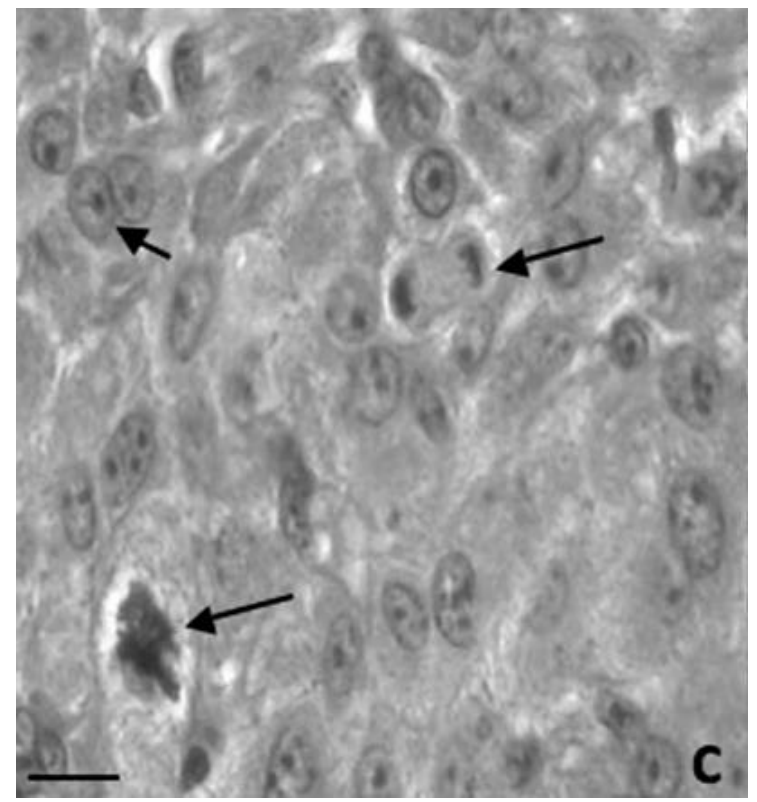

Figure 1-9: Polyploid cytotrophoblast (short arrow) and mitotic division (long arrows) in implantation site Giant cells show incomplete cell division and increase their chromosomal numbers greatly (Maia et al., 2010).

Four TGC subtypes have been identified in the mouse placenta; these reside in either the implantation site or the maternal decidual or foetal blood vessels. All of the TGC subtypes have large polyploid nuclei and secrete factors which can affect the blood flow (Hu and Cross, 2010). They are: parietal TGCS (P-TGCS), which express thrombomodulin, are located at the implantation 
Chapter 1

site, and are in direct contact with the decidual and immune cells in the uterus (Hemberger et al., 2003); spiral artery-associated TGCs (SpA-TGCs), which are located on the maternal supply vessels; maternal blood canal-associated TGCs (C-TGCs); and sinusoidal TGCs (S-TGCs), which are located within the sinusoidal blood spaces of the labyrinth (Simmons et al., 2007, Hu and Cross, 2010). Please refer to Table 1-3, Figure 1-8, and Figure 1-10. 
Table 1-3: The mouse trophectoderm giant cells, location, appearance time, gene expression and suggested function. modified from Hu and Cross, 2010.

\begin{tabular}{|c|c|c|c|c|}
\hline Name & Location & Time & $\begin{array}{l}\text { Gene } \\
\text { expression }\end{array}$ & Suggested function \\
\hline SpA-TGC & $\begin{array}{l}\text { Lining maternal spiral arteries } \\
\text { bringing blood into placenta }\end{array}$ & E10.5 & PIf & $\begin{array}{l}\text { Regulate maternal spiral artery } \\
\text { remodelling and blood flow into } \\
\text { the placenta }\end{array}$ \\
\hline P-TGC & $\begin{array}{l}\text { Lining implantation site and } \\
\text { outer layer of parietal yolk sac }\end{array}$ & E7.5 & $\mathrm{PIf}, \mathrm{Pl} 1, \mathrm{Pl} 2$ & $\begin{array}{l}\text { Facilitate implantation and } \\
\text { initial maternal vascular } \\
\text { connections, regulate decidual } \\
\text { cell differentiation, and } \\
\text { maternal physiology }\end{array}$ \\
\hline C-TGC & $\begin{array}{l}\text { Lining canals that bring } \\
\text { maternal blood to base of } \\
\text { labyrinth }\end{array}$ & E10.5 & PIf, PI2 & $\begin{array}{l}\text { Regulate maternal vasculature } \\
\text { remodelling and maternal } \\
\text { physiology }\end{array}$ \\
\hline S-TGC & $\begin{array}{l}\text { Within maternal blood } \\
\text { sinusoids of the labyrinth } \\
\text { layer }\end{array}$ & E10.5 & Ctsq, $\mathrm{Pl} 2$ & $\begin{array}{l}\text { Modulation of hormone and } \\
\text { growth factor activity before } \\
\text { they enter foetal and/or } \\
\text { maternal circulation, regulate } \\
\text { maternal physiology }\end{array}$ \\
\hline
\end{tabular}
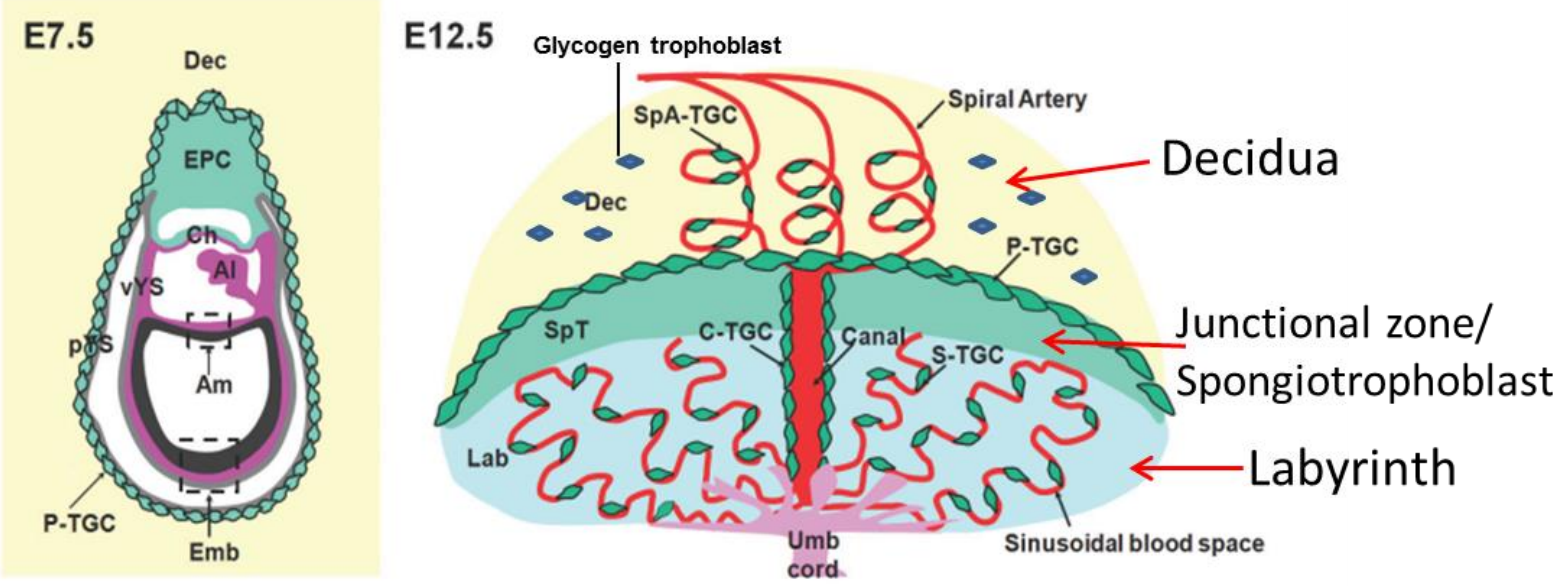

Figure 1-10: Day 7.5 and 12.5, the components of the yolk sac and mature placenta and

different subtypes of TGCs. Al, allantois; Am, amnion; Ch, chorion; Dec, decidua; Emb, embryo;

Epc, ectoplacental cone; Lab, Labyrinth; pYS, parietal yolk sac; SpT, spongiotrophoblast; TGC, trophoblast giant cell; Umb Cord, umbilical cord; vYS, visceral yolk sac

Four TGC subtypes are located in different places: S-TGC, binding to the maternal blood sinusoids of the labyrinth layer; C-TGC, lining the vascular canals; P-TGC, over the outer layer of spongiotrophoblast; SpA-TGC, migrates out of the embryonic placenta and form a line over the incoming maternal spiral arteries. The glycogen trophoblast cells also migrate out into the maternal decidua. 


\subsubsection{The Placenta}

The placenta is the organ which exchanges nutrients, gas and waste between mother and foetus, and is formed of tissues from both organisms. It also produces long lasting hormones, such as placental lactogens, angiogenic factors and vascular endothelial growth factor (VEGF). The mature placenta has three major layers. The outer maternal layer is called the decidua, and is formed from the uterus; some foetal glycogen trophoblast cells migrate into this layer. The middle layer is called the junctional zone (or spongiotrophoblast), and is formed from trophectoderm. The inner layer is called the labyrinth, and contains the embryonic villi; it extends into the maternal blood sinuses where nutrients and waste products pass between maternal and foetal blood. (See Figure $1-10)$.

\subsubsection{Endoreduplication}

Endoreduplication is replication of the nuclear DNA without cellular separation, which causes polyploidy. All TGC subtypes are polyploid (Ilgren, 1983), although there is disagreement about which subtypes are multinuclear and which maintain their chromosomes within a single nuclear envelope. In the mitotic cell cycle, the phase order is $\mathrm{G} 1-\mathrm{S}-\mathrm{G} 2-\mathrm{M}$. A cell grows in the Gap 1 phase, then DNA is synthesised and replicated in the S phase. After the $S$ phase is the Gap 2 phase, during which the cell continues to grow. It then enters the mitotic phase, during which it divides into two daughter cells.

The endocycle of trophoblast cells lacks the $M$ (mitotic) phase when compared to the usual cell cycle, and the accumulation of DNA causes the cells to become polyploidy. Several proteins appear specific to this process, and may be relevant in causing endoreduplication. The cyclins D1, D2 and D3 and their substrates Cdk4 and Cdk6 (cyclin-dependent kinases) are active in the early G1 phase, which cause cells to enter the cell cycle, and show a distinct expression profile in TE differentiation. For instance, cyclin D expression switches from D3 to D1 with giant cell differentiation, and this is believed to alter the cell cycle checkpoint (MacAuley et al., 1998). Further, cyclin B function is altered during TGC formation. This acts via Cdk1 (Sherr and Roberts, 2004); however, the Cdk1 inhibitor p57Kip2 is upregulated during TGC differentiation, blocking cyclin B function and affecting mitosis. Failure of the $c y c l i n B / C d k 1 / S u r v i v i n$ complex means that the cell reaches the $\mathrm{G} 2$ phase of the cell cycle but fails to produce a mitotic spindle, and so does not separate the chromosomes into daughter nuclei. Presumably p57Kip2 allows other functions 
of the cyclinB/Cdk1/Survivin complex to occur, and so endoreduplication occurs without initiating the apoptotic pathway seen in most other cell types when spindle formation is hindered (Hattori et al., 2000).

\subsubsection{TE Gene expression}

The correct differentiation into the multiple TE lineages is complex and crucial in embryonic development. Also the expression of specific markers can be used to characterize trophoblast stem cell (TS) differentiation. Below is some brief information on markers used to specify the TE and TGC forms. (Table 1-4)

Table 1-4: Gene expression and cell markers Modified from Quinn et al., 2006

\begin{tabular}{llll} 
Gene Name & Expression & TS cell expression profile & Reference \\
\hline Cdx2 & Trophectoderm E3.5 & TSC marker & (Strumpf et al., 2005) \\
Nodal & Spongiotrophoblast E10 & $\begin{array}{l}\text { Spongiotrophoblast } \\
\text { marker }\end{array}$ & (Ma et al., 2001) \\
PI1 (Placental & P-TGC E 7.5 & Giant cell marker & (Colosi et al., 1988, \\
lactogen 1) & & & Faria et al., 1990, Shida \\
PI2 (placental & P-TGC, C-TGC, S-TGC & Giant cell marker & et al92) \\
lactogen 2) & E7.5 E10.5 & & \\
PLF (proliferin) & P-TGC, C-TGC E7.5 E10.5 & Giant cell marker & \\
Ctsq & S-TGC E10.5 & Giant cell marker & \\
Aldh1a3 & E8.5 E14.5 & Glycogen trophoblast & (Outhwaite et al.,
\end{tabular}

\section{$\mathrm{Cdx2}$}

Caudal-like transcription factor $(\mathrm{Cd} \times 2)$ is a key control element in trophectoderm differentiation, placental development and axial elongation (Chawengsaksophak et al., 2004). At E3.5, Cdx2 is exclusively expressed in the TE (Beck et al., 1995a) and it is used as one of the markers of the initiation of TE lineage specification in the late morula. $\mathrm{Cd} \times 2^{-/-}$mutant mice do not survive the peri-implantation period (Chawengsaksophak et al., 1997) and fail to form a blastocoel. Further, null embryos express Oct4 and Nanog markers, normally limited to the central cells and the ICM, in outer cells. This suggests that $\mathrm{Cd} \times 2$ has a regulating role on the differentiation path of ICM cells (Strumpf et al., 2005), with Cdx2 and Oct4 / Nanog in a mutual repressive loop. Cdx2 is regulated by the upstream transcription factor gene Tead4 and its co-activator protein YAP (see Figure 1-5 


\section{Chapter 1}

and Figure 1-11), the Tead4 null mouse failing to express Cdx2 at the morula stage (Nishioka et al., 2009). Cdx2 activates the transcription of a series other of TE genes (Figure 1-11), and overexpression of $\mathrm{Cdx} 2$ in ES cells drives them to differentiate into TE-like cells (Niwa et al., 2005).

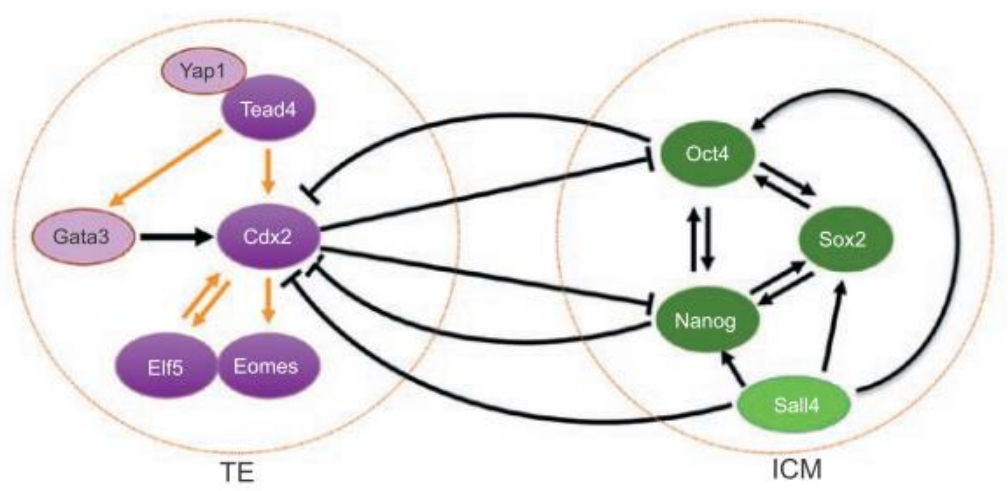

Figure 1-11: The transcription factors regulate between TE and ICM. The transcription factors regulating the crosstalk between TE and ICM cells. Cdx2, Tead4, Eomes, and Elf5 are the major TEspecific transcription factors. GATA3 directly binds the intron 1 region of the Cdx2 locus and upregulates Cdx2. Oct4 and Nanog are homeodomain transcription factors critical for early embryo development. Sox2 is an HMG-box transcription factor for ICM formation. Sall4 activates Oct4, Nanog, and Sox 2 but also suppresses Cdx2 expression. It is believed that the interplay between the cells is through LIF, FGFs and BMPs. From Chen et al., 2010a.

\section{Nodal}

Nodal is a transforming growth factor-beta (TGF- $\beta$ ) superfamily protein. It is necessary for early embryo left-right asymmetry and placenta development (Shen, 2007). Nodal appears to regulate the differentiation of trophoblast cells, driving them toward spongiotrophoblasts and limiting their further differentiation into giant cells. It shows both paracrine and autocrine effects, being also expressed by spongiotrophoblast cells and their direct precursors (Ma et al., 2001). In vitro, over-expression of Nodal inhibits trophoblast giant cell differentiation, and in vivo Nodal null mice fail to form the spongiotrophoblast and labyrinth layers, but increase the number of trophoblast giant cells formed (lannaccone et al., 1992, Ma et al., 2001). At E7.5, Nodal/-- mice lose expression of $\mathrm{Cdx} 2$ in their trophectodermal layers, and FGF4 expression - which is important in driving trophectoderm formation - is markedly reduced (Guzman-Ayala et al., 2004). This suggests that Nodal signalling is crucial in maintaining the trophectodermal differentiation pathway once it has been initiated by the Cdx2 pathway. 


\section{PI1, PI2, PLF, Ctsq}

Placental lactogen 1 (PI1/Csh1), placental lactogen 2 (PI2/Csh2), proliferin (PIf) and Cathepsin Q (Ctsq) are important gene markers used to distinguish the subtypes of TGC cells. PI1, PI2, PIf are placental hormones, with $\mathrm{Pl} 1$ and $\mathrm{Pl} 2$ supporting progesterone production and also increasing insulin secretion, while Plf stimulates endothelial cell migration in cell culture (Jackson et al., 1994). Ctsq is a cysteine protease active with MMPS, and is important for trophoblast invasion into the uterine epithelium (Hu and Cross, 2010). They all have important endocrine, invasive and migration roles.

SpA-TGC expresses only PIf; C-TGC expresses PIf and PI2; S-TGC expresses Ctsq and PI2, while PTGC expresses PI1, PI2 and PIf. Refer to Table 1-4 (Simmons et al., 2007).

\section{Aldh1a3 (aldehyde dehydrogenase 1 family, member A3)}

Aldh1a3 has recently been shown to be a specific marker of glycogen trophoblast cells, although it is also expressed in ectoplacental cone - presumably in precursor cells. The enzyme modifies retinal in order to provide a local source of retinoic acid (Outhwaite et al., 2015), which is needed along with thyroid hormone (T3) to drive the synthesis of placental lactogen by syncytiotrophoblast cells.

\section{Regulation of trophoblast differentiation}

A number of gene products, such as SOCS3, LIF, TSSC3 and FGF4, regulate TE differentiation. The main ones will be described below:

\section{Leukemia Inhibitory Factor (LIF) and Suppressor Of Cytokine Signalling 3 (SOCS3) Pathway}

Leukemia Inhibitory Factor (LIF) is well known to be essential in maintaining the pluripotency and self-renewal of murine ES cells (Smith et al., 1988, Williams et al., 1988). However, in vivo, this factor is produced by the uterine stromal cells and promotes giant cell differentiation (Takahashi et al., 2003) from both TS cells and the ectoplacental cone. Indeed, LIF ${ }^{-1-}$ embryos can develop to adult, provided they are implanting into a LIF producing mother (Stewart et al., 1992). However, 


\section{Chapter 1}

overexpression of LIF is lethal - presumably due to the excessive driving of trophoblast precursors cells toward giant cells (Conquet et al., 1992).

Suppressor of cytokine signalling 3 (SOCS3) is an essential regulator of the LIFR pathway blocking STAT signalling. Hence, in trophoblast differentiation, SOCS3 is a negative regulator of giant cell formation (Takahashi et al., 2003). Overexpression of SOCS3 in Rcho-1 cells (a trophoblast stem cell line) completely blocks LIF-induced giant cell differentiation (Takahashi et al., 2003); rather, such cells differentiate toward mesoderm and endoderm lineages (Niwa et al., 1998).

\section{TSSC3}

TSSC3 is a maternally-expressed imprinted gene which negatively regulates placenta growth (Frank et al., 2002). In mice, TSSC3 is expressed at high levels in cytotrophoblast cells of the placenta (Saxena et al., 2003), in the ectoplacental cone and chorion (Dunwoodie and Beddington, 2002). This gene is located in mice chromosome 7 and human 11p15.5, and rearrangement in this region is connected with the overgrowth syndrome BWS in man (Maher et al., 2003). The placenta of intrauterine growth restriction (IUGR) babies shows greater TSSC3 immunostaining in cytotrophoblast than that of normal weight newborns (McMinn et al., 2006), an inverse correlation between birth weight and expression of TSSC3 - in both human umbilical cord (Lim et al., 2012) and placenta (Apostolidou et al., 2007) - having also been observed in normal children.

In TS cells, TSSC3 functions by regulating the Mash2 transcription factor, with overexpression of TSSC3 upregulating Gcm1 and Mash2, both of which are trophoblast marker genes (Takao et al., 2012). In the TSSC3 knockout mouse, the placenta shows marked overgrowth with excessive spongiotrophoblast cells (Frank et al., 2002, Sala et al., 2004), while overexpression of TSSC3 reduced the ratio between spongiotrophoblast and glycogen cells (Tunster et al., 2010), suggesting that TSSC3 drives the differentiation of TS cells away from this cell lineage key for placental functioning. Interestingly, there is another paternally-expressed gene, MEST, which shows the opposite effects in promoting placental growth, with the TSSC3/MEST mRNA ratio showing a negative correlation with placental weight in human (McMinn et al., 2006). It is suggested that these gene functions are antagonistic and together maintain a normal level of placental development. 


\section{FGF4 (Fibroblast Growth Factor 4)}

FGF4 is a member of the fibroblast growth factor protein family. There are 23 FGFs and 5 known receptors (FGFR). FGF4 is a conventionally secreted protein, containing a single $\mathrm{N}$-linked glycosylation site (Bellosta et al., 1993). It signals to cells through one of four transmembrane FGF receptor tyrosine kinases (FGFR1-4). For signalling, it requires the presents of heparan sulphate (HS), usually on proteoglycans, which results in an active ternary complex: FGF-FGFR-HS (Figure 112). Heparin, an analogue for heparan sulphate, is often used in cell culture where FGF signalling is needed and where cell surface heparan sulphate proteoglycans (HS-PG) may be absent (Ornitz et al., 1992).

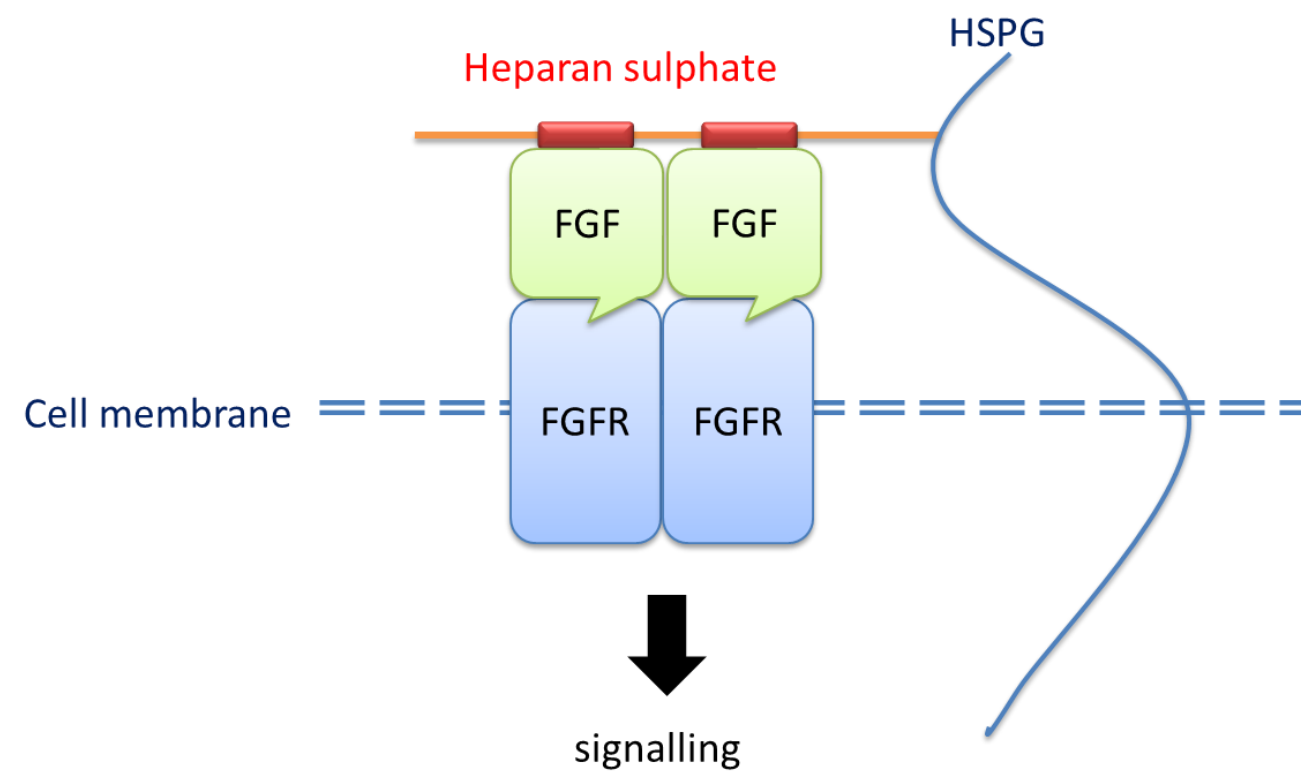

\section{Figure 1-12: The ternary complex of FGF-FGFR-HS}

In mouse embryos, FGF4 is expressed in the 8-16 cell morula, but it becomes restricted to epiblast cells as differentiation proceeds. Absence of FGF4 in mice is lethal at the peri-implantation stage (Feldman et al., 1995 ), and this is believed to be caused by altering the FGFR2 signalling pathway, as blocking this also results in a peri-implantational lethality (Arman et al., 1998 ). FGF4 is believed to be needed to maintain both the trophoblastic and primitive endodermal lineages in the implanting embryo (Goldin and Papaioannou, 2003). FGF4 and heparin are also necessary for isolating and maintaining mouse trophectoderm stem cells in culture (Tanaka et al., 1998), with the withdrawal of FGF4 from the culture medium inducing TS cell differentiation. 


\subsection{Stem cells}

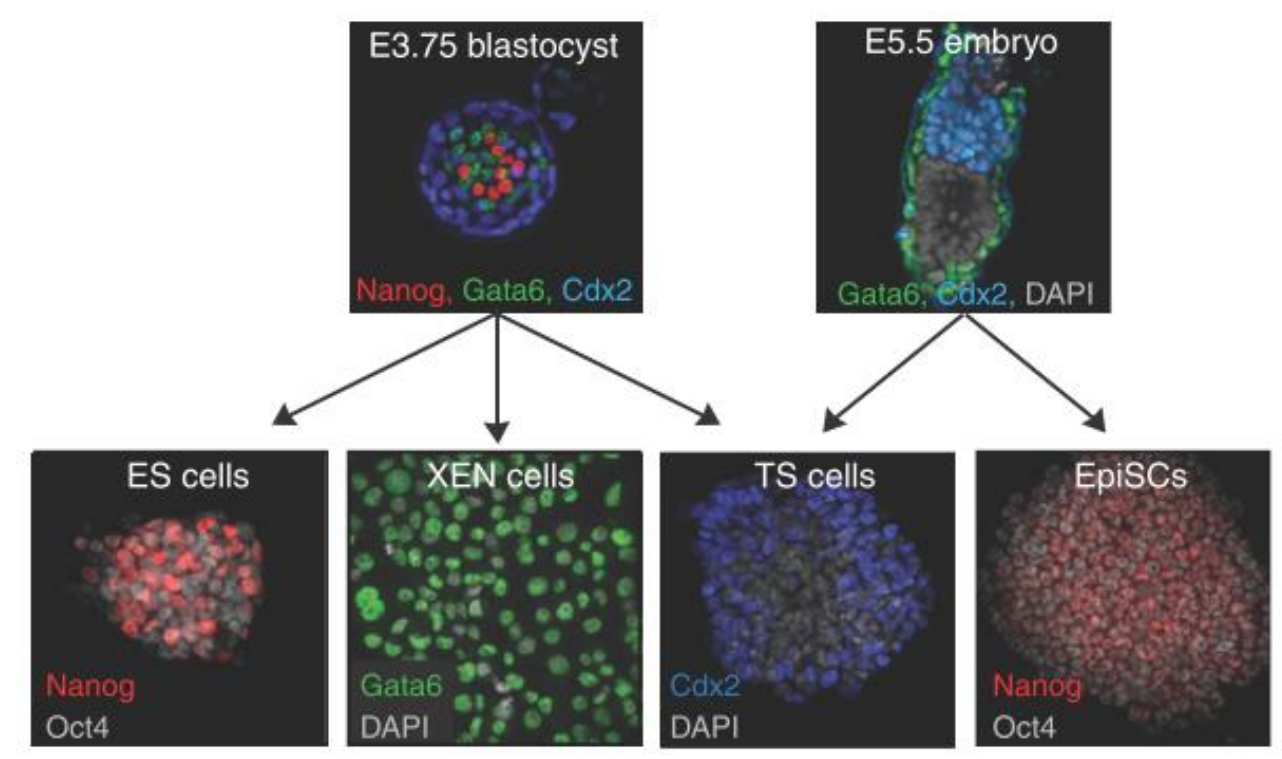

Figure 1-13: Stem cells derived from embryos at different stages with different markers

There are several lineages of stem cells derivable from the peri-implantation mouse embryo.

Blastocysts cultured at E3.5 can be used to produce ES cells, extraembryonic endoderm stem (XEN) cells and TSCs. While at E5.5, the embryo can be cultured and produced both TS and epiblast stem cells (EpiSCs) (Lanner and Rossant, 2010).

\subsubsection{Embryonic stem cells}

Embryonic stem cells (ESCs) are derived from the inner cell mass (Martin, 1981). These can be maintained as an undifferentiated cell line under the appropriate conditions in culture, and show the ability for unlimited self-renewal. However, they can differentiate into all three germ layers ectoderm, mesoderm, and endoderm - and are considered fully pluripotent, forming all the cell types in the foetus. The differentiation ability of mouse ESCs can be tested by either making a chimera (through injecting ESCs into donor blastocysts and reimplanting this into a primed pseudo pregnant mouse), or by injecting the stem cells into an adult animal to form a teratoma, where tissues of all three germ layers derived from these cells can be observed. When making a chimera, ESCs can be genetically modified either through the mutation of an endogenous gene, or by the addition of a transgene; both of these genetic alterations may be transmitted to later generations if the chimera contains this change in its germ cells (Beddington and Robertson, 1989). Although there are ES cells produced from many species including human, to date only murine and rat ES cells have shown the ability to produce a full animal, suggesting that the so- 
called ES cells isolated from other mammalian species are already primed and have lost full pluripotency. When culturing mouse ESCS, additional LIF is necessary to prevent cell differentiation. LIF drives STAT3 activity, which regulates the expression of KLF4/5, GBX2 and most importantly TFCP2L1 - the latter being a regulator of the key pluripotency transcription factor NANOG (Smith et al., 1988). ESCs can be driven to differentiate in vitro by a number of culture conditions, in particular by the formation of aggregates known as embryoid bodies. These have been used as an in vitro model for the study of mouse early embryo development, as well as in understanding how development can be altered by changes in environment.

\subsubsection{Trophectoderm stem cells}

Trophoblast stem cells (TSCS) are isolatable from progenitor cells present in the polar TE of the blastocyst or within the ectoplacental region of the early post-implantation embryo. It is believed that the ICM and the epiblast produce essential growth factors needed to maintain the selfrenewal and multipotency of these cells.

In vivo, TSC progenitors rapidly differentiate; however, under conditions which presumably recapitulate their early stem cell niche, isolation of self-renewing multipotent TSCs becomes possible. TSCs are diploid, permanent and self-renewing if maintained in suitable conditions (Tanaka et al., 1998). They are multipotent, and can differentiate into trophoblast subtypes both in vitro and in vivo when they are introduced into blastocysts (Hemberger et al., 2004, Hughes et al., 2004). Chimeric placentas produced in such experiments using marked TS cells show that these cells differentiate to ExE, EPC, and giant cells (Tanaka et al., 1998) (see Figure 1-13). The maintenance of TSCs in vitro requires: fibroblast growth factor 4 (FGF4), heparin, and embryonic fibroblasts (EMFIs) or embryonic fibroblast-conditioned medium (FCM) which contains as yet unknown factors to maintain the stem cells undifferentiated state (Tanaka et al., 1998). The EMFIs are known to provide a suitable collagen and fibronectin matrix for TSC maintenance. TSCs can also be induced from ESCs by deletion of the maintenance DNA methyltransferase, Dmnt1 (Ng et al., 2008). Very recently, TSCs have been shown to be isolatable under defined culture conditions in the presence of FGF2, Activin B and the Wnt inhibitor XAV939 (Ohinata and Tsukiyama, 2014). However, this appears to be highly strain dependant (Ohinata and Tsukiyama, 2014).

Under optimum conditions, the TSC cells grow as tight adherent epithelial colonies. On removal of FGF4, expression of Esrrb - a downstream FGF target - is reduced (Latos et al., 2015) and TS cells differentiate into giant cells with the classical abundant cytoplasm, large defined nuclei and high 
Chapter 1

ploid count (4N-8N) (Tanaka et al., 1998). Activin B acts to inhibit BCOR (BCL-6 corepressor), which blocks the trophoblast regulator genes Eomes and Cebpa (Zhu et al., 2015). Therefore, Activin B reduces the differentiation of TSCs. 


\subsection{Aims}

Much recent research has suggested that the extraembryonic tissues are epigenetically regulated in response to changes in the maternal environment. Furthermore, these changes go on to have wider effects on the foetus. Previous work in our laboratory identified changes in the yolk sac caused by nutritional limitation solely between days E0 - E3.5 (when only the precursor cells are present in these embryos), suggesting that there must be modifications in stem cell populations at these early stages. Indeed, there are changes in ES cells isolated from embryos where a low protein diet has been given.

These studies on the blastocyst, yolk sac and ES cell-derived endoderm showed an upregulation in the endocytotic pathway after an early embryonic low protein diet; however, no work has addressed such effects on the trophectodermal precursor cells which go on to form the placenta itself. My overall goal is to utilise TSCS to provide an in vitro model in order to understand this mechanism and the cellular responses occurring in the placenta in response to an early embryonic maternal low protein diet.

My aims are:

1. To optimise a method to isolate TSCs from mouse embryos

2. To obtain and characterise TSCs from mice receiving different maternal diets

3. To follow how maternal diet may affect lineage differentiation - and so aspects of endocytosis - in these cells lines 


\section{Chapter 2. General Material and Methods}

\subsection{Animal Use}

All animal care and experimental procedures were conducted using protocols approved by, and in accordance with, the UK Home Office Animal (Scientific Procedures) Act 1986 and the local ethics committee of the University of Southampton. Experiments were carried out under the UK Home Office Project Licences PPL30/2467 and PPL30/3001. To culture TS cells CBA/C57BL6 hybrid embryos were initially produced. However, despite the hybrid vigour of these it proved difficult to establish TS cell lines from such embryos. Later studies were carried out using embryos derived from MF1 mice for different diet groups. Virgin female MF-1 mice (aged 7-10 weeks) had been previously maintained ad libitum on standard laboratory chow (Special Diet Services) and were housed on a controlled $07.00-19.00 \mathrm{~h}$ light cycle at $21^{\circ} \mathrm{C}$. Animals were naturally mated with male MF1 mice of 10-30 weeks of age and on the day of mating placed randomly into groups receiving either low protein diet (LPD; 9\%) or normal protein diet (NPD; 18\%) (Table2-1) during preimplantation development (from the time of vaginal plug identification E0.5 until 3.5 days;

Table 2-1: Nutrient composition of diets used in these studies

$\underline{\mathrm{g} / \mathrm{kg} \text { of component }}$

\begin{tabular}{|l|r|r|r|r|}
\hline \multicolumn{4}{c}{ NPD } & LPD \\
\hline Starch Maize & & 425 & 485 \\
\hline Sucrose & & 213 & & 243 \\
\hline Casein & & 180 & & 90 \\
\hline Corn Oil & 100 & & 100 \\
\hline Cellulose & & 50 & & 50 \\
\hline Mineral mix ${ }^{1}$ & & 20 & & 20 \\
\hline Vitamin mix ${ }^{2}$ & & 5 & 5 \\
\hline DL-methionine & & 5 & 5 \\
\hline Choline Chloride & & 2 & 2 \\
\hline \\
Gross Energy & & 18.39 & 18.27 \\
Protein \% & & $18 \%$ & $9 \%$ \\
\hline
\end{tabular}

${ }^{1}$ Mineral Mix (AIN-76) (Special Diet Services)

${ }^{2}$ Vitamin Mix (AIN-76) (Special Diet Services) 


\subsection{Isolation of Blastocysts}

The pregnant mice were euthanized by cervical dislocation, the dissection area over the abdomen was cleaned with $70 \%$ ethanol and the uterus removed, with the uterine horns connected. Any mesometrial tissue was cleared and the uteri where rinsed to minimise blood cell contamination. Each horn was flushed with approximately $0.5 \mathrm{ml}$ of pre-warmed M6 / BSA using blunted hypodermic needles (G27). The uterus was removed and the fluid quickly searched for embryos which were washed through drops of M6/BSA before being placed into warm KSOM media equilibrated to $5 \% \mathrm{CO}_{2}$ where they were maintained at $37^{\circ} \mathrm{C}$ until further processed (see later in thesis). The composition of media used to collect and maintain the embryos used in these studies is listed below:

Table 2-2: Composition of stocks used for embryo handling media in these studies

\begin{tabular}{|c|c|c|}
\hline \multicolumn{3}{|c|}{ Embryo media } \\
\hline & \multicolumn{2}{|l|}{ Stock B (stored at 4-8C for up to 2 weeks) } \\
\hline & Deionised water, sterile & $10 \mathrm{ml}$ \\
\hline & Sodium hydrogen carbonate $\left(\mathrm{NaHCO}_{3}\right)$ & $0.2106 \mathrm{~g}$ \\
\hline & \multicolumn{2}{|l|}{ Stock E (stored at 4-8C for up to 3 months) } \\
\hline & Deionised water, sterile & $50 \mathrm{ml}$ \\
\hline & Hepes & $2.9785 \mathrm{~g}$ \\
\hline & \multicolumn{2}{|l|}{ Stock F (stored at 4-8C for up to 3 months) } \\
\hline & Sodium chloride $(\mathrm{NaCl})$ & $4.720 \mathrm{~g}$ \\
\hline & Potassium Chloride (KCL) $0.110 \mathrm{~g}$ & $0.110 \mathrm{~g}$ \\
\hline & Sodium dihydrogen orthophosphate $\left(\mathrm{NaH}_{2} \mathrm{PO}_{4} \cdot 2 \mathrm{H}_{2} \mathrm{O}\right)$ & $0.060 \mathrm{~g}$ \\
\hline & Magnesium chloride $\left(\mathrm{MgCl}_{2}\right)$ & $0.100 \mathrm{~g}$ \\
\hline & D-glucose & $1.000 \mathrm{~g}$ \\
\hline & DL-lactic acid & $3.4 \mathrm{ml}$ \\
\hline & Deionised water to a final total volume of & $100 \mathrm{ml}$ \\
\hline & \multicolumn{2}{|l|}{ Stock G (stored at $4-8 \mathrm{C}$ for up to 2 weeks) } \\
\hline & Deionised water, sterile & $10 \mathrm{ml}$ \\
\hline & Pyruvic acid & $0.030 \mathrm{~g}$ \\
\hline & Penicillin & $0.060 \mathrm{~g}$ \\
\hline & Streptomycin & $0.050 \mathrm{~g}$ \\
\hline & \multicolumn{2}{|l|}{ Stock H (stored at 4-8C for up to 3 months) } \\
\hline & Deionised water, sterile & $10 \mathrm{ml}$ \\
\hline & Calcium chloride dehydrate $\left(\mathrm{CaCl}_{2} \cdot 2 \mathrm{H}_{2} \mathrm{O}\right)$ & $0.260 \mathrm{~g}$ \\
\hline & \multicolumn{2}{|l|}{$20 \%$ Sodium Chloride } \\
\hline & Deionised water, sterile & $10 \mathrm{ml}$ \\
\hline & Sodium Chloride ( $\mathrm{NaCl})$ & $2.0 \mathrm{~g}$ \\
\hline
\end{tabular}


Chapter 2

To prepare $100 \mathrm{ml}$ of $\mathrm{H6}$-BSA the following where mixed:

Deionised water, sterile

Stock B

Stock E

Stock F

Stock G

Stock H

$20 \% \mathrm{NaCl}$
$78 \mathrm{ml}$

$1.6 \mathrm{ml}$

$8.4 \mathrm{ml}$

$10 \mathrm{ml}$

$1.0 \mathrm{ml}$

$1.0 \mathrm{ml}$

$0.6 \mathrm{ml}$

BSA (Sigma, embryo culture tested, A3311) $0.4 \mathrm{~g}$

The $\mathrm{pH}$ was adjusted to 7.4 , and osmolarity adjusted to $270-280 \mathrm{mOsm}$ with small volumes of $20 \%$ $\mathrm{NaCl}$. The solution was sterile filtered using a $0.22 \mu \mathrm{M}$ syringe filter and aliquots stored at $4{ }^{\circ} \mathrm{C}$. These were used within seven days.

\section{Table 2-3: Final Composition of KSOM media}

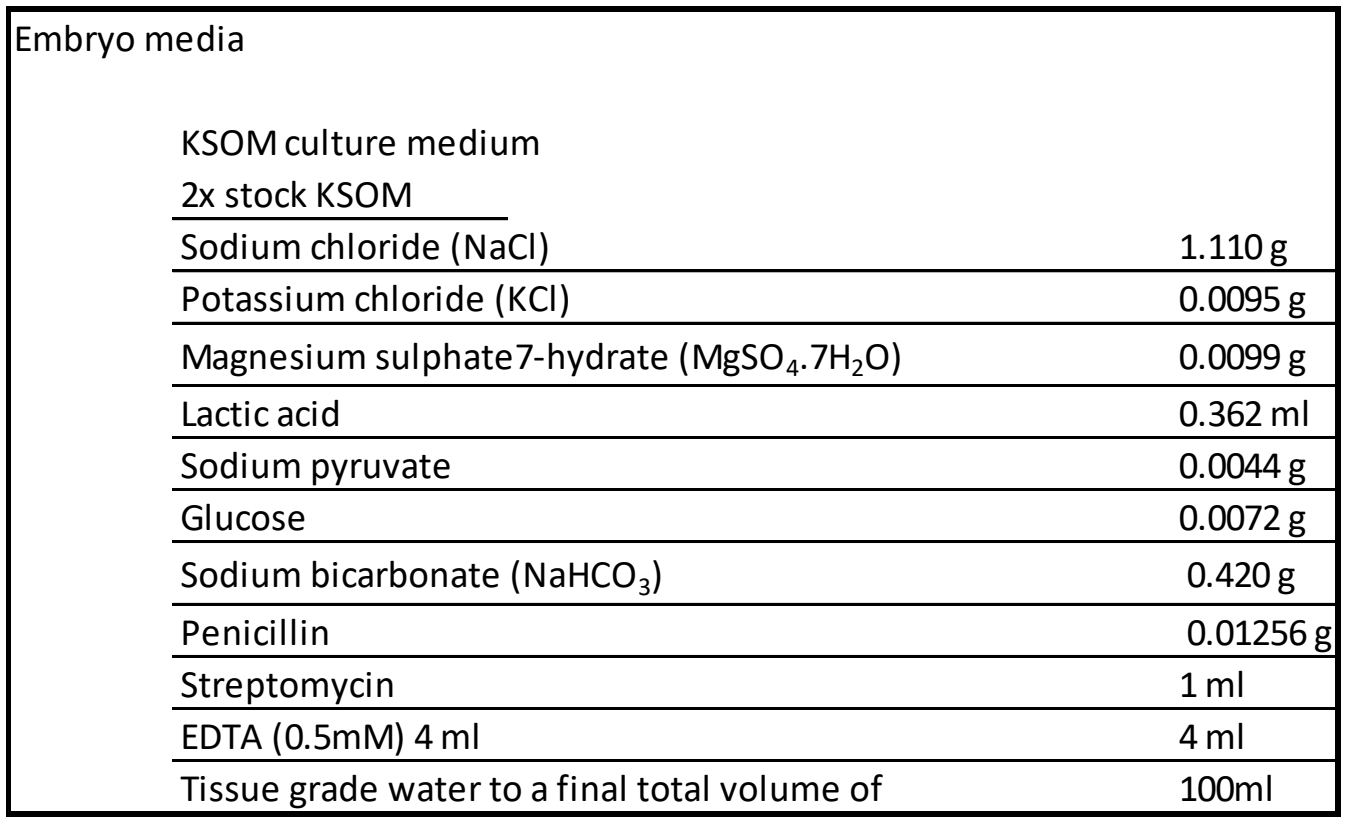

$5 \mathrm{ml}$ aliquots of the above were stored at $-80^{\circ} \mathrm{C}$ for up to 2 months. 
To prepare $10 \mathrm{ml}$ of KSOM media the following where mixed:

$\begin{array}{ll}\text { 2x KSOM stock } & 5 \mathrm{ml} \\ \text { Calcium chloride }\left(\mathrm{CaCl}_{2} ; 100 \text { x stock } 25 \mathrm{mg} / \mathrm{ml}\right) & 100 \mu \mathrm{l} \\ \text { Non-essential amino acids (100x stock; } 10 \mathrm{mM}) & 50 \mu \mathrm{l} \\ \text { Essential amino acids (50 x stock) } & 100 \mu \mathrm{l} \\ \text { L-glutamine (200 mM) } & 50 \mu \mathrm{l} \\ \text { Deionised water, sterile } & 4.75 \mathrm{ml} \\ \text { BSA } & 0.040 \mathrm{~g}\end{array}$

The $\mathrm{pH}$ was adjusted to 7.4 , and osmolarity adjusted to $255 \pm 5 \mathrm{mOsm}$, mOsm using $20 \% \mathrm{NaCl}$. The solution was sterile filtered using a $0.22 \mu \mathrm{M}$ syringe filter and aliquots stored at $4{ }^{\circ} \mathrm{C}$. These were used within seven days.

\subsection{Cell culture}

All mammalian cells were maintained in culture at $37^{\circ} \mathrm{C}, 5 \% \mathrm{CO}_{2}$ and $>95 \%$ humidity.

\subsubsection{Production of Embryonic Fibroblasts}

The embryonic murine fibroblasts (EMFI) cells to be used as feeder cells (see below), were prepared from E13.5 to E15.5 foetuses, they were isolated after cervical dislocation of the mother using careful aseptic technique. The gravid uteri were removed from the mother and all the following steps were carried out in a class 2 cell culture hood. After removal of the foetuses from the uterus their brains were destroyed (following schedule 1 procedures). The head and internal organs were then removed, so reducing contaminating astrocytes and hepatocytes. The carcasses were washed twice in phosphate buffered saline (PBS) -Dulbecco A, (Oxoid BR0014) to reduce any red blood cells in the final cell preparation, before being thoroughly minced with razor blades. The tissue slurry was again washed with PBS and then incubated in Trypsin- EDTA 0.05\% (Gibco 25300-054) for 15 minutes at $37^{\circ} \mathrm{C}$. The tissue was triturated through a $10 \mathrm{ml}$ pipette every 5 minutes to aid cell release. An equal volume of culture media containing $10 \%$ FCS (fetal calf serum, Sigma F9665) was added to the cells, to inhibit the trypsin. Bovine pancreatic DNAse 1 (Sigma DN25), at a final concentration of $10 \mu \mathrm{g} / \mathrm{ml}$ was added and the cell suspension incubated for a further 5 minutes. This cleaved any genomic DNA released by the prior procedure which lysed many cells and resulted in a far higher final yield of viable cells. The cells were washed by 
Chapter 2

centrifugation at $2000 \mathrm{~g}$ for 5 minutes and then plated on $15 \mathrm{~cm}$ diameter plates in EMFI culture media, roughly every 3 embryos per plate and $20 \mathrm{ml}$ of media per plate. After overnight culture the cells were carefully inspected for contamination and the media changed. Once confluent and generally within $48 \mathrm{hrs}$ of initial plating, the cells were harvested and frozen in liquid nitrogen, with approximately $20 \%$ of a plate being stored per vial.

\subsubsection{Archiving cultured cells}

Cells were frozen with a cryoprotectant mixture containing $10 \%$ dimethyl sulphoxide (DMSO) (Sigma-Aldrich D5879) which prevents ice lattice formation and reduces cell membrane damage by ice crystals. This method was used for storage of all mammalian cells and cell lines produced in this thesis, including MEFs, HEK-293, and TS cells.

Media had been changed on the cells 6-12 hours prior to freezing, in order to maintain the cells in a rapidly dividing state. They were washed with PBS and then trypsinised $(2 \mathrm{ml} 0.05 \%$ Trypsin-EDTA for a $15 \mathrm{~cm}$ culture dish) for 5 minutes. Once the cells had detached they were triturated in culture media and pelleted by centrifugation. They were resuspended in ice cold freezing media (culture media containing 20\% FCS and 10\%DMSO) and aliquot into freezing vials (Sigma V7884). Freezing was carried out slowly by placing the vials in a 1 inch thick styrofoam box at $-80^{\circ} \mathrm{C}$. After the cells had been frozen at $-80^{\circ} \mathrm{C}$ for 48 hours, they were placed in long term storage in liquid nitrogen at $-196^{\circ} \mathrm{C}$.

\subsubsection{Mitomycin C treatment}

Laboratory culture of many cell types, and in particular almost all stem cells, requires the presence of feeder cells. These produce a suitable extracellular matrix for the cell attachment and secrete into the media a set of undefined growth factors which support the undifferentiated maintenance of the stem cell. However dividing feeder cells compete with stem cells for nutrition, will contaminate later cultures and actually produce less matrix, hence these cells must be mitotically inactivated either by chemical means or ionising radiation. Both ES cells and TS cells are routinely grown on Mitomycin C inactivated EMFI cells. Mitomycin C is a potent DNA crosslinking agent which reduces cell proliferation. It links guanine between two DNA strands (Figure 21). 


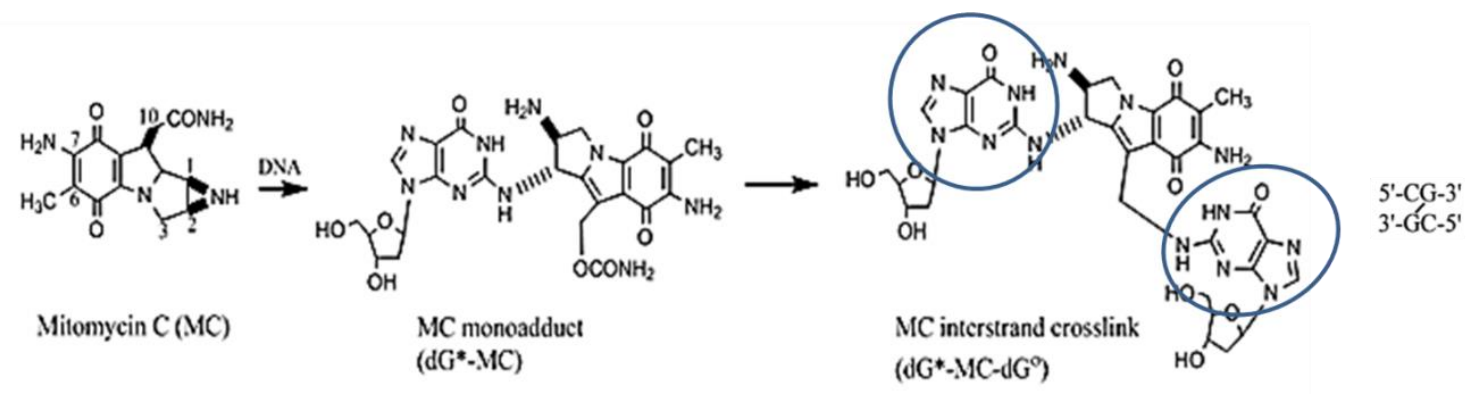

B

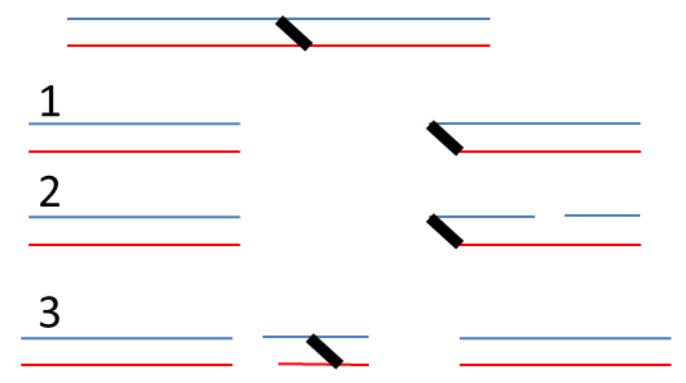

Figure 2-1: The DNA sequence and chemical form of the interstrand cross-links caused by Mitomycin C between guanine residues

(A) In trying to repair these changes double strand DNA breaks are induced, (B) in most cell types these are only poorly repaired and this prevents further mitosis (Dronkert and Kanaar, 2001)

Confluent EMFI cells, at less than passage 4, had half their culture media removed, Mitomycin C (Fisher BioReagents BP2531-2) was added at $10 \mu \mathrm{g} / \mathrm{mL}$ for 2-3 hours. After this the cell plate was washed twice with PBS, the cells were trypsinised, washed again after being pelleted by centrifugation at $200 \mathrm{~g}$ for 5 minutes and plated out. Following attachment, the plates were used after 12-24 hours. Prior to use the media was removed and the cells again washed with PBS to ensure any residual Mitomycin $\mathrm{C}$ had been eliminated.

\subsubsection{Cell counting and viability assays}

Viable cells numbers present in cultures were determined using trypan-blue exclusion (Mesner et al., 1992, Songyang et al., 1997). The presence of intact cell membranes prevents entry of this cellular dye and thus allows the identification of dead cells. Following trypsinisation and gentle trituration, cells were mixed with an equal volume of a $0.4 \%$ trypan blue/ PBS solution (Sigma T8154) and triplicate samples were counted on a Neubauer haemocytometer. 


\subsubsection{MTT assays}

Viable cell number / oxidative activity was also analysed with MTT (3-(4,5-dimethylthiazol-2-yl)2,5-diphenyltetrazolium bromide) assays which detects the cells' mitochondrial activity, as the yellow tetrazolium is reduced by $\mathrm{NAD}(\mathrm{P}) \mathrm{H}$ - dependent oxidoreductase enzymes to an insoluble purple formazan. A working stock solution of MTT (Sigma M5655) was dissolved in water at $10 \mathrm{mg} / \mathrm{ml}$ and filter sterilised. The cells were cultured in a 96 or 48 well plate in a volume of $100 \mu \mathrm{l}$ or $200 \mu \mathrm{l}$ and after various time periods of growth they were incubated with MTT at a final concentration of $1 \mathrm{mg} / \mathrm{ml}$ ) for 2 hours. The medium was gently aspirated without disturbing the cells sheet, and $100 \mu \mathrm{l}$ of lysis solution (see appendix) added to each well. The plate was incubated for 5-10 minutes prior to mixing to thoroughly solubilise the blue crystals. Absorption was measured by a photometer at wavelength of $550-570 \mathrm{~nm}$ with a reference wavelength of $630 \mathrm{~nm}$.

\subsection{Immunofluorescent Staining of Cultured Cells}

TS cells were cultured on coverslips in the wells of 24 well plates, these had been sterilised with $70 \%$ ethanol, washed with PBS and coated with gelatine (Sigma G1393) (0.2\% solution in PBS). The cells were allowed to grow to the desired confluency, rinsed three times with ice-cold PBS, and fixed by incubating with 4\% PFA (paraformaldehyde) (Sigma-Aldrich P6148) for 5-20 minutes depending on the antibody used. Following three washes with PBS the coverslips were removed from 24-well plate. The cells were permeabilised and non-specific antibody binding blocked by incubating with $0.25 \%$ Triton-100x (Sigma-Aldrich X100) and $1 \%$ serum from a species chosen to match that of the secondary antibody) for 45 minutes. Following washing the cells where incubated in the primary antibody at a suitable dilution (generally between 1;100 and 1:2000) in $0.1 \%$ Tween 20 (Sigma-Aldrich P1379) in PBS overnight at $4^{\circ} \mathrm{C}$, or at room temperature for one hour. After primary staining, the cells were rinsed three times with $0.1 \%$ Tween 20-PBS and incubated with the labelled secondary antibody paired with first antibody for one hour in darkness. Following washing, the coverslips were mounted with $5 \mu$ l mounting media (Vectashield $\mathrm{H}-1000)$ to reduce fading and prevent drying of the sample. In some cases nuclei were stained with DAPI (1:500 in 0.1\% Tween 20 in PBS) for 30 minutes in darkness as a final step prior to washing and mounting. Second antibody alone staining was also prepared as a control. The samples were visualised under bright field or a fluorescent source. 


\subsection{SDS Page electrophoresis and Immunoblotting}

SDS polyacrylamide gel electrophoresis was used to separate different proteins, and subsequently transfer these to a PVDF (polyvinylidene fluoride) membrane for immunodetection.

\subsubsection{SDS-PAGE electrophoresis}

Protein separation was carried out using the method of Laemmli, 1970. Different concentrations of polyacrylamide gel give optimum separation of different protein molecular masses. For instance in the detection of FGF4 (Mwt 19.4kDa), a 12\% gel was chosen (see appendix). The vertical gel consists of a $5 \%$ stacking gel (see appendix), which concentrates the loaded sample and the $12 \%$ resolving gel to obtain separation of proteins in the range of $12-60 \mathrm{kDa}$. Gels were allowed to polymerise for an hour prior to use. For analysis of soluble samples from cell media, the sample was precipitated from serum free media by addition of sodium acetate to give a $0.3 \mathrm{M}$ solution followed by a ten -fold volume of absolute ethanol. The samples were stored at $-80^{\circ} \mathrm{C}$ overnight, centrifuged to pellet the protein (5000g for 15 minutes), the solvent removed and after drying the pellet, the protein samples were dissolved in water and SDS-loading buffer (4x SDS load-buffer being-0.25 M Tris. $\mathrm{HCl}, 40 \%$ (v/v) Glycerol, $2.8 \mathrm{M} \mathrm{SDS}, 0.1 \%$ Bromophenol Blue), 10\% (v/v) 2-Mercaptoethanol was added fresh to generate reducing conditions. Samples were heated at $95^{\circ} \mathrm{C}$ for $5 \mathrm{~min}$ to thoroughly denature the sample prior to gel separation. Samples were run in 1x SDS running buffer (see appendix), at 30mA for 30-60 minutes with current limiting. After running the gel, it was either protein stained with Coomassie brilliant blue G250 or the separated proteins were transferred to a PVDF membrane for immunodetection.

\subsubsection{Western Blotting}

After separation, proteins were transferred from the SDS-gel to PVDF membrane (Immobilon-FL, $0.2 \mu \mathrm{m}$ membrane; Millipore) by electro-elution using a mini tank wet transfer system (Hoefer). Low-fluorescent PVDF was cut to fit inside the cassette and cover the gel. PVDF is highly hydrophobic so was wetted prior to use by soaking in methanol for 15 seconds, rinsing in water for 2 minutes, and then leaving in transfer buffer (see appendix) for a minimum of 5 minutes. The gel was placed in contact with the membrane, with buffer saturated Whatmann $3 \mathrm{MM}$ paper placed on either side. Following transfer, (300 mA current limiting, overnight with the cooler system running), the blot was briefly stained with the reversible dye Ponceau $S$ to verify the 
presence of protein and allow the marking of the position of molecular weight markers. Following staining the membranes were destained in water and dried for storage.

\subsubsection{Immunodetection}

The membrane was blocked by incubation at room temperature in blocking buffer (5\% milk powder in PBS-0.2\%Tween20, PBS-T) for 30 minutes; the membrane received gentle agitation over this period. The membrane was probed with primary antibodies in blocking solution either overnight at $4^{\circ} \mathrm{C}$, or at room temperature for $2 \mathrm{hrs}$. The membrane was washed with PBS-T three times for five minutes each time. Protein bands were visualised by fluorescence-based immunodetection, an IRDye conjugated secondary antibody 800CW (Rockland inc. Molecular probes) near-infrared (IR) fluorochrome (diluted typically at 1:10000 in 5\% BSA in TBS-T) was then added for 1 to 2 hours in blocking solution. The membrane was washed with PBS-T three times and once in PBS. Analysis of the membrane was made using infrared fluorescence scanning the membrane using the LI-COR Odyssey IR imaging system (LI-COR Biosciences).

\subsection{General DNA preparation and analysis}

\subsubsection{Genomic DNA extraction and analysis}

Feeder free confluent TS cells were washed with PBS and lysis buffer containing $10 \mathrm{mM}$ Tris, $\mathrm{pH}$ 8, $100 \mathrm{mM} \mathrm{NaCl}, 10 \mathrm{mM}$ EDTA, pH 8, 0.5\% sodium dodecyl sulphate (SDS), $1 \mathrm{mg} / \mathrm{ml}$ proteinase $\mathrm{K}$ was added fresh. Plates were incubated overnight at $55^{\circ} \mathrm{C}$ in a humid environment to avoid evaporation. The lysates were removed and two volumes of cold absolute ethanol added to precipitate the genomic DNA. The DNA pellet was obtained by centrifugation, washed in $70 \%$ ethanol, and allowed to air-dry before being resuspended in nuclease-free water and quantified using the Nanodrop ND-100- spectrophotometer.

\subsubsection{DNA Mini-prep}

The plasmid DNA was prepared by QIAprep kit (Qiagen 27014) which uses a modified alkaline lysis procedure which utilises the fact that chromosomal and plasmid DNA show differential denaturation. Bacteria were lysed in SDS (Fisher Scientific S/5200/53) and sodium hydroxide (Fisher Scientific S/4800/60) and all DNA denatured. Potassium acetate (Sigma P5708) was used to neutralize the solution and covalently closed plasmid DNA rapidly reanneals and remains solubilized (Ehrt and Schnappinger, 2003), while chromosomal DNA and proteins are retained in 
the precipitate with potassium and SDS. When this high salt supernatant is passed through the silica-gel-membrane, the plasmid DNA is differentially bound to the member and can be eluted by ethanol or water later.

The DNA from picked clones was isolated from $1 \mathrm{ml}$ LB (Lab M MC001) culture media after growing overnight at $37^{\circ} \mathrm{C}$ with shaking. The eluted DNA was obtained in $50 \mu$ l Buffer EB $(10 \mathrm{mM}$ Tris. $\mathrm{Cl}, \mathrm{pH} 8.5$ ) or water prior to analysis of use in further protocols.

\subsubsection{Vector ligation and sub cloning}

Where further subcloning of DNA from vector was required, the new vector and insert were cut with suitable restructuring enzymes and the former dephosphorylated with calf alkaline phosphatase (Promega, UK) The restriction enzyme purified DNA fragments were mixed at approximately 1: 4 molar ratios (vector : insert) and ligated with T4 ligase enzyme at $14^{\circ} \mathrm{C}$ overnight.

\subsubsection{Competent cells and vector Transformation}

Competent cells were produced by the low temperature culture method of (Inoue et al., 1990). Transformation and uptake of extracellular DNA occurs upon a rapid temperature increase which creates pores in bacteria membrane and induces heat shock proteins, this allows plasmid DNA to enter and be retained by the bacteria. The tube of competent cells was thawed on ice for 10 minutes. Then the vector and cells were mixed and left on ice for 30 minutes. After heat shock for 10 seconds at $42^{\circ} \mathrm{C}$, the tube was placed on ice for a minute, prior to addition of SOC media and culture for an hour to allow expression of the antibiotic resistance enzyme present on the plasmid. Following this cells were plated on a LB agar plate containing suitable selective antibiotics.

\subsubsection{Polymerase chain reaction}

Polymerase chain reaction (PCR) samples containing final concentrations of $1 \times$ PCR buffer (20 $\mathrm{mM}$ Tris- $\mathrm{HCl}, \mathrm{pH} 8.4,50 \mathrm{mM} \mathrm{KCl}$ ), $2.5 \mathrm{mM} \mathrm{MgCl} 2$ (Invitrogen), $250 \mu \mathrm{M}$ of each dNTP (Invitrogen), $250 \mathrm{nM}$ of each oligonucleotide primer, $0.625 \mathrm{U}$ Hot-Start Taq50 (Qiagen), and $50 \mathrm{ng}$ sample DNA were prepared in a total volume of $25 \mu \mathrm{l}$. The PCR was performed on a DNA Engine ${ }^{\circledR}$ Peltier Thermal Cycler (BioRad, UK). Reaction conditions were typically as follows (for some primer pairs this was altered and will be noted in the specific materials and methods): Initiation by Hot-Start Taq activation at $95^{\circ} \mathrm{C}$ for 15 minute, followed by 35 cycles each consisting of a denaturation step at $94^{\circ} \mathrm{C}$ for 60 second, annealing at $55^{\circ} \mathrm{C}$ for 30 second, and extension at $72^{\circ} \mathrm{C}$ for 60 second. After the last cycle, samples were kept at $72^{\circ} \mathrm{C}$ for 10 minute. 


\subsubsection{Gel electrophoresis}

DNA products were separated by gel electrophoresis through suitable concentrations of agarose gel (0.7-3\%) in 1 X TBE buffer ( $50 \mathrm{mM}$ Tris, $100 \mathrm{mM}$ Borate, $10 \mathrm{mM}$ EDTA, $\mathrm{pH} 8.2$ ) at $70 \mathrm{~V}$ and visualised by ethidium bromide staining under ultraviolet (UV) illumination.

\subsection{Statistical Analysis}

All statistical analysis was performed using Minitab 16.1.0. or GraphpadPRISM. Data was checked for assumptions of normality using the Shapiro-Wilk normality test or the D'Agostino and Pearson normality test depending upon the number of samples. Data was considered normal where p $>0.05$ (significance level). Variance homogeneity was analysed using the F-test. Variance was similar where $p<0.05$. Unless otherwise stated, differences between dietary treatment groups or between genders were performed using the independent Student's t-test (for normally distributed data), or Mann-Whitney rank sum test (for nonnormal data sets). $\mathrm{P}<0.05$ was considered statistically significant. 


\section{Chapter 3. Production of recombinant murine FGF4}

\subsection{Introduction}

The fibroblastic growth factors are a family of 22 proteins (in both human and mouse) which are important in embryonic development, in the adult in angiogenesis and wound healing. All extracellularly-acting FGFs require heparan sulphate proteoglycans as a cofactor for signal transduction; for this reason, heparin is added in all cell assays of their function. FGFs 1-10 all function through binding to transmembrane FGF receptors, of which there are 4 closely related members (FGFR1-4) and FGFR5, which lacks the tyrosine kinase domains present in the others. The diversity of the receptor family is further expanded by extensive alternative splicing. The receptors have three extracellular immunoglobulin domains, with the third (D3) providing ligand specificity and the site for heparan sulphate binding.

FGF4 has a broad mitogenic activity and is important for cell survival. It was first identified as a transforming factor driving tumours including Kaposi's sarcoma, hence its original name of K-FGF (Sakamoto et al., 1986). Subsequently, it has been shown to be involved in many embryonic processes, such as limb development, mesenchymal proliferation and left-right patterning. Most importantly, it has major roles in maintaining various groups of stem cells (Kosaka et al., 2009). Stem cells responding to FGF4 include epiblast stem cells; these primed pluripotent stem cells form all three germ layers. FGFR2 is considered the main form of receptor for FGF4 in the early embryo, with mutations of FGFR2-IIIb causing limb defects and loss of SHH. FGF4 expression is often controlled by Wnt/LEF1 signalling or in SHH feedback loops (Kratochwil et al., 2002).

FGF4 is required for embryo survival after day 5.5 in the mouse, with its loss probably causing a failure in the primitive endoderm (PE) at this stage (Feldman et al., 1995). This is slightly later than seen if FGF signalling is inhibited, which leads to embryonic loss as a failure of expansion of the blastocyst. The difference may be caused by the presence of FGF8, which is not needed for early development but may compensate for FGF4 as it does in other situations (Naiche et al., 2011). 
Chapter 3

Signalling through the FGFR induces four distinct paths (Figure 3-1):

Janus Kinase / Signal Transducer and Activator of Transcription (JAK/STAT)

Phospholipase C gamma (PLC $)$

Phosphoinositide 3 Kinase (P13Kinase)

Extracellular signal regulated kinase / Mitogen -activated protein kinases (ERK/MAPK)

Signalling through these pathways is highly relevant for early development and early stem cell formation, and the null mutants of many of the intermediates in the pathway including the FGF4/-, Frs2a (FGF receptor substrate 2a) -/-, Grb2-/- and Erk1/2 -/- mice all show an embryonic lethality (Gotoh et al., 2005, Cheng et al., 1998, Fremin et al., 2015).

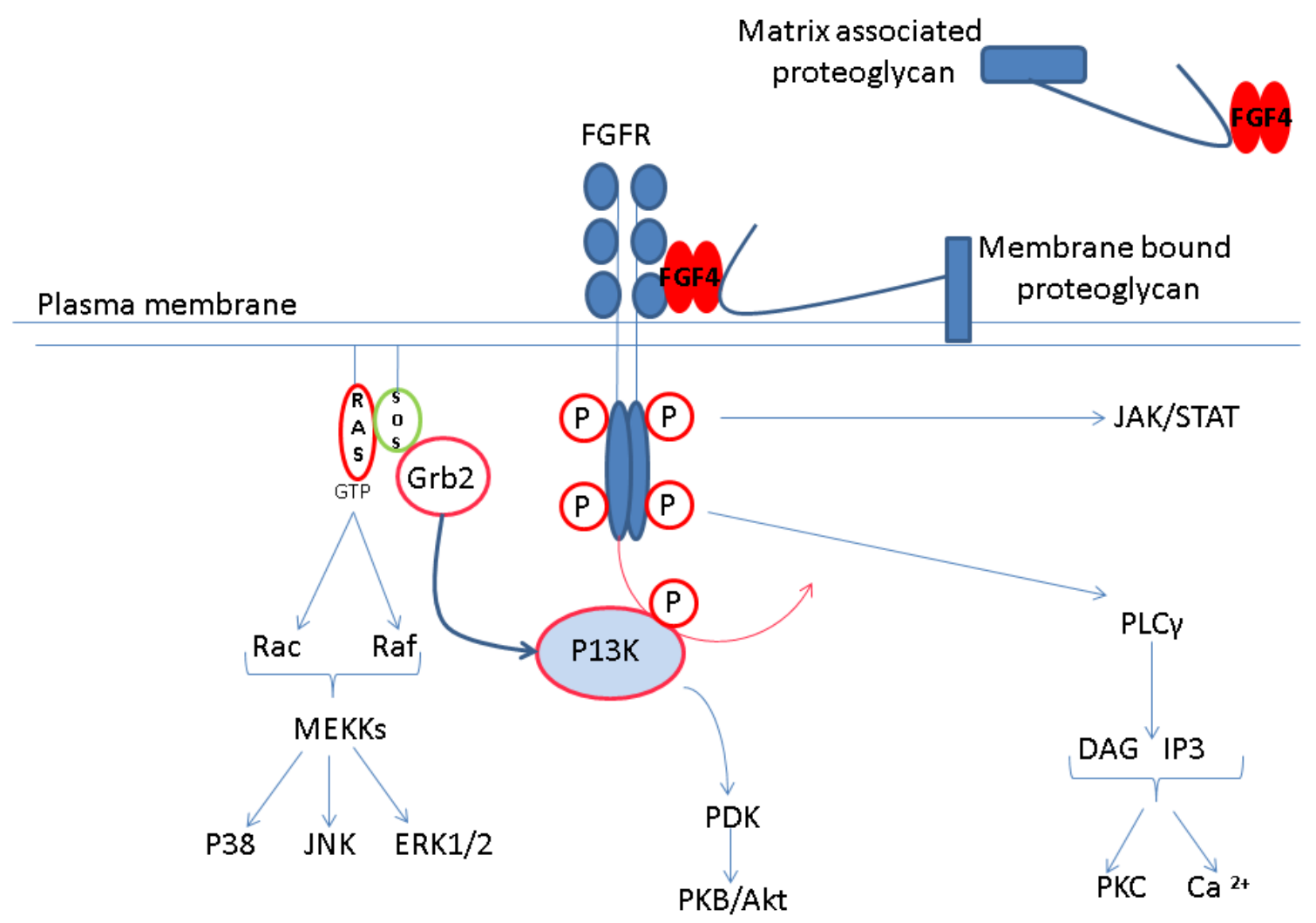

Figure 3-1: Main signalling paths induced through FGF signalling For signalling to occur, a heparin sulphate proteoglycan inducer must be present. Modified from Lanner and Rossant, 2010.

There are four / five stem cells types isolatable from the early embryo, and FGF4 has effects on all of them; either being required for their derivation and maintenance, or - in the case of murine ES cells - driving their differentiation (Table 3-1). 


\section{Table 3-1: The effect of FGF4 on the formation and maintenance of early embryo stem cells}

$\begin{array}{lll}\text { Stem Cell } & \text { Requirement for FGF4 } & \text { Production of FGF4 } \\ \text { TS } & \text { Required } & \text { Produced } \\ \text { XEN } & \text { Required for initial (?) derivation } & \text { Produced } \\ \text { ES } & \text { Not required* } & \text { Produced } \\ \text { EpiSC } & \text { Required } & \text { Not Produced } \\ \text { HuES } & \text { Required } & \text { Not Produced } \\ \text { * induces neural differentiation } & \end{array}$

Mouse ES cells produce FGF4, and this is known to increase the likelihood of their differentiation; indeed, blocking FGF4 signalling with chemical inhibitors or preventing the Erk1/2 pathway will increase the efficiency of ES cell derivation (Kunath et al., 2007, Ying et al., 2008). Furthermore, species which have appeared to be intransigent for the derivation ES cells with Lif, respond when ICM cells are co-cultured with FGF4/Erk inhibitors and Lif. Hence, germ-line competent rat ES cells have been obtained only after inhibition of FGF signalling (Li et al., 2008). Similarly, blocking the expression or activity of the enzymes needed in proteoglycan production, so inhibiting FGF signalling, also results in ES which appear more stable and less prone to spontaneous differentiation (Kunath et al., 2007, Ying et al., 2008). 


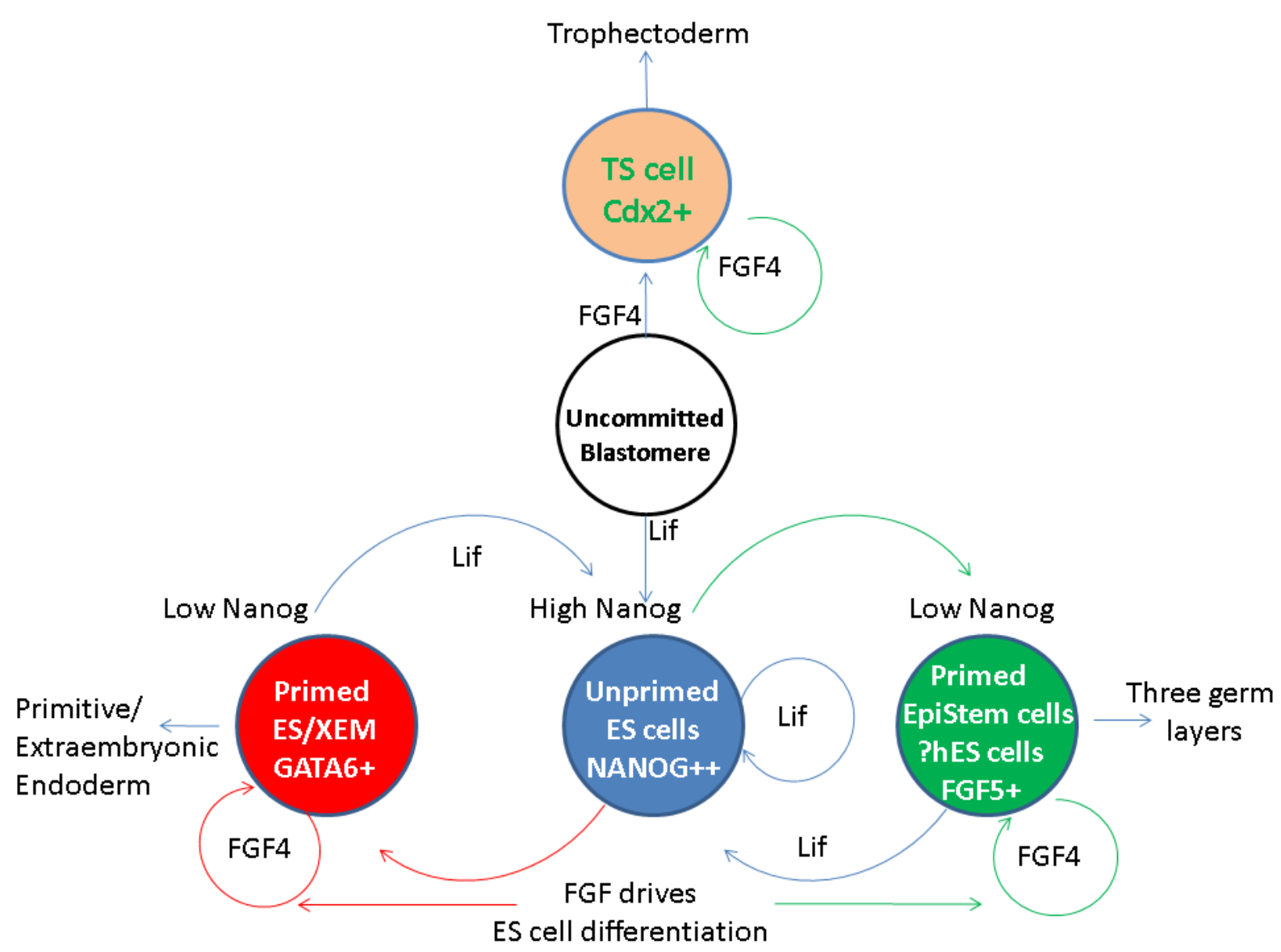

Figure 3-2: Linkage between the main early stem cell types and the role of FGF4 and Lif. FGFs maintain the primed stem cells; however, they drive differentiation of uncommitted blastomeres and the unprimed ES cells. Modified from Lanner and Rossant, 2010.

EpiStem cells express the pluripotency markers Sox2 and Oct4; however, while they may differentiate into all three germ layers, they are considered to be in a "metastable" state and are partially committed, as they differ from ES cells transcriptionally and fail to contribute to chimeras (Brons et al., 2007). The cells show the typical $X$ inactivation marks seen in post implantation epiblast cells, and also express FGF5 typical of the late epiblast rather than the ICM. They require FGF2 (and activin A) to prevent both their differentiation (especially to neuronal cells) and also their re-conversion to ES cells (Brons et al., 2007). If FGF signalling is inhibited in the presence of Lif, EpiStem cells undergo $X$ reactivation and can repopulate blastocysts to form chimeras (Guo et al., 2009). 
Human ES cells are transcriptionally closer to EpiStem cells than Murine ES cells; however, they do respond to Lif and show an increase in Stat3 phosphorylation (Chen et al., 2015). This is not sufficient to drive self-renewal: for this they require FGF and Activin signalling like EpiStem cells (see earlier). It also appears that FGF4 signalling blocks the differentiation of these cells toward other cell types (Mayshar et al., 2008). Inhibiting FGFR signalling and blocking Erk1/2 will allow EpiStem cells to pass back through a murine ES-like stage (stabilised by Lif) through XEN stem cells to Sox7 expressing PE cells, or to Cdx2 expressing TE cells (stabilised by the later reapplication of FGF4) (Guo et al., 2009) (Figure 3-2).

In summary, fluctuation and driven interconversion between all the stem cell types present in the early embryo is possible in both human and mouse, and FGF signalling pathways have a diversity of effects and stabilise a number of these different stem cell types.

\section{FGF production}

FGF4 is necessary for the isolation and culture of TSCs. It is needed in an abundant and stabilized supply for the long term undifferentiated culture of these cells. For this reason, we produce FGF4 as a recombinant protein in a eukaryotic expression system.

\section{Mammalian protein expression systems}

There are several different expression systems for the production of recombinant proteins: both prokaryotic and eukaryotic systems have their own advantages and disadvantages. While E. coli is easy, cost-effective to culture, grows quickly and the vector is easy to transfer into cells, prokaryotes do not have the eukaryotic post-translational modifications - in particular, those seen in extracellular proteins. Hence, changes occur in disulphide bond closure and the correct $\mathrm{N}$ or O-linked glycosylation. FGF4 shows glycosylation, and all members of the FGF family share conserved cysteines; in other members of the FGF family, these are known to be used in stabilising disulphide bonds. The absence of these may affect the protein's folding and hence function (Jenkins et al., 2008).

Eukaryotic systems grow slower than prokaryote systems, generally give lower yields, need a stricter culture environment and are often more complex to purify. Of the eukaryotic systems 
available, mammalian cells have more repeatable post-translational processing than insect or yeast cells, so we chose a mammalian cell system for the production of the FGF4 protein.

\subsection{Material and Methods}

\subsubsection{Amplification of FGF4 cDNA}

Primers were designed based upon the murine FGF4 sequence (Figure 3-3)

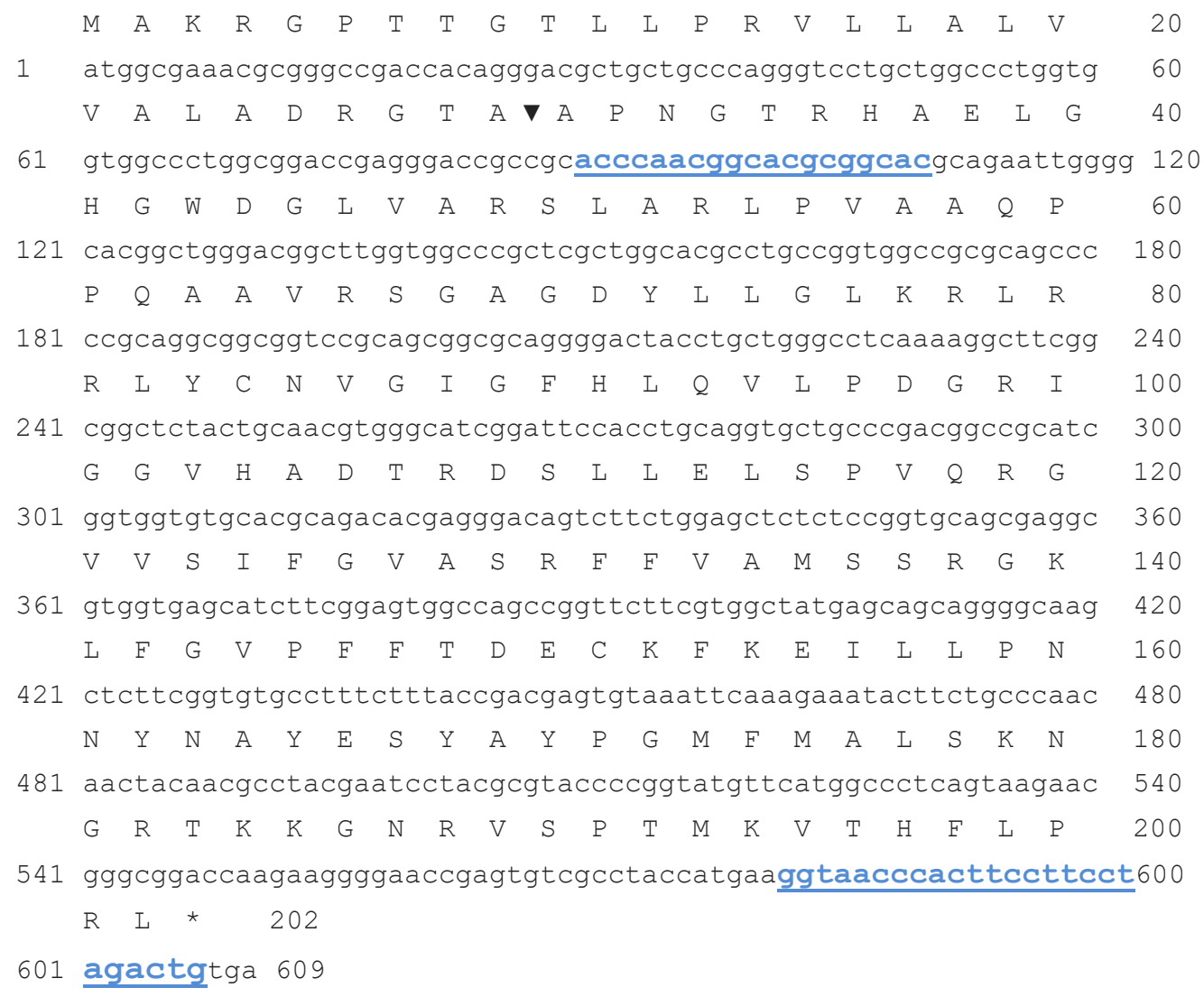

Figure 3-3: The Mus musculus FGF4 sequence from NCBI (BC104312)

The arrow is the position of the cleavage site of the signal peptidase. The asterisk is the translational stop codon.

The primer site is labelled in Figure 3-3 in blue and two restriction enzymes (Nhe1 and Not1) with different cutting sites were added to the $5^{\prime}$ and $3^{\prime}$ primers respectively. These were placed so as to produce a fusion protein as shown below. The enzymes were selected due to their suitability for the vector PCEP-Pu (Figure 3-4). Additional adenine/thymine sequences were added to the beginning of the primers to optimise their AT/CG ratios; these regions are non-coding and will be cleaved from the amplified region by the restriction digestion. 


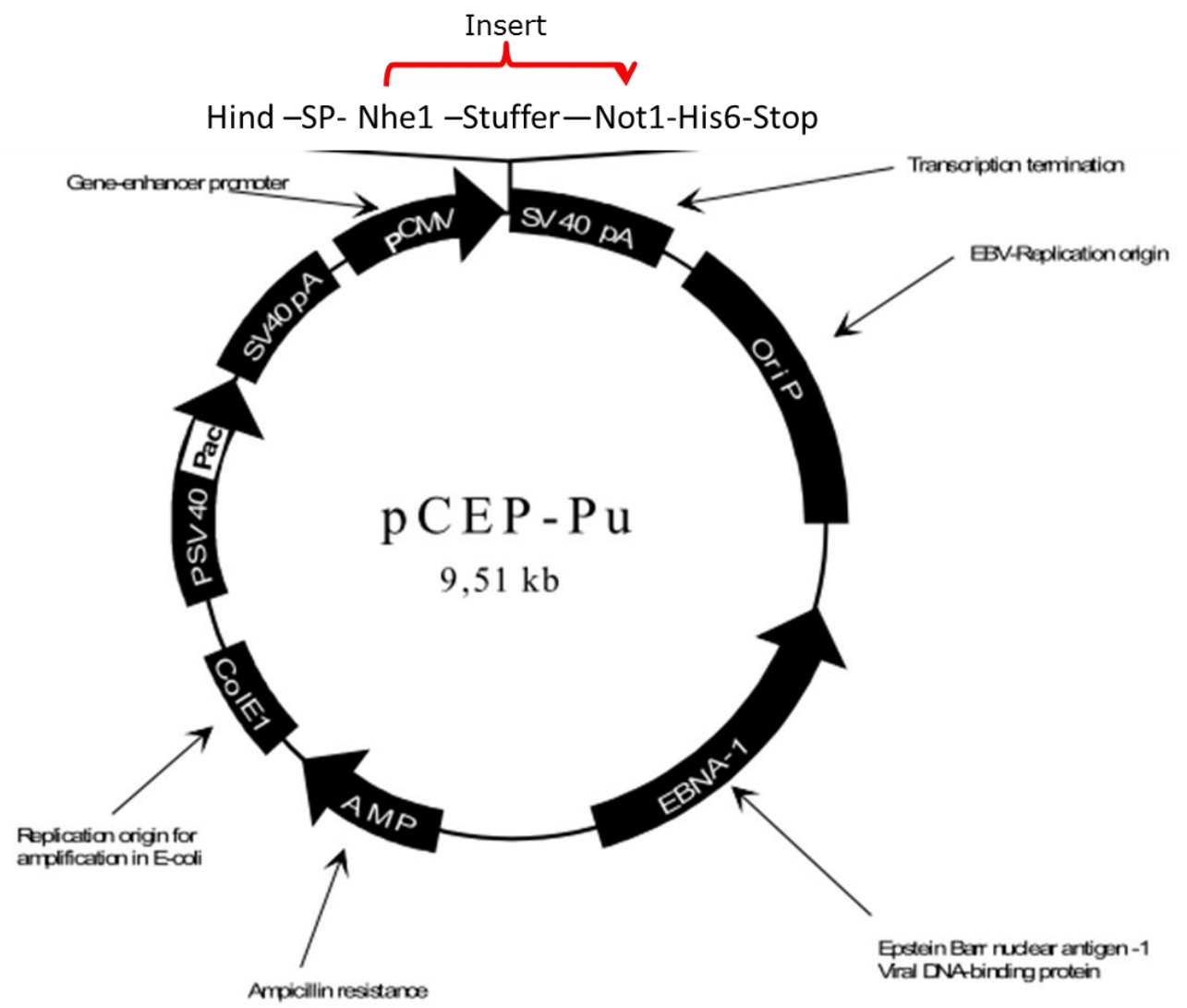

Figure 3-4: The structure of pCEP-Pu. (Kanigicherla et al., 2013)

The pCEP-Pu vector has different functional sites, including AMP (ampicillin resistance) which can be selected in E. coli, and a ColE1 replication origin for plasmid amplification in E. coli. A puromycin $\mathrm{N}$ acetyl transferase resistance $(\mathrm{Pac}$ ) gene is also present in this vector, which allows the selection of transfected eukaryotic cells. The EBNA-1 gene (Epstein-Barr nuclear antigen 1) drives extrachromosomal replication of the plasmid in mammalian cells through the binding and activation of the EBV- OriP replication initiation sequence. Thus the vector replication rate remains high and independent of cell proliferation; so very many copies of the plasmid (typically 50-200) are present in transfected mammalian cells. The CMV promoter (pCMV), which is highly expressed in many human cell lines, drives strong transcription of any insert. A 6-His-tag is added on the C-terminal of the recombinant protein for ease of purification and detection. Thus this system produces high protein levels but does not result in clones, as the expression plasmid is retained extrachromosomally. For the proper secretion pathway, which is needed for any $\mathrm{N}$ linked glycosylation and closure of disulphide bonds, a signal peptide from BM-40 (SP) was included as an in-frame $\mathrm{N}$ terminal fusion; this is highly efficient and has been extensively used to drive release of proteins into the endoplasmic reticulum. 
Chapter 3

The primers designed for amplification of murine FGF4 cDNA are shown below:

MuFGF4-Foward

5’ AATTGCTAGCACCCAACGGCACGCGGCAC

The underlined region is the Nhe1 recognition sequence

MuFGF4-Reverse

5' AATTTGCGGCCGCCAGTCTAGGAAGGAAGTGGGTTACC

The underlined region is the Not1 recognition sequence

PCR was carried out using random primed cDNA produced by reverse-transcribing mRNA from murine ES cells as a template. These cells express high levels of FGF4 and little of any other FGF mRNA. Total RNA was extracted with Tryzol (Guanadinium and Phenol) and then differentially isolated by chloroform separation (Chomczynski and Sacchi, 1987). cDNA was produced by extension of $1 \mu \mathrm{g}$ RNA after random hexamer annealing using AMV reverse transcriptase (Table 3$2,3-3)$.

Table 3-2: Conditions to produce random primed total cDNA

\begin{tabular}{|l|l|l|}
\hline Ingredient & Volume & Note \\
\hline Water (RNA free) & $16 \mu \mathrm{l}$ & \\
\hline $5 x$ buffer $(25 \mathrm{mM} \mathrm{MaCl} 2)$ & $2.5 \mu \mathrm{l}$ & Promega A3500 \\
\hline Random Primers (hexamer) & $2 \mu \mathrm{l}(1 \mu \mathrm{g})$ & \\
\hline dNTP & $1 \mu \mathrm{l}$ & (final concentration 1mM) \\
\hline RNA template & $2 \mu \mathrm{l}$ & $(\sim 1 \mu \mathrm{g})$ \\
\hline AMV reverse transcriptase & $1 \mu \mathrm{l}$ & Promega A3500 \\
\hline $\begin{array}{l}\text { Recombinant RNasin } \\
{ }^{\circledR}\end{array}$ & $0.5 \mu \mathrm{l}$ & \\
Ribonuclease Inhibitor & & \\
\hline
\end{tabular}

Prior to setting up the reaction on ice, the RNA was denatured by heating for 10 minutes at $70^{\circ} \mathrm{C}$. The reaction was carried out at $42^{\circ} \mathrm{C}$ for 30 minutes, and then at $37^{\circ} \mathrm{C}$ for a further 30 minutes. The enzyme in the sample was then destroyed by heat at $95^{\circ} \mathrm{C}$ for 5 minutes.

The amplification was carried out as below, using a gradient of annealing temperatures between 50 and $66^{\circ} \mathrm{C}$. 
Table 3-3: PCR conditions to amplify FGF4 mRNA

\begin{tabular}{|c|c|c|}
\hline Ingredient & Volume & Note \\
\hline Water & $90 \mu \mathrm{l}$ & \\
\hline 10x buffer & $10 \mu \mathrm{l}$ & Roche Cat. 11146173001 \\
\hline $5^{\prime}$ primer & $2 \mu l$ & $\begin{array}{l}10 \mathrm{mM} \text { stock } \\
\text { (final concentration } 200 \mu \mathrm{M} \text { ) }\end{array}$ \\
\hline $3^{\prime}$ primer & $2 \mu l$ & $\begin{array}{l}10 \mathrm{mM} \text { stock } \\
\text { (final concentration } 200 \mu \mathrm{M} \text { ) }\end{array}$ \\
\hline dNTP & $1 \mu l$ & $\begin{array}{l}\text { TaKaRa } 2.5 \mathrm{mM} \text {, Cat. } 4030 \\
\text { (final concentration } 250 \mu \mathrm{M} \text { ) }\end{array}$ \\
\hline DNA template & $2 \mu l$ & $\begin{array}{l}\text { random primed cDNA } \\
(\sim 0.2 \mu \mathrm{g})\end{array}$ \\
\hline Polymerase & $1 \mu l$ & $\begin{array}{l}\text { Taq polymerase, } \\
\text { Roche Cat. No. } 11146173001\end{array}$ \\
\hline
\end{tabular}

\subsubsection{Ligation and cloning into sequencing and expression vectors}

The cDNA fragment was isolated after running on an agarose gel, using a QIAquick Gel Extraction Kit (Qiagen - ID 28704). This was initially subcloned into the pDRIVE TA cloning vector (Qiagen ID231122), making use of the thymidine addition at the 3' end of Taq amplified DNA. Inserts were tested by sequencing using M13 forward and reverse primers present in the multiple cloning of the pDRIVE vector. The insert from correct clones was released by restriction enzyme digestion with Not1 and Nhe1 and cloned into pCEP-Pu (Table 3-4).

Table 3-4: Conditions to digest the expression vector by the restriction enzymes Nhe1 and Not1

\begin{tabular}{|l|l|l|}
\hline pCep-Pu/ pDrive-FGF4 & $10 \mu \mathrm{l}$ & $0.3 \mu \mathrm{g} / \mu \mathrm{l}$ \\
\hline $10 x$ Buffer 2 & $2 \mu \mathrm{l}$ & NEBiolabs B7002S \\
\hline Nhe1 & $0.5 \mu \mathrm{l}$ & NEBiolabs R0131L \\
\hline Water & $7.5 \mu \mathrm{l}$ & \\
\hline Final volume & $20 \mu \mathrm{l}$ & Incubated at $37^{\circ} \mathrm{C}$ for 1 hour \\
\hline
\end{tabular}

\begin{tabular}{|l|l|l|}
\hline Vector cut by Nhe1 & $20 \mu \mathrm{l}$ & \\
\hline $10 x$ Buffer 3 & $4 \mu \mathrm{l}$ & NEBiolabs B7003S \\
\hline $10 x$ BSA & $4 \mu \mathrm{l}$ & NEBiolabs \\
\hline Not1 & $0.5 \mu \mathrm{l}$ & NEBiolabs R0189L \\
\hline Water & $11.5 \mu \mathrm{l}$ & \\
\hline Final volume & $40 \mu \mathrm{l}$ & Incubated at $37^{\circ} \mathrm{C}$ for 1 hour \\
\hline
\end{tabular}

Digested DNA possesses a 5' phosphate group that is needed for ligation. To prevent self-ligation, this phosphate can be removed from the cut vector DNA prior to ligation, which reduces background in the cloning process and also makes the correct ligation reaction more efficient. Following digestion, the pCEP-Pu vector was treated with Calf Intestinal Alkaline Phosphatase (CIP) (NEBiolabs M0290), and the T4 DNA ligase enzyme repaired the DNA strand breaks. Once vectors 
Chapter 3

and inserts had been cut run and isolated, they were mixed together at approximately a molar ratio of 5:1 (insert to vector) and incubated with the enzyme at $14^{\circ} \mathrm{C}$ overnight. Controls of vector and insert alone were also included (Table 3-5).

Table 3-5: cDNA Ligation conditions

\begin{tabular}{|l|l|l|}
\hline Vector cut by restriction enzyme & $2 \mu \mathrm{l}$ & \\
\hline Insert DNA & $6 \mu \mathrm{l}$ & \\
\hline $10 x$ Ligase buffer & $1 \mu \mathrm{l}$ & Promega C126 \\
\hline Ligase enzyme & $1 \mu \mathrm{l}$ & Promega M1801 \\
\hline Total volume & $10 \mu \mathrm{l}$ & \\
\hline
\end{tabular}

\subsubsection{Transfection into mammalian cells}

The plasmid expression vectors need to be transferred into mammalian cells for recombinant protein production. This procedure (called "transfection") was carried out using lipofection, with FuGENE 6 (Promega E2691) - a multi-component lipid-based transfection reagent. Its cationic lipids form an aggregate with the negatively charged (anionic) genetic material, and can readily merge with the cell membrane.

The lipofection mixture was prepared by warming $100 \mu \mathrm{l}$ of serum-free DMEM media in a sterile polystyrene tube. $6 \mu \mathrm{l}$ of the Fugene reagent was added and mixed into the medium, then incubated for 5 minutes. $1 \mu \mathrm{l}$ of the plasmid $(1 \mu \mathrm{g} / \mu \mathrm{l})$ was added and mixed with the DMEM/Fugene. Following incubation for a further 15 minutes at room temperature, the medium/transfection agent/DNA mixture was added directly to the cells in their growth media. The plates were gently shaken to spread the DNA, and they were then cultured at $37^{\circ} \mathrm{C}, 5 \% \mathrm{CO}_{2}$. After 48 hours, the cells were split to two $10 \mathrm{~cm}$ petri dish and puromycin selection $(1 \mu \mathrm{g} / \mathrm{ml})$ was started. Untransfected cells were included as a control for puromycin activity. 


\subsection{Results}

\subsubsection{PCR amplification of FGF4 CDNA.}

The amplification of the murine FGF4 fragment was performed using mouse ES cells. The PCR products were analysed by running on an agarose gel (Figure 3-5). The expected band of $546 \mathrm{bp}$ was observed in lanes 4, 5, and 6. This is expected from the estimated annealing temperatures of the primers, as the primer MuFGF4-Reverse has an estimated annealing temperature to the cDNA of $\sim 56^{\circ} \mathrm{C}$.

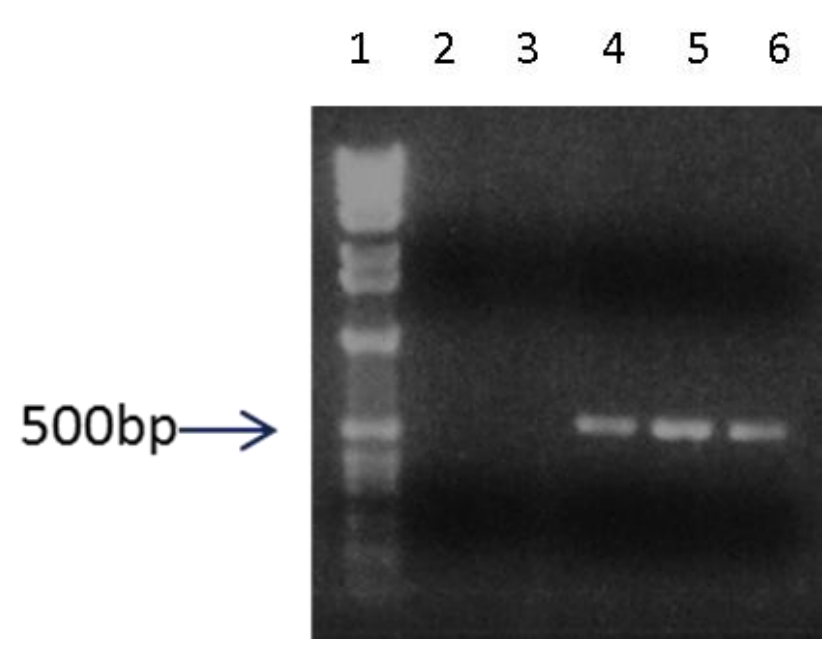

Figure 3-5: The amplification of the FGF4 CDNA from mouse ES cells.

Lane 1, 1Kb marker, lane 2, negative control from mock reverse transcription reaction lacking any enzyme, 3-6 amplification using a gradient of annealing temperature from $66^{\circ} \mathrm{C}$ (lane 3) to $50^{\circ} \mathrm{C}$ (lane 6).

\subsubsection{Vector and insert purification}

The PCR product was purified from the gel, and through silica column binding (Qiaquick Gel Extraction kit Qiagen), the DNA was eluted into water. Initial attempts to Nhe1- Not1 digest the PCR product, purify it and directly clone it into the pCEP-Pu vector failed, possibly due to the relatively small amounts of product. Therefore, we changed the strategy: pDrive vector allows direct cloning of Taq amplified products, and so minimises digestion and extra purification steps. The cDNA was directly inserted into pDrive vector, which allowed selection by blue/white LacZ disruption. The pDrive vectors with insert were amplified and purified (Figure 3-4). The clones 
were tested for the presence of an insert by running both undigested DNA and EcoR1-digested DNA (the latter releases the full insert on 540bp) (Figure 3-6).
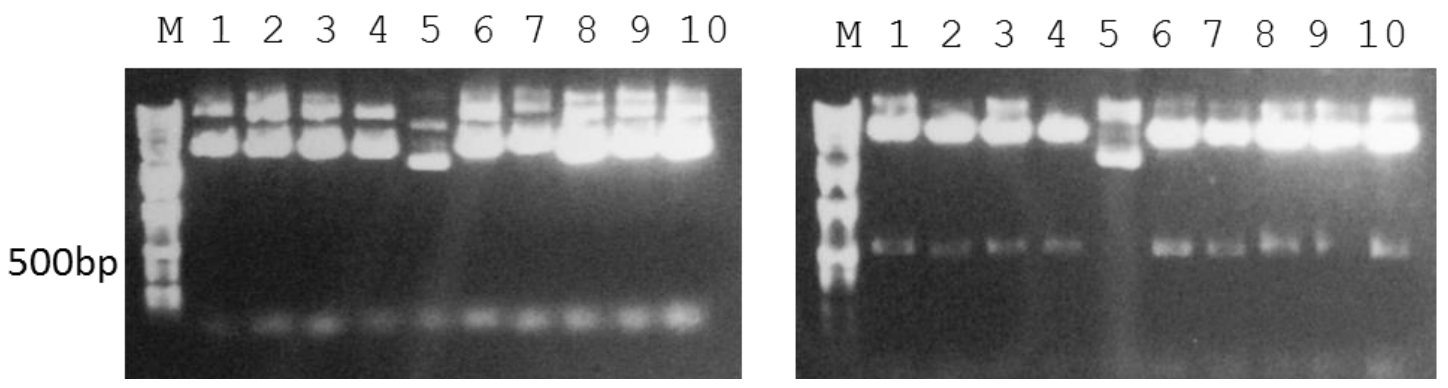

Figure 3-6: Extracted plasmids following ligation of the FGF4 DNA fragment into the pDrive vector

Left panel undigested, right panel EcoR1 cut plasmid DNA Lane 1-10 are clones picked from blue/white LacZ expression. All clones except 5 appeared to contain the correct insert. Three samples (\#1, \#3 and \#6 from the above) were chosen and cultured as midi-preps.

Three clones were further analysed by sequencing (MRC-PPU, DNA sequencing and services). Two clones contained no changes to the protein coding of the sequence (when compared to NCBI Reference Sequence: NM_010202.6). These two clones (FGF4-Mu-1 and FGF-Mu-3) were then cut with Nhe1 and Not1 to release the insert; the third clone, FGF4-Mu-6 (which also had no evident mutation) did not appear to cut. The insert was purified as described above after agarose gel electrophoresis (Figure 3-7).

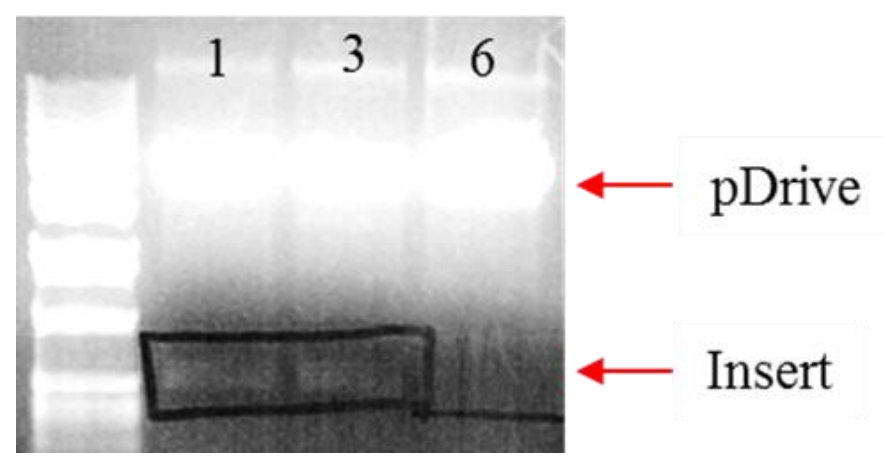

Figure 3-7: The insert cut after cloning FGF CDNA into the pDrive vector.

Clones FGF4-Mu -1 and FGF-MU-3 released the insert, but not clone FGF4-Mu -6

The fragment was successful ligated into the Nhe1 / Not1 cut and the CIP-treated pCEP-Pu vector and transformed into DH5 a competent E Coli, which were selected on ampicillin plates. Clones were picked and cultured for DNA mini-preparation. DNA preps were tested by digestion with 
HindIII / Not I, which releases the whole expression coding region - including the signal peptide from the plasmid (Figure 3-8).

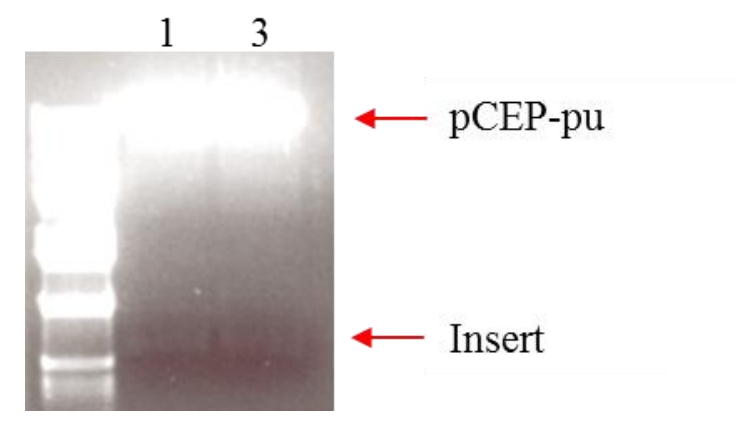

Figure 3-8: Analysis of the pCep-Pu vector containing FGF4-Mu, from the pDRIVE

Clones FGF4-Mu-1 and FGF-Mu-3. Digestion of the plasmids with HindIII / Not1 produces a band of $650 \mathrm{bp}$.

\subsubsection{Transfection of HEK-293 cells and Analysis of FGF4 Expression}
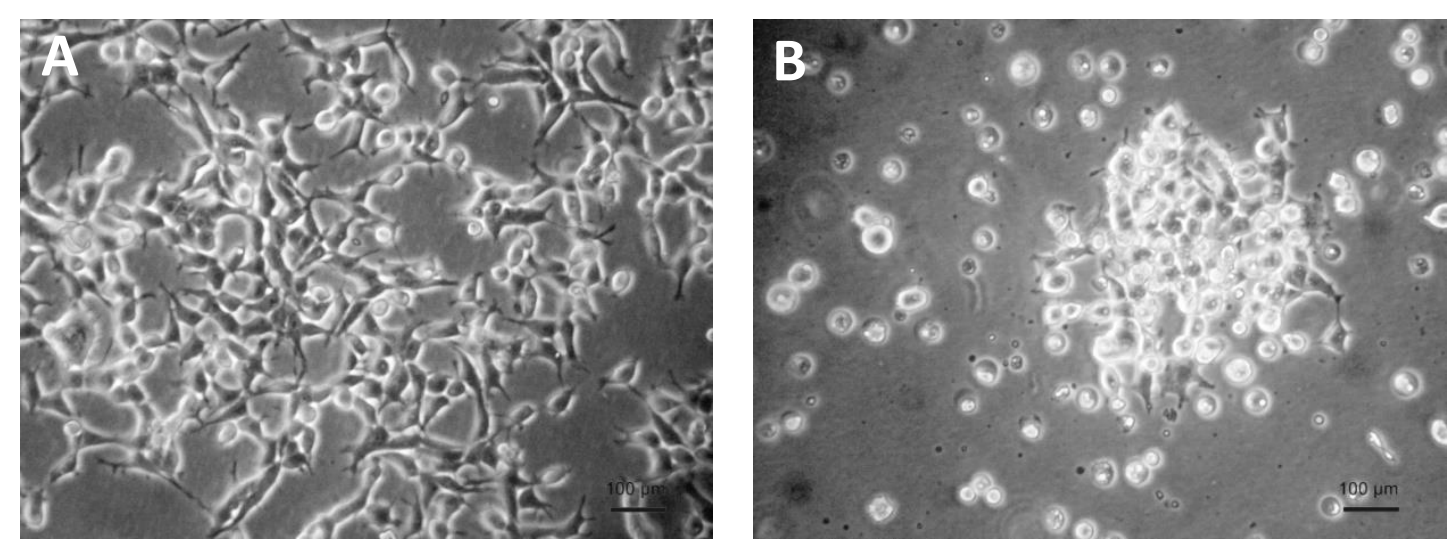

Figure 3-9: HEK-293 cells were selected by puromycin

(A) Untransfected control (B) Transfected cells after 4 days selection.

The midi-prep purified DNA from the above clones was then used for transfection of 293 HEK (human embryonic kidney) cells. 48 hours after transfection, selection with puromycin was initiated (Figure 3-9). After the puromycin selection was finished, the puromycin-resistant cells had become fully confluent in approximately 6 days. The culture medium was then changed from selection to serum and puromycin free medium for harvesting and analysis of protein expression. After 48 hours in the serum-free medium, the supernatant was collected and analysed for FGF4 expression.

The protein was concentrated by ethanol precipitation, with 10 times the volume of pure ethanol, after incubation at $-20^{\circ} \mathrm{C}$ overnight. Precipitated protein was obtained by centrifugation, washed with $70 \%$ ethanol, dried and then re-suspended in water. The protein equivalent of $0.5 \mathrm{ml}$ of 
Chapter 3

supernatant (a tenfold concentration) was separated by PAGE and transferred to a PVDF

membrane. The recombinant protein was produced as a C-terminal 6 His-tag fusion, and the blot was probed with an antibody directed against the tag. A visible band signal is seen at 20kDa shown in lanes 1 and 3 of (Figure 3-10), close to the recorded size of murine FGF4 (22kDa).

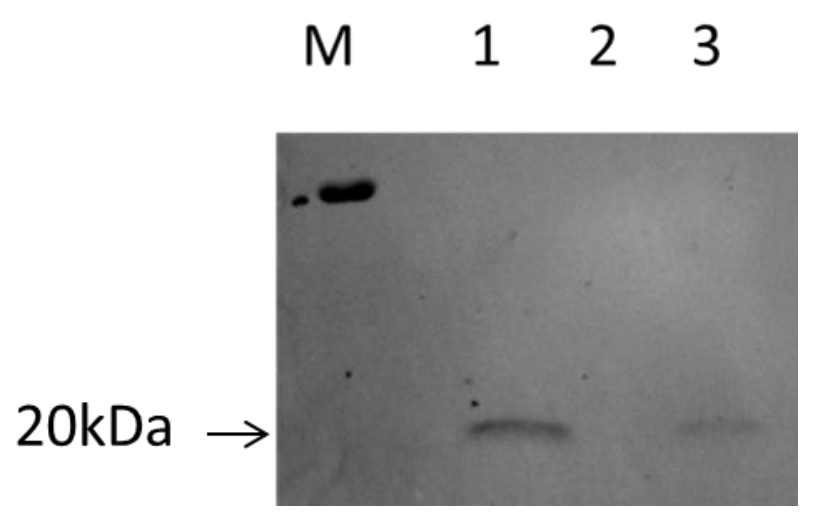

Figure 3-10: The Western blotting result indicated FGF4 present in lanes 1 and 3 with a band of molecular weight of approximately $20 \mathrm{kDa}$

M: Low molecular weight marker. Lane 2 is the supernatant from untransfected 293 cells acting as a negative control.

\subsection{Testing of FGFs Biological Activity}

FGF4 can induce NIH-3T3 cell proliferation in serum-free medium (Talarico and Basilico, 1991). We then tested our FGF4-containing supernatant against commercial FGF4 (Sigma F8424).

\subsubsection{Material and methods}

Both live cell counts and an MTT assay were carried out. The cells were cultured in medium which contained varying dilutions of FGF4-conditioned media, as secreted by the HEK-293 cells. These were then compared with the commercial standard culture media containing $25 \mathrm{ng} / \mathrm{ml} \mathrm{FGF4} \mathrm{to}$ determine the level of bioactivity. The method used for the MTT assay is as described in Chapter 2.

\section{Cell count}

The day before the test, NIH-3T3 cells were split into 6-well plates, at a density of $5 \times 10^{4}$ cells per well. After 24 hours the medium was changed, as per the following table: 
Table 3-6: The medium used in bio-activity test

\begin{tabular}{|c|c|}
\hline FBS control & DMEM/F12+ 10\%FBS \\
\hline Negative control & DMEM/F12, 50 $\mu \mathrm{g} / \mathrm{ml}$ Heparin \\
\hline $25 \mathrm{ng} / \mathrm{ml} \mathrm{FGF4}$ & $\begin{array}{l}\text { DMEM/F12, } 50 \mu \mathrm{g} / \mathrm{ml} \text { Heparin, } 25 \mathrm{ng} / \mathrm{ml} \text { commercially } \\
\text { available FGF4 (R\&D systems) }\end{array}$ \\
\hline $10 \% \mathrm{CM}$ & $\begin{array}{l}\text { DMEM/F12, } 50 \mu \mathrm{g} / \mathrm{ml} \text { Heparin, } 10 \% \text { conditioned medium } \\
\text { from FGF4 expressing HEK- } 293 \text { cells }\end{array}$ \\
\hline $10 \%$ CM-NT & $\begin{array}{l}\text { DMEM/F12, } 50 \mu \mathrm{g} / \mathrm{ml} \text { Heparin, } 10 \% \text { conditioned medium } \\
\text { from HEK-293 cells }\end{array}$ \\
\hline $2 \% \mathrm{CM}$ & $\begin{array}{l}\text { DMEM/F12, 50 } \mu \mathrm{g} / \mathrm{ml} \text { Heparin, } 2 \% \text { conditioned medium } \\
\text { from FGF4 expressing HEK-293 cells }\end{array}$ \\
\hline $1 \% \mathrm{CM}$ & $\begin{array}{l}\text { DMEM/F12, 50 } \mathrm{gg} / \mathrm{ml} \text { Heparin, } 1 \% \text { conditioned medium } \\
\text { from FGF4 expressing HEK-293 cells }\end{array}$ \\
\hline
\end{tabular}

The cell numbers were counted and an MTT assay performed on days 2, 4 and 6 .

\subsubsection{Results}

The direct cell count numbers showed that though the presence of FBS had a continued effect on cell growth, both the FGF and conditioned media maintained cell numbers at levels over the serum-free, negative control (Figure 3-11). The effects were evident at day 2 and lesser at days $4 / 6$, presumably due to the poor stability of FGF and/or heparin in presence of the cells.

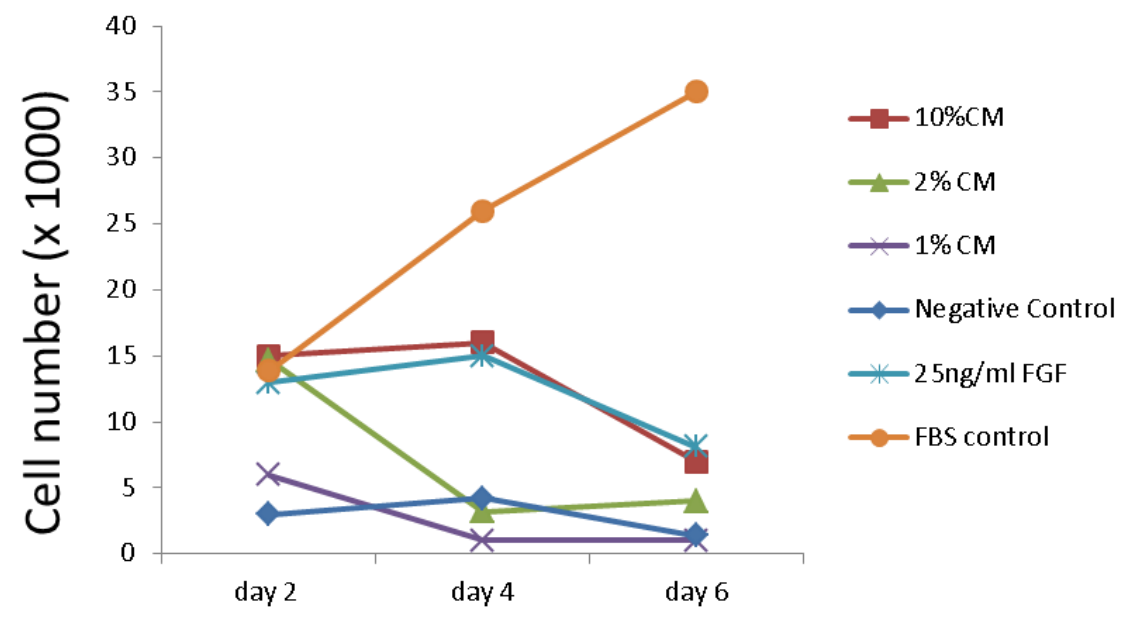

Figure 3-11: Effects on 3T3 cell numbers upon culture in FGF4 and dilutions of conditioned media (CM) - all assays were carried out in the presence of heparin. 
Chapter 3

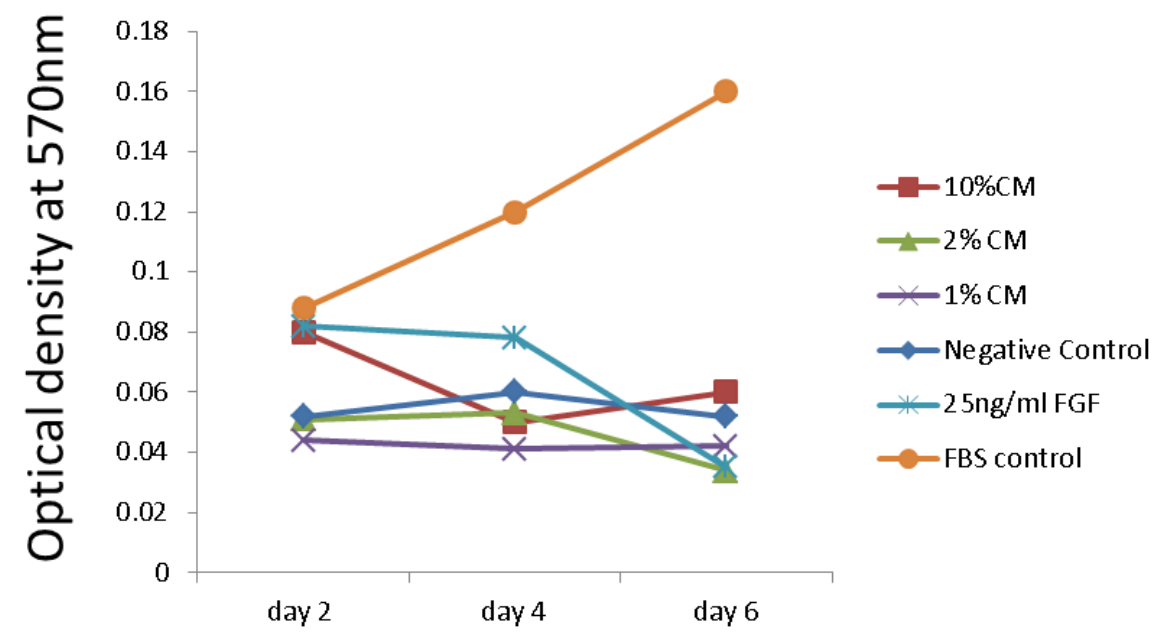

Figure 3-12: MTT conversion assay upon culture of 3T3 fibroblasts in FGF4 and dilutions of conditioned media (CM) - all assays were carried out in the presence of heparin.

The cell counting assay suggested that 1:10 diluted condition media resulted in similar numbers of cells as were observed with the standard $25 \mathrm{ng} / \mathrm{ml}$ concentration of FGF4. However, the effect was reduced after 4 days in both media - possibly due to destruction of either the FGF4 or the heparin sulphate. The MTT assay shows variable results (possibly due to the low numbers of cells) but all indicated the activity decreased at day 6 .

To be certain the effects were effective over a prolonged culture, the above assays were repeated but the media was changed daily. Again, cell numbers and MTT conversion was measured every second day. An increase in cell numbers was observed in the presence of $10 \%$ and $2 \%$ conditioned media over the full period of the study, and the response of the $10 \% \mathrm{CM}$ appeared close to that of the $25 \mathrm{ng} / \mathrm{ml}$ standard (Figures 3-13 and 3-14). 


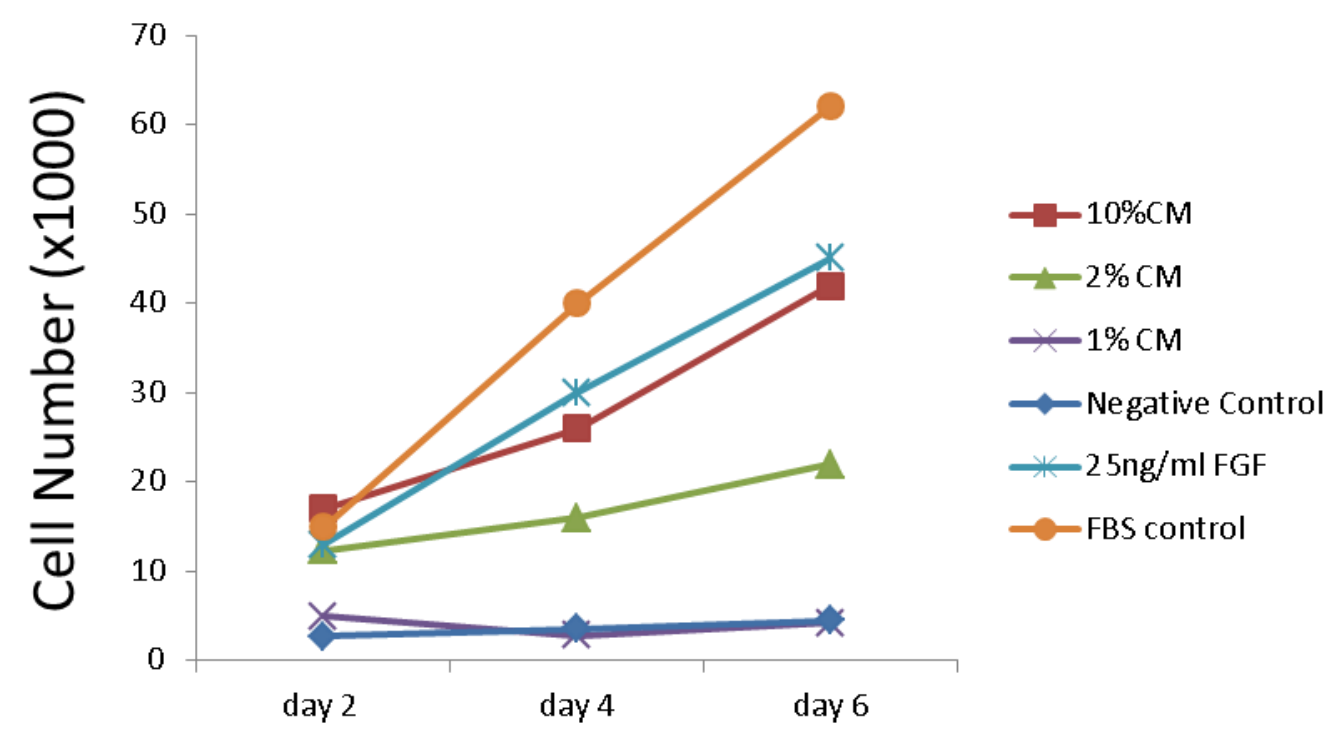

Figure 3-13: Effects on 3T3 cell numbers upon culture in FGF4 and dilutions of conditioned media (CM)

All assays were carried out in the presence of heparin, here the media was changed daily.

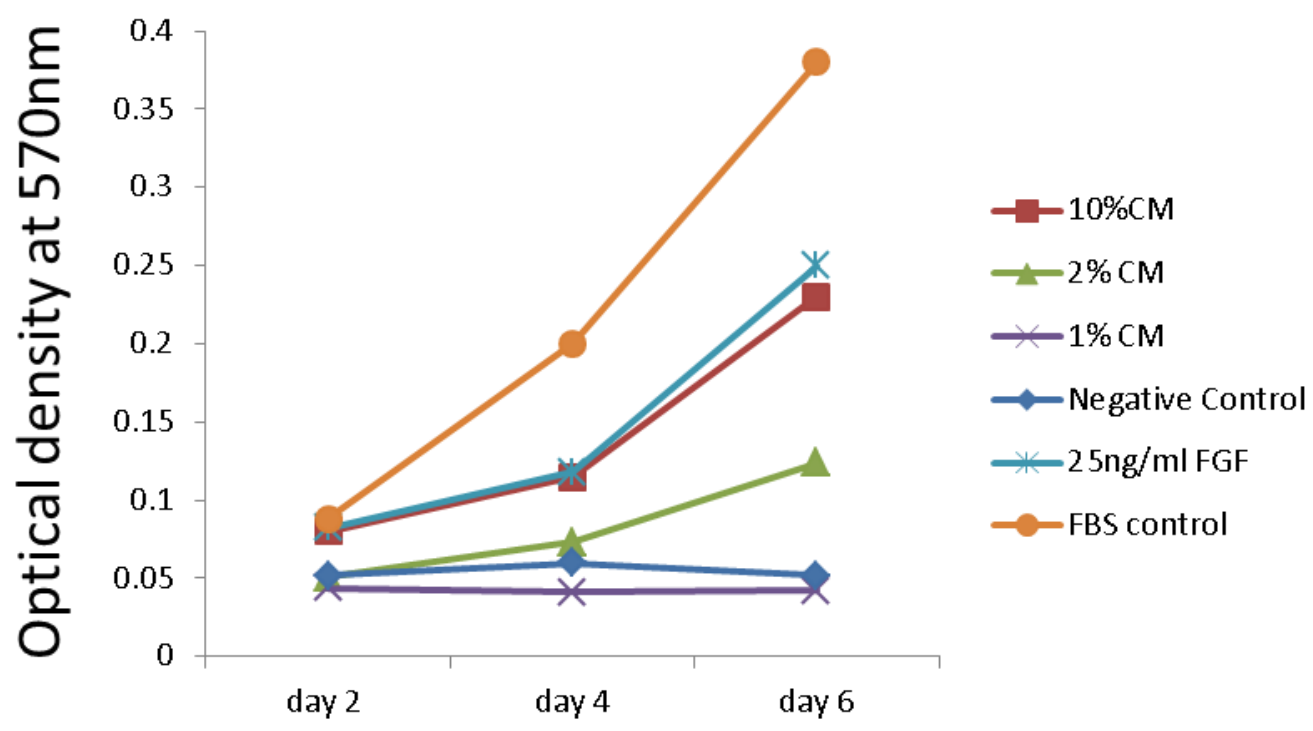

Figure 3-14: MTT conversion assay upon culture of 3T3 fibroblasts in FGF4 and dilutions of conditioned media (CM)

All assays were carried out in the presence of heparin, here the media was changed daily.

Finally, to rule out other factors in the conditioned media causing the cell proliferation, media from non-transfected 293-HEK (NT) cells was compared. Further, the effect of heparin was analysed for its effect on NIH-3T3 cells (Figure 3-14). This demonstrated that the effect of the conditioned media from cells transfected with the FGF construct (CM) was heparin dependant 
Chapter 3

and there was very little effect when 3T3 cells were cultured with conditioned media from untransfected HEK-293 cells, showing that the FGF4 expressed by the 293 cells was active and functioning in a heparin/heparin sulphate dependent manner.

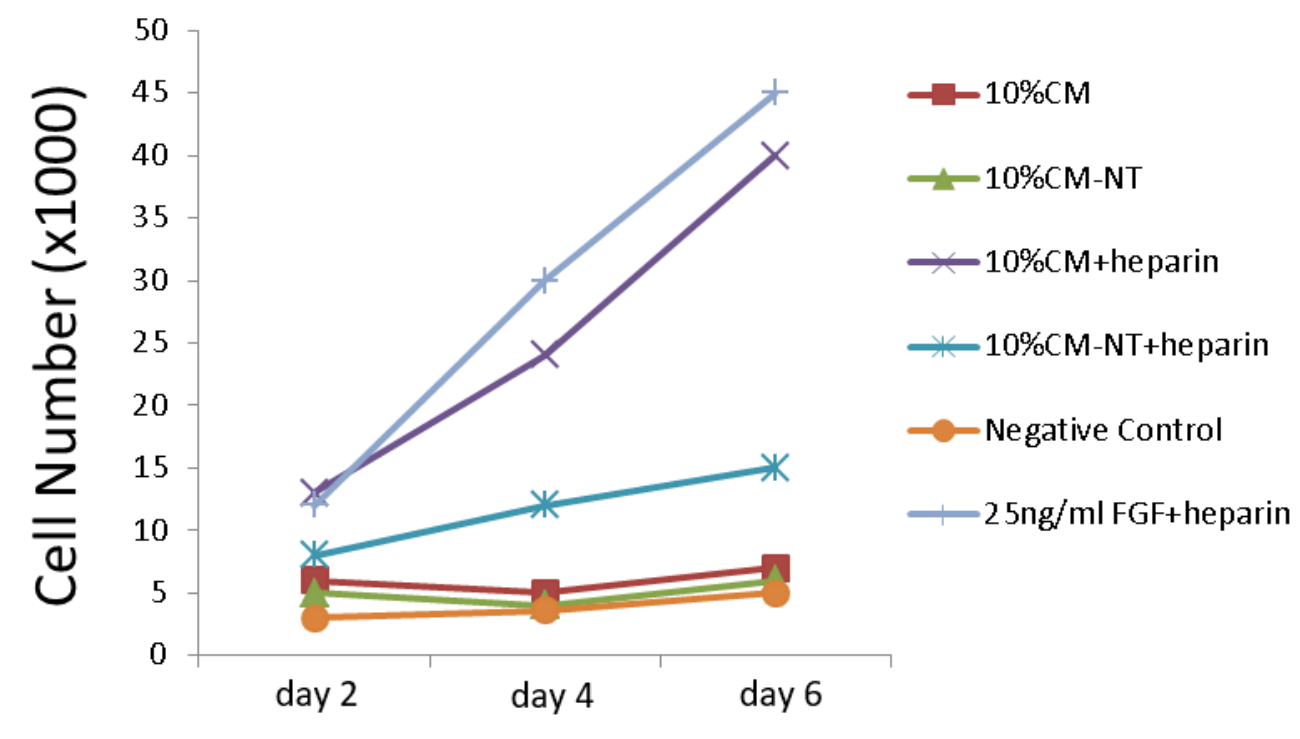

Figure 3-15: Effects on 3T3 cell numbers upon culture in FGF4 and dilutions of conditioned media (CM)

Here, assays were carried out in the presence and absence of heparin and the media was changed daily. CM is conditioned media from cells transfected with the FGF4 construct. CM-NT is conditioned media from untransfected HEK-293 cells, with a small heparin dependent effect.

\subsection{Discussion}

Here we cloned and expressed murine recombinant FGF4 in mammalian cells. The protein is highly expressed in ES cells, so we utilised this as our source of mRNA. The cDNA was subcloned and sequenced to verify its identity and check for any PCR-induced mutation prior to its cloning into the pCEP-Pu vector. This vector has the ability to act as an episome in cells carrying the EBNA gene, so it will replicate independently of the cells' own replication cycle, and can produce many copies of the plasmid in the cell. This results in the potential for producing extremely high yields (Odenthal et al., 2004). The vector used results in the recombinant protein being produced as a fusion protein; at the $\mathrm{N}$ terminus, the modified sequence carries the signal peptide of the BM40/SPARC protein for efficient translocation of the transcript/forming protein to the rough endoplasmic reticulum. This leads to the entry of the immature protein into the eukaryotic secretory pathway, and results in correct folding and other post-translational modifications. This has major advantages in that refolding of the protein is not required - a procedure which results 
in much protein loss and which is needed in bacterial expression system. Furthermore, correct closure of di-sulphide bonds occurs - stabilising the structure - and suitable glycosylation occurs, neither of which is seen prokaryotes. Finally, a major advantage of this system over bacterial expression is the removal of the risk of endotoxins being present in any purified recombinant proteins. The LPS part of the E.coli coat is known to dramatically alter cell division in ES cells, can affect their differentiation, and is known to be toxic to stem cells at levels far lower than that observed with other stable cells lines (Nagy, 2003). At the C-terminus, the FGF4 is fused to a His6 sequence placed in the parental plasmid 3' of the Not1 site. The addition of this tag allows purification of the protein from the medium, as well as its identification in immunoblots using antisera raised against poly His peptides (see Figure 3-10).

We analysed the activity in the medium by comparing the conditioned media from the transfected 293 cells with commercial FGF4. Initial experiments showed that the conditioned media had a dose-dependent mitotic effect upon 3T3 cells grown in serum free media, though it was evident that both assays showed a reduced response after 4 and 6 days. It is possible the activity of the mitogen was lost as the cytokine had degraded by proteases in the medium, as studies by others have shown that FGFs have a short half-life both in cell culture and in vivothough this is somewhat extended by their interaction with proteoglycans (Beenken and Mohammadi, 2009).

We then analysed the cells after regular media replacement, and this showed an extended effect, with cell proliferation continuing over the full 6 days of the assay period. This also shows that to maintain any desired effect will require the regular, at least every two days, replenishment of media. This mitogenic action - which was heparin dependant - was lost in its absence. To verify if there was any other mitogen present, conditioned media from untransfected HEK-293 cells was also tested; this showed a very slight mitogenic effect, about $15 \%$ of that seen with the FGF4 expressing cell media. This was also heparin dependant, suggesting that the HEK-293 cells naturally produce low levels of FGF.

Comparing different dilutions of the conditioned media in the cell counting and MTT proliferation assays, both suggested that there was approximately $250 \mathrm{ng} / \mathrm{ml}$ active FGF4 in the pooled supernatant - assuming that the commercial recombinant FGF4 was fully active (this may not be 
Chapter 3

correct, as this was bacterially expressed and would be expected to have a lower activity than the eukaryotic form).

In summary, we have cloned and expressed the active FGF4, and we next tested this for its ability to maintain TS cells in culture. 


\section{Chapter 4. Optimization of Methods to Establish TS Cell Lines}

\subsection{Introduction}

The first TS cell line was established by Professor J. Rossant's group (Tanaka et al., 1998). Unlike ES cells, where many lines have been established by different laboratories and most have been extensively characterised, far fewer TS lines have been produced. Also, perhaps because these cells have a limited differentiation capacity, they have not been studied as extensively. In fact, most work has utilised the $\mathrm{TS}_{3.5}$ line, the first one described in Tanaka et al., 1998, (Liu et al., 2004, Zhong et al., 2004, Xie et al., 2005). It was a further four years before another laboratory reported being able to repeat the process, and only four other labs had established TS cell lines over the next decade (Mak et al., 2002, Yang et al., 2006, Wen et al., 2007, Chiu et al., 2008). To date, only some 30 independent TS cell lines have been produced from only about 15 different laboratories - most having transgenic modifications (Table 4-1). From this, it must be assumed that the routine isolation of stable TS cell lines has proved difficult to repeat. Factors which may play a part in the isolation and maintenance of TS cells include the genetic background of the embryos used to isolate the cells, the timing of the culture, the timing and extent of trypsinisation, and the inclusion of contaminating cells which may drive differentiation.

TS cells are cultured in high concentrations of FCS (15-20\%) with the addition of FGF and its cofactor heparin. The medium also contains conditioned medium from foetal fibroblasts (see below). Furthermore, the cells are maintained during their derivation and when not used experimentally by growing on a feeder layer of mitotically inactivated murine fibroblasts. As a result, the culture medium is enriched for many other non-specified growth factors, which may vary over time and have a major effect upon the efficiency of derivation and the maintenance of the cells in an undifferentiated state. 
Chapter 4

In this chapter, we describe how culture conditions were optimised to obtain TS cell lines. The methods used were based upon those of Tanaka et al., 1998 with some variations. 
Table 4-1: TS cell lines established to date

\begin{tabular}{|c|c|c|}
\hline Name & Description & Reference \\
\hline $\mathrm{TS}_{3.5}$ & $\begin{array}{l}\text { The first TS cell line establish from E3.5 embryo, Strain: } \\
\text { 129/Sv }\end{array}$ & \multirow[t]{3}{*}{ (Tanaka et al., 1998) } \\
\hline $\mathrm{TS}_{6.5}$ & The first TS cell line establish from E6.5 embryo, Strain: ICR & \\
\hline $\begin{array}{l}\text { EGFP-TS }_{3.5} \\
\text { EGFP-TS } 6.5^{2}\end{array}$ & Strain: B5/EGFP transgenic mice & \\
\hline$A 2, B 1, B 7$ & $\begin{array}{l}\text { Mixed genetic cell lines from C57BL6 x CBA: F1 females with } \\
\text { PGK males }\end{array}$ & (Mak et al., 2002) \\
\hline $\begin{array}{l}\text { Wild-type; and } \\
\mathrm{C} \times 31^{-/}\end{array}$ & C57BL/6J inbred strain and Cx31-deficient strain & (Kibschull et al., 2004) \\
\hline $\mathrm{Cd} \times 2^{+/-}$ & $\begin{array}{l}\text { Cdx2 targeted mutation with ICR strain mixed genetic } \\
\text { background }\end{array}$ & (Strumpf et al., 2005) \\
\hline TS & A TS cell line derived from C57BL/6NCrj mouse blastocysts & (Hattori et al., 2007) \\
\hline $\begin{array}{l}\text { Ets2 } \\
\text { Ets2 }{ }^{\mathrm{db} 1 /+} \\
\mathrm{Ets}^{\mathrm{db} 2 /+} \\
\mathrm{A72/A72}\end{array}$ & TS cells from Ets $2^{\mathrm{db} 1 /+}$ heterozygote (129/Sv background) & (Wen et al., 2007) \\
\hline $\begin{array}{l}\text { SENP2 }{ }^{+/+} \\
\text {SENP2 }\end{array}$ & SENP2 mutant mouse & (Chiu et al., 2008) \\
\hline $\begin{array}{l}\text { AG } \\
\text { PG } \\
\text { Wild-type }\end{array}$ & B6D2F1 (C57BL/6 x DBA2) mice were used as oocyte donors. & (Ogawa et al., 2009) \\
\hline $\begin{array}{l}\text { MEKK4 }{ }^{\mathrm{WT} / \mathrm{K} 1361 \mathrm{R}} \\
\mathrm{TS}^{\mathrm{K} 14} / \mathrm{TS}^{\mathrm{WT}}\end{array}$ & (C57BL/6 x 129/SvEv) and pure (129/Sv Ev) backgrounds, & $\begin{array}{l}\text { (Abell et al., 2009, Abell } \\
\text { et al., 2011) }\end{array}$ \\
\hline $\begin{array}{l}\text { ICR-GFP } \\
\text { F1 }\end{array}$ & C57BI/6 x Balb/c F1- mixed genetic background & $\begin{array}{l}\text { (Epple-Farmer et al., } \\
\text { 2009) }\end{array}$ \\
\hline ntTS & TS cell lines from nuclear transfer & (Oda et al., 2009) \\
\hline Dicer $^{\mathrm{fx} / \mathrm{fx}}$ & Dicer ${ }^{\mathrm{fx} / \mathrm{fx}}$ mice - mixed $129 /$ Sv genetic background & $\begin{array}{l}\text { (Spruce et al., 2010, } \\
\text { Santos et al., 2010) }\end{array}$ \\
\hline TS & B6 x CAST F1 mixed genetic background & (Golding et al., 2010) \\
\hline TSC-BK12 & Bl6D2/F1 mixed genetic background & $\begin{array}{l}\text { (Kidder and Palmer, } \\
\text { 2010, Kidder and } \\
\text { Palmer, 2012) }\end{array}$ \\
\hline TS & Strain: CD1 & (Saito et al., 2011) \\
\hline $\begin{array}{l}\text { 1FTSC } \\
4 \text { FTSC }\end{array}$ & $\begin{array}{l}\text { Oct-GFP-positive embryos directly derived to TS cells (1FTSC) } \\
\text { or transduced with lentiviruses (4FTSC) }\end{array}$ & $\begin{array}{l}\text { (Kuckenberg et al., } \\
\text { 2011) }\end{array}$ \\
\hline $\mathrm{Cdh} 1^{\mathrm{GT} / \mathrm{GT}}$ & Cdh1+/GT $\mathrm{C} 57 \mathrm{BL} / 6$ background mice & (Naoe et al., 2013) \\
\hline $\begin{array}{l}\mathrm{I} 6, \mathrm{~K} 2, \mathrm{~K} 4 \\
\mathrm{~F} 3, \mathrm{~F} 2\end{array}$ & $\begin{array}{l}3 \text { GFP lines from 129/Sv.Hprt }{ }^{\text {bm1 }} . \text { Pgk.1a x 129.Tgn.GFPX4 } \\
2 \text { control from 129/Sv.Hprt }{ }^{\text {bm1 }} \text {.Pgk.1a x 129/Sv }\end{array}$ & (Dubois et al., 2013) \\
\hline CAT1 & $\begin{array}{l}\text { BALB/CAJcl mice, collected at E2.5 and cultured to blastocyst } \\
\text { stage }\end{array}$ & (Aikawa et al., 2014) \\
\hline $\mathrm{Hif}^{-/-}$ & $\begin{array}{l}\text { TSCs derived from HIF-null mice (129/Sv mixed } \\
\text { background) }\end{array}$ & (Choi et al., 2013) \\
\hline
\end{tabular}




\subsection{Materials and Methods}

\subsubsection{TS cell culture}

\section{Fibroblast condition medium preparation}

For optimal growth of TS cells, we first prepared fibroblast condition medium (FCM). Early passage murine fibroblasts were grown to confluency and treated with mitomycin C. Following extensive washing, the cells were trypsinised and plated at $\sim 1 \times 10^{6}$ cells per $10 \mathrm{~cm}$ dish and allowed to attach. The medium on the plates was replaced with TS medium (see appendix) and was collected as conditioned medium every 72 hours for up to 10 days following the mitomycin $C$ treatment. The medium was centrifuged and filtered prior to storage at $-20^{\circ} \mathrm{C}$. The $\mathrm{FCM}$ was generally used at $70 \%$ FCM with 30\% TS medium along with FGF4 and heparin for routine culture of TS cells.

\section{General method for the establishment of TS cell lines}

The TS cell culture was performed by following the protocol of Quinn, et al., 2005. Blasotcysts were collected on day E3.5 and cultured in a 6-well plate upon mitomycin-treated MEFs as feeder cells. They were cultured in $100 \%$ TS medium supplemented with FGF4 and heparin until the embryos had attached to the plate and cells had initiated an outgrowth from the blastocyst. After this initial plating and attachment, the medium was changed every 48 hours. After 6-8 days, the blastocysts were considered to be an appropriate size for disaggregation; they typically contained a central region of cells corresponding to the differentiating ICM and a surrounding halo of cells containing a proportion of TS cells (Figure 4-1).

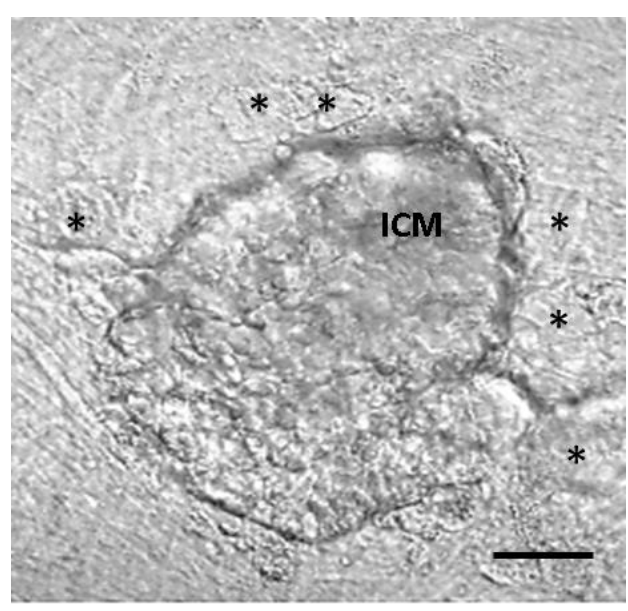

Figure 4-1: Embryonic outgrowth on MEF cells at day 5 ICM - is the differentiating inner cell mass, * are the outgrowing trophoblast cells spreading over the feeder cells (note their well-defined border) Bar- $50 \mu m$ 


\section{Collected E3.5 embryos}

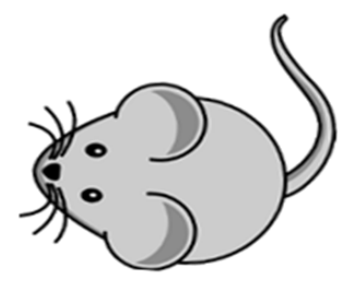

Total: 6 to 8 weeks

\section{TS medium with feeder cells}

[RPMI1640, FGF4, heparin, 20\% serum]
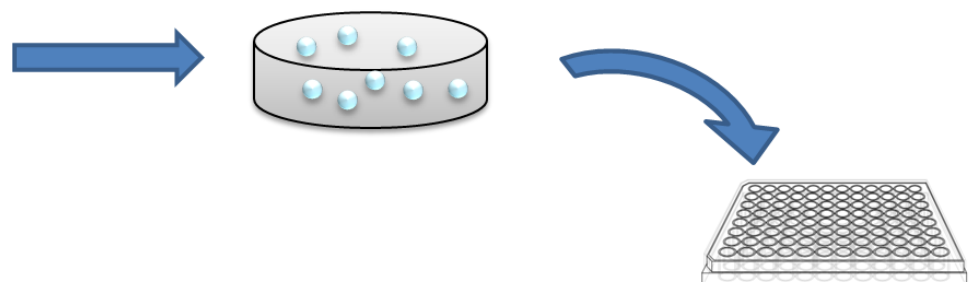

Disaggregate $0.125 \%$ trypsin

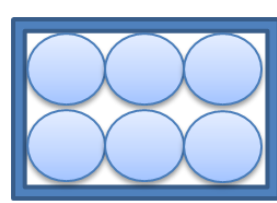

6-well

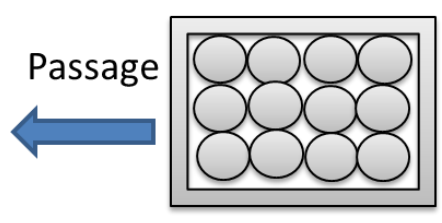

12-well

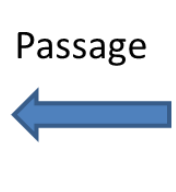

48-well

Figure 4-2: Diagram of the steps used in the establishment of TS cell lines

For the first disaggregation, we used trypsin at $0.125 \%$ concentration (diluted from $0.25 \%$ trypsin 1mM EDTA; Gibco 25200-056) upon the suggestion of Dr Myriam Hemberger (Babraham Research Institute). The medium was aspirated and cells rinsed with PBS. 10 $\mu$ l of warmed trypsin was placed in U-bottomed microwells, the embryonic outgrowth was picked using a $200 \mu \mathrm{l}$ yellow tip, and the outgrowth was then isolated in $2-3 \mu$ l of media. These were then transferred into microwells, incubated for 5 minutes, and pipetted under a microscope until they became single cell suspensions. The suspension drops were moved to a 48 -well plate containing MEFs. $400 \mu \mathrm{l}$ of medium (30\%TS: 70\%FCM media, see appendix) was added to each well in order to stop the trypsin. The media was changed the next day (30\%TS: 70\%FCM media). Where colonies appeared, the cells were maintained in a 48-well plate for 6-10 days until they were approximately 50\% confluent (see Figure 4-2). Clones were expanded further, provided their morphology remained undifferentiated. In some cases, obvious contamination with primitive endoderm was seen in some clones; these cells appear as evenly spaced small round cells which rapidly proliferate and occur upon differentiation of the ICM (see Figure 4-3). These usually appeared within the initial outgrowth or after the first split - especially if the ICM was inadvertently carried over. Where endoderm contamination was extensive, the clones were discarded. 


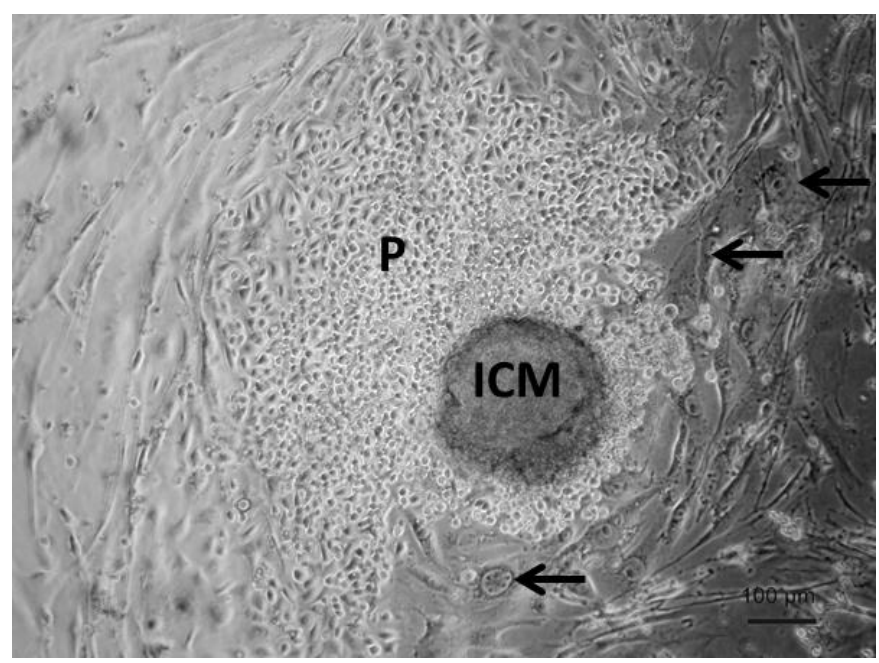

Figure 4-3: Parietal Cells (P) appearing from the ICM in a differentiating embryonic outgrowth.

These cells had been grown for 6 days after collection initial collection. There are a small number of large flat trophoblast cells present, but they appear to be differentiating with obvious large nuclei (arrows)

The cells were passaged from 48-well plates into 12-well plates. In the first several (2-7) passages, gross differentiation of the TS cells still occurred in some wells. After early passages, TS cells could be spilt at approximately 1:20 ratio every 5-7 days. Once cells were able to be stably passaged without overt differentiation - generally at the $3^{\text {rd }}$ or $4^{\text {th }}$ split - they were frozen in liquid nitrogen with TS freezing medium (see appendix) for future studies.

\subsection{Results}

\subsubsection{Optimisation TS cell culture}

Our initial attempts were based upon using the inbred strain C57BL/6 - this strain is genetically understood and is highly inbred. However, we failed to obtain any TS colonies surviving past the second passage. Generally, while the blastocysts hatched, attached and produced an initial outgrowth, they showed marked differentiation and parietal endoderm formation. The laboratory has had success in producing ES cells from this strain of mice (Andrew Cox PhD thesis, 2013), and the experience gained from this work suggested that C57BL/6 embryos matured earlier, hatching approximately 6 hours quicker than outbred mice such as MFI. To obtain ES cells, the initial splitting after out-growth had to be carried out some 48 hours earlier than described for other 
mouse strains (Behringer et al., 2014). Hence we attempted to derive TS cells with an initial removal of the outgrowth 2 days earlier; however, only one cell line [0920]E1 was obtained from 322 picked embryos and expanded past the second passage.

As genetically hybrid ES cells produced from $\mathrm{F} 1$ embryos from crosses of two highly inbred strains have been described as being easily obtainable and stable in culture (Eggan et al., 2001), and as many of the existing TS cells come from such backgrounds, we attempted to produce such hybrid strain TS cells. Embryos from 7 week old C57BL6 female mice crossed with CBA male animals were produced and cultured as above; however, while these again resulted in embryonic outgrowths and colonies of TS cells at passage 1 and 2, no further expansion was possible, with large amounts of cell death and differentiation.

The culture of murine ES cells requires the regular splitting and the thorough trypsinisation to give a single cell suspension. However, such treatment of hES cells, epiblast stem cells and TS cells is believed to be detrimental to their culture, leading to cell death and the surviving cells appearing prone to differentiation. Subsequently, we took line [0920]E1 and cultured it, disaggregating the cells with varying concentrations of trypsin-EDTA, incubating the cells in each case for exactly 5 minutes at $37^{\circ} \mathrm{C}$. We found that both $0.5 \%$ and $0.25 \%$ trypsin-EDTA very efficiently broke up the colonies but resulted in no $(0.5 \%)$ or very few surviving colonies, while $0.125 \%$ trypsin-EDTA resulted in sheets of cells which needed further trituration but had a far better survival rate. After trituration, we were left with small colonies of 2-5 cells which would grow further in an undifferentiated state. Lower concentrations of trypsin, reduced incubation times or cooler incubation temperatures resulted in colonies that either failed to separate from the MEF cells or which would not break into smaller groups of cells. We then investigated the disaggregation time point, passaging the cells on days 5 to 10 days, and found that dividing the colonies at 7 or 8 days after plating resulted in the best survival: later than this and the colonies did not disaggregate as well and required amounts of trituration, which resulted in far greater cell death.

The FGFs are relatively rapidly destroyed in vivo by denaturation and enzymatic degradation (Zakrzewska et al., 2009), as the initial disaggregation lacks a washing step and small amounts of 


\section{Chapter 4}

trypsin is carried over into the later culture. We adjusted the culture medium so at disaggregation, $1.8 \times 70 \%$ FCM medium was used with somewhat higher FGF $(45 \mathrm{ng} / \mathrm{ml})$ and heparin $(1.8 \mu \mathrm{g} / \mathrm{ml})$ concentrations (see appendix). This medium was changed on the next day to $1.5 x 70 \%$ FCM.

\subsubsection{Isolation of TS cells from MF1 mothers}

Given the knowledge gained from handling clone [0920]E1, we then attempted to obtain TS cells from fully outbred mice, and found that it was possible to obtain MF1 TS cells (Figure 4-4). This strain of mouse has been used extensively to study maternal effects upon later development, and while the efficiency was low, we did manage to obtain clones from both animals whose mothers received a normal protein and a low protien diet between day of plugging (E0.5 and blastocyst retreival E3.5).

In total, 13 stable clones were able to be maintained, frozen and retreived. Five clones from two NPD mothers were isolated and 8 from three LPD mothers, and these grew somewhat faster than the C57BI/6 cells (Table 4-3, Figure 4-5).

Overall, this is summaried in Table 4-2. We found that both in-bred and hybrid embryos gave a very low yield of TS clones, which were unstable - with only a single embryo producing a stable line - while the outbred MF1 mice would produce more robust clones, though many were still lost at passage. 

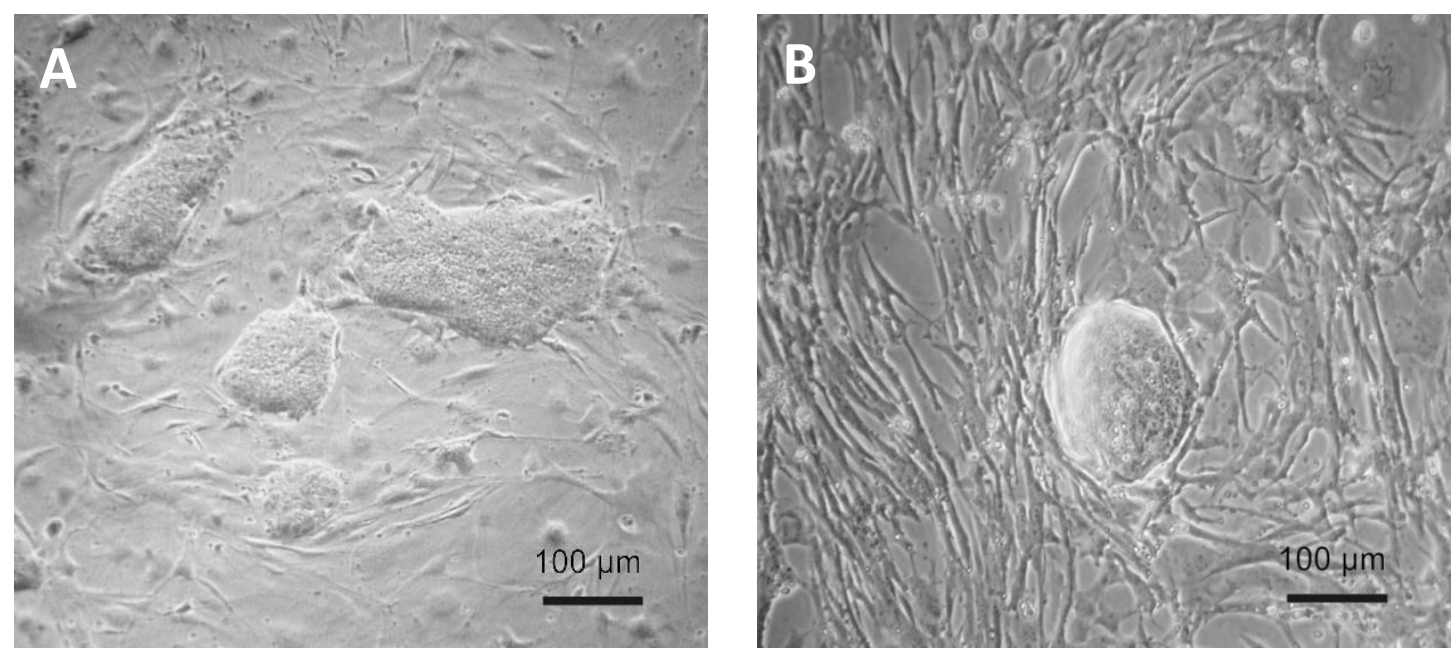

Figure 4-4: MF1 TS cells

(A) TS cells cultured on MEF, 4 days after passage. They are showing their classical morphology, with a defined and tight boundary.

(B) Culture in 1.5x 70\% FCM for 4 days. These cells were cultured without the addition of further MEF cells when passaged; the original MEF are retained in the culture. 
Table 4-2: TS cell lines establishment from different backgrounds

\begin{tabular}{|c|c|c|c|c|c|c|}
\hline Strain & Number of females donors & No. of embryos cultured & Numbers forming pickable outgrowths & Passage 1 & Passage 2 & Frozen clones \\
\hline C57/BI6 & 65 & 520 & 322 embryos - $62 \%$ & 12 & 4 & 1 clone $-0.2 \%$ \\
\hline C57/CBA & 65 & 442 & 327 embryos - 74\% & 15 & 7 & $0 \%$ \\
\hline MF1 & 14 & 163 & 78 embryos - $48 \%$ & 59 & 31 & 13 clones - $8 \%$ \\
\hline MF1-NPD & 10 & 119 & 47 embryos - 39\% & 30 & 15 & 5 clones $-4.2 \%$ \\
\hline MF1-LPD & 6 & 74 & 32 embryos - $43 \%$ & 28 & 13 & 8 clones - $11 \%$ \\
\hline
\end{tabular}


Table 4-3: TS cell lines established and frozen in liquid nitrogen, all were frozen at passage 3/4

\begin{tabular}{|c|c|c|c|c|}
\hline Cell line name & $\begin{array}{l}\text { Frozen passage } \\
\text { number }\end{array}$ & Mother's ID & Diet & Strain \\
\hline [0920]E1 & -- & $41 / 12 / 571$ & Chow & C57BL6 \\
\hline [1014]N, D2 & P3, P4 & $210 / 13 / 327-1$ & $18 \%$ protein & MF1 \\
\hline [1014]N, A2 & P3, P4 & $210 / 13 / 327-1$ & $18 \%$ protein & MF1 \\
\hline [1014]N, B3 & P4 & $210 / 13 / 327-1$ & $18 \%$ protein & MF1 \\
\hline [1014]N, E3 & P3 & $210 / 13 / 327-1$ & $18 \%$ protein & MF1 \\
\hline [1014]N, B1 & P4 & $210 / 13 / 327-2$ & $18 \%$ protein & MF1 \\
\hline [1021]L, E1 & P4 & $210 / 13 / 352-1$ & $9 \%$ protein & MF1 \\
\hline [1021]L, D2 & P4 & $210 / 13 / 352-1$ & $9 \%$ protein & MF1 \\
\hline [1021]L, D3 & P3 & $210 / 13 / 352-2$ & $9 \%$ protein & MF1 \\
\hline [1021]L, B5 & P3 & $210 / 13 / 352-3$ & $9 \%$ protein & MF1 \\
\hline [1021]L, F5 & P3 & $210 / 13 / 352-3$ & $9 \%$ protein & MF1 \\
\hline [1021]L, D5 & P3 & $210 / 13 / 352-3$ & $9 \%$ protein & MF1 \\
\hline [1021]L, A6 & P3 & $210 / 13 / 352-3$ & $9 \%$ protein & MF1 \\
\hline [1021]L, B6 & P3, P4 & $210 / 13 / 352-3$ & $9 \%$ protein & MF1 \\
\hline
\end{tabular}




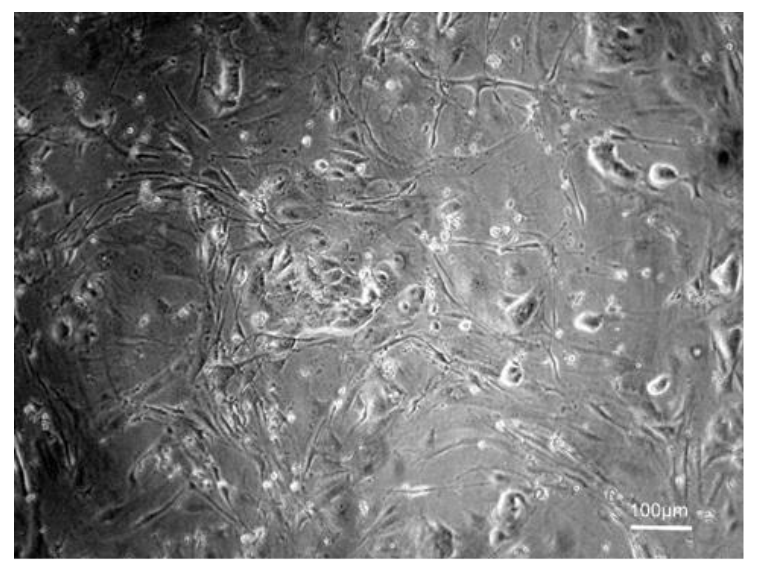

ND2

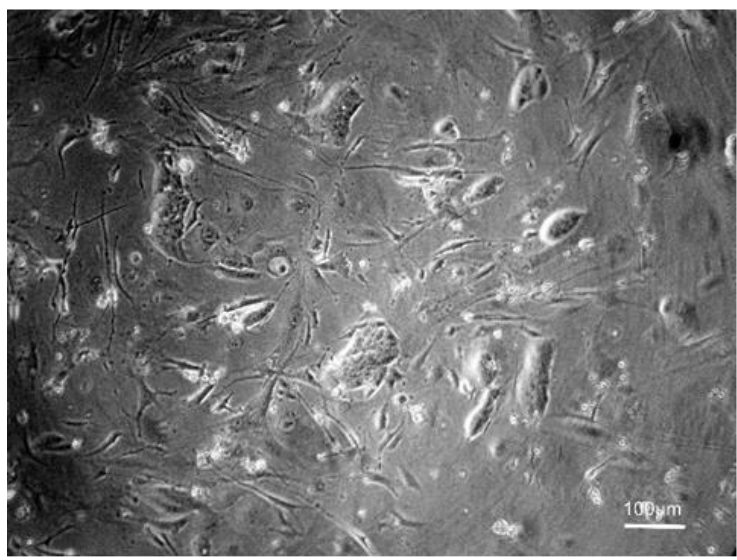

NB1

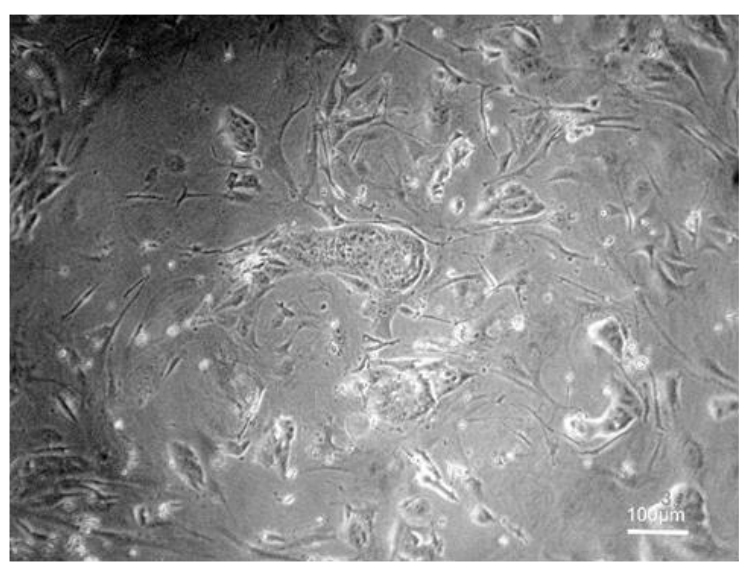

NE3

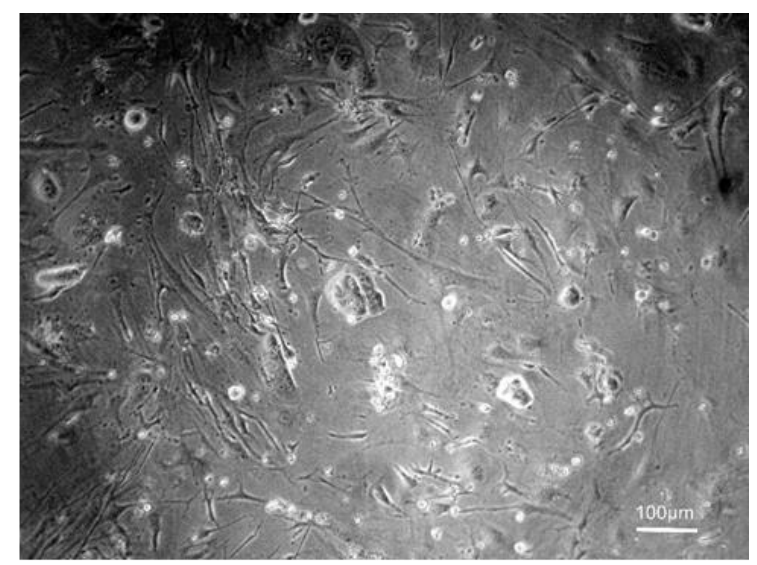

NB3

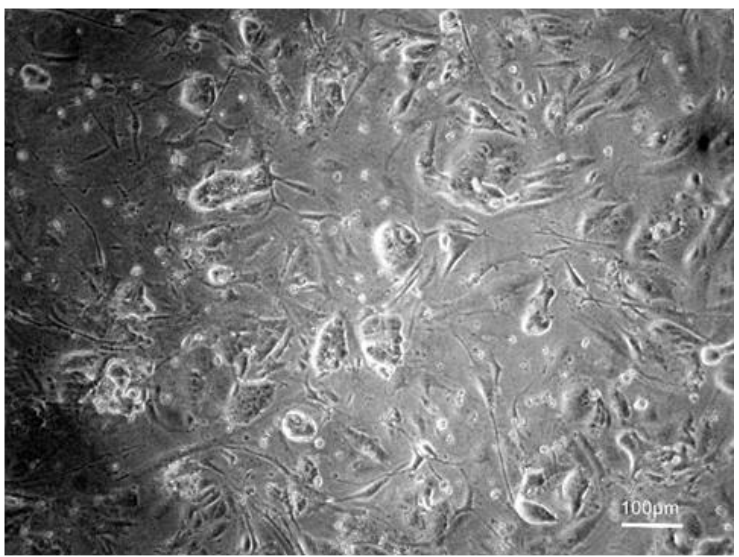

NA2 


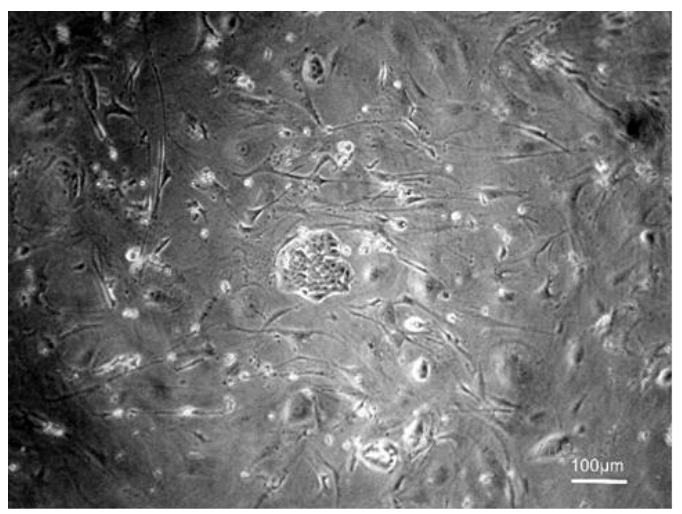

\section{LA6}

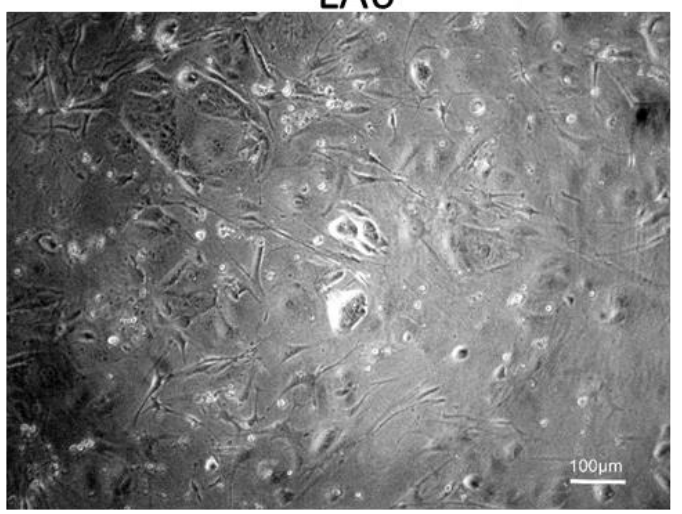

LB6

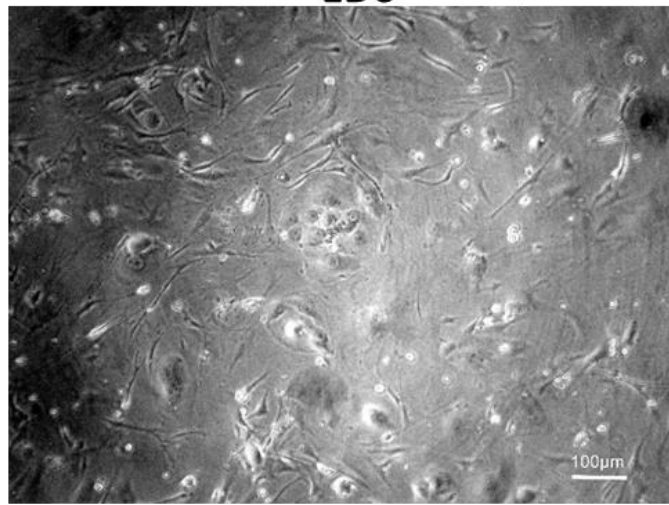

LD3

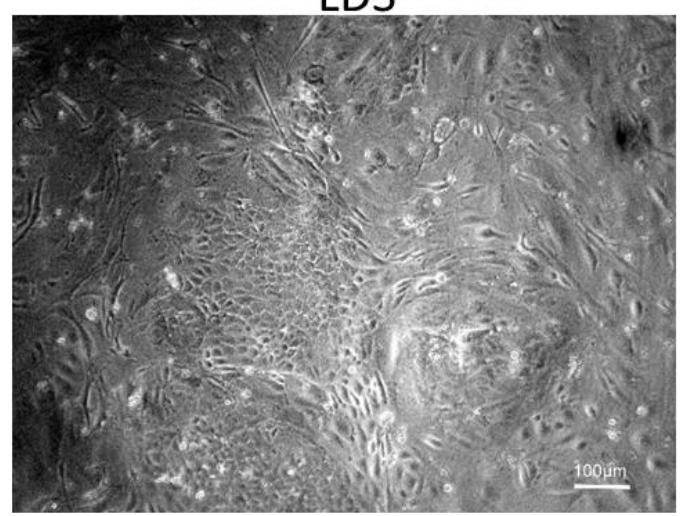

LE1

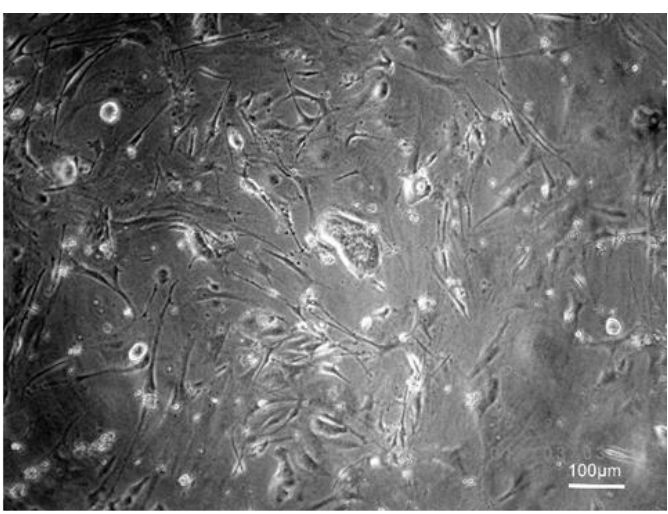

LB5

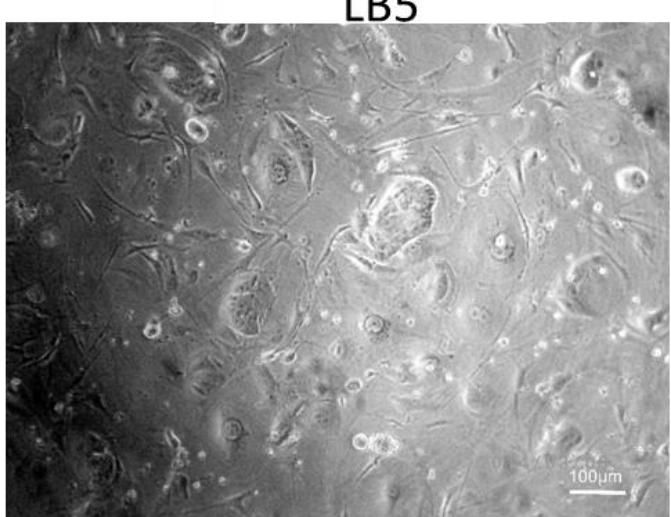

LD2

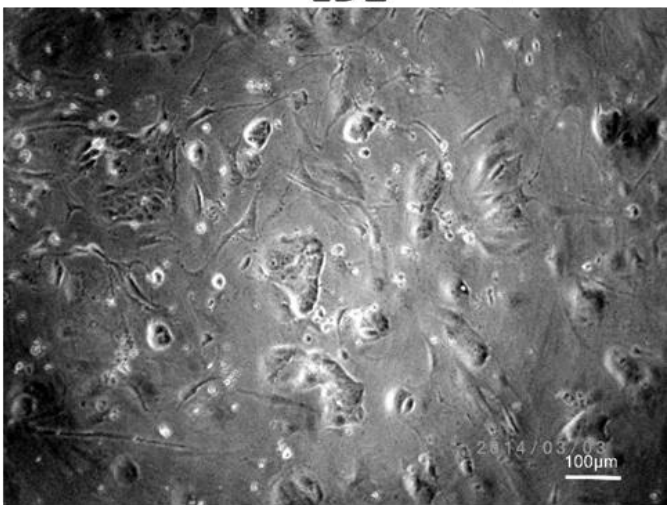

LF5

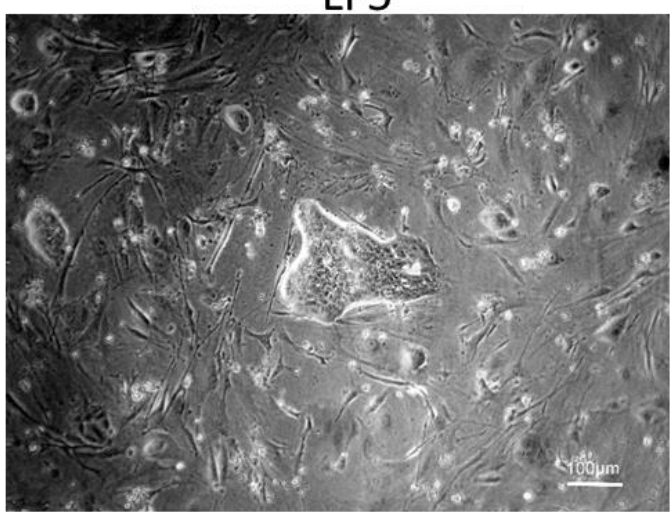

LD5

Figure 4-5: TS cell lines 4 days after passage; photomicrographs of TS cells after passage 3 or 4.

Pictures taken two days after last passage. Note the colonies showed some variation and in certain cases differentiation is evident (see LE1) 


\subsection{Discussion}

Here we established TS cells lines from 14 E3.5 embryos, and our initial trials used blastocysts from C57/BI6 and CBA x C57/B16 mating. These showed a very low efficiency: generally an initial group of cells with TS-like morphology was obtained, but this either failed to survive passaging or showed obvious differentiation on its second or third passage. TS cells are very adherent both to the tissue plastic and to each other, requiring harsh trypsinisation and vigorous trituration when compared to other cell types. This was likely to result in a low cell survival at passage, and as TS cells are relatively slow growing and prone to differentiate when in large colonies, this would explain in part the poor derivation rates. In early studies with mouse ES cells, isolation of C57/BI6 cells was also only poorly successful, and it was not until defined media and serum replacements were produced that this became routine (See A Cox PhD thesis). It was hoped that cells from hybrid mice strains would be easier to isolate; however, we failed to obtain a single line from CBA x C57/BI6 embryos, despite this cross being used to obtain EpiStem cells (Brons et al., 2007) and having been described as an efficient background for ES cell derivation. Others have described TS cells from F1 hybrid mice (see Table 4-1); however, the efficiency of derivation is rarely given. A previous study using highly outbred embryos (129 crosses) (Strumpf et al., 2005) described a remarkable efficiency of some $60 \%$ in the production of TS cells from Cdx2-/+ embryos; however, no description of these lines is given, nor were they studied in depth in this work other than as controls in an experiment showing that $\mathrm{Cdx} 2$ is required for TS cell formation. 129 mice are known to be prone to tumour formation and have been used as the basis for the derivation of many forms of stem cell. It is of note that many of the papers listed in Table 4-1 report TS cells with 129 in their genetic background.

Personal communication with Dr Myriam Hemberger (head of the Trophoblast Stem Cells. Laboratory Babraham Institute) suggested that TS cells show an adaption to culture conditions which results in a more rapid growth after one or two passages. This was certainly observed with the TS cells isolated here, suggesting that with an alteration in culture, this may more readily occur in MF1 embryos, and might explain why it was possible to obtain TS lines in these mice. It should be noted that these will not have the close genetic identity occurring in the highly inbred mice, and it may be that this variation leads to the presence of certain embryos being more capable of forming TS cells. 
TS cells have been isolated from other rodents, and rat embryos have produced TS-like cells which will differentiate into all trophoblasts forms (Asanoma et al., 2011). In man, however, although there are some tumour cell lines which can differentiate into trophoblast-like cells, no definitive TS line has been derived from human blastocysts. Indeed, FGFR2 - the FGF receptor in the mouse blastocyst - is not expressed in human blastocysts (Kunath et al., 2014), and possibly the human TSC niche may only occur in the postimplantation embryo. Alternatively, human TS cells may require quite a different set of growth factors for their isolation, and it may be that the undefined nature of the current growth conditions for murine TS cells is not ideal. (Ohinata and Tsukiyama, 2014) have described murine TS cell derivation under defined conditions, which required Activin as well as the Wnt inhibitor (XAV939) and the ROCK inhibitor (Y27632), with loss of any other these agents resulting in differentiation of the cells. Also, with these 4 factors, the cells grew far faster than under classical conditions used in this chapter, and showed little differentiation.

In summary, while we produced a group of TS cell lines from E3.5 embryos of mothers which have received either NPD (18\%) or LPD (9\%) diets, this was only possible from mice on the MF1 strain. Why this strain was more permissive is open to question; however, (Saito et al., 2011) has also produced TS lines from outbred strains, and it is possible that the diversity of genetic makeup in such mice - selected primarily for fertility - leads to some individual embryos being more able to produce surviving stem cells lines (although the efficiency was relatively low even from this background). Previous studies with ES cell derivation suggested that maternal LPD reduced the stem cell lines isolation rate, with $17 \%$ of the blastocysts producing ES cells as compared to $41 \%$ of blastocysts from NPD mothers (A Cox PhD thesis 2013). However, here the reverse to that seen with ES cells was observed, with somewhat more LPD TS cells being isolated - although this was based upon very low overall efficiency, and may simply be related to a general difficulty in obtaining TS cells. Previous studies have shown that a low protein diet induces embryo/offspringspecific changes (see introduction), as embryo transfer at E3.5 shows that these are retained independent of the mother. Changes in the endocytosis function of the yolk sac (Watkins et al., 2008a) and in the trophectoderm of the blastocyst have also been observed in embryos subjected to a LPD; furthermore, there appears to be differential growth in between the inner cell mass and the trophectoderm. The TS cells isolated here will allow us to follow these changes and the underlying mechanisms in more detail. 


\section{Chapter 5. Characterisation of TS cell lines}

\subsection{Introduction}

Once the cell lines were established, their TSC characteristics needed to be confirmed by testing for expression of the $\mathrm{Cdx} 2$ homeobox transcription factor. It is generally considered the defining marker for TS cell lineages - although it is not as specific as NANOG is in pluripotent stem cells, as $\mathrm{Cdx} 2$ is also found expressed in other differentiated epithelial cells, particularly those related to the intestine, and is upregulated in a number of epithelial derived tumours (Phillips et al., 2003). Cdx2 is known to be crucial for TS cells self-renewal - although it is dispensable for the initial differentiation toward trophectodermal lineages, which is believed to be caused by downregulation of Oct4 (Niwa et al., 2005).

We also wanted to analyse the cells in regard to their gender, as there is a possibility that this may cause differences in their behaviour. A gender bias has been well recognised in murine ESCs, with the marked predominance of stable cells lines being male. Female murine ES lines do not show inactivation of one of the $\mathrm{X}$ chromosomes, and the presence of two active $\mathrm{X}$ chromosomes leads to difficulty in the establishment and /or maintenance of stable female mES cell lines. The instability is believed to result in the selective loss of one of the $X$ chromosomes, which is observed in many female ES cells lines; alternatively, the presence of two active $\mathrm{X}$ chromosomes may cause lethality (Sugawara et al., 2006). Interestingly, the opposite occurs in human ES cells, and it is believed that this is a result of $X$ chromosome inactivation - or possibly expression loss of X-linked genes critical for cell metabolism occurring in male human cells. This difference can be explained by the part primed status of hESC which have characteristics more in common with epiSC, and also show $X$ linked inactivation (Ben-Yosef et al., 2011). While the random epigenetic silencing of the $X$-chromosome that occurs in somatic tissues of female mammals (which equalizes the dosage of $X$-linked genes) is essentially irreversible, the imprinted inactivation of the paternal $X$ of the mouse extra-embryonic tissues appears unstable (Dubois et al., 2014). Both TS cells and XEN cells - the two extraembryonic stem cell lines - show imprinted X inactivation (Senner et al., 2012) with loss of all or part of the expression from the paternal X. Despite this variation in degree of inactivation, it may be expected that female TS (and XEN) cell lines might be more stable than female ES cells. 
Finally, we also investigated the karyotype of our putative TS cells lines so as to understand their degree of aneuploidy and polyploidy. This would also give us an idea of the stability of our cell lines, as differentiation toward polyploid giant cells is a common event in TS cells. These polypoid cells are viable but no longer proliferative, so their presence can be viewed as a marker for the presence of a TS cell population. Further, a predominance of aneuploid cells suggests a general genetic instability in the clone.

\subsection{Methods}

\subsubsection{Immunofluorescence staining for $\mathrm{Cdx2}$}

Cells were stained after culture on coverslips in 24 wells plates. They were fixed with $4 \%$ PFA and permeabilized with Triton prior to incubation with a recombinant rabbit monoclonal antibody raised against the $\mathrm{N}$ terminal of Human Cdx2 (aa 1-100) (Abcam Ab 76541) to detect TS cells. This was used at a 1:100 dilution in these assays. Binding was detected with the anti-rabbit Alexa 488 conjugate.

\subsubsection{Sex Determination of TS cells}

TS cells lines were quick-thawed and grown on MEFs until confluent. In order to remove contaminating MEF DNA, TS cells were purified from MEF cells by pre-plating and grown feederfree for 2-3 passages (7-10 days). As differentiation was not important for this study, FGF4 was be excluded, as this was thought also to reduce the numbers surviving feeders cells further (see Chapter 3 and 4). For DNA extraction, the cells were washed twice with PBS and 50 $\mu$ l of lysis buffer, containing $10 \mathrm{mM}$ Tris, pH 8, $100 \mathrm{mM} \mathrm{NaCl}, 10 \mathrm{mM}$ EDTA, pH 8, 0.5\% sodium dodecyl sulphate (SDS), and $1 \mathrm{mg} / \mathrm{ml}$ proteinase $\mathrm{K}$ (added fresh) was added to each well (Ramirez-Solis et al., 1992). Plates were incubated overnight at $55^{\circ} \mathrm{C}$ in a humid environment. The following day, lysates were transferred to $1.5 \mathrm{ml}$ Eppendorf tubes and two volumes of cold absolute ethanol was added. The tubes were left at room temperature until the precipitated nucleic acid was visible. Tubes were centrifuged at $2000 \mathrm{rpm}$ for $5 \mathrm{~min}$ and supernatant was discarded by gentle inversion. Pellets were washed twice in 70\% ethanol and allowed to air-dry for 15-20 minutes. The DNA was 


\section{Chapter 5}

resuspended in nuclease-free water and quantified using the Nanodrop ND-100spectrophotometer.

Polymerase chain reaction (PCR) samples containing final concentrations of $1 \times$ PCR buffer (20 $\mathrm{mM}$ Tris- $\mathrm{HCl}, \mathrm{pH} 8.4,50 \mathrm{mM} \mathrm{KCl}$ ), $2.5 \mathrm{mM} \mathrm{MgCl2}$ (Invitrogen), $250 \mu \mathrm{M}$ of each dNTP (Invitrogen), $250 \mathrm{nM}$ of each oligonucleotide primer, $0.625 \mathrm{U}$ HotStart Taq (Qiagen), and $50 \mathrm{ng}$ sample DNA were prepared in a total volume of $25 \mu \mathrm{l}$. Multiplex PCR was set up with primers amplifying the Zfy gene (Mardon and Page, 1989) located in one of the sex-determining regions of the $Y$ chromosome was used to verify male TSC lines, while primers targeting the DXNds3 (Love et al., 1990) sequence on $X$ chromosome were used as a control. Primers were synthesised by Sigma UK using sequences identical to those described by (Kunieda et al., 1992), and are detailed in Table 51. The PCR was performed on a DNA Engine ${ }^{\circledR}$ Peltier Thermal Cycler (BioRad, UK). Reaction conditions were as follows: Initiation by HotStart Taq activation at $95^{\circ} \mathrm{C}$ for $15 \mathrm{~min}$, followed by 35 cycles each consisting of a denaturation step at $94^{\circ} \mathrm{C}$ for 60 seconds, annealing at $55^{\circ} \mathrm{C}$ for 30 seconds, and extension at $72^{\circ} \mathrm{C}$ for 60 seconds. After the last cycle, samples were kept at $72^{\circ} \mathrm{C}$ for 10 minutes. Male and female controls (from tail lysates) and a water blank (no DNA) were also subjected to the multiplex PCR procedure along with the TSC samples. Amplified DNA products $(10 \mu \mathrm{l})$ were separated by gel electrophoresis using a 3\% agarose gel with TBE buffer, at 70V for 1 hour. Amplification was visualised under UV light.

\section{Table 5-1: Details of Sex specific primers.}

The primers designed to amplify the Zfy gene, located on the $Y$ chromosome, were used to identify male ES cell lines. Primers targeting DXNds3, located on the X chromosome, were used as a control.

\begin{tabular}{|l|l|l|l|}
\hline Gene Name & $\begin{array}{l}\text { Forward Primer } \\
\text { Sequence }\end{array}$ & $\begin{array}{l}\text { Reverse Primer } \\
\text { Sequence }\end{array}$ & Amplicon Length (bp) \\
\hline Zfy & $\begin{array}{l}\text { AAGATAAGCTTACATA } \\
\text { ATCACATGGA }\end{array}$ & $\begin{array}{l}\text { CCTATGAAATCCTTTG } \\
\text { CTGCACATGT }\end{array}$ & 599 \\
\hline DXNds3 & $\begin{array}{l}\text { GAGTGCCTCATCTATAC } \\
\text { TTACAG }\end{array}$ & $\begin{array}{l}\text { TCTAGTTCATTGTTGA } \\
\text { TTAGTTGC }\end{array}$ & 244 \\
\hline
\end{tabular}




\subsubsection{Karyotyping of TS cells}

Basic karyotyping was carried out and chromosomal numbers assessed. This allowed us to identify the cell lines with correct chromosomal numbers, and as DNA reduplication is common in trophectodermal cells, it allowed us to gauge the degree of differentiation as well as gross genetic divergence occurring in the culture. The protocol was modified from that of Dr Congsan Sun:

Karyotyping was carried out on cells in low density, as these have more active division and a greater percentage of condensed metaphase chromosomes are present. TS cells were trypsinised, washed and pelleted. The cells were resuspended by addition of $0.075 \mathrm{M} \mathrm{KCl}$ dropwise and gentle flicking of the cell pellet so as to suspend them but not cause their destruction. Once in suspension, the cells were diluted in $7 \mathrm{ml} \mathrm{KCl}$ and left for 15 minutes at room temperature. This hypotonic solution causes the cells to swell and the chromosomes to separate from one another (hence allowing them to become visible on staining). The cells were then fixed by addition of $0.5 \mathrm{ml}$ of $-20^{\circ} \mathrm{C}$ Carnoy's fluid ( $2 \mathrm{ml}$ glacial acetic acid: $5 \mathrm{ml}$ methanol) for 5 minutes. Chromosome spreads were prepared by dropping the cells onto humidified ethanol-treated glass slides at a distance, and were allowed to air-dry. Chromosomes were stained with Giemsa stain (Sigma, G500; 1:25 dilution) for 10-20 minutes and coverslips were mounted using DPX mounting medium (BDH labs). Spreads were analysed using a bright-field microscope (a more detailed protocol is provided in the appendix)

\subsection{Results}

\subsubsection{Cdx2 staining}

Cdx2 staining was seen in all clones obtained in Chapter 4, suggesting that they all had TSC characteristics, with small colonies of 10-30 cells being labelled for the nuclear staining transcription factor (Figure 5-1). However, two clones - NB1 and ND2 - had relatively few positive colonies. No signal was seen in the surrounding and underlying feeder cells. 
Chapter 5
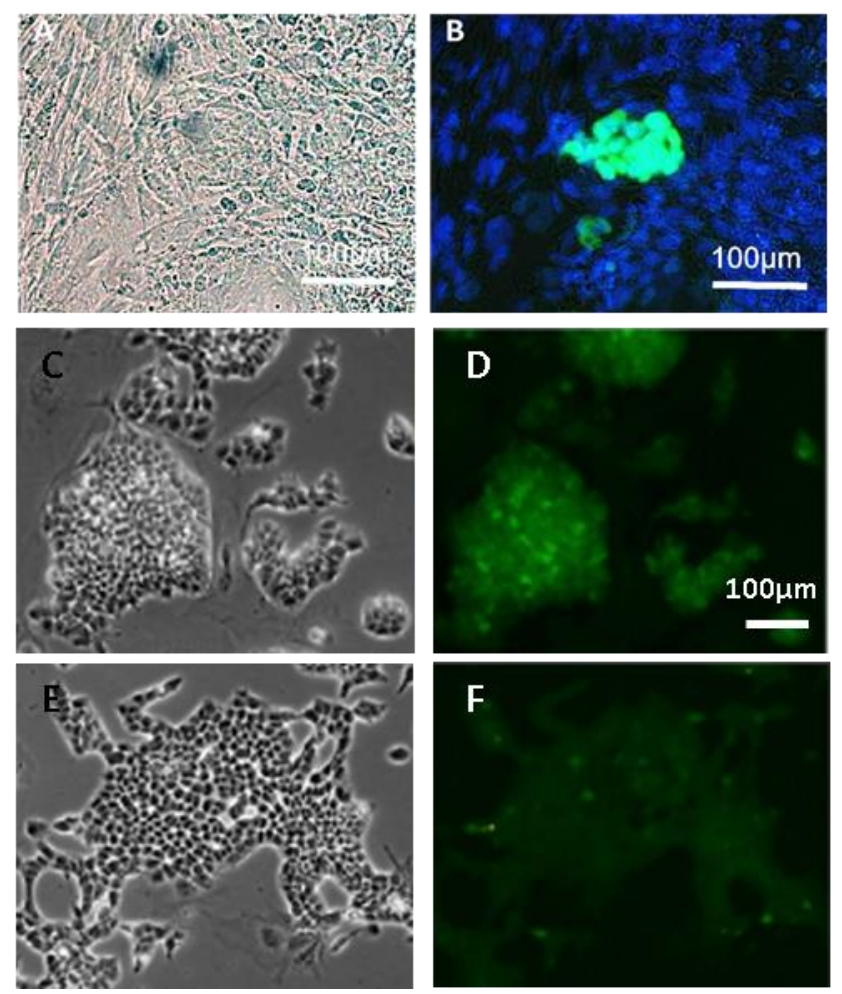

Figure 5-1: Immunostaining of TS cells for Cdx2.

TS cells appear as defined Cdx2 positive colonies (Green), nuclear counter staining (Blue) with DAPI showed the underlying layer of Cdx2 negative MEF cells. (A) Brightfield and (B) Fluorescent image of the same field of view. The numbers of positive cells and intensity of staining did vary between clones. For instance clone ND1 $(C, D)$ and clone NB1 $(E, F)$ had relatively few strongly positive cells (these clones were cultured free of feeder cells for staining).

\subsubsection{Sex Determination of TS cells}

A multiplex PCR analysis for markers on either the $\mathrm{X}$ or $\mathrm{Y}$ chromosome was used to define the sex of the TS cell lines; the band of 599 bp being amplified from the Zfy gene encoding a male specific zinc finger transcription factor, while the amplification of the $244 \mathrm{pb}$ band from the DXNds3 microsatellite (X chromosome) was present in both male and female as shown in Figure 5-2. 


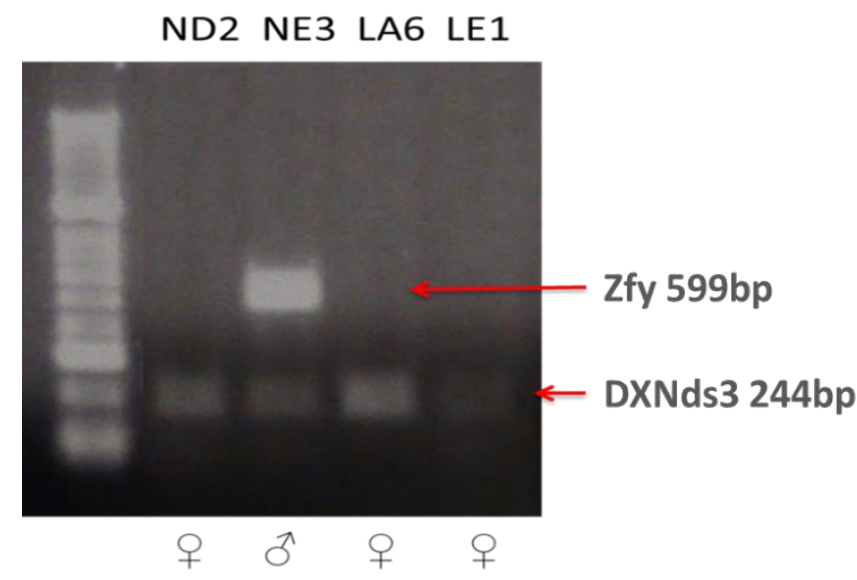

Figure 5-2: Example of PCR analysis of sex of TSC clones.

The 599 Zfy gene being seen in male cell lines (NE3 above), while the 244 product from the DXNds3 X chromosomal microsatellite was present in both male (NE3) and female (ND2, LA6 and LE1 cells)

We found that unlike ESCs, there was no obvious sex bias in TSCs, with equal numbers of male and female cell lines having been obtained (6 of each), as listed in Table 5-2. 


\section{$\underline{\text { Table 5-2 Sex of TSC lines }}$}

\begin{tabular}{|l|l|l|l|}
\hline Cell line name & Mother's ID & Maternal Diet & Sex \\
\hline ND2 & $210 / 13 / 327-1$ & $18 \%$ protein & F \\
\hline NA2 & $210 / 13 / 327-1$ & $18 \%$ protein & M \\
\hline NB3 & $210 / 13 / 327-1$ & $18 \%$ protein & M \\
\hline NE3 & $210 / 13 / 327-1$ & $18 \%$ protein & M \\
\hline NB1 & $210 / 13 / 327-2$ & $18 \%$ protein & M \\
\hline LE1 & $210 / 13 / 352-1$ & $9 \%$ protein & F \\
\hline LD2 & $210 / 13 / 352-1$ & $9 \%$ protein & $\mathbf{F}$ \\
\hline LB5 & $210 / 13 / 352-3$ & $9 \%$ protein & M \\
\hline LF5 & $210 / 13 / 352-3$ & $9 \%$ protein & M \\
\hline LD5 & $210 / 13 / 352-3$ & $9 \%$ protein & F \\
\hline LA6 & $210 / 13 / 352-3$ & $9 \%$ protein & F \\
\hline LB6 & $210 / 13 / 352-3$ & $9 \%$ protein & F \\
\hline
\end{tabular}

\subsubsection{Karyotyping}

To understand the genetic stability of the TSC lines, we carried out karyotyping. Each of the cell lines showed some degree of aneuploidy, and many also showed polypoid chromosomal spreads (Figure 5-3). In many cases, the numbers of chromosomes showed a bimodal distribution with peaks at 40 and 80, suggesting either cell division (the cells had not been arrested at metaphase or prometaphase as is typical for stem cells) or that cells were in the process of differentiating to true tetraploid cells in line with their differentiation toward giant cells. However, both diet groups also showed high degrees of aneuploidy (although this did vary with the cell line). Examples of the degree of spread is shown in Figure 5-3, 5-4 and listed for each cell line tested in Table 5-3. 

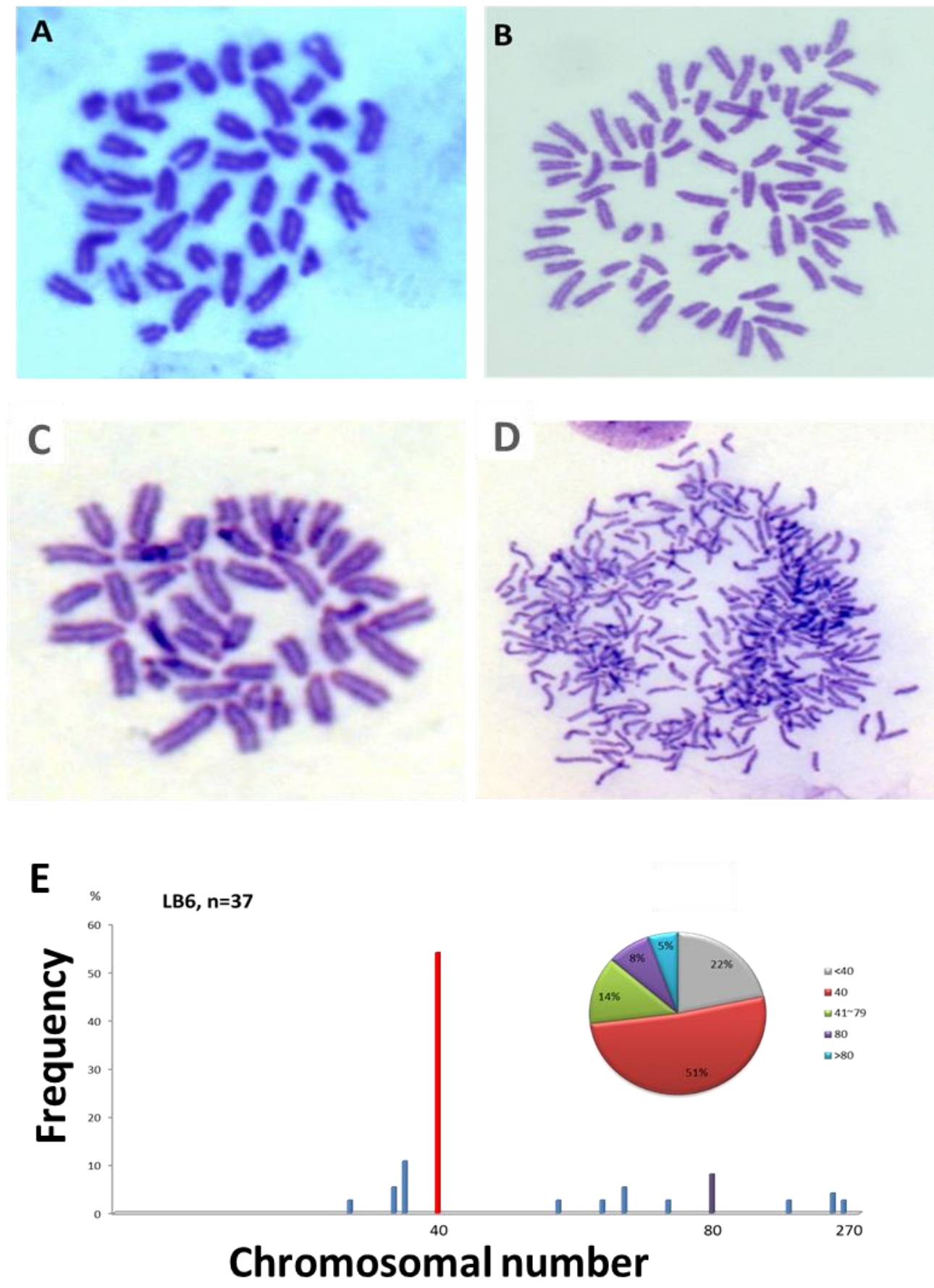

Figure 5-3: Chromosomal spreads of TSC lines

$A$ and $B$ : show spreads of cells line LE1, (A) has the normal 40 chromosomes, $(B)$ shows tetraploidy with 80 chromosomes. $C$ and $D$ are spreads from TSC line LB6, which showed the maximal chromosome number. (C) spreads from LB6 with the normal 40 chromosomes (D) a small number of cells form LB6 showed large numbers of chromosomes up to 270. (E) Histogram of the chromosomal number found in cells from clone LB6. 


\section{Chapter 5}

Figure 5-4: (following page) Analysis of karyotype of TS cell lines.

NB1 and NA2 cells lines from embryos of mothers on a normal diet. LD2 and LE3 cells lines from embryos of mothers on a low protein diet. NB1 and LD2 show a closely diploid karyotype, while NA2 and LE3 have a large percentage of aneuploid cells 

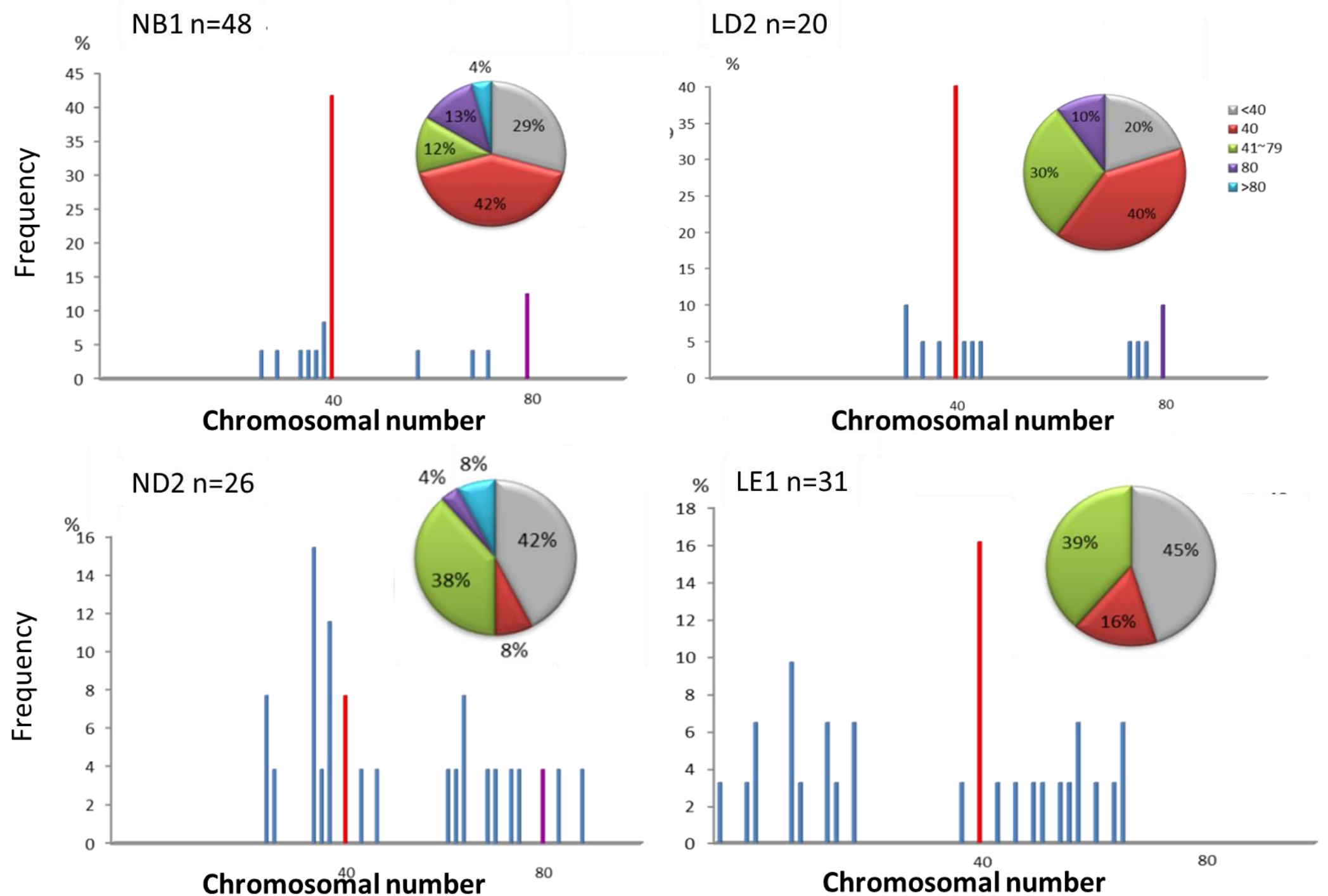
Table 5-3: Spread of Chromosomes in TSC lines (numbers are given as percentages)

\begin{tabular}{|l|l|l|l|l|l|l|}
\hline $\begin{array}{l}\text { Cell } \\
\text { line } \\
\text { name }\end{array}$ & $\begin{array}{l}\text { Maternal } \\
\text { Diet }\end{array}$ & $<40$ & 40 & $41-79$ & 80 & $>80$ \\
\hline ND2 & $18 \%$ protein & 42 & 8 & 38 & 4 & 8 \\
\hline NA2 & $18 \%$ protein & 24 & 38 & 26 & 12 & 0 \\
\hline NB3 & $18 \%$ protein & 30 & 54 & 16 & 0 & 0 \\
\hline NE3 & $18 \%$ protein & 28 & 38 & 20 & 14 & 0 \\
\hline NB1 & $18 \%$ protein & 29 & 42 & 12 & 13 & 4 \\
\hline LE1 & $9 \%$ protein & 45 & 16 & 39 & 0 & 0 \\
\hline LD2 & $9 \%$ protein & 20 & 40 & 30 & 10 & 0 \\
\hline LB5 & $9 \%$ protein & 10 & 27 & 28 & 14 & 21 \\
\hline LF5 & $9 \%$ protein & 20 & 44 & 14 & 20 & 2 \\
\hline LD5 & $9 \%$ protein & 17 & 55 & 24 & 4 & 0 \\
\hline LA6 & $9 \%$ protein & 28 & 48 & 20 & 4 & 0 \\
\hline LB6 & $9 \%$ protein & 22 & 52 & 14 & 8 & 5 \\
\hline
\end{tabular}

\subsection{Discussion}

In this chapter, we have confirmed the TSCs characteristics using the stem cell marker Cdx2. The expression was observed to be present in each of the lines using immunofluorescence; however, its intensity did vary and it is possible that a proportion of the cells in these low $\mathrm{Cdx2}$ expressing clones may have either entered a differentiation pathway or have become mixed with other cell types (such as EpiScs). It should be noted that these low expressing Cdx2 clones showed the expected morphology of TSCs.

In vivo, following the initial expression of $\mathrm{Cdx} 2$ in the trophectoderm, the expression of $\mathrm{Cdx} 2$ is limited in selected cellular descendants. For instance, it is lost when mural trophoblasts differentiate into trophoblastic giant cells or in the more superficial part of the ectoplacental cone 
(Beck et al., 1995b), which suggests that Cdx2 may be lost from some cultures as they differentiate. It may well be that these low expression clones have entered a differentiation path.

We showed equal isolatability of male and female TSC clones. Murine ESCs show a strong gender bias, which has been ascribed to the absence of $X$ inactivation in these cells, with the pluripotent transcription triad Nanog, Oct4, and Sox2 playing a role in repressing Xist (Navarro et al., 2008) and hence $\mathrm{X}$ inactivation in the mouse. The transcription of genes from both $\mathrm{X}$ chromosomes is believed to result in the high expression of either potentially toxic genes or the production of prodifferentiation factors by these cells. We and others (Sugawara et al., 2006) have shown this bias and indeed the few female ( $X X$ rather than $\mathrm{XO}$ ) murine stem cell clones that have been derived usually have limited germ line transmission. In general, long term culture of female murine ES cells lines ends in XO karyotypes predominating (Zvetkova et al., 2005). It should be noted that cells differentiating from normal female $\mathrm{mESC}$ clones do show random $\mathrm{X}$ inactivation. In mice, $\mathrm{X}$ inactivation occurs by 5.5 days, and has been described in both EpiSC and TSC, leading to the assumption that these are primed cells and are isolatable as stem cells after this $\mathrm{X}$ inactivation event - even if the embryos are actually harvested prior to it. This would be in agreement with our findings that our TS cells showed an even male:female ratio. Human ESCs behave differently to either mouse ES or TS cells in that they have been described as showing a marked female bias (Ben-Yosef et al., 2011), with up to $75 \%$ of all karyotype normal hESC lines being female. In man, it is believed that methods for hESC derivation may induce aberrant $\mathrm{X}$ inactivation, favouring $\mathrm{XX}$ hESC survival over the XY counterparts. Additionally, in man, G6PD with key metabolic functions is present on the $X$ chromosome while it is autosomal (chromosome 5 ) in mice. This may allow $X X$ hESc survival and growth in suboptimal culture conditions, and may suggest a selection pressure to retain at least one of these chromosomes active in such cells.

We then tested the TSC clones' karyotypes. In an attempt to minimise changes caused through selection in culture, we used relatively early passage cells - none were more than passage 1 . In agreement with other studies (Dubois et al., 2013), we found that even without active differentiation (removal of FGF), TSCs appeared less stable and tended to have more polyploid cells when compared to ESCs. However, there appeared to be no major difference between different diet groups. We assume that the cells showing tetraploid chromosomal numbers were either differentiating toward giant cells, or had been caught in anaphase/telophase rather than 


\section{Chapter 5}

metaphase. This might have been eliminated by the use of Colcemid, which blocks the cell cycle at metaphase, and perhaps should have been introduced into the culture. The percentages of aneuploid cells varied greatly from $88 \%$ in one clone to less than $36 \%$. In ES cells, diploid cell percentages of $>50 \%$ are taken as a good indicator that the cell line overall may retain its genetic integrity, though this is a rule of thumb and there have been no studies on TS cells behaviour.

Aneuploidy in normal tissues may be more prevalent than thought, as it may be masked by "normal" cells. Cultured cells subjected to continuous growth stimuli also have an increased likelihood of mitotic errors that can lead to polyploidy and aneuploidy. While human iPSC lines have been considered to be homogeneously euploid, more recent data (Peterson et al., 2011) has suggested that levels of up to $35 \%$ of cells being aneuploid is quite common.

In summary, in this chapter we have ascertained the sex of our TS cells, shown that they express the trophoblast stem cell marker $\mathrm{Cd} \times 2$ and provided a measure of their genetic stability through karyotype. 


\section{Chapter 6. Analysis of the functional characteristics of TS cell lines}

\subsection{Introduction}

The term trophoblast comes from the Greek "to feed", due to their crucial role in nutrient transfer to the developing offspring. The giant cell is the first terminally differentiated cell to be formed in the embryo, and is also required for implantation. In the mouse, these cells are polyploid and generally mononucleate - a state which differs in other mammals (Zybina and Zybina, 1996).

The mural trophoblast giant cells in the implanting blastocyst are needed for attachment of the blastocyst to the uterine epithelium and induce decidua formation, through paracrine signals, possibly progesterone (Bany and Cross, 2006). These parietal trophoblast giant cells express numerous proteases and integrins, allowing them to attach to and remodel various components of the extracellular matrix. This results in highly invasive and motile cells being able to penetrate into the uterine wall. These giant cells also produce the outer cell layer of the parietal yolk sac, which is lined internally by parietal endoderm. The parietal yolk sac is the major site of nutrient and gas exchange in the early foetus. This invasive nature is also observed in later forming trophoblast giant cell lineages, as well as in cytotrophoblasts (or extravillous trophoblast), which are closely related to the mural cells of the blastocyst.

While numerous glucose and amino acid transporters are expressed by the trophoblast cells, trophectodermal endocytosis also plays a role in embryonic and foetal nutrition (Akour et al., 2013). It has been shown that endocytosis occurs as a route for protein transfer in the ovine blastocyst in culture (Pullar et al., 1990), and that the lining giant cells of the yolk sac and the syncytiotrophoblast in the mature placenta carry many coated pits (Ockleford et al., 1977) and express the multiligand endocytosis receptor megalin (Zheng et al., 1998). These cells, which are in direct contact with the stroma of the uterine wall or blood in the intervillous space, are 


\section{Chapter 6}

especially important for nutrient transfer to the embryo and foetus, and these findings suggest that trophectodermal endocytosis is significant for the function of these tissues.

Trophoblast behaviour has been linked with changes in the periconceptional environment so that murine LPD embryos change their blastocyst phenotype with both increased proliferation of blastocyst trophectoderm and greater their invasive activity, as seen by more rapid trophoblastic spreading and outgrowth when allowed to differentiate during in vitro culture (Eckert et al., 2012); the latter being a proxy for an increase in invasive potential in vivo. Such alterations may link with the metabolic changes occurring in both mother and offspring, as altered levels of AAs were found in the uterine fluid of LPD mothers, together with reduced mTORC1 signalling within their blastocysts (Eckert et al., 2012). Moreover, outgrowth of cells from the ectoplacental cone isolated from day 8 LPD embryos demonstrated enhanced spreading and TGCs proliferation after 24 and 48 hours in culture (Watkins et al., 2015), although this was not so pronounced in cells isolated from later gestation embryos.

Further culture of blastocysts from LPD mothers showed that they displayed an increase in trophectodermal endocytosis in terms of numbers of endocytic vesicles and volume per cell of vesicles (Sun et al., 2014). This was in line with changes observed in previous studies where there was enhanced nutrient transfer by the foetal yolk sac's visceral endoderm after transient periconceptional protein restriction (Watkins et al., 2008a). Further modelling of this with ES cells isolated from LPD embryos showed that embryoid bodies formed of such cells grew to a larger size, had increased endocytosis in their lining primitive endoderm (the precursor of visceral endoderm), and showed alteration in Gata6 expression - a regulator of endoderm differentiation (Sun et al., 2015). Together, these results suggest a possible mechanism used to maintain embryonic and foetal growth where possible nutritional challenge is present.

Based upon these findings, we ask in this chapter whether similar changes to those induced in the early embryo persist as long term effects inheritable in our TS cell lines. Thus, we have analysed them for changes in gene expression, cell metabolism, proliferation, and endocytosis. 


\subsection{Methods}

\subsubsection{Reverse Transcription Quantitative PCR (RT-qPCR) analysis}

\section{RNA extraction and reverse transcription}

Total RNA from TSC clones was isolated using the RNeasy mini kit (Qiagen, UK). DNA was selectively precipitated using $70 \%$ ethanol and the lysate and precipitate transferred to an RNeasy spin-column, allowing binding of RNA to a silica-based membrane. Contaminants were washed away by centrifugation in high salt buffers. RNA was finally eluted in $30-50 \mu l$ of water. On-column DNase I digestion was performed using the RNase-free DNase kit (Qiagen, UK) according to the manufacturers' instructions. RNA was quantified using the Nanodrop ND-1000 spectrophotometer.

First-strand cDNA was synthesized by using $250 \mathrm{ng}$ of RNA combined with $0.5 \mu \mathrm{g}$ random primers in an Improm- IITM Reverse Transcriptase System (Promega, UK) reaction (20 $\mu$ l Recombinant RNasin Ribonuclease Inhibitor, $0.5 \mathrm{mM}$ of each dNTP, and $3 \mathrm{mM} \mathrm{MgCl}_{2}$ ), prepared in a final $20 \mu \mathrm{l}$ volume in thin-walled, nuclease-free tubes. Tubes were transferred to a DNA Engine Peltier Thermal Cycler (BioRad, UK) for reverse transcription where primer/templates were annealed at $25^{\circ} \mathrm{C}$ for 5 minutes, extended at $42^{\circ} \mathrm{C}$ for 1 minute, and finally incubated at $70^{\circ} \mathrm{C}$ for 15 minutes for RT inactivation. Reverse Transcriptase negative (RT-) controls were also prepared as a control for genomic DNA contamination. cDNA was diluted to a concentration equivalent to $5 \mathrm{ng} / \mu \mathrm{l}$ RNA and stored at $-20^{\circ} \mathrm{C}$.

\section{Quantitative PCR}

Each target gene was amplified with the primers listed below in Table 6-1, and was then quantified using the SYBR-green detection method (PrimerDesign, UK). All primer pairs spanned exon boundaries. SYBR-green dye detects PCR products by intercalating between double stranded DNA present in samples and fluorescing. The fluorescence intensity is proportionate to the amount of PCR product produced (gene expression). Samples were analysed in triplicate. Absence of genomic DNA was confirmed by analysis of RT- samples, and no template controls (water only) 


\section{Chapter 6}

were also included in each assay. Thermal cycling was performed using a DNA Engine thermal cycler and Chromo4 Real-time Detector (BioRad, UK) with Opticon Monitor v3.1 software under the following conditions: $95^{\circ} \mathrm{C}$ for 10 minutes (enzyme activation), then 40 cycles of $95^{\circ} \mathrm{C}$ for 15 seconds (denaturation) followed by $60^{\circ} \mathrm{C}$ for 1 minute (annealing), and a final extension step at $72^{\circ} \mathrm{C}$ for 10 minutes. Melting curves were generated for each sample to confirm target-specific amplification by fluorescence detection at $0.2^{\circ} \mathrm{C}$ steps between $60^{\circ} \mathrm{C}$ and $95^{\circ} \mathrm{C}$.

\section{Statistics}

In order to achieve the RT-qPCR result, the delta/delta CT method was used to calculate gene expression. This uses a stable, widely-expressed gene as a reference gene, the expression of which is then compared with our target gene: $\Delta C t 1=C t(T a r g e t$ gene-TSC) $-C t($ Ref gene-TSC). The feeder cells (MEF) were co-cultured with TSCs, and the expression of the MEFs was used as the control gene expression, which is $\Delta \mathrm{Ct} 2=\mathrm{Ct}($ Target gene-MEF) $-\mathrm{Ct}($ Ref gene-MEF). $\Delta \Delta \mathrm{Ct}=\Delta \mathrm{Ct} 1-$ $\Delta \mathrm{Ct} 2$, then the normalized target gene expression level is $2^{-\Delta \Delta C \mathrm{Ct}}$. The formula is:

$$
\begin{aligned}
\Delta \mathrm{Ct} 1=\mathrm{Ct}(\text { Target gene in TSCs })-\mathrm{Ct} \text { (Reference gene in TSCs) } \\
\Delta \mathrm{Ct2}=\mathrm{Ct}(\text { Target gene in MEFs })-\mathrm{Ct} \text { (Reference gene in MEFs) } \\
\quad \Delta \Delta \mathrm{Ct}=\Delta \mathrm{Ct} 1-\Delta \mathrm{Ct} 2
\end{aligned}
$$

Normalized target gene expression level $=2^{-\Delta \Delta C t}$ 
Table 6-1: Primers used in RT-qPCR

\begin{tabular}{|l|l|l|l|}
\hline $\begin{array}{l}\text { Gene } \\
\text { Name }\end{array}$ & Forward Primer Sequence & Reverse Primer Sequence & $\begin{array}{l}\text { Amplicon } \\
\text { Length (bp) }\end{array}$ \\
\hline Nanog & TGCTTACAAGGGTCTGCTACTG & GAGGCAGGTCTTCAGAGGAA & 76 \\
\hline Oct4 & GTTGGAGAAGGTGGAACCAA & CTCCTTCTGCAGGGCTTC & 61 \\
\hline Sox2 & TGGGCTCTGTGGTCAAGTC & TGATCATGTCCCGGAGGT & 105 \\
\hline S100a4 & GGAGCTGCCTAGCTTCCTG & TCCTGGAAGTCAACTTCATTGTC & 102 \\
\hline Cdx2 & CGTTCATGCTCTTTGCCAGG & CCTTGTCGCAGGGGCCTGGC & 96 \\
\hline Hand1 & GCGGAATTCTCCTATGGTCCAGACGCCAG & GGCGAATTCGCGCAGAGTCTTGATCTTGG & 220 \\
\hline PI1 & ATTTTTTCGATAAAACTTGG & TGCAGCGGCATAGATTATAA & 402 \\
\hline Eomes & TGTTTTCGTGGAAGTGGTTCTGGC & AGGTCTGAGTCTTGGAAGGTTCATTC & 323 \\
\hline BMP4 & CGTTACCTCAAGGGAGTGGA & ATGCTTGGGACTACGTTTGG & 116 \\
\hline Nodal & ACTTTGCTTTGGGAAGCTGA & ACCTGGAACTTGACCCTCCT & 140 \\
\hline Tpbpa & TGCAAGAGCAGAAGGATAAA & CTCTCTGTGTAATCCTCAAAT & 253 \\
\hline Megalin & CAATGGAGGATGCAGCCATATCT & GTGTGGACACTGGCACTCAG & 62 \\
\hline BActin & GACGGCCAGGTCATCACTAT & AAGGAAGGCTGGAAAAGAGC & 70 \\
\hline
\end{tabular}




\subsubsection{Endocytosis Assays}

Fluorescent-labelled dextran was used to track endocytosis activity in cells. The pHrodo Green $(10,000 \mathrm{kDa})$ dextran (Life technologies, P35368) carries a pH-sensitive fluorescence emission that increases in intensity at lower $\mathrm{pH}$, being non-fluorescent in the extracellular environment. Upon internalization, it produces a green-fluorescent signal in the acidic environment of the endosomes.

The cells were plated in 8-well chamber slides (Ibidi, IB-80826) and cultured for 24 hours in $70 \% \mathrm{FCM}+\mathrm{F} 4 \mathrm{H}$ medium. On the day of the experiment, cells were washed and the medium replaced with $200 \mu$ l pre-warmed PBS per well. pHrodo dextran was added at a final concentration of $100 \mu \mathrm{g} / \mathrm{mL}$, along with the Hoechst 33258 (Molecular Probes ${ }^{\mathrm{TM}}, \mathrm{H} 3569$ ) $25 \mu \mathrm{g} / \mathrm{mL}$, and incubated at $37^{\circ} \mathrm{C}$ for 30 minutes. After loading with dye, the cells were washed with pre-warmed dye-free medium, then cultured in dye-free medium and observed under a Leica TCS-SP8 laser scanning confocal microscope in an environmental chamber at $37^{\circ} \mathrm{C}$ with $5 \% \mathrm{CO}_{2}$. Pictures were taken at the times shown.

\subsubsection{Cell differentiation}

\section{Differentiation media}

To drive TSC clones to differentiate, we compared changes occurring upon stopping the supply of FGF4 and heparin. Cells were then cultured for a further six days. The morphology of the cells was observed, and the immunostaining for the TS cell marker $\mathrm{Cdx} 2$ was performed. Table 6-2 lists the media used: 
Table 6-2: The differentiation media

\begin{tabular}{|l|l|l|l|}
\hline Name & Medium Used & FCS & Supplement \\
\hline A & $70 \%$ FCM, 30\% TS & $20 \%$ & FGF4 $(37.5 \mathrm{ng} / \mathrm{ml})$, Heparin $(1 \mu \mathrm{g} / \mathrm{ml})$ \\
\hline B & $70 \%$ FCM, 30\% TS & $20 \%$ & $10 \%$ recombinant FGF conditioned media \\
\hline C & $70 \%$ FCM, 30\% TS & $20 \%$ & - \\
\hline D & RPMI & $10 \%$ & - \\
\hline
\end{tabular}

FCM - fibroblast conditioned media, TS- trophoblast stem cell media (see chapter 2 and appendix)

\subsubsection{Trophoblast Invasion/Migration Assay}

To measure the invasive ability of TS cells and their differentiated lineages, an extracellular matrix-based migration assay was produced (Watkins et al., 2015). Pre-made Matrigel (basement membrane extracted proteins from Engelbreth-Holm-Swarm mouse tumour) containing culture inserts, with a pore size of $8 \mu \mathrm{m}$ in 24 well plate format, were used (Becton Dickinson, Corning). Cells were trypsinised and placed upon the wells in triplicate, with $1 \times 10^{4}$ cells per well. The cells were cultured for 5 days, either in the presence of FGF4 and EMFI conditioned medium (medium A - see 6.2.3), or in differentiation media (medium D). After 5 days, the inserts were removed and the upper (non-migrating) cells removed by carefully rubbing with a cotton bud and gentle rinsing with PBS. The insert was then fixed with $4 \%$ paraformaldehyde for 10 minutes and stained with DAPI. The number of nuclei visible on the lower surface of the Matrigel insert was then counted from 5 fields of view (at 40x magnification). Assays were carried out in triplicate for each cell line. 


\subsection{Results}

\subsubsection{Selection of TSC clones}

As some of the established TSC lines showed different morphologies (Chapter 4) and the clones had markedly different expression levels of $\mathrm{Cdx2}$ (chapter 5), we questioned whether this was due to the presence of other contaminating cell types. While ESC and EpiSC are also isolatable from the early embryo, they have differing requirement for exogenous growth factors for their maintenance and expansion in vitro. However, EpiScs have a epithelial morphology similar to TSCs, and are isolated in the presence of FGF family members, so may be contaminants of the TSC cultures (Ohinata and Tsukiyama, 2014). To test for this, we analysed the mRNA expression of pluripotency markers (Nanog, Sox2 and Oct4); these are expressed in both ESC and EpiSC but have only low or no expression in TS cells. Expression levels were compared to those in ES cells (Figure 6-1), and levels of contaminating feeder cells were checked by testing levels of S100a4, which is highly expressed in fibroblasts. Levels of both Nanog and Oct4 were very low, suggesting that there were no EpiS or ES cells present in the clones. In order to detect expression of S100a4, we used ESCs which express it at a low rate as the RT-qPCR control cells. However, there was appreciable expression of Sox2, which has been described previously by (Avilion et al., 2003). 


\section{Figure 6-1: Expression of pluripotency markers in TSC clones (overleaf)}

(A) PCR products produced in the RT-qPCRs. (B) RT-qPCR showed low expression of s100a4, a protein highly expressed in MEF feeder cells. (C) Expression of the pluripotency markers NANOG,

(D) Oct4 and (E) Sox2 are shown for the TS cells as compared to ES cells. (F) Melting curves of the products of the RT-qPCR for NANOG, (G) Oct4 and (H) Sox2. 


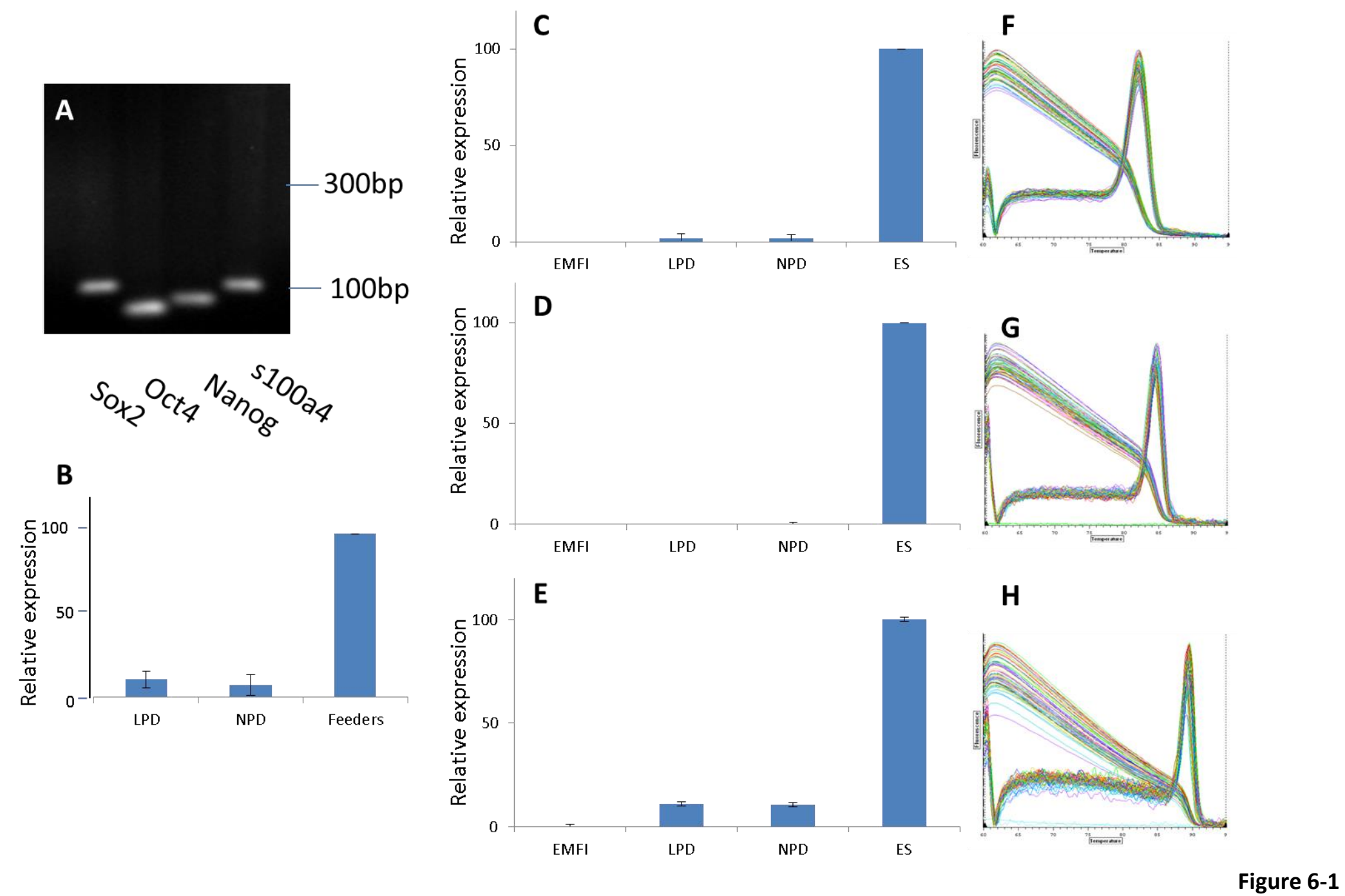


We then checked the degree of variation in the levels of Cdx2 mRNA in the clones, and whether this might suggest differences in the clones. Testing by RT-qPCR using levels of expression in MEF feeder cells as control showed a very great difference (Figure 6-2). Some clones had very low levels, suggesting major differentiation to specialised cell types and/or the presence of other unidentifiable cells in the original clone (Mak et al., 2002, Hattori et al., 2007, Dubois et al., 2013). These clones were felt to be unsuitable for further study for TSC behaviour.
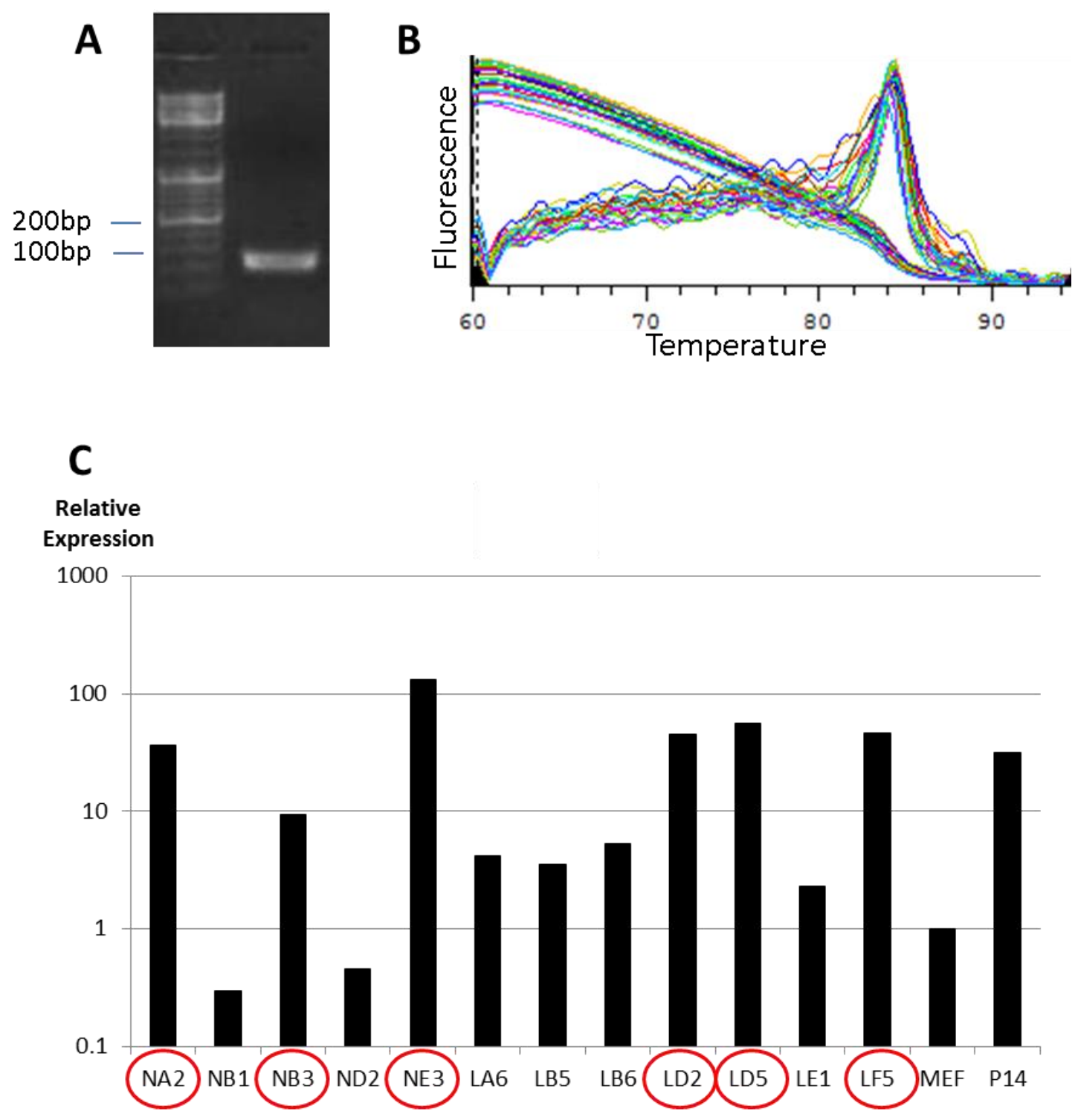

\section{Figure 6-2: Cdx2 expression in TS cell lines}

MEF: mouse embryonic fibroblast feeder cells, P14: day 14 placenta sample (positive control) (A) $R T$-qPCR product (96bp), (B) melting curve of product, (C) relative $C d \times 2$ mRNA expression. The marked clones showed the highest relative expression of $C d \times 2$. 
For further study, we selected the three highest samples from each diet group: NA2, NB3, and NE3 from NPD and LD2, LD5, and LF5 from LPD (Figure 6-2, red circles). These cells also had the most stable diploid karyotype (Chapter 5). It was noted that these cells appeared to show a male bias.

\subsubsection{Gene expression}

We then tested these selected clones by RT-qPCR for markers expected to be expressed by TS cells. Expression of the target genes was normalized against the corresponding levels $\beta$-actin, and each assay was carried out in triplicate. RNA was first tested for quality (Figure 6-3).

Eomes is a TS cell marker and transcription factor which, along with BMP4, is regulated by Cdx2 (Roberts et al., 2004). Eomes is required for TS cell isolation and full trophectoderm formation, and its absence results in embryonic lethality prior to E6 with a failure in trophoblast lineages both in vivo and in vitro (Strumpf et al., 2005).

We also checked for expression of markers seen in the early stages of the differentiation of TS cells. Hand1 is a transcription factor normally present in TS cells, but strongly upregulated on differentiation due to loss of FGF signals. This is believed to drive an increase in PI1 hormone expression which is observed early in differentiation, as TS cells enter the path toward giant cells (Hughes et al., 2004, Carney et al., 1993).

Tpbpa is a regulatory protein expressed by and needed for spongiotrophoblast formation. Its absence prevents spiral artery remodelling in vivo. Finally, Nodal expression was tested, which is also formed by spongiotrophoblast cells.

Signals were observed for each of the genes; however, the levels of Hand1 and Tpbpa were relatively low when compared with the other markers. No differences between the TSC clones from the two dietary groups were detected (Figure 6-4). The production of Eomes and BMP4 
along with $\mathrm{Cdx} 4$ suggests that these are indeed TS cells; however, there would appear to be some differentiation. It is of note that Hand1 and Tpbpa1 levels appeared low, and this may suggest that some cells have passed into terminal differentiation while the majority are retained in a stem cell state (see section 6.3.6).

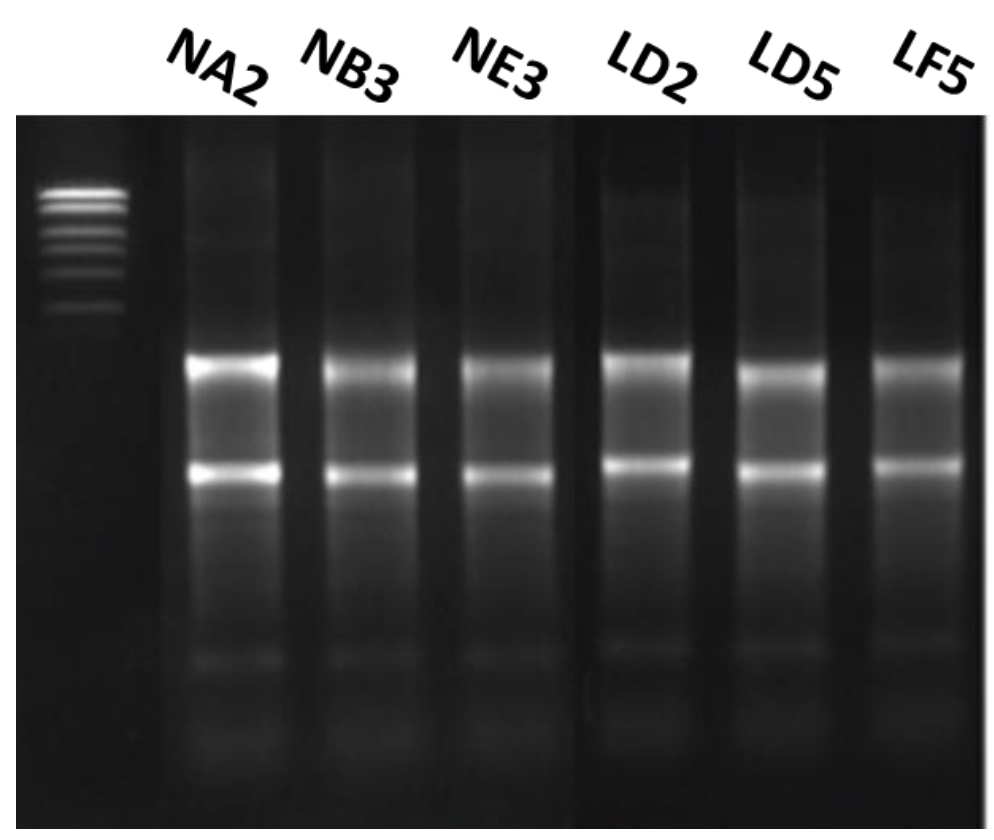

Figure 6-3: Electrophoresis of TS cell line's total RNA -Tested to confirm RNA integrity.

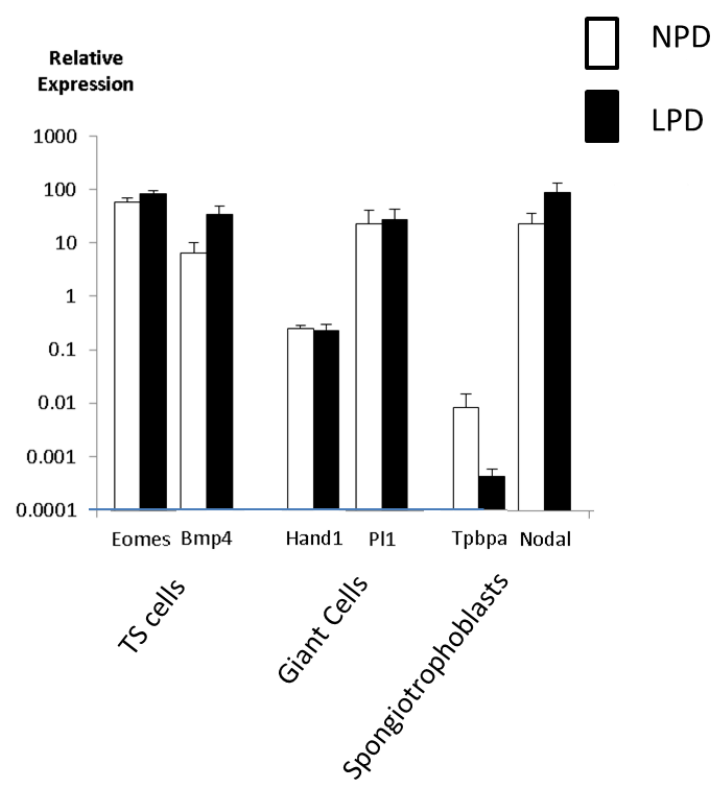

Figure 6-4: RT-qPCR of Trophectodermal markers in undifferentiated TS cells

Expression is shown relative to 6 -actin. Error bars - SEM. 


\subsubsection{Cell proliferation}

Trophoblast proliferation has been described as being increased in embryos following low protein challenge; hence, as an initial assay we measured TS cell multiplication. TS cells at passages 5 to 7 were pre-plated to remove feeders and the stem cells seeded in 24-well plates in triplicate, with a seeding density of $1.5 \times 10^{4} \mathrm{cell} / \mathrm{ml}, 0.5 \mathrm{ml}$ per well $(7500$ cells). The cells were cultured in TS growth medium (70\%FCM+F4H - see appendix). The medium was changed every two days. The cells were collected and counted with a haemocytometer at days 4,6 , and 8 (on day 2 there were not enough cells to allow for counting). Each well was counted in triplicate. The numbers of cells counted and the doubling time are presented in Table 6-3 and Figures 6-5 and 6-6: these show a greater proliferation of the TS cells isolated from embryos of low protein fed mothers, the difference becoming significant after day 6. By day 8 , there were threefold more LPD cells compared to NPD cells, suggesting that the NPD-derived cells were proliferating $\sim 40 \%$ slower than the LPD cells.

\section{Table 6-3: Proliferation of TS cells}

Cell counts with SD and doubling times

\begin{tabular}{|l|c|c|c|c|c|}
\hline \multicolumn{1}{r|r|}{ Day } & 0 & 4 & 6 & 8 & Doubling Time- days \\
\hline Celltine & & & & & 3.2 \\
\hline NA2 & 7500 & $9000 \pm 0$ & $18000 \pm 3000$ & $42000 \pm 6000$ & 2.3 \\
\hline NB3 & 7500 & $13500 \pm 1500$ & $28500 \pm 4500$ & $91500 \pm 7500$ & 2.6 \\
\hline NE3 & 7500 & $15000 \pm 0$ & $28500 \pm 1500$ & $63000 \pm 15000$ & 1.6 \\
\hline LD2 & 7500 & $25500 \pm 1500$ & $72000 \pm 3000$ & $222000 \pm 9000$ & 1.8 \\
\hline LD5 & 7500 & $13500 \pm 1500$ & $39000 \pm 0$ & $162000 \pm 6000$ & 1.7 \\
\hline LF5 & 7500 & $27000 \pm 3000$ & $69000 \pm 3000$ & $214500 \pm 7500$ & \\
\hline & & & & & \\
\hline & & & & & \\
\hline Mean & 0 & 4 & 6 & & $1.7 \pm 0.1$ \\
\hline NPD & 7500 & $12500 \pm 2549$ & $25000 \pm 4949$ & $65500 \pm 20285$ & \\
\hline LPD & 7500 & $22000 \pm 6041$ & $60000 \pm 14899$ & $199500 \pm 26692$ & \\
\hline
\end{tabular}


Chapter 6

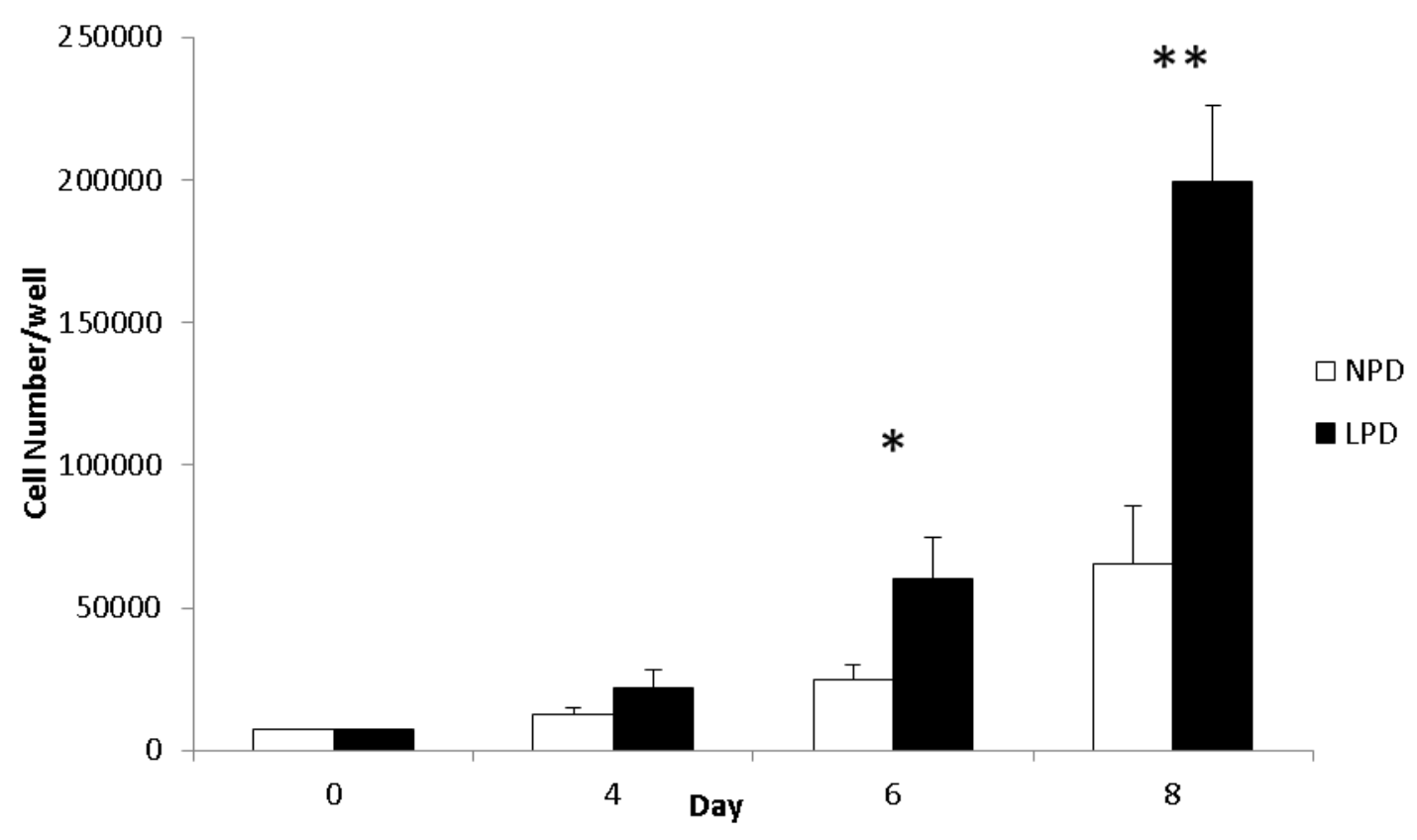

Figure 6-5: TS cell proliferation.

Cell counts measured at days 4,6 , and 8 after plating. Error bars- SD. ${ }^{*} P$ value $<0.05 ;{ }^{*} P$ value $<0.01$ 
Chapter 6

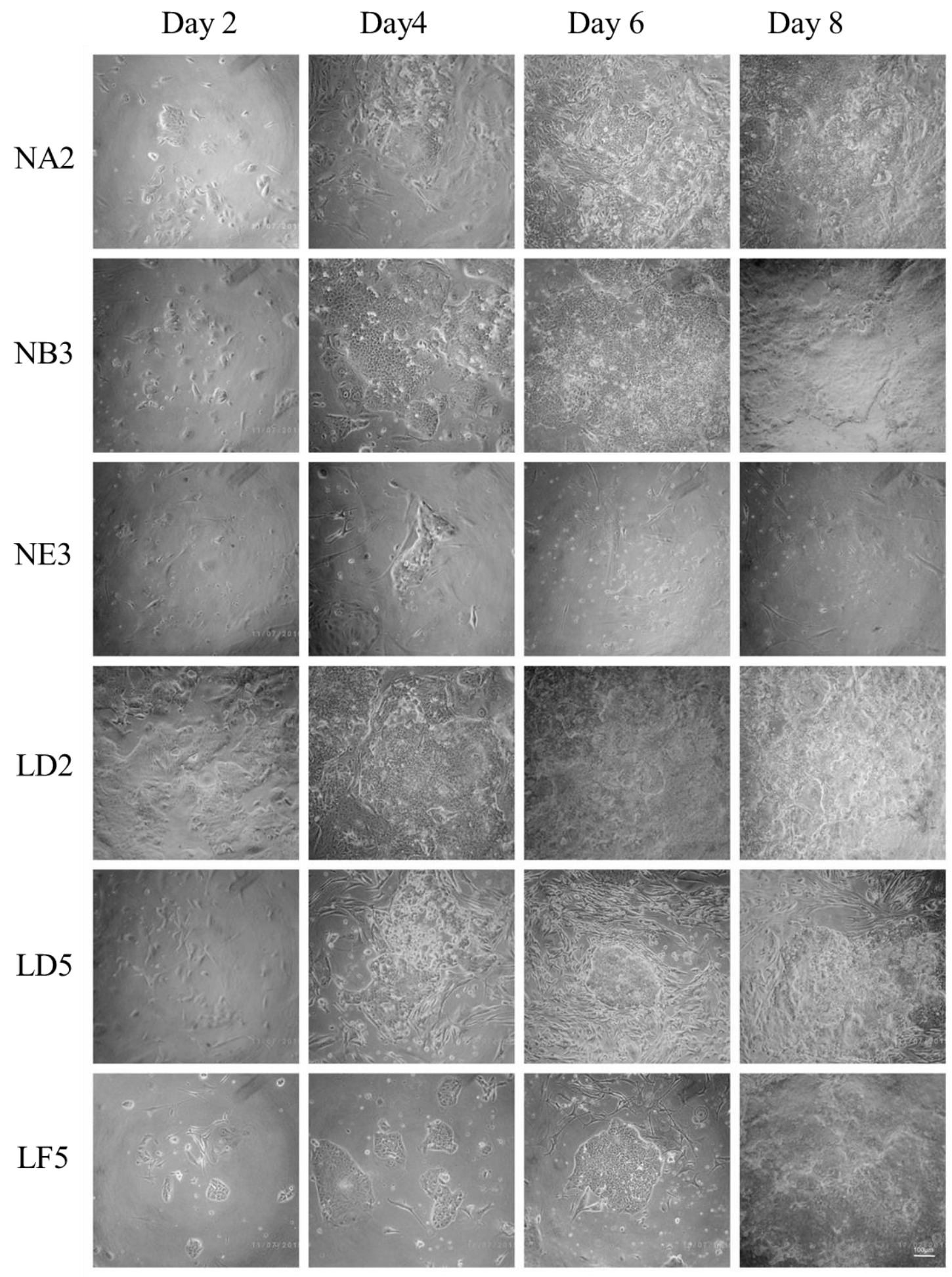

Figure 6-6: Representative photomicrographs of proliferating TS cells 


\subsubsection{Cell metabolism}

Given this change in cell proliferation, we then used MTT assays to determine the TS cells' mitochondria activity. NAD(P)H-dependent (and hence mitochondrial dependent), cellular oxidoreductase catalyses yellow thiazolyl blue tetrazolium bromide (MTT) to blue formazan crystals. Higher absorbance indicates that the sample contains a higher level of mitochondrial activity, which can be a higher number of cells, more active cells, or both.

TS cells were cultured on a 24-well plate, in triplicate for each cell line, and analysed upon days 2 8. They were incubated with MTT at a final concentration of $1 \mathrm{mg} / \mathrm{ml}$ for 2 hours prior to lysis. Absorbance was measured at $540 \mathrm{~nm}$ with a reference wavelength of $620 \mathrm{~nm}$ (Figure 6-7). While in general there appeared to be a greater MTT conversion in LPD cells, the difference was not significant between the two groups.

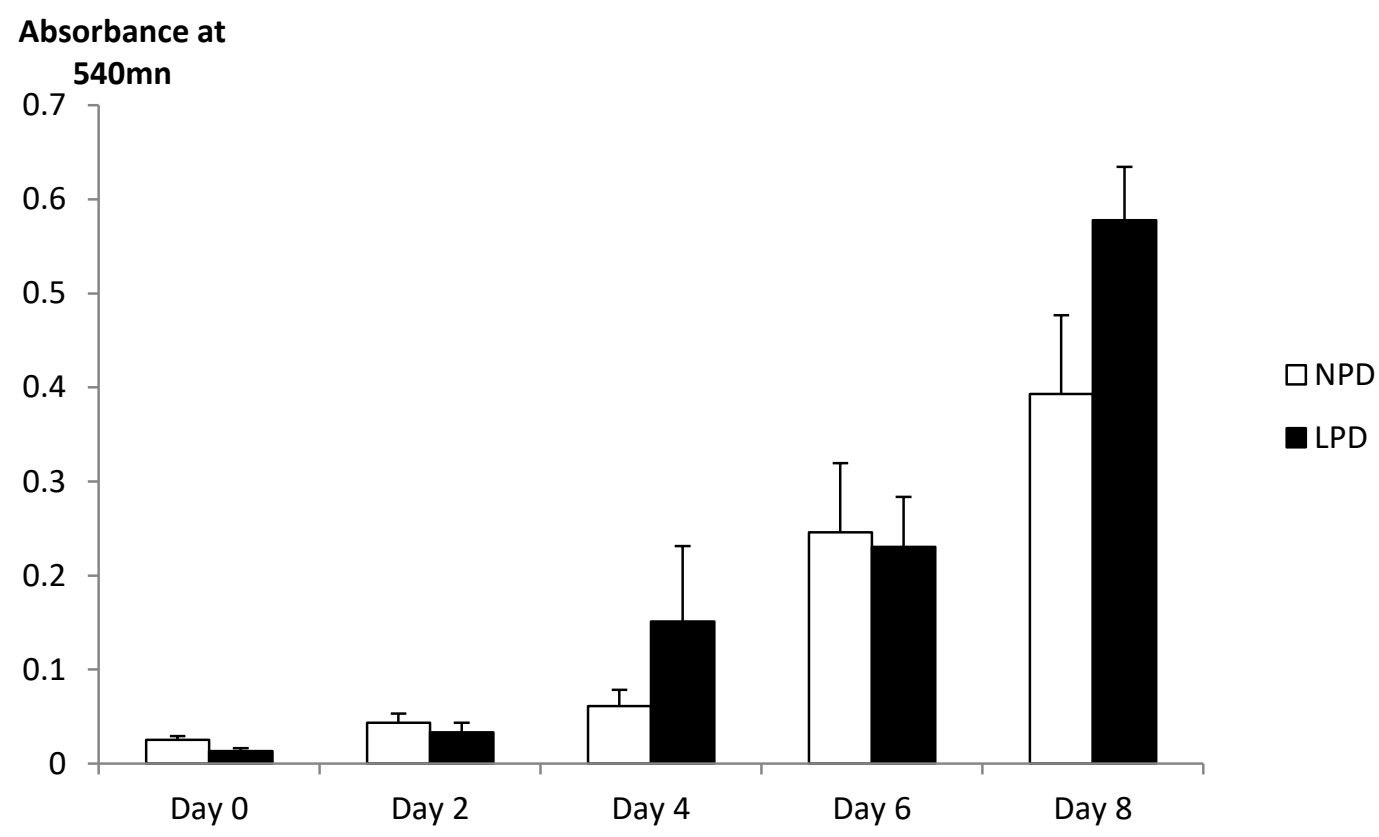

Figure 6-7: MTT assay to compare metabolism of the different diet groups

Error bar- S.D 


\subsubsection{Endocytosis analysis}

We next analysed these cells for their endocytic ability. This has been shown to be altered in the yolk sac visceral endoderm of foetuses (Watkins et al., 2008) and the trophectoderm of blastocysts when challenged by low protein maternal diets (Sun et al., 2014). Further, in an ES cell based model, maternal LPD increased endocytosis by embryonic body derived primitive endoderm (Sun et al., 2014).

The TSC endocytosis was studied by analysing the uptake of dextran conjugated pHrodo, which fluoresces as the $\mathrm{pH}$ in the endosome reduces, giving a robust signal only in the late endosome $\mathrm{pH}^{\sim 5} 5$ and the lysosome $\mathrm{pH}^{\sim} 4.5$. In an initial assay, we tested a single cell line to obtain an estimate of the likely time course of uptake. Line (LF5) was loaded by culturing in pHrodo-dextran for 30 minutes, and then endocytosis was followed by confocal microscopy after washing in dyefree medium. The cells were photographed at 15 minute intervals (Figure 6-8). Volocity 3D imaging software (Perkin Elmer) was used to quantify the cell numbers, nuclear volume and pHrodo volume. The change in pHrodo signal as volume per cell is shown in Figure 6-9. This continued to increase over the time course of the experiment. A strong signal was seen at 90 minutes following pHrodo addition, and this was chosen as the time for analysis of the cells.

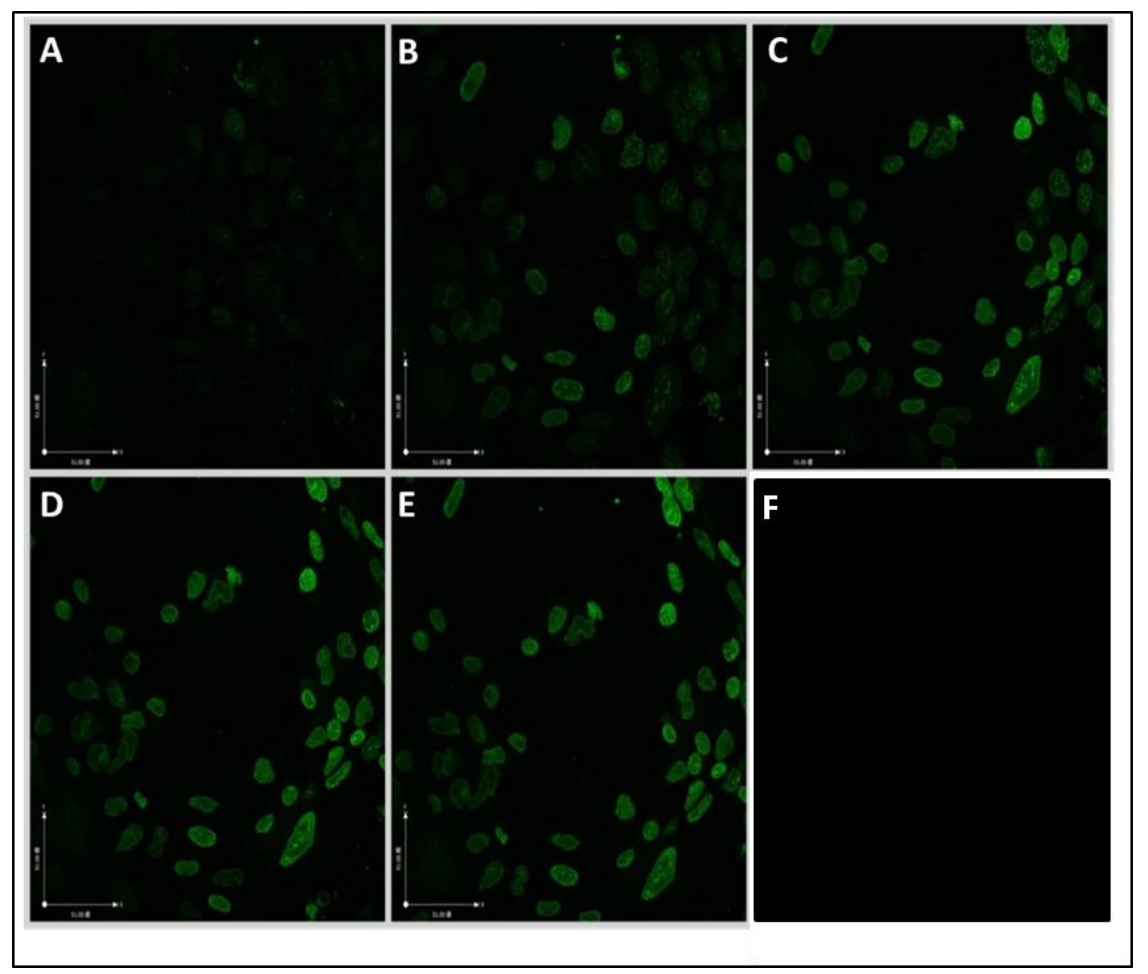

Figure 6-8: Time points after pHrodo was added

(A) 30 minutes, (B) 45 minutes, (C) 60 minutes, (D) 75 minutes, (E) 90 minutes. (F) negative control. 


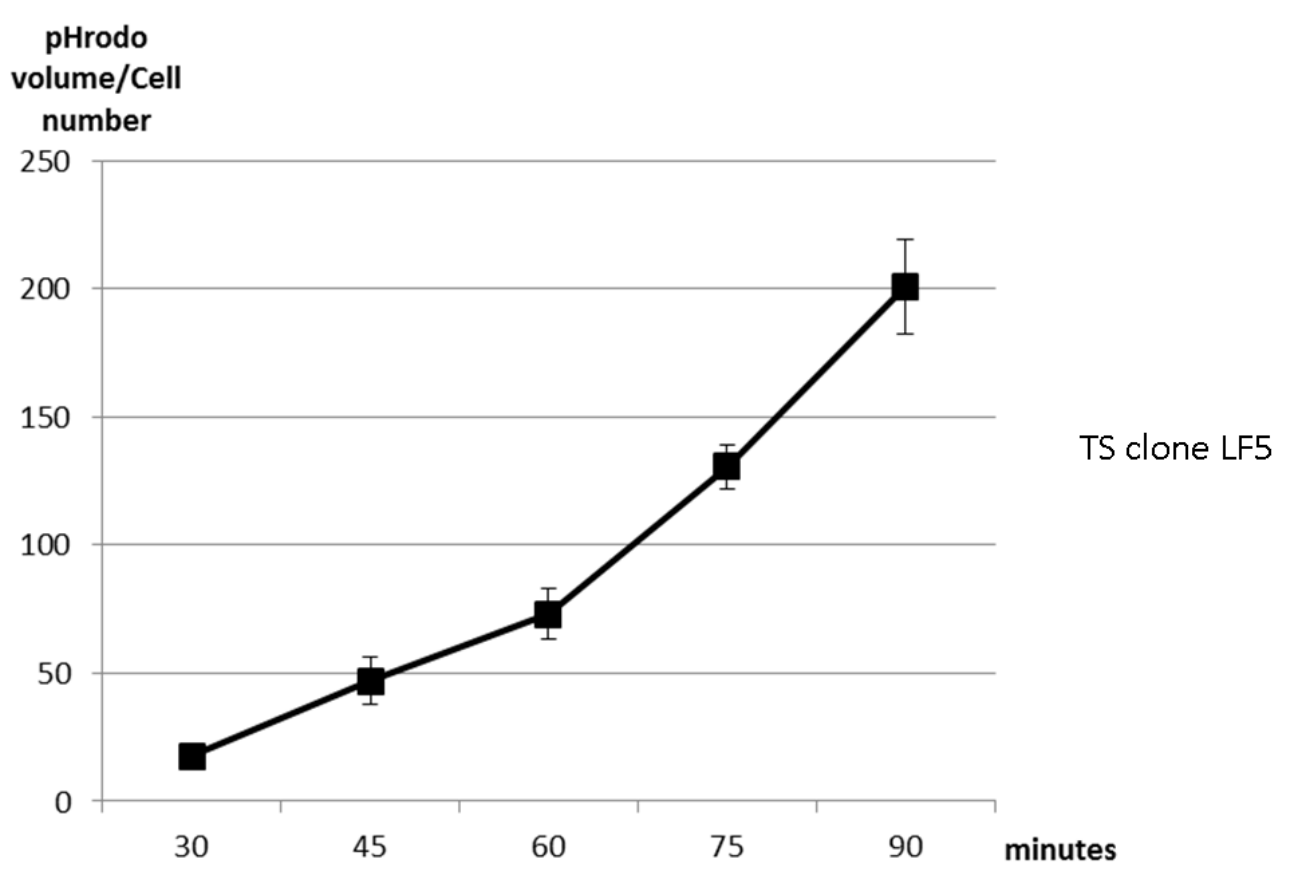

Figure 6-9: pHrodo signal over time after initial incubation of TS cells from clone LF5 Error Bar-S.E.M.

We analysed the three TS cell lines present in each of the low and high protein groups (Figure 610). Twenty fields of view were analysed for each culture well of the cell lines, and each individual line was analysed in triplicate. As a percentage of cells in TS cultures are differentiating toward giant cells, there are always a number of polyploid or multinuclear cells present (see Chapter 5); these are observed as large and irregular cell nuclei. For analysis, we measured both pHrodo signal volume/cell and the pHrodo signal volume:nuclear volume ratio (Figure 6-11). While there was no difference in the volume of pHrodo staining per cell between the two diet groups, there is a significant difference in the latter measurement. 
NPD
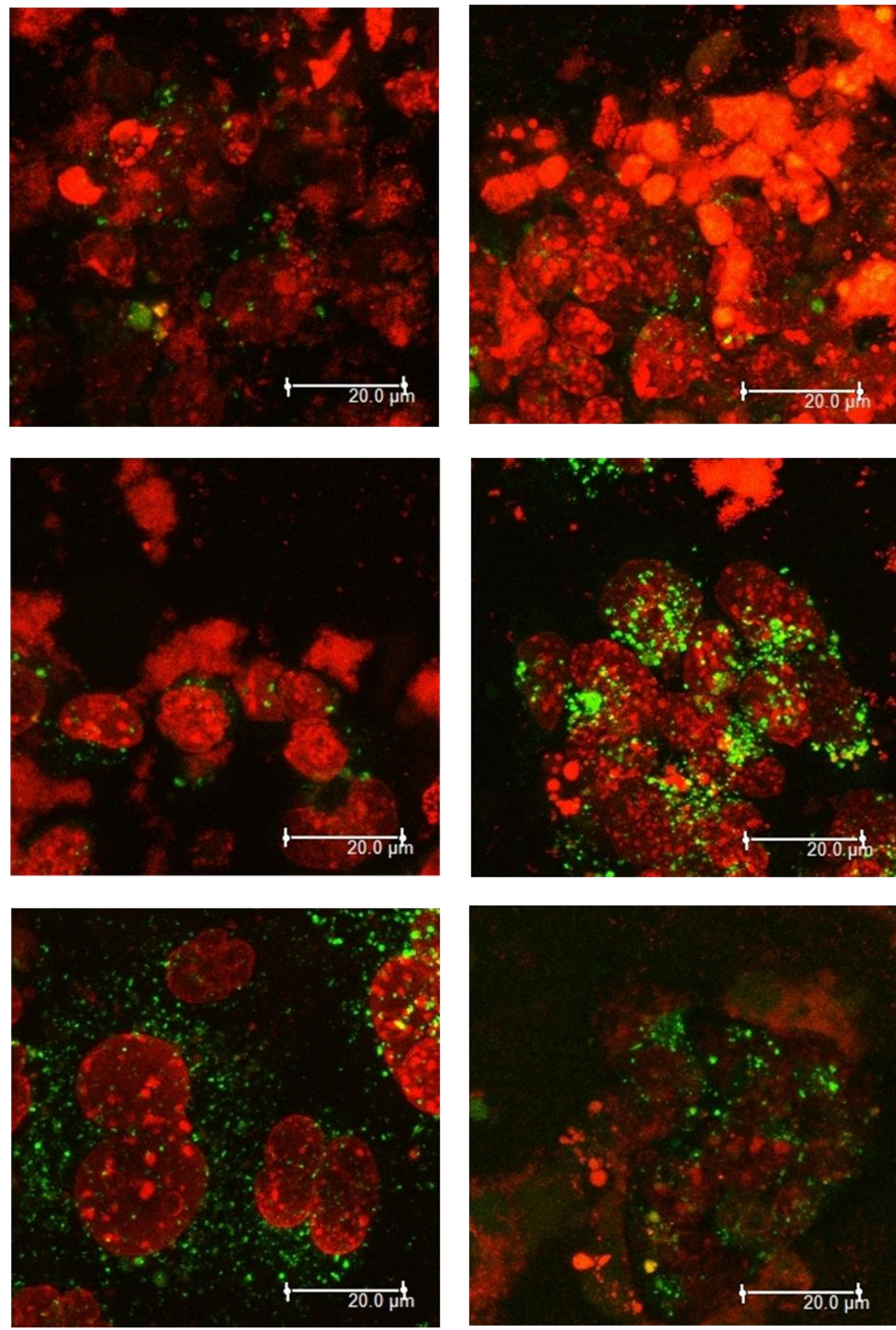

\section{Figure 6-10: TSC endocytosis}

Red: cell nuclei, Green: pHrodo dextran; Left panel: NA2, NB3, NE3; Right panel: LD2, LD5, LF5 (from top to bottom). 
A pHrodo
volume/cell

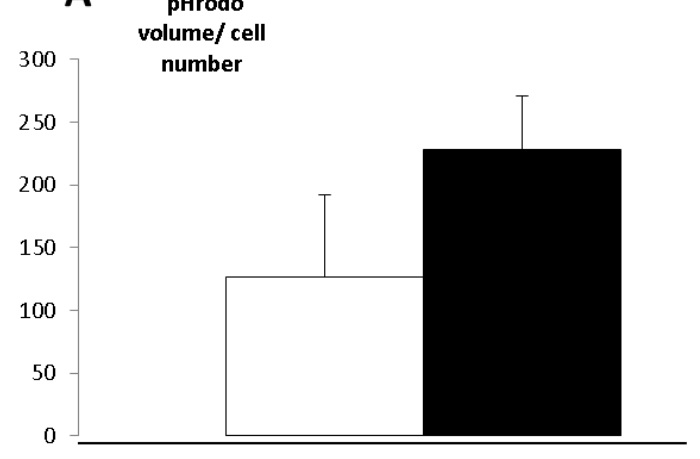

B

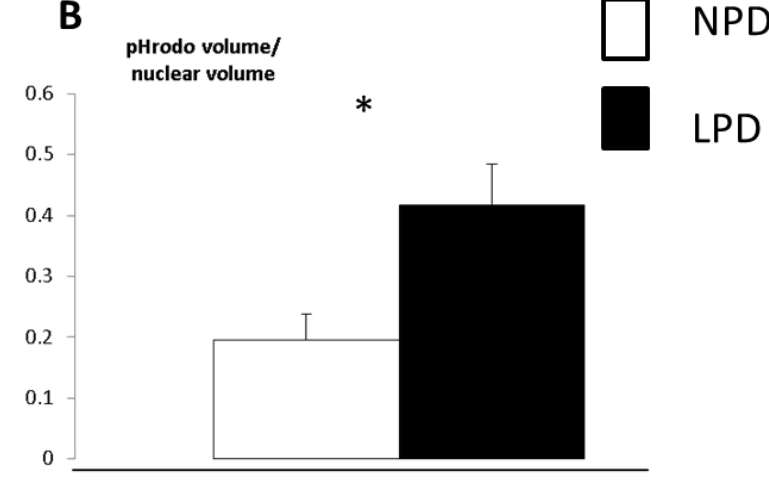

Figure 6-11: Analysis of TSC pHrodo staining

(A) pHrodo volume per cell number, (B) pHrodo volume: cell nuclear volume ratio. Error bar- S.E.M. $* p<0.05$.

As there was some evidence that there may be an increase in endocytosis, we tested for expression of megalin mRNA. This multi-ligand binding protein, which mediates endocytosis, has been shown to be regulated by the mTOR pathway (Gleixner et al., 2014), with mTOR inhibition causing reduction of Megalin levels and reduce endocytosis. Surprisingly, megalin mRNA was reduced in LPD TS clones (Figure 6-12). 


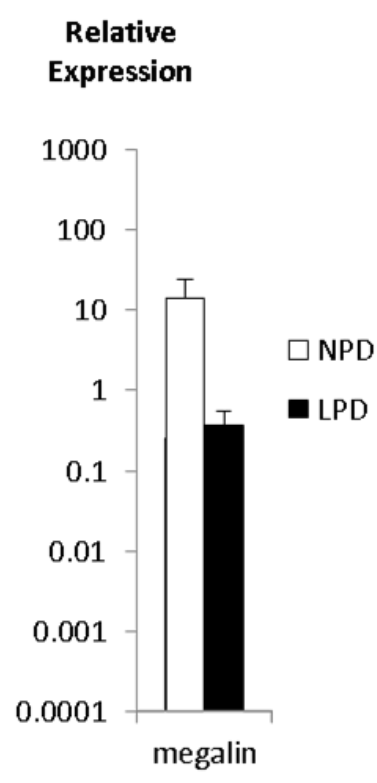

Figure 6-12: Expression of megalin in TS cells. Expression was normalized against the corresponding levels of B-actin and represented as mean triplicate reactions. Error bars- S.E.M.

\subsubsection{Cell differentiation assays}

The previous analyses were carried out on TS cells which had not been forced to differentiate. Next, we compared the differentiation of these cells. When FGF4 was present - whether commercial recombinant FGF4 or through culture in conditioned media from FGF4-expressing 293 cells - the TS cells remained stable and the cultures contained tight colonies, which in time expanded and coalesced as described before (Tanaka et al., 1998); see Figure 6-13. Interestingly, the cells cultured in the 293-FGF4 conditioned media (B) generally grew faster than those in the commercial FGF4 (A), suggesting that the 293 cells might be producing other growth-enhancing factors in the FCM which were not formed by fibroblasts. Two forms of differentiation media were tested: in (C) the cells were cultured under the same basic media used to maintain TS cells (with 20\% FCS and 70\% FCM); however, no FGF4 was supplemented, while in (D) the cells were grown in RPMI with $10 \%$ FBS, in the absence of FGF4 (and heparin).

The cell morphology changed clearly in the absence of FGF4 and heparin (Figure 6-13 C and D). Additionally, we observed that MEF cells stopped proliferating, and were gradually lost from the culture. The cells which were cultured in the absence of FGF4 and heparin showed slower or no 
growth, and after 6 days, the colonies had separated into individual cells - many of which were a spindle shape. The cells which were in the presence of FGF had become confluent.

We also observed that the cells in media $\mathrm{C}$ started differentiation by day 3 , with their colonies losing their defined edges and the peripheral cells becoming multinuclear (Figure 6-14 circles and arrows).
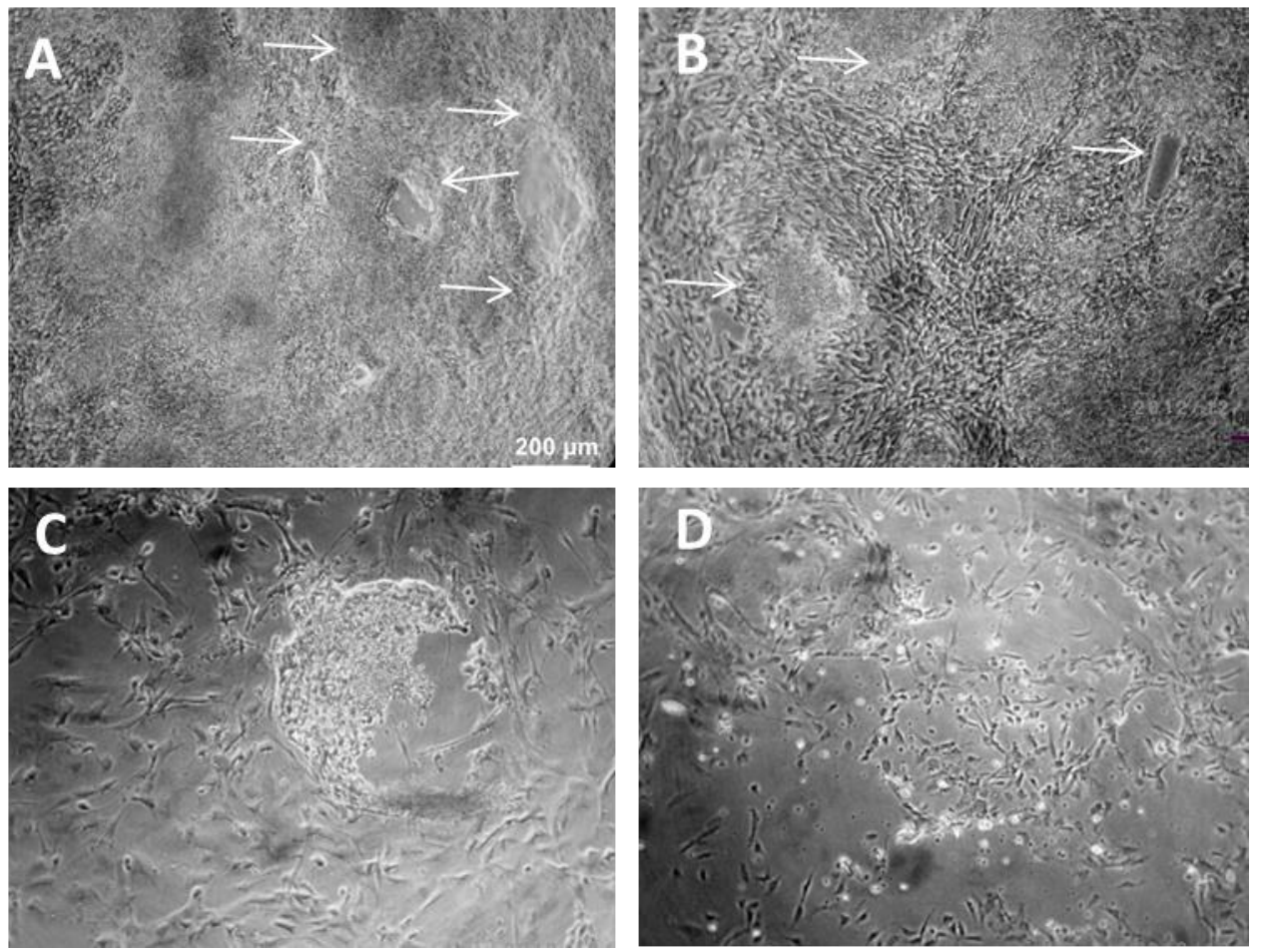

Figure 6-13: TS cells cultured with various media

Cells retained their tight flat morphology (arrows) in the presence of either the commercial FGF4 or the conditioned media from recombination cells ( $A$ and $B$ respectively), even after becoming confluent following 6 days in culture. In the absence of FGF4 ( $C$ and D), the clones lost their colony appearance and differentiated. The composition of the media is listed below: 


\begin{tabular}{|l|l|l|l|}
\hline Medium & & FCS & Supplement \\
\hline A & $70 \%$ FCM, 30\% TS & $20 \%$ & FGF4 $(37.5 \mathrm{ng} / \mathrm{ml})$, Heparin $(1 \mu \mathrm{g} / \mathrm{ml})$ \\
\hline B & $70 \%$ FCM, 30\% TS & $20 \%$ & $10 \%$ recombinant FGF conditioned media \\
\hline C & $70 \%$ FCM, 30\% TS & $20 \%$ & - \\
\hline D & RPMI & $10 \%$ & - \\
\hline
\end{tabular}

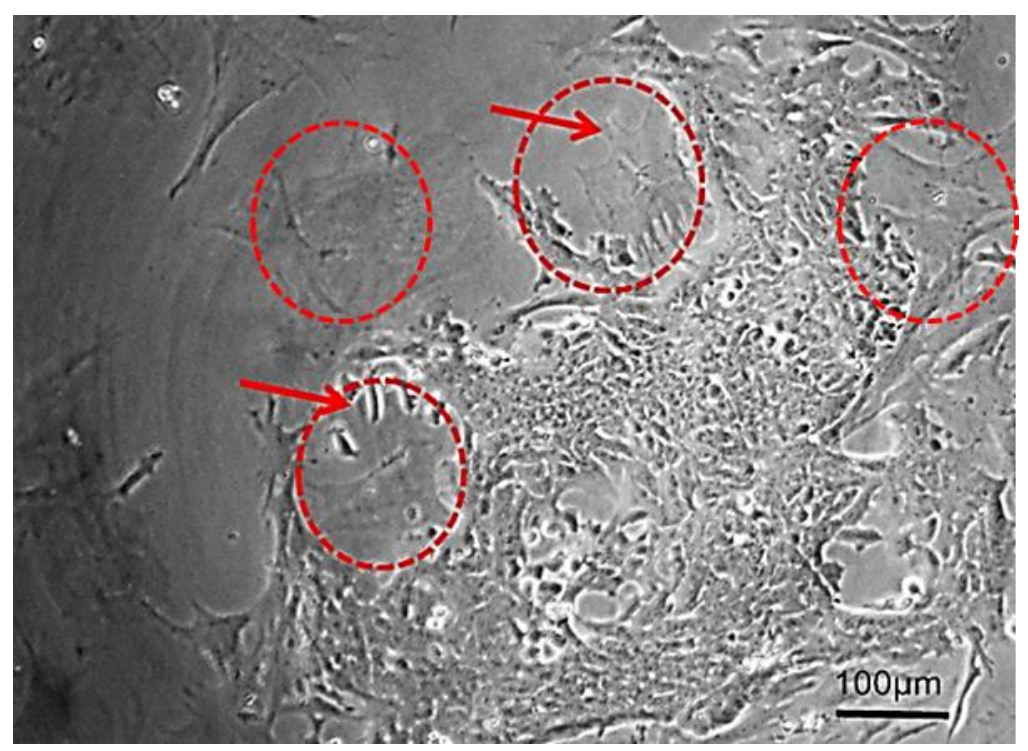

Figure 6-14: TS cells with FGF4 and heparin withdrawn (medium C) showing emergence of numerous large flat cells by day 3

Cdx2 and Eomes are expressed by, and are required for, TS cell formation (Strumpf et al., 2005). We tested for their presence in the differentiating cells. Cells cultured in both media containing FGF4 showed colonies expressing Cdx2 with highest staining in the 293 conditioned media (Figure 6-15 A) - again suggesting that the 293-conditioned media may also contain other growth factors. In the RPMI (media D), the cells had lost all Cdx2 staining, with a few cells staining in the fibroblast-conditioned media (media C) (Figure 6-15B). We then looked at the change of the mRNA levels for Cdx2 and Eomes, both reduced markedly within 48 hours of removal of FGF4 (only RMPI - media D was tested). There was no obvious difference between the two cell groups (Figure 6-15 $\mathrm{G}$ and $\mathrm{H}$ ). 
Figure 6-15: Cdx2 and Eomes expression in differentiating TS cells (following page)

FGF4 and heparin containing media (A) and differentiation media lacking supplemented FGF4 and heparin (B-70\%FCM 30\% TS and C-RPMI). Cells had been grown in the media for 6 days. The nuclei are counter stained with DAPI (blue). Scale bar $50 \mu m$.

$R T$-qPCR for $C d \times 2(G)$ and Eomes $(H) m R N A$, over 6 days in culture changes are given relative to undifferentiated cells
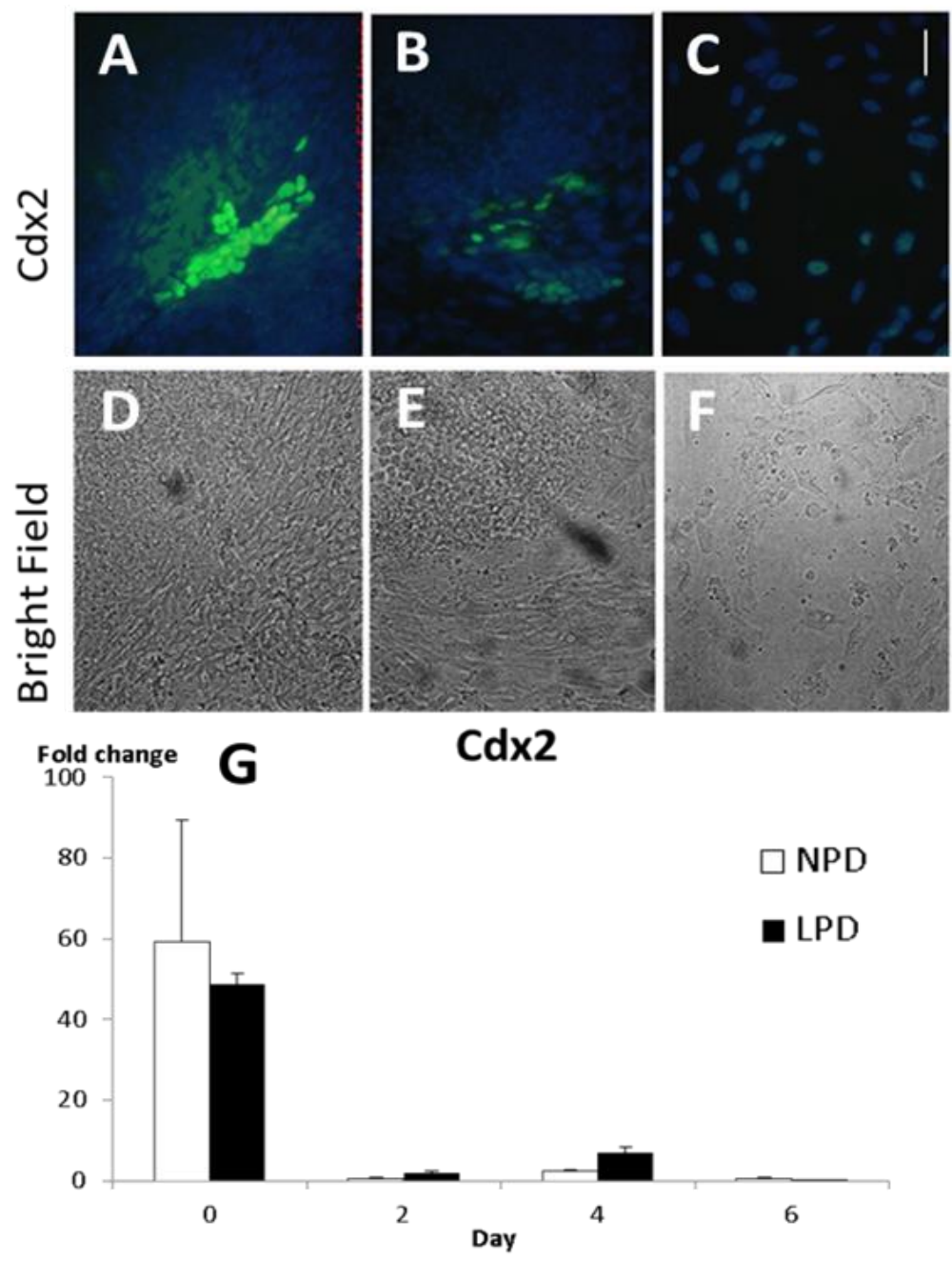

Cdx2

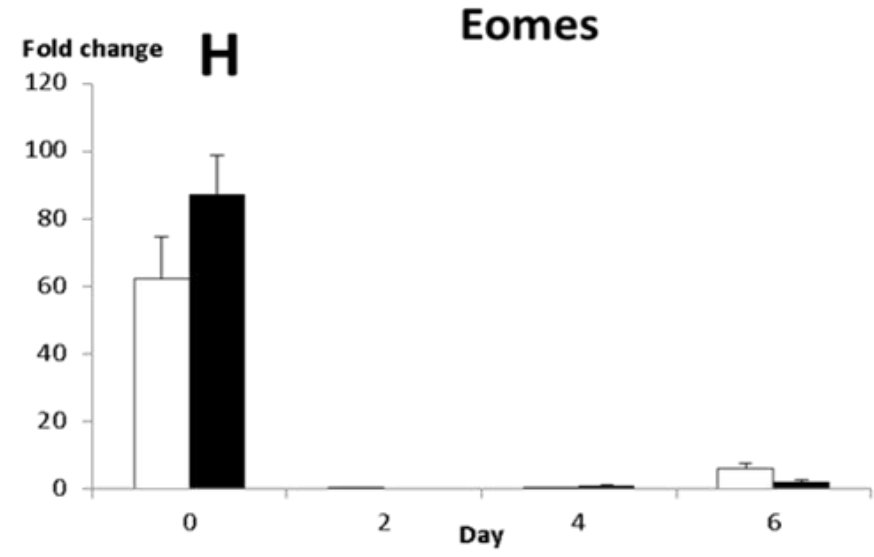




\subsubsection{Cell proliferation during differentiation}

As cells differentiate from the stem cell stage, they slow their cell cycle and finally stop proliferating. With TS cells, this is complicated by the cells entering the giant cell lineage, where DNA proliferation in the absence of cell division occurs. We questioned whether the cell proliferation during differentiation caused by FGF4 removal might be altered by the NPD/LPD origin of the TS cells. For this reason, after plating the cells as described earlier, the cells were placed in RMPI differentiation media (D), with cell numbers counted on alternate days (each was measured in triplicate). For both the NPD and LPD cells, the numbers increased until day 6 (Figure 6-16). As with the undifferentiated cells, the proliferation rate was greater for the TS cells isolated from LPD embryos, with statistical significance being observed after 4 and 8 days. The overall reduction in cell numbers after 8 days might have been caused by cell death becoming dominant, as proliferation ceases upon differentiation.

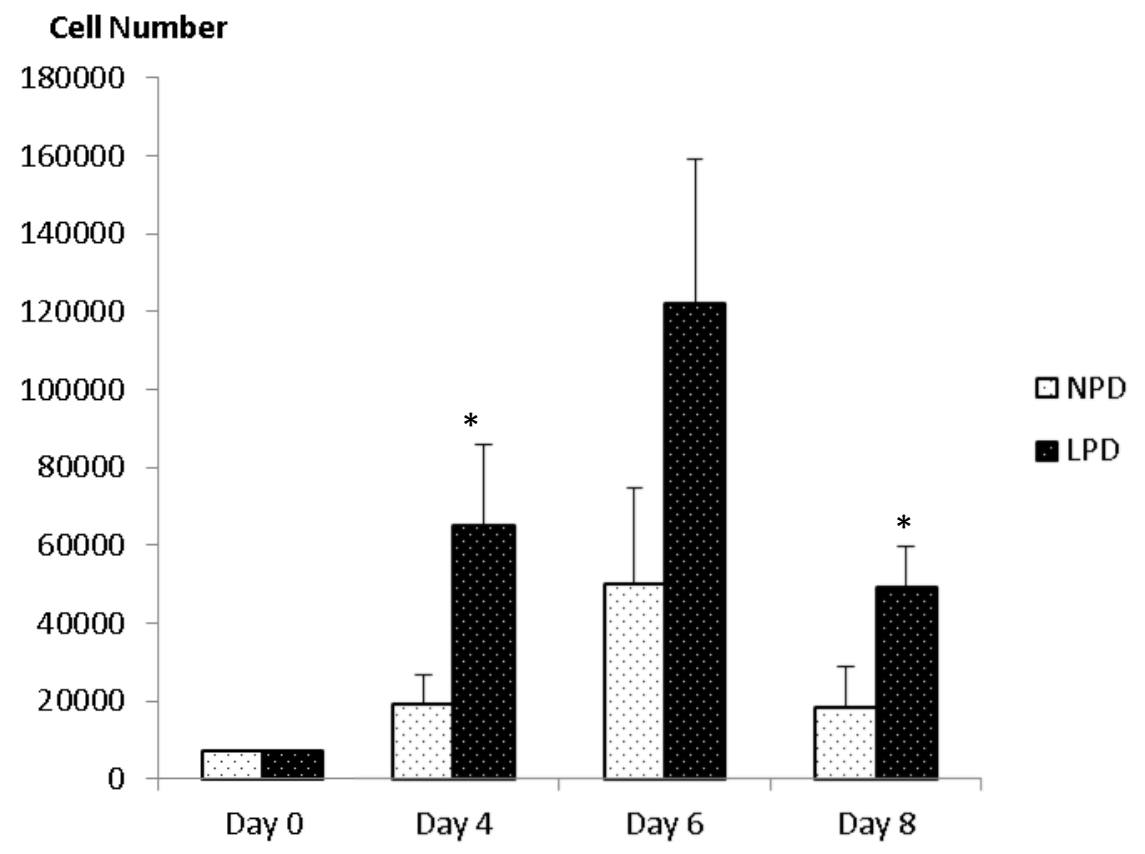

Figure 6-16: Cell numbers after culture in differentiation medium.

${ }^{*} p<0.05$. Error bars- S.E.M.

\subsubsection{Metabolic Activity of Differentiating Cells}

To understand if the mitochondrial activity was altered between the two groups during differentiation, we then carried out MTT assays on the TS cells when grown in RMPI medium 
(medium D). While the LPD cells appeared to be more active than NPD (Figure 6-17), this difference never reached statistical significance.

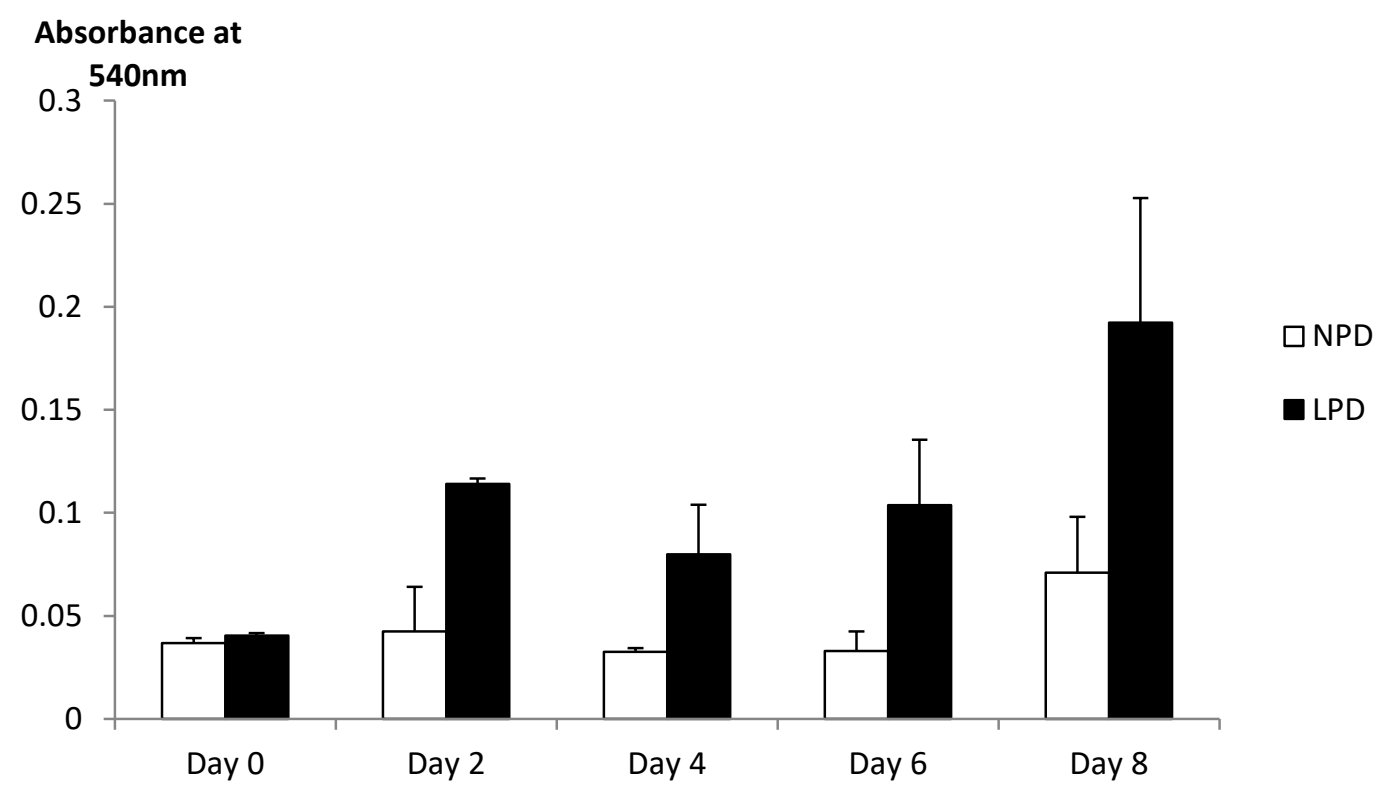

Figure 6-17: MTT conversion by differentiating TSCS

Error bars- S.E.M.

\subsubsection{Trophoblast invasion assays}

Trophoblast cells formed from TS cells differentiation in vitro are highly motile and invasive (Hemberger et al., 2004), unlike the stem cells which, when undifferentiated, remain in a tight defined colony. Studies with trophoblasts cultured from blastocysts (Eckert et al., 2012) and ectoplacental cone (Watkins et al., 2015) have suggested that motility and/or invasiveness may be altered following an early embryonic low protein challenge. To test whether the TS cells and their differentiated cells showed a change in invasive activity, a transwell-Matrigel invasion assay was carried out.

An initial experiment studied the rate of invasion to discover the optimal time to analyse the cells. One cell line was cultured in differentiation media, and the numbers of cells migrating over the insert was measured over the following 7 days (Figure 6-18). The number of transferred cells 
Chapter 6

reached a plateau after 5 days, and the very slight increase seen two days later was accompanied by an increase in cell death, as seen by floating cells in the upper chamber. As a result, 5 days was used as the investigation period for the following experiments.
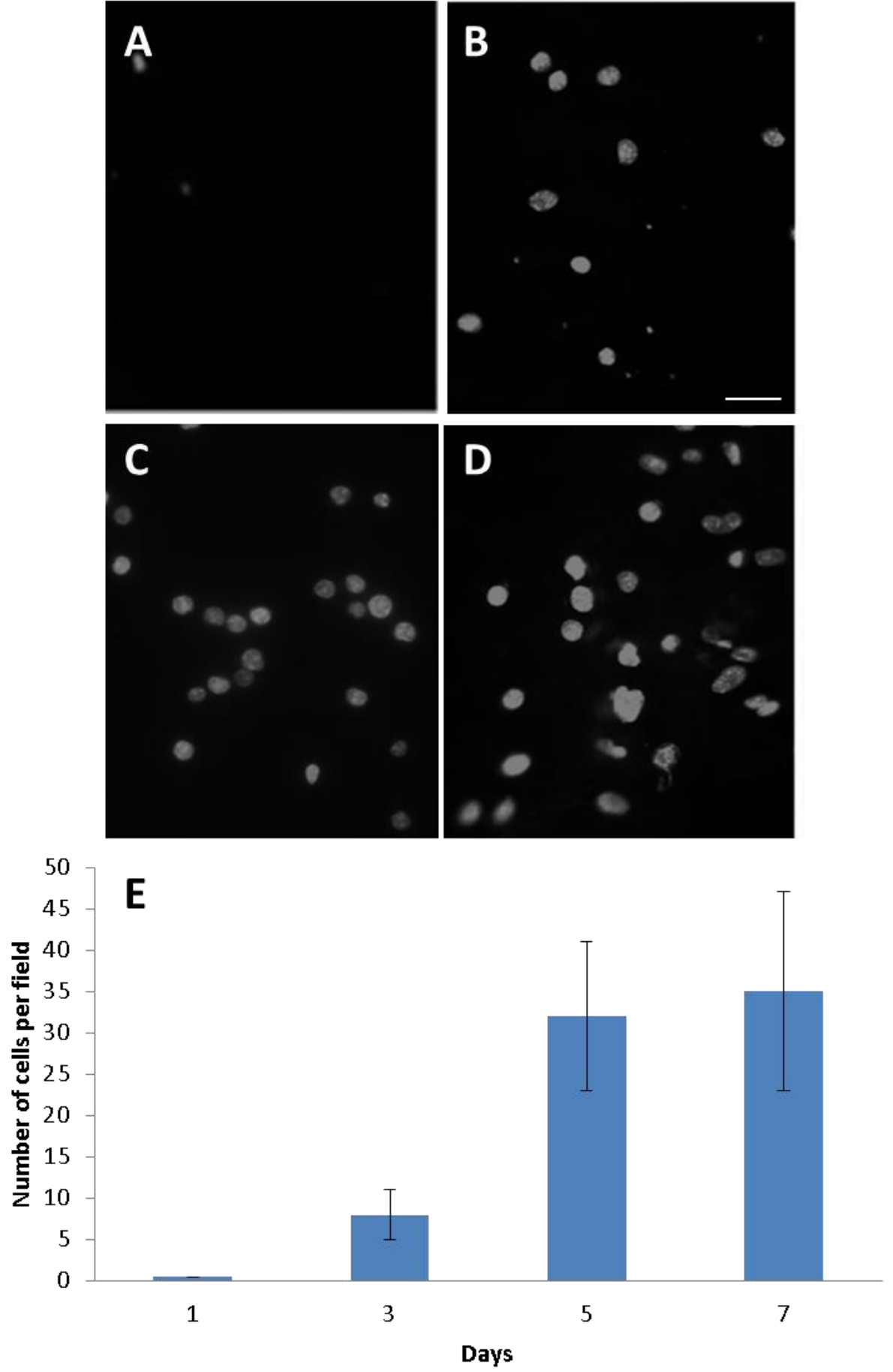

\section{Figure 6-18: Matrigel invasion assay}

DAPI stained cells from TS clone LF5 appearing on the underside of matrigel invasion insert on 1 (A), 3(B), 5(C) and $7(D)$ days after plating in RMPI media. Collated data (E) scale bars 10 $4 m-S D$. 
Migration of differentiating TS cells at day 5 showed no statistical difference between the two treatments (Figure 6-19), as control cells were also grown in FGF4 containing media (where few cells migrated through the matrigel insert).

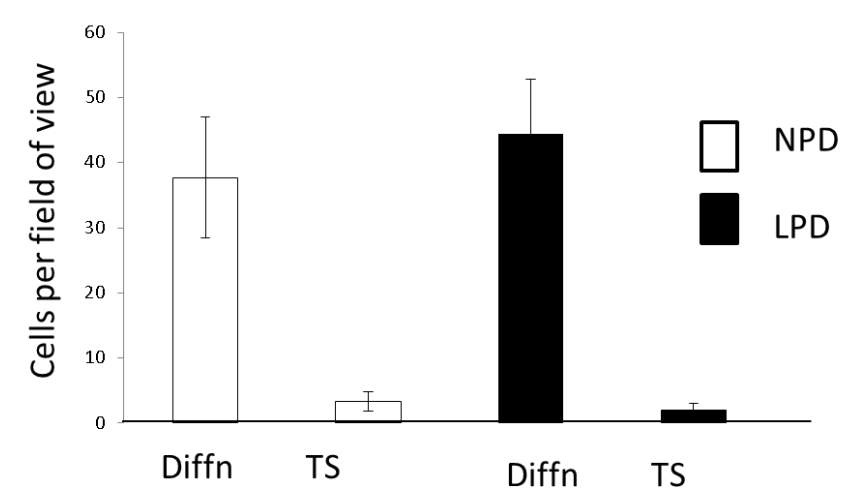

Figure 6-19: Differentiating TS cell matrigel invasion assay

DAPI stained migratory cells were counted after 5 days in RMPI differentiation media (Diffn) and TS culture media (media A) error bars- SEM.

\subsection{Discussion}

In this chapter, we attempted to analyse the behaviour of our TSC clones. We had initially produced 12 clones: 5 from normal protein diet mothers and 7 from low protein diet. These clones were all FGF4 dependant, and had been treated in a similar manner in culture. While all appeared to have a tight epithelial-like structure, and were similar to side colonies occasionally seen on ES cell derivation ( $\mathrm{A}$ Cox PhD thesis), they showed differences in their growth characteristics - and hence colony size - and in their $\mathrm{Cdx} 2$ staining phenotype. As a result, we checked them for the levels of Cdx2 mRNA expression: a marker used to define TS cells (Niwa et al., 2005, Tanaka et al., 1998).

As shown in Motomura et al., 2016, $\beta$-actin and GAPDH gene expression by TSCs were stable and suitable for use as reference genes. We compared $C d \times 2$ expression normalised against that of $\beta$ actin as described for genome studies (Motomura et al., 2016). From our results, the $\beta$-actin CT values were very similar in all TSCs. 
On this basis, we could separate the colonies into two groups with high and low Cdx2 expression levels. We tested whether there could be contaminating EpiSCs in the cultures, as this has been described by others (Ohinata and Tsukiyama, 2014) as these cells are morphologically not dissimilar to TS cells. It is of interest that most of the cells expressing high levels of Cdx2 were male (5/6), and while 5/6 of the low-expressing clones were female, the lowest expression of all was seen in clone NB1, which was male. While variation in Cdx2 expression has been discussed by others (Motomura et al., 2016), such a low level of expression was surprising. However, our finding that TSC lines are heterogeneous, with colonies of different morphology and sizes, is in agreement with other others (Tanaka et al., 1998, Motomura et al., 2016, Kubaczka et al., 2014). Furthermore, TS clones are known to change their characteristics over time in culture, so it is possible that we have inadvertently selected for low $\mathrm{Cd} \times 2$ but highly proliferative cells.

It is known that there are sex-caused differences in certain species in regard to placental morphology (Kalisch-Smith et al., 2016) and in blastocyst development; hence in mice and cattle, accelerated development is displayed by male blastocysts (Mittwoch, 1993). However, to our knowledge, there has been no description of difference in expression of markers such as Cdx2 between male and female TS cells.

TS cells undergo profound DNA methylation quite different to that seen in ES and EpiSC, and closely mimic the epigenetic changes seen in placental tissue in vivo (Senner et al., 2012). As genomic imprinting is prevalent and crucial for the placenta, and is known to be needed for the maintenance of stem cell identity (Lefebvre, 2012), it is possible that epigenetic mechanisms have been disrupted in our isolation procedure. We used a semi-defined medium to isolate the cells with purified commercial recombinant FGF4, as we found that cells grown in our own 293 cellFGF4 transfected conditioned media grew faster, and felt that other agents in the media might alter the stability of the cells, so this was not used in the initial isolation of the cells. The use of only three from each of the treatments, together with the lack of a perfect gender match, will mean a lack of sensitivity in our assays; however, it was felt that robust expression of Cdx2 was a needed criterion for further use of these TS clones.

The selected high-Cdx2 cells showed similar levels of expression of markers expected of TS cells and of the two main lineages seen in the main differentiation pathways. Furthermore, both LPD and NPD cells showed FGF4 dependence. Two days after the cytokine was removed, the growth 
characteristics and differentiation status both changed: growth was reduced, giant cells appeared, and Eomes and Cdx4 were lost. These findings are in line with (Motomura et al., 2016). We carried out an initial study of expression of differentiation markers on TS clones; however, these were highly variable, both between clones and over the time course in differentiation media. This may represent inherent variation in the stem cells, or the fact that TS cells have the ability to form many trophoblast lineages, and defined differentiation is not as well understood in TS cells as it is in ES cells. The lack of robust antibodies to define the individual placental cell types in the mouse is a major hindrance to follow TS differentiation.

ES cells have a doubling time of $\sim 18 \mathrm{hrs}$ and show no or only limited check points. The doubling times of the TS clones was considerably longer. Furthermore, the slower doubling time of the NPD-derived cells when compared to LPD appeared to be a robust finding, and is line with the studies of Eckert et al., 2012, who found increases in trophoblast numbers in the blastocyst. It would be of interest to know at what point or points in the cell cycle this increased rate is occurring, as it might give a suggestion as to what controls on cell division have been changed to produce such an increase. As discussed earlier, cell sex has been implicated in more rapid early embryonic and placental development, with both being more rapid in the male; however, the one female cell line LD2 actually showed the most rapid growth. The fact that there was no statistical difference in the MTT assay between the two groups was surprising; however, formazan assays have known problems and may be compromised by high serum albumin levels (here total levels of FCS are used) (Instruments and Winooski, 2007). Furthermore, high cell numbers may have effects either on cell differentiation or directly on the reductive capacity of the cell line, as changes in glucose supply or pH of the medium can alter MTT conversion (Vistica et al., 1991, Goodwin et al., 1995).

We failed to show an increase in invasive behaviour with the matrigel assay as set up here. Very few cells migrated when in an undifferentiated state, hence this assay will depend on both cell numbers and differentiation state. As cell proliferation was increased in differentiation media in the LPD cells, it is possible that there is an underlying but masked alteration in migratory behaviour in the TS cells. Furthermore, while removal of FGF leads to changes in phenotype, these cells have the ability to enter many cell types, and it would have been useful to have analysed the migrating cells so as to define their trophoblast cell types. 
Chapter 6

LPD has been shown to induce an increase in compensatory endocytosis in the yolk sac endoderm (Watkins et al.,2008) and embryoid body endoderm (Sun et al., 2014), and we saw a similar response in our TSC model. However, quantifying the endocytic activity is difficult. TSCs tend to show a degree of spontaneous differentiation with multinuclear and/or polyploid cells appearing in culture, and as a result, calculating true cell numbers is problematic based upon nuclear staining. Furthermore, it appeared that the differentiating/differentiated cells showed the greatest endocytosis when estimated by pHrodo. For this reason, we compared the total nuclear volume with fluorescent endosome volume; using this criterion in attempt to normalise cell quantity, we could see a statistically significant increase in endocytosis. However, we cannot be certain that the cell differentiation status was due to LPD/NPD treatment, or whether other factors were the underlying cause. 


\section{Chapter 7. Discussion}

The overall hypothesis underlying this work is that cell models derived from the early embryo could be used to extend our understanding of the DOHaD theory. While there is a much evidence to support this hypothesis - that changes in the environment during development can induce permanent metabolic changes and increase long term disease risk - the initial and most compelling data (as far as disease risk) comes from epidemiological studies, with the poor maternal nutrition during the Dutch and Chinese famines resulting in increased incidence of adult onset cardiovascular disease and type 2 diabetes being the classical study (Roseboom et al., 2006, Li et al., 2010). Recently, such studies have been extended to looking for molecular causes by comparing changes in children conceived at times of drought and rains. This demonstrated that seasonal changes in maternal nutritional status during early pregnancy result in alterations in the DNA methylation pattern in offspring, with persistent systemic changes at metastable alleles (Dominguez-Salas et al., 2014). Over the last decades, the main cause for concern has involved children produced from assisted reproductive techniques; these may be associated with preterm parturition, low birth weight and evidence of increased imprinting disorders (Basatemur and Sutcliffe, 2008, Odom and Segars, 2010). There is also evidence in these children of altered cardiac and metabolic homeostasis, along with raised diastolic and systolic blood pressures (Ceelen et al., 2008a, Sakka et al., 2010), elevated levels of fasting glucose (Ceelen et al., 2008a), and an increase in total body fat composition (Ceelen et al., 2007).

Many of these changes appear related to altered growth rates and / or trajectories. Not only is low birth weight known to correlate to increased CVD risk, but increased placental size is also associated with hypertension in male offspring (van Abeelen et al., 2011). Placental growth responds to the maternal nutritional environment: for instance, exposure to famine during different gestation periods affects placental size and shape (Thornburg et al., 2010), and when exposed to famine in early gestation, the placenta becomes more efficient (Roseboom et al., 2011a) - a finding also seen in mouse models (Coan et al., 2010). All the above strongly suggest that changes in the placenta may underlie the potentially disease-inducing metabolic alterations in the offspring, so studying the cells forming this organ is logical. In animal models, LPD-fed dams increase their placental ATP levels (Chiaratti et al., 2015), and other extra-embryonic tissues such as the visceral yolk sac endoderm (VYSE) also show increased fluid-phase endocytosis in LPD (Watkins et al., 2008a). 
Studying the underlying causes of these environmentally-induced adaptations is complex; epidemiological analysis, even with the most stringent of controls and largest datasets, is at best correlative and prone to error. Rodent models allow for better-controlled and defined interventions; however, they are also highly complex physiologically. The fact that environmental challenge in the very early embryo results in postnatal changes (Kwong et al., 2000) strongly implicates epigenetic alteration in the stem cells present at this stage. Furthermore, ES cells and their differentiation products isolated from mice fed a low protein diet show changes which mimic those seen in vivo (Cox PhD thesis; Sun et al., 2014). ES cells are known to show only limited epigenetic changes, in part as they must retain their pluripotent state. This is not the case with the other stem cells isolatable from the early embryo. As a result, it might be expected that changes in the EpiSC and the TSC pools would closer mirror those occurring in vivo and provide better models. It is to be hoped that our TS model might provide a new way to study the mechanisms underlying embryonic programming, giving a more defined in vitro model.

Unlike ESCs and EpiSCs, TS cells have a limited array of progeny, so their differentiation trajectory should be easier to follow. However, these cells appear more complex to retain in an undifferentiated state in culture. This may be due in part to longer and more widespread laboratory use of both mouse and human ES cells, where thirty years of experience in their culture has resulted in defined non-FCS based culture systems and ES cell optimised media giving highly reproducible results. Indeed, such media formulation was required not only for the reproducible culture of human ES cell lines, but allowed the derivation of ES cells from many mouse strains which had previously been considered impossible to obtain (Sato et al., 2009). Defined media components are not yet fully understood for TS cells, which are grown by relatively few laboratories (Ohinata and Tsukiyama, 2014). We had tried growing the TS cells in ES cell defined media and serum replacement in the presence of FGF4; however, this media lacks fibrin and fibronectin and both TS cells and feeder fibroblasts adhere very poorly to the plastic culture dishes when grown in it, and ultimately, attempts to grow TS cells in such media fail (our findings and Hemberger personal communication). The high concentration of FCS and the lack of commercially TS-tested FCS also complicate novel TS clone isolation. Our TS cells have a high percentage of polyploidy karyotypes - TS cells seem to spontaneously become polyploidy even under stem cell culture conditions. This is one of the early steps in giant cell formation, and is related to their characteristics in vivo, as they differentiate toward mature trophectoderm lineages. TS cells are relatively slow growing in culture compared to other stem cell forms, and this may be a cause of this disproportionately high differentiation when compared to ES cells, where rapid formation of new cells and hence high passage rate may simply prevent the 
differentiated cells predominating. It should be noted that the differentiated cells also often produce cytokines which then push stem cells to lose their undifferentiated characteristics (Lanner and Rossant, 2010). The presence of polyploid and multinucleate TS progeny is well described (Tanaka et al., 1998), and a high percentage of female TS cells have more than two X chromosomes (Dubois et al., 2013). While the Dubois study did not link that to a loss of stability of the female clones, it might explain why we obtained fewer female clones expressing high levels of Cdx2.

In most blastocyst cultures we could obtain obvious and classical TS cell colonies which remained present for 2-3 passages at most before being lost, which suggests that the clones that did survive must adapt to the culture conditions, and prior to this are extremely sensitive. It is possible that the trypsinisation and colony division was imperfect and stressed the cells, inducing their differentiation. It is of interest to note that many of the studies on TS cells published use the original clones from the Rossant laboratory, and that despite the seeming long list of TS cells given in Table 4-1, few of the clones listed have been extensively characterised.

One issue complicating our culture of TS cells was the long term survival of mitomycin-treated feeder fibroblasts in media containing FGF4; this protection from mitotic inactivation has been described by others (Gallicchio et al., 1991). There is no fully effective method to prevent the feeder cells from continuing to grow when FGF4 is present, as they appear necessary during the initial TS cell isolation, and when the fibroblasts are in large numbers they may place any slower growing TS clones under a stress. Also, while we found the conditioned media from the HEK-293 cells producing the FGF4 protein capable of maintaining TS cells, it resulted in faster growing colonies than with the purified recombinant FGF, suggesting other non-identified growth factors were also present. While the cells grown in the conditioned media did not appear to have more differentiated cells, it was felt to be a risk, so the commercial FGF was used in the later assays.

An underlying issue with the studies carried out was the small numbers of TS clones finally obtained. Initially, we hoped to use the hybrid embryos produced from crossing the two inbred mouse strains C57BL/6 and CBA to establish our TS cell model. This would have the advantage of a defined genetic background and hybrid vigour; however, in all cases these cells stopped growing 
after one or two passages in culture. The reason for this is not certain, as others have produced TS cells from hybrid mice (see Table 4-1), and hybrid ES cells are known to be more robust than ES cells from inbred backgrounds. We turned to the MF1 strain, and had success establishing TS cell lines from this strain. These embryos develop somewhat slower than C57BL6 - at least to the blastocyst stage, which occurs on average 8 hrs later in MF1, a variation which may continue into later development (Thiel et al., 1993, Miyake et al., 1997). It is possible that this is significant in the derivation of TS cells in our hands, although others have isolated such cells even from postimplantation embryos, suggesting that TS cells or their precursors remain present for extended periods in vivo.

Compared with other cell types (e.g. MEFs, ES, HEK-293 cells), once attached to a substrate, TS cells are very adherent and difficult to separate using trypsin. We found that high trypsin concentration ( $\sim 2.5$ times that in use to detached standard adherent cells) and a longer incubation period was needed to remove the colonies from either the plastic substrate or the feeder layer. It is possible that this exposure in the early stages of clone derivation was detrimental to the cells; on the other hand, separation and colony division is needed to prevent differentiation. Similar difficulties are seen in the isolation and maintenance of human ES cells, where often purely physical means are used to maintain these cells.

We did manage to produce TS cells from embryos of mothers receiving both high and low protein diets, though both at very low frequencies. These clones appeared phenotypically to be TS cells, as they expressed Cdx2 (a known marker); however, the cells showed variation in both cell proliferation and $\mathrm{Cdx} 2$ expression levels. TS cells have been described as highly pleotropic (Latos and Hemberger, 2016), and there have been reports that there are actually four different TS cell forms in culture, although they may be limited in their ability to form all the placental trophectoderm lineages (Motomura et al., 2016). For further study, we chose the highest Cdx2 expressing cell lines from each group. The exact identity of the low $\mathrm{Cdx2}$-expressing clones is unknown; it might be that they had undergone differentiation, as $\mathrm{Cdx} 2$ appears to be lost very rapidly in FGF4-lacking media, and it may be that other inducers of differentiation can cause a similar effects. Certainly, these clones initially appeared to have a TS cell -like morphology.

We tested the cell metabolism through MTT conversion assays and the proliferation of the TS cells. The LPD group has a significantly higher proliferation rate, which was in agreement with an 
earlier study on blastocyst cell number and trophectodermal outgrowths (Eckert et al., 2012). This would fit with the hypothesis of a possible compensatory mechanism, where in a poor nutritional environment, extra-embryonic lineages tend to show increased proliferation and endocytosis activity in order to provide more nutrition to the developing embryo. By using fluorescentlabelled dextran tracking, we found that early pregnancy LPD increased endocytosis in the derived TS cells. This corresponds with an earlier study on embryo bodies formed from ES cells, which had increased endocytosis in the LPD group (Sun et al., 2014). An underlying confounding issue in our studies is the spontaneous differentiation of TS cells and the absence of robust lineage-defining antibodies suitable for the mouse.

3D culture of so-called "trophospheres" is a new technique used to form differentiated trophectodermal cells from TS cell aggregates (Rai and Cross, 2015), and is described as being more reproducible than simple monolayer differentiation. This technique results in cavitated structures lined by parietal TGCs which surround maternal blood sinuses in the placenta; such forced and defined differentiation may make interpretation of endocytosis assays more robust, and could be applied to our TS cells.
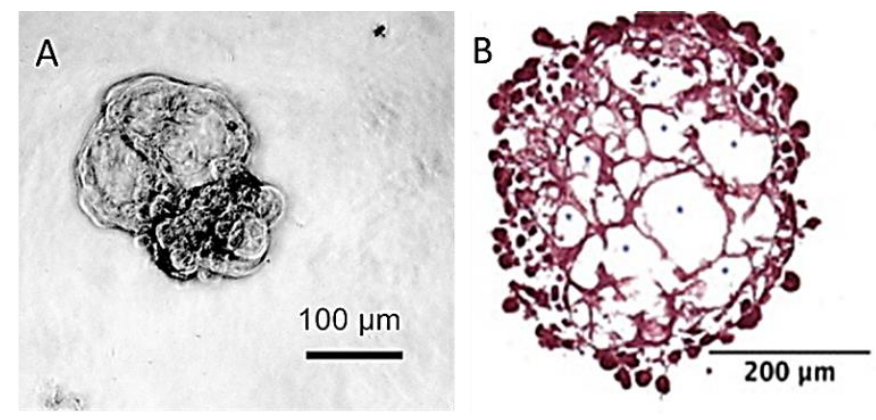

Figure 7-1: Formation of trophospheres by TSC aggregates (A) using clone LE5 and (B) section taken from Rai and Cross, 2015

This method was attempted for our TS clones, using hanging drops to culture TSCs. After trypsinisation, drops $(30-50 \mu l)$ of 500 TSCs were placed in a non-adhesive culture dish, then hung upside down to culture. After 6-8 days, these TSCs formed spheres with hollow cavities, similar to those described in this report. This method could potentially be explored further in future. 
A major problem in this study has been the difficulty in isolating suitable numbers of representative TSC lines. Discussions with other researchers have highlighted the difficulties in producing these lines, and have suggested that there may be specific changes induced by cell culture where clonal growth and TSC isolation becomes possible. Recent studies using defined media may make producing a greater number of TSC lines simpler (Ohinata and Tsukiyama, 2014); their use of XAV939 (Wnt-inhibitor) and Y-27632 (ROCK-inhibitor) did result in greater frequencies of TS cells. However, these authors also noted difficulties with certain genetic backgrounds - in particular C57BL6 hybrid animals.

A recent study showed that there are epigenetic changes, such as reduced histone $\mathrm{H} 3$ and $\mathrm{H} 4$ acetylation, in LPD ESC-derived mouse embryoid bodies (Sun et al., 2015). TSCs may experience similar changes, and it will be crucial to analyse the overall histone modifications and pinpoint any epigenetic changes in CpG sequences in the major genes driving cell proliferation in TSCs, allowing us to make proper use of our model to understand the changes occurring in man.

In summary, we have produced a foundation for the derivation of TS cell lines from mouse embryos, and have delineated some of the major factors which must be considered in their culture. The variability we showed present in the lines is in agreement with an increasing understanding that these cells, once they begin to differentiate, are highly pleomorphic. We found that despite this, it was possible to obtain some stable clones which have proved useful for initial characterisation of their behaviour. With an increased number of clones of different sex and from different parental origin, it should be possible to pinpoint both developmental and epigenetic systems changing in the extraembryonic tissues, which may be important in causing the DoHAD effects observed in later life. 


\section{Appendix A}

MTT lysis solution

\begin{tabular}{|l|l|l|}
\hline Reagent & For 10ml & For 5ml \\
\hline DMSO & $9940 \mathrm{ul}$ & $4970 \mathrm{ul}$ \\
\hline HCL $(0.5 \mathrm{~N})$ & $60 \mathrm{ul}$ & $30 \mathrm{ul}$ \\
\hline SDS & $1 \mathrm{~g}$ & $0.5 \mathrm{~g}$ \\
\hline Total & $10 \mathrm{ml}$ & $5 \mathrm{ml}$ \\
\hline
\end{tabular}

SDS-PAGE gel

\begin{tabular}{|l|l|}
\hline $12 \%$ resolving gel & $5 \%$ stacking gel \\
\hline $3.3 \mathrm{ml} \mathrm{H} O$ & $3.4 \mathrm{ml} \mathrm{H}_{2} \mathrm{O}$ \\
\hline $4 \mathrm{ml}$ of $30 \%$ Acrylamide* (Sigma A3574) & $0.83 \mathrm{ml}$ of $30 \%$ Acrylamide \\
\hline $\begin{array}{l}2.5 \mathrm{ml} \text { of } 1.5 \mathrm{M} \text { Tris pH8.8 (BioReagents } \\
\text { BP1521) }\end{array}$ & \\
\hline $100 \mu \mathrm{l}$ of $10 \%$ SDS (Fisher BioReagents & $0.63 \mathrm{ml}$ of $1 \mathrm{M}$ Tris $\mathrm{pH} 6.8$ \\
\hline BP166-500) & $50 \mu \mathrm{l}$ of $10 \%$ SDS \\
\hline $100 \mu \mathrm{l}$ of $10 \%$ APS (Sigma A3678) & $50 \mu \mathrm{l}$ of $10 \%$ APS \\
\hline $4 \mu l$ of TEMED (Sigma T9281) & $5 \mu \mathrm{l}$ of TEMED \\
\hline Final Volume of $10 \mathrm{mls}$ & Final Volume of $5 \mathrm{mls}$ \\
\hline
\end{tabular}

* $29 \% \mathrm{w} / \mathrm{v}$ acrylamide and $1 \% \mathrm{w} / \mathrm{v} 1.0 \% \mathrm{~N}, \mathrm{~N}^{\prime}$-methylene-bisacrylamide in $\mathrm{H}_{2} \mathrm{O}$

$1 x$ Loading buffer (final concentration)

50mM Tris $\mathrm{pH} 6.8$

$2 \% \mathrm{w} / \mathrm{v}$ SDS

$0.1 \%$ bromophenol blue

$10 \% \mathrm{v} / \mathrm{v}$ glycerol

0.18M $\beta$-mercaptoethanol (Sigma M7522) 
Appendix

This was produced as a $4 x$ concentrate in a fume cupboard

SDS-PAGE running buffer

\begin{tabular}{|l|l|}
\hline 1 litre of $10 \mathrm{x}$ running buffer & Final concentration \\
\hline $30.3 \mathrm{~g}$ of Tris base, & $25 \mathrm{mM}$ Tris \\
\hline $144 \mathrm{~g}$ of glycine, & $250 \mathrm{mM}$ glycine \\
\hline $10 \mathrm{~g}$ of SDS, & $0.1 \% \mathrm{w} / \mathrm{v}$ SDS \\
\hline
\end{tabular}

Western blotting transfer buffer

\begin{tabular}{|l|}
\hline Transfer Buffer \\
\hline $48 \mathrm{mM}$ Tris \\
\hline $39 \mathrm{mM}$ glycine \\
\hline $0.0375 \%$ SDS \\
\hline methanol up to $10 \%$ \\
\hline
\end{tabular}

TS medium stock

\begin{tabular}{|l|l|}
\hline Name & Final concentration \\
\hline RPMI1640 (Gibico 61870-010) & \\
\hline Sodium pyruvate (Gibco 11360-039) & $1 \mathrm{mM}$ \\
\hline Pen Strep Glutamine (Gibco 10378-016) & $100 \mathrm{unit} / \mathrm{ml}$ Penicillin \\
\hline 2-Mercaptoethanol (Sigma M7522) & $100 \mu \mathrm{g} / \mathrm{ml}$ Streptomycin \\
\hline FBS (Sigma F9665) & $292 \mu \mathrm{g} / \mathrm{ml}$ L-Glutamine \\
\hline
\end{tabular}


1x TS medium

\begin{tabular}{|l|l|}
\hline TS medium stock & $80 \%$ \\
\hline FGF4 & $25 \mathrm{ng} / \mathrm{ml}$ \\
\hline Heparin (Sigma H3149) & $1 \mu \mathrm{g} / \mathrm{ml}$ \\
\hline
\end{tabular}

1.5x TS medium

\begin{tabular}{|l|l|}
\hline TS medium stock & $80 \%$ \\
\hline FGF4 & $37.5 \mathrm{ng} / \mathrm{ml}$ \\
\hline Heparin (Sigma H3149) & $1.5 \mu \mathrm{g} / \mathrm{ml}$ \\
\hline
\end{tabular}

1.8x TS medium

\begin{tabular}{|l|l|}
\hline TS medium stock & $80 \%$ \\
\hline FGF4 & $45 \mathrm{ng} / \mathrm{ml}$ \\
\hline Heparin (Sigma H3149) & $1.8 \mu \mathrm{g} / \mathrm{ml}$ \\
\hline
\end{tabular}

70\%FCM (Fibroblast condition medium)

\begin{tabular}{|l|l|}
\hline TS medium stock & $30 \%$ \\
\hline Fibroblast condition medium & $70 \%$ \\
\hline
\end{tabular}

$1.5 \times 70 \% \mathrm{FCM}$

\begin{tabular}{|l|l|}
\hline TS medium stock & $30 \%$ \\
\hline Fibroblast condition medium & $70 \%$ \\
\hline
\end{tabular}


Appendix

\begin{tabular}{|l|l|}
\hline FGF4 & $37.5 \mathrm{ng} / \mathrm{ml}$ \\
\hline Heparin (Sigma H3149) & $1.5 \mu \mathrm{g} / \mathrm{ml}$ \\
\hline
\end{tabular}

1.8x 70\%FCM

\begin{tabular}{|l|l|}
\hline TS medium stock & $30 \%$ \\
\hline Fibroblast condition medium & $70 \%$ \\
\hline FGF4 & $45 \mathrm{ng} / \mathrm{ml}$ \\
\hline Heparin (Sigma H3149) & $1.8 \mu \mathrm{g} / \mathrm{ml}$ \\
\hline
\end{tabular}

2X TS frozen medium

\begin{tabular}{|l|l|}
\hline FBS (Sigma F9665) & $50 \%$ \\
\hline DMSO (Sigma-Aldrich D5879) & $20 \%$ \\
\hline TS medium stock & $30 \%$ \\
\hline
\end{tabular}




\section{TS cells Karyotyping}

- $\mathrm{KCL}$ (potassium chloride) solution: 0.599gKCL in $100 \mathrm{ml}$ water $(0.75 \mathrm{M})$

- Carnoy's fluid(fixative): $2 \mathrm{ml}$ glacial acid and $5 \mathrm{ml}$ methonal, make 50 or $100 \mathrm{ml}$, store at $-20^{\circ} \mathrm{C}$ until use

Change medium at least one hour before collect cells

\begin{tabular}{|l|l|l|}
\hline $\begin{array}{l}\text { Glacial } \\
\text { acetis acid }\end{array}$ & methonal & $\begin{array}{l}\text { Total } \\
\text { volume }\end{array}$ \\
\hline $14 \mathrm{ml}$ & $35 \mathrm{ml}$ & $49 \mathrm{ml}$ \\
\hline
\end{tabular}

1. Collect TS cells into centrifuge tube

2. Centrifuge $5 \min (1000 \mathrm{r} / \mathrm{m})$ aspirate supernatant

3. Add $37 \mathrm{C} \mathrm{KCL}(0.559 \mathrm{gKCL}$ in $100 \mathrm{ml}$ water) drop by drop. Flick pellet with each drop for the first 10-15drops. Do not pipette up and down or all the cells will stick to the inside of your pipette. Bring the volume to $5 \mathrm{ml}$. invert several times and incubate in room temperature for 6 min

4. Spin down the cells at $500 \mathrm{rpm}$ for 5 minutes. Remove sup. Add $1 \mathrm{ml}$ fix. Flick tube to resuspend pellet, add 4 more mls fix. Incubate 5 mins RT

5. $\quad$ Repeat step 4 three more times

6. In the end suspend cell in 1-2ml Canoy's fluid and store it in the $-20 \mathrm{C}$ fridge.

Drop the slide

- $\quad$ Chilled slides in $70 \%$ ethanol

- Dip the slides in chilled $70 \%$ ethanol

- Leave slides in the chilled ehanol until you are ready to use them.

- Use glass pipette aspire some of the cells and drop them on the clean wet and chilled slides either at arms $(15 \mathrm{~cm}$ or so) length away or at varying height from the floor.

- Dry slides at room temperature

- Stain slides with diluted Giemsa (diluted ration 1:20 in water) for 20min and wash them 


\section{List of References}

AAGAARD-TILLERY, K. M., GROVE, K., BISHOP, J., KE, X., FU, Q., MCKNIGHT, R. \& LANE, R. H. 2008. Developmental origins of disease and determinants of chromatin structure: maternal diet modifies the primate fetal epigenome. Journal of Molecular Endocrinology, 41, 91-102.

ABELL, A. N., GRANGER, D. A., JOHNSON, N. L., VINCENT-JORDAN, N., DIBBLE, C. F. \& JOHNSON, G. L. 2009. Trophoblast stem cell maintenance by fibroblast growth factor 4 requires MEKK4 activation of Jun N-terminal kinase. Mol Cell Biol, 29, 2748-61.

ABELL, A. N., JORDAN, N. V., HUANG, W., PRAT, A., MIDLAND, A. A., JOHNSON, N. L., GRANGER, D. A., MIECZKOWSKI, P. A., PEROU, C. M., GOMEZ, S. M., LI, L. \& JOHNSON, G. L. 2011. MAP3K4/CBP-regulated H2B acetylation controls epithelial-mesenchymal transition in trophoblast stem cells. Cell Stem Cell, 8, 525-37.

ACETI, A., SANTHAKUMARAN, S., LOGAN, K., PHILIPPS, L., PRIOR, E., GALE, C., HYDE, M. \& MODI, N. 2012. The diabetic pregnancy and offspring blood pressure in childhood: a systematic review and meta-analysis. Diabetologia, 55, 3114-3127.

AIKAWA, H., TAMAI, M., MITAMURA, K., ITMAINATI, F., BARBER, G. N. \& TAGAWA, Y. 2014. Innate immunity in an in vitro murine blastocyst model using embryonic and trophoblast stem cells. J Biosci Bioeng, 117, 358-65.

AKOUR, A. A., KENNEDY, M. J. \& GERK, P. 2013. Receptor-mediated endocytosis across human placenta: emphasis on megalin. Mol Pharm, 10, 1269-78.

APOSTOLIDOU, S., ABU-AMERO, S., O'DONOGHUE, K., FROST, J., OLAFSDOTTIR, O., CHAVELE, K. M., WHITTAKER, J. C., LOUGHNA, P., STANIER, P. \& MOORE, G. E. 2007. Elevated placental expression of the imprinted PHLDA2 gene is associated with low birth weight. $J$ Mol Med (Berl), 85, 379-87.

ARMAN, E., HAFFNER-KRAUSZ, R., CHEN, Y., HEATH, J. K. \& LONAI, P. 1998 Targeted disruption of fibroblast growth factor (FGF) receptor 2 suggests a role for FGF signaling in pregastrulation mammalian development. Proc. Natl. Acad. Sci. USA, 95, 5082-5087.

ASANOMA, K., RUMI, M. A., KENT, L. N., CHAKRABORTY, D., RENAUD, S. J., WAKE, N., LEE, D. S., KUBOTA, K. \& SOARES, M. J. 2011. FGF4-dependent stem cells derived from rat blastocysts differentiate along the trophoblast lineage. Dev Biol, 351, 110-9.

AVILION, A. A., NICOLIS, S. K., PEVNY, L. H., PEREZ, L., VIVIAN, N. \& LOVELL-BADGE, R. 2003. Multipotent cell lineages in early mouse development depend on SOX2 function. Genes \& development, 17, 126-140.

BANY, B. M. \& CROSS, J. C. 2006. Post-implantation mouse conceptuses produce paracrine signals that regulate the uterine endometrium undergoing decidualization. Developmental biology, 294, 445-456.

BARCROFT, L. C., OFFENBERG, H., THOMSEN, P. \& WATSON, A. J. 2003. Aquaporin proteins in murine trophectoderm mediate transepithelial water movements during cavitation. Developmental Biology, 256, 342-354.

BARD, J. 1994. EMBRYOS Color Atlas of Development, England.

BARKER, D. 2004. The developmental origins of adult disease. Journal of the American College of Nutrition, 23, 588S-595S. 
BARKER, D. J. P. 1995. The fetal and infant origins of disease. European Journal of Clinical Investigation 25, 457-463.

BARKER, D. J. P. \& OSMOND, C. 1986. Infant mortality, childhood nutrition, and ischaemic heart disease In england and wales. Lancet, 327, 1077-1081.

BARKER, D. J. P., OSMOND, C., WINTER, P. D., MARGETTS, B. \& SIMMONDS, S. J. 1989. Weight In Infancy And Death From Ischaemic Heart Disease. Lancet, 2, 577-580.

BÁRTOVÁ, E., KREJČí, J., HARNIČAROVÁ, A., GALIOVÁ, G. \& KOZUBEK, S. 2008. Histone modifications and nuclear architecture: a review. Journal of Histochemistry \& Cytochemistry, 56, 711-721.

BASATEMUR, E. \& SUTCLIFFE, A. 2008. Follow-up of children born after ART. Placenta, 29, 135-140.

BAZER, F. W., SPENCER, T. E., JOHNSON, G. A., BURGHARDT, R. C. \& WU, G. 2009. Comparative aspects of implantation. Reproduction, 138, 195-209.

BECK, F., ERLER, T., RUSSELL, A. \& JAMES, R. 1995a. Expression of Cdx-2 in the Mouse Embryo and Placenta: Possible Role in Patterning of the Extra-Embryonic Membranes Developmental Dynamics 204, 219-227.

BECK, F., ERLER, T., RUSSELL, A. \& JAMES, R. 1995b. Expression of Cdx-2 in the mouse embryo and placenta: possible role in patterning of the extra-embryonic membranes. Developmental Dynamics, 204, 219-227.

BEDDINGTON, R. \& ROBERTSON, E. 1989. An assessment of the developmental potential of embryonic stem cells in the midgestation mouse embryo. Development, 105, 733-737.

BEENKEN, A. \& MOHAMMADI, M. 2009. The FGF family: biology, pathophysiology and therapy. Nat Rev Drug Discov, 8, 235-53.

BEHRINGER, R., GERTSENSTEIN, M., NAGY, K. \& NAGY, A. 2014. Manipulating the Mouse Embryo: A Laboratory Manual, Third edition, Cold spring harbor laboratory Cold Spring Harbor, NY.

BELLOSTA, P., TALARICO, D., ROGERS, D. \& BASILICO, C. 1993. Cleavage of K-FGF produces a truncated molecule with increased biological activity and receptor binding affinity. The Journal of Cell Biology, 121, 705-713.

BELVA, F., ROELANTS, M., PAINTER, R., BONDUELLE, M., DEVROEY, P. \& DE SCHEPPER, J. 2012. Pubertal development in ICSI children. Human reproduction, des001.

BEN-YOSEF, D., AMIT, A., MALCOV, M., FRUMKIN, T., BEN-YEHUDAH, A., ELDAR, I., MEY-RAZ, N., AZEM, F., ALTARESCU, G. \& RENBAUM, P. 2011. Female sex bias in human embryonic stem cell lines. Stem cells and development, 21, 363-372.

BERGER, S. L., KOUZARIDES, T., SHIEKHATTAR, R. \& SHILATIFARD, A. 2009. An operational definition of epigenetics. Genes Dev, 23, 781-3.

BERMEJO-ALVAREZ, P., RIZOS, D., RATH, D., LONERGAN, P. \& GUTIERREZ-ADAN, A. 2008. Epigenetic differences between male and female bovine blastocysts produced in vitro. Physiological Genomics, 32, 264-272.

BERTRAM, C., TROWERN, A., COPIN, N., JACKSON, A. \& WHORWOOD, C. 2001. The Maternal Diet during Pregnancy Programs Altered Expression of the Glucocorticoid Receptor and Type 2 
$11 \beta$-Hydroxysteroid Dehydrogenase: Potential Molecular Mechanisms Underlying the Programming of Hypertension in Utero 1. Endocrinology, 142, 2841-2853.

BLOISE, E., LIN, W., LIU, X., SIMBULAN, R., KOLAHI, K. S., PETRAGLIA, F., MALTEPE, E., DONJACOUR, A. \& RINAUDO, P. 2012. Impaired placental nutrient transport in mice generated by in vitro fertilization. Endocrinology, 153, 3457-3467.

BOGDARINA, I., WELHAM, S., KING, P. J., BURNS, S. P. \& CLARK, A. J. 2007. Epigenetic modification of the renin-angiotensin system in the fetal programming of hypertension. Circulation research, 100, 520-526.

BRONS, I. G., SMITHERS, L. E., TROTTER, M. W., RUGG-GUNN, P., SUN, B., CHUVA DE SOUSA LOPES, S. M., HOWLETT, S. K., CLARKSON, A., AHRLUND-RICHTER, L., PEDERSEN, R. A. \& VALLIER, L. 2007. Derivation of pluripotent epiblast stem cells from mammalian embryos. Nature, 448, 191-5.

CARNEY, E. W., PRIDEAUX, V., LYE, L. S. J. \& ROSSANT, J. 1993. Progressive expression of trophoblast-specific genes during formation of mouse trophoblast giant cells in vitro. Molecular Reproduction And Development, 34, 357-368.

CARSON, D. D., BAGCHI, I., DEY, S. K., ALLEN C. ENDERS, FAZLEABAS, A. T., LESSEY, B. A. \& YOSHINAGA, K. 2000. Embryo Implantation. Developmental Biology, 223, 217-237.

CEELEN, M., VAN WEISSENBRUCH, M. M., PREIN, J., SMIT, J. J., VERMEIDEN, J. P., SPREEUWENBERG, M., VAN LEEUWEN, F. E. \& DELEMARRE-VAN DE WAAL, H. A. 2009. Growth during infancy and early childhood in relation to blood pressure and body fat measures at age 8-18 years of IVF children and spontaneously conceived controls born to subfertile parents. Human reproduction, 24, 2788-2795.

CEELEN, M., VAN WEISSENBRUCH, M. M., ROOS, J. C., VERMEIDEN, J. P., VAN LEEUWEN, F. E. \& DELEMARRE-VAN DE WAAL, H. A. 2007. Body composition in children and adolescents born after in vitro fertilization or spontaneous conception. The Journal of Clinical Endocrinology \& Metabolism, 92, 3417-3423.

CEELEN, M., VAN WEISSENBRUCH, M. M., VERMEIDEN, J. P., VAN LEEUWEN, F. E. \& DELEMARREVAN DE WAAL, H. A. 2008a. Cardiometabolic differences in children born after in vitro fertilization: follow-up study. J Clin Endocrinol Metab, 93, 1682-8.

CEELEN, M., VAN WEISSENBRUCH, M. M., VERMEIDEN, J. P., VAN LEEUWEN, F. E. \& DELEMARREVAN DE WAAL, H. A. 2008b. Growth and development of children born after in vitro fertilization. Fertility and sterility, 90, 1662-1673.

CHANDRASEKAR, R. 2013. Alcohol and NMDA receptor: current research and future direction. Frontiers in molecular neuroscience, 6.

CHASON, R. J., CSOKMAY, J., SEGARS, J. H., DECHERNEY, A. H. \& ARMANT, D. R. 2011. Environmental and epigenetic effects upon preimplantation embryo metabolism and development. Trends Endocrinol Metab, 22, 412-20.

CHAWENGSAKSOPHAK, K., DE GRAAFF, W., ROSSANT, J., DESCHAMPS, J. \& BECK, F. 2004. Cdx2 is essential for axial elongation in mouse development. Proc Natl Acad Sci U S A, 101, 76415.

CHAWENGSAKSOPHAK, K., JAMES, R., HAMMOND, V. E., KÖNTGEN, F. \& F.BECK 1997. Homeosis and intestinal tumours in Cdx2 mutant mice. Nature, 386, 84-87. 
CHEN, H., AKSOY, I., GONNOT, F., OSTEIL, P., AUBRY, M., HAMELA, C., ROGNARD, C., HOCHARD, A., VOISIN, S., FONTAINE, E., MURE, M., AFANASSIEFF, M., CLEROUX, E., GUIBERT, S., CHEN, J., VALLOT, C., ACLOQUE, H., GENTHON, C., DONNADIEU, C., DE VOS, J., SANLAVILLE, D., GUERIN, J. F., WEBER, M., STANTON, L. W., ROUGEULLE, C., PAIN, B., BOURILLOT, P. Y. \& SAVATIER, P. 2015. Reinforcement of STAT3 activity reprogrammes human embryonic stem cells to naive-like pluripotency. Nat Commun, 6, 7095.

CHEN, L., WANG, D., WU, Z., MA, L. \& DALEY, G. Q. 2010a. Molecular basis of the first cell fate determination in mouse embryogenesis. Cell research, 20, 982-993.

CHEN, S.-L., SHI, X.-Y., ZHENG, H.-Y., WU, F.-R. \& LUO, C. 2010b. Aberrant DNA methylation of imprinted $\mathrm{H} 19$ gene in human preimplantation embryos. Fertility and sterility, 94, 23562358. e1.

CHEN, T. S., LAI, R. C., LEE, M. M., CHOO, A. B. H., LEE, C. N. \& LIM, S. K. 2010c. Mesenchymal stem cell secretes microparticles enriched in pre-microRNAs. Nucleic acids research, 38, 215224.

CHENG, A. M., SAXTON, T. M., SAKAI, R., KULKARNI, S., MBAMALU, G., VOGEL, W., TORTORICE, C. G., CARDIFF, R. D., CROSS, J. C., MULLER, W. J. \& PAWSON, T. 1998. Mammalian Grb2 Regulates Multiple Steps in Embryonic Development and Malignant Transformation. Cell, $95,793-803$.

CHIARATTI, M. R., MALIK, S., DIOT, A., RAPA, E., MACLEOD, L., MORTEN, K., VATISH, M., BOYD, R. \& POULTON, J. 2015. Is Placental Mitochondrial Function a Regulator that Matches Fetal and Placental Growth to Maternal Nutrient Intake in the Mouse? PloS one, 10, e0130631.

CHINNATHAMBI, V., BALAKRISHNAN, M., RAMADOSS, J., YALLAMPALLI, C. \& SATHISHKUMAR, K. 2013. Testosterone Alters Maternal Vascular Adaptations Role of the Endothelial NO System. Hypertension, 61, 647-654.

CHIU, S. Y., ASAI, N., COSTANTINI, F. \& HSU, W. 2008. SUMO-specific protease 2 is essential for modulating $\mathrm{p} 53-\mathrm{Mdm} 2$ in development of trophoblast stem cell niches and lineages. PLoS Biol, 6, e310.

CHOI, H. J., SANDERS, T. A., TORMOS, K. V., AMERI, K., TSAI, J. D., PARK, A. M., GONZALEZ, J., RAJAH, A. M., LIU, X., QUINONEZ, D. M., RINAUDO, P. F. \& MALTEPE, E. 2013. ECMdependent HIF induction directs trophoblast stem cell fate via LIMK1-mediated cytoskeletal rearrangement. PLoS One, 8, e56949.

CHOMCZYNSKI, P. \& SACCHI, N. 1987. Single-step method of RNA isolation by acid guanidinium thiocyanate-phenol-chloroform extraction. Analytical biochemistry, 162, 156-159.

COAN, P., VAUGHAN, O., SEKITA, Y., FINN, S., BURTON, G., CONSTANCIA, M. \& FOWDEN, A. 2010. Adaptations in placental phenotype support fetal growth during undernutrition of pregnant mice. The Journal of physiology, 588, 527-538.

COCKBURN, K. \& ROSSANT, J. 2010. Making the blastocyst: lessons from the mouse. J Clin Invest, 120, 995-1003.

COLOSI, P., SWIERGIEL, J. J., WILDER, E. L., OVIEDO, A. \& LINZER, D. I. 1988. Characterization of proliferin-related protein. Molecular Endocrinology, 2, 579-586. 
CONQUET, F., PEYRIIRAS, N., TIRET, L. \& BROLETT, P. 1992. Inhibited gastrulation in mouse embryos overexpressing the leukemia inhibitory factor. Proc. Natl. Acad. Sci. USA 89, 8195-8199.

DE ROOIJ, S. R., ROSEBOOM, T. J. \& PAINTER, R. C. 2014. Famines in the Last 100 Years: Implications for Diabetes. Current diabetes reports, 14, 1-10.

DESOUZA, M. M., SURVEYOR, G. A., PRICE, R. E., JULIAN, J., KARDON, R., ZHOU, X., GENDLER, S., HILKENS, J. \& CARSON, D. D. 1999. MUC1/episialin: a critical barrier in the female reproductive tract. Journal of Reproductive Immunology, 45, 127-158.

DOMINGUEZ-SALAS, P., MOORE, S. E., BAKER, M. S., BERGEN, A. W., COX, S. E., DYER, R. A., FULFORD, A. J., GUAN, Y., LARITSKY, E. \& SILVER, M. J. 2014. Maternal nutrition at conception modulates DNA methylation of human metastable epialleles. Nature communications, 5 .

DRONKERT, M. L. G. \& KANAAR, R. 2001. Repair of DNA interstrand cross-links. Mutation Research 486 (2001) 217-247.

DUBOIS, A., DEUVE, J. L., NAVARRO, P., MERZOUK, S., PICHARD, S., COMMERE, P. H., LOUISE, A., ARNAUD, D., AVNER, P. \& MOREY, C. 2013. Spontaneous reactivation of clusters of Xlinked genes is associated with the plasticity of $\mathrm{X}$-inactivation in mouse trophoblast stem cells. Stem Cells, 32, 377-90.

DUBOIS, A., DEUVE, J. L., NAVARRO, P., MERZOUK, S., PICHARD, S., COMMERE, P. H., LOUISE, A., ARNAUD, D., AVNER, P. \& MOREY, C. 2014. Spontaneous Reactivation of Clusters of XLinked Genes Is Associated with the Plasticity of X-Inactivation in Mouse Trophoblast Stem Cells. Stem Cells, 32, 377-390.

DUMOULIN, J. C., LAND, J. A., VAN MONTFOORT, A. P., NELISSEN, E. C., COONEN, E., DERHAAG, J. G., SCHREURS, I. L., DUNSELMAN, G. A., KESTER, A. D., GERAEDTS, J. P. \& EVERS, J. L. 2010. Effect of in vitro culture of human embryos on birthweight of newborns. Hum Reprod, 25, 605-12.

DUNWOODIE, S. L. \& BEDDINGTON, R. S. P. 2002. The expression of the imprinted gene Ipl is restricted to extra-embryonic tissues and embryonic lateral mesoderm during early mouse development. Int. J. Dev. Biol, 46, 459-466.

EATON, J., LIEBERMAN, E., STEARNS, C., CHINCHILLA, M. \& RACOWSKY, C. 2012. Embryo culture media and neonatal birthweight following IVF. Human reproduction, 27, 375-379.

ECKERT, J. J., PORTER, R., WATKINS, A. J., BURT, E., BROOKS, S., LEESE, H. J., HUMPHERSON, P. G., CAMERON, I. T. \& FLEMING, T. P. 2012. Metabolic induction and early responses of mouse blastocyst developmental programming following maternal low protein diet affecting lifelong health. PLoS One, 7, e52791.

EGGAN, K., AKUTSU, H., LORING, J., JACKSON-GRUSBY, L., KLEMM, M., RIDEOUT, W. M., YANAGIMACHI, R. \& JAENISCH, R. 2001. Hybrid vigor, fetal overgrowth, and viability of mice derived by nuclear cloning and tetraploid embryo complementation. Proceedings of the National Academy of Sciences, 98, 6209-6214.

EHRT, S. \& SCHNAPPINGER, D. 2003. Isolation of Plasmids from E. coli by Alkaline Lysis. E. coli Plasmid Vectors Humana Press.

EKELUND, U., ONG, K., LINNÉ, Y., NEOVIUS, M., BRAGE, S., DUNGER, D. B., WAREHAM, N. J. \& RÖSSNER, S. 2006. Upward weight percentile crossing in infancy and early childhood 
independently predicts fat mass in young adults: the Stockholm Weight Development Study (SWEDES). The American journal of clinical nutrition, 83, 324-330.

EPPLE-FARMER, J., DEBEB, B. G., SMITHIES, O. \& BINAS, B. 2009. Gender-dependent survival of allogeneic trophoblast stem cells in liver. Cell Transplant, 18, 769-76.

ERIKSSON, J. G., FORSEN, T., TUOMILEHTO, J., OSMOND, C. \& BARKER, D. J. P. 2001. Early growth and coronary heart disease in later life: longitudinal study. BMJ, 322, 949-953.

ESKILD, A., MONKERUD, L. \& TANBO, T. 2013. Birthweight and placental weight; do changes in culture media used for IVF matter? Comparisons with spontaneous pregnancies in the corresponding time periods. Human Reproduction, 28, 3207-3214.

FAN, Z., ZHANG, Z. X., LI, Y., WANG, Z., XU, T., GONG, X., ZHOU, X., WEN, H. \& ZENG, Y. 2010. Relationship between birth size and coronary heart disease in China. Ann Med, 42, 596602.

FARIA, T. N., DEB, S., KWOK, S., TALAMANTES, F. \& SOARES, M. J. 1990. Ontogeny of placental lactogen-I and placental lactogen-II expression in the developing rat placenta. Developmental biology, 141, 279-291.

FELDMAN, B., POUEYMIROU, W., PAPAIOANNOU, V. E., DECHIARA, T. M. \& GOLDFAR, M. 1995 Requirement of FGF-4 for Postimplantation Mouse Development. Science, 267, 246-249.

FELDMAN, B., POUEYMIROU, W., PAPAIOANNOU, V. E., DECHIARA, T. M. \& GOLDFARB, M. 1995. Requirement of FGF-4 for postimplantation mouse development. SCIENCE, 267.

FERNÁNDEZ-GONZALEZ, R., MOREIRA, P., BILBAO, A., JIMÉNEZ, A., PÉREZ-CRESPO, M., RAMÍREZ, M. A., DE FONSECA, F. R., PINTADO, B. \& GUTIÉRREZ-ADÁN, A. 2004. Long-term effect of in vitro culture of mouse embryos with serum on mRNA expression of imprinting genes, development, and behavior. Proceedings of the National Academy of Sciences of the United States of America, 101, 5880-5885.

FERNANDEZ-TWINN, D. S., ALFARADHI, M. Z., MARTIN-GRONERT, M. S., DUQUE-GUIMARAES, D. E., PIEKARZ, A., FERLAND-MCCOLLOUGH, D., BUSHELL, M. \& OZANNE, S. E. 2014. Downregulation of IRS-1 in adipose tissue of offspring of obese mice is programmed cellautonomously through post-transcriptional mechanisms. Molecular metabolism, 3, 325333.

FERNANDEZ-TWINN, D. S., CONSTÂNCIA, M. \& OZANNE, S. E. Intergenerational epigenetic inheritance in models of developmental programming of adult disease. Seminars in cell \& developmental biology, 2015. Elsevier.

FERNANDEZ-TWINN, D. S., EKIZOGLOU, S., WAYMAN, A., PETRY, C. J. \& OZANNE, S. E. 2006.

Maternal low-protein diet programs cardiac $\beta$-adrenergic response and signaling in 3-moold male offspring. American Journal of Physiology-Regulatory, Integrative and Comparative Physiology, 291, R429-R436.

FRANK, D., FORTINO, W., CLARK, L., MUSALO, R., WANG, W., SAXENA, A., LI, C. M., REIK, W., LUDWIG, T. \& TYCKO, B. 2002. Placental overgrowth in mice lacking the imprinted gene Ipl. Proc Natl Acad Sci U S A, 99, 7490-5.

FREMIN, C., SABA-EL-LEIL, M. K., LEVESQUE, K., ANG, S. L. \& MELOCHE, S. 2015. Functional Redundancy of ERK1 and ERK2 MAP Kinases during Development. Cell Rep, 12, 913-21. 
GALLICCHIO, V. S., HUGHES, N. K., HULETTE, B. C., DELLA PUCA, R. \& NOBLITT, L. 1991. Basic fibroblast growth factor (B-FGF) induces early-(CFU-s) and late-stage hematopoietic progenitor cell colony formation (CFU-gm, CFU-meg, and BFU-e) by synergizing with GMCSF, Meg-CSF, and erythropoietin, and is a radioprotective agent in vitro. Stem Cells, 9, 220-232.

GAO, H., YALLAMPALLI, U. \& YALLAMPALLI, C. 2012a. Gestational protein restriction reduces expression of Hsd17b2 in rat placental labyrinth. Biol Reprod, 87, 68.

GAO, H., YALLAMPALLI, U. \& YALLAMPALLI, C. 2012b. Maternal protein restriction reduces expression of angiotensin I-converting enzyme 2 in rat placental labyrinth zone in late pregnancy. Biol Reprod, 86, 31.

GIRITHARAN, G., DELLE PIANE, L., DONJACOUR, A., ESTEBAN, F., HORCAJADAS, J., MALTEPE, E. \& RINAUDO, P. 2012. In vitro culture of mouse embryos reduces differential gene expression between inner cell mass and trophectoderm. Reproductive Sciences, 19, 243252.

GIRITHARAN, G., TALBI, S., DONJACOUR, A., DI SEBASTIANO, F., DOBSON, A. T. \& RINAUDO, P. F. 2007. Effect of in vitro fertilization on gene expression and development of mouse preimplantation embryos. Reproduction, 134, 63-72.

GLEIXNER, E. M., CANAUD, G., HERMLE, T., GUIDA, M. C., KRETZ, O., HELMSTÄDTER, M., HUBER, T. B., EIMER, S., TERZI, F. \& SIMONS, M. 2014. V-ATPase/mTOR signaling regulates megalinmediated apical endocytosis. Cell reports, 8, 10-19.

GLUCKMAN, P. D., HANSON, M. A. \& SPENCER, H. G. 2005. Predictive adaptive responses and human evolution. Trends Ecol Evol, 20, 527-33.

GOLDIN, S. N. \& PAPAIOANNOU, V. E. 2003. Paracrine action of FGF4 during periimplantation development maintains trophectoderm and primitive endoderm. Genesis, 36, 40-47.

GOLDING, M. C., ZHANG, L. \& MANN, M. R. 2010. Multiple epigenetic modifiers induce aggressive viral extinction in extraembryonic endoderm stem cells. Cell Stem Cell, 6, 457-67.

GOMES, M., HUBER, J., FERRIANI, R., NETO, A. A. \& RAMOS, E. 2009. Abnormal methylation at the KVDMR1 imprinting control region in clinically normal children conceived by assisted reproductive technologies. Molecular human reproduction, 15, 471-477.

GOODWIN, C., HOLT, S., DOWNES, S. \& MARSHALL, N. 1995. Microculture tetrazolium assays: a comparison between two new tetrazolium salts, XTT and MTS. Journal of immunological methods, 179, 95-103.

GOTOH, N., MANOVA, K., TANAKA, S., MUROHASHI, M., HADARI, Y., LEE, A., HAMADA, Y., HIROE, T., ITO, M., KURIHARA, T., NAKAZATO, H., SHIBUYA, M., LAX, I., LACY, E. \& SCHLESSINGER, J. 2005. The docking protein FRS2alpha is an essential component of multiple fibroblast growth factor responses during early mouse development. Mol Cell Biol, 25, 4105-16.

GOYAL, R., GOYAL, D., LEITZKE, A., GHEORGHE, C. P. \& LONGO, L. D. 2009. Brain renin-angiotensin system: fetal epigenetic programming by maternal protein restriction during pregnancy. Reproductive Sciences.

GUERRERO-BOSAGNA, C. \& SKINNER, M. K. 2014. Environmentally induced epigenetic transgenerational inheritance of male infertility. Current opinion in genetics \& development, 26, 79-88. 
GUO, G., YANG, J., NICHOLS, J., HALL, J. S., EYRES, I., MANSFIELD, W. \& SMITH, A. 2009. KIf4 reverts developmentally programmed restriction of ground state pluripotency. Development, 136, 1063-9.

GUZMAN-AYALA, M., BEN-HAIM, N., BECK, S. \& CONSTAM, D. B. 2004. Nodal protein processing and fibroblast growth factor 4 synergize to maintain a trophoblast stem cell microenvironment. Proceedings of the National Academy of Sciences of the United States of America, 101, 15656-15660.

HALES, C. N., BARKER, D. J. P., CLARK, P. M. S., COX, L. J., FALL, C., OSMOND, C. \& WINTER, P. D. 1991. Fetal and infant growth and impaired glucose tolerance at age 64. British Medical Journal, 303, 1019-1022.

HATTORI, N., DAVIES, T. C., ANSON-CARTWRIGHT, L. \& CROSS, J. C. 2000. Periodic expression of the Cdk inhibitor p57Kip2 in trophoblast giant cells. Molecular Biology of the Cell, 11, 1037-1045.

HATTORI, N., IMAO, Y., NISHINO, K., HATTORI, N., OHGANE, J., YAGI, S., TANAKA, S. \& SHIOTA, K. 2007. Epigenetic regulation of Nanog gene in embryonic stem and trophoblast stem cells. Genes Cells, 12, 387-96.

HE, X.-J., CHEN, T. \& ZHU, J.-K. 2011. Regulation and function of DNA methylation in plants and animals. Cell research, 21, 442-465.

HEIJMANS, B. T., TOBI, E. W., STEIN, A. D., PUTTER, H., BLAUW, G. J., SUSSER, E. S., SLAGBOOM, P. E. \& LUMEY, L. 2008. Persistent epigenetic differences associated with prenatal exposure to famine in humans. Proceedings of the National Academy of Sciences, 105, 17046-17049.

HEMBERGER, M., HUGHES, M. \& CROSS, J. C. 2004. Trophoblast stem cells differentiate in vitro into invasive trophoblast giant cells. Dev Biol, 271, 362-71.

HEMBERGER, M., NOZAKI, T., MASUTANI, M. \& CROSS, J. C. 2003. Differential expression of angiogenic and vasodilatory factors by invasive trophoblast giant cells depending on depth of invasion. Developmental Dynamics, 227, 185-191.

HORI, N., NAGAI, M., HIRAYAMA, M., HIRAI, T., MATSUDA, K., HAYASHI, M., TANAKA, T., OZAWA, T. \& HORIKE, S.-I. 2010. Aberrant CpG methylation of the imprinting control region KVDMR1 detected in assisted reproductive technology-produced calves and pathogenesis of large offspring syndrome. Animal reproduction science, 122, 303-312.

HU, D. \& CROSS, J. C. 2010. Development and function of trophoblast giant cells in the rodent placenta. Int J Dev Biol, 54, 341-54.

HUANG, H. Y. 1998. Cytokine-Mediated Regulation of 92-Kilodalton Type IV Collagenase, Tissue Inhibitor of Metalloproteinase-1 (TIMP-1), and TIMP-3 Messenger Ribonucleic Acid Expression in Human Endometrial Stromal Cells. Journal of Clinical Endocrinology \& Metabolism, 83, 1721-1729.

HUGHES, M., DOBRIC, N., SCOTT, I. C., SU, L., STAROVIC, M., ST-PIERRE, B., EGAN, S. E., KINGDOM, J. C. \& CROSS, J. C. 2004. The Hand1, Stra13 and Gcm1 transcription factors override FGF signaling to promote terminal differentiation of trophoblast stem cells. Dev Biol, 271, 2637. 
IANNACCONE, P., ZHOU, X., KHOKHA, M., BOUCHER, D. \& KUEHN, M. 1992. Insertional mutation of a gene involved in growth regulation of the early mouse embryo. Developmental dynamics, 194, 198-208.

ILGREN, E. B. 1983. Review article control of trophoblastic growth. Placenta 4, 307-328.

ILLERA, M. J., CULLINAN, E., GUI, Y., YUAN, L., BEYLER, S. A. \& LESSEY, B. A. 2000. Blockade of the $\alpha v \beta 3$ integrin adversely affects implantation in the mouse. Biology of reproduction, 62 , 1285-1290.

ILLERA, M. J., LORENZO, P., GUI, Y.-T., BEYLER, S. A., APPARAO, K. \& LESSEY, B. A. 2003. A role for $\alpha v \beta 3$ integrin during implantation in the rabbit model. Biology of reproduction, 68, 766771.

INOUE, H., NOJIMA, H. \& OKAYAMA, H. 1990. High efficiency transformation of Escherichia coli with plasmids. Gene, 96, 23-28.

INSTRUMENTS, B.-T. \& WINOOSKI, V. 2007. Serum albumin leads to false-positive results in the XTT and the MTT assay. Biotechniques, 43, 178-186.

JACKSON, D., VOLPERT, O. V., BOUCK, N. \& LINZER, D. 1994. Stimulation and inhibition of angiogenesis by placental proliferin and proliferin-related protein. Science, 266, 15811584.

JANSSON, N., PETTERSSON, J., HAAfiZ, A., ERICSSON, A., PALMBERG, I., TRANBERG, M., GANAPATHY, V., POWELL, T. L. \& JANSSON, T. 2006. Down-regulation of placental transport of amino acids precedes the development of intrauterine growth restriction in rats fed a low protein diet. J Physiol, 576, 935-946.

JENKINS, N., MURPHY, L. \& TYTHER, R. 2008. Post-translational modifications of recombinant proteins: significance for biopharmaceuticals. Mol Biotechnol, 39, 113-8.

JOHNSON, M. H. \& ZIOMEK, C. A. 1981. The foundation of two distinct cell lineages with in the mouse morula Cell, 24, 71-80.

KAFRI, T., ARIEL, M., BRANDEIS, M., SHEMER, R., URVEN, L., MCCARREY, J., CEDAR, H. \& RAZIN, A. 1992. Developmental pattern of gene-specific DNA methylation in the mouse embryo and germ line. Genes \& development, 6, 705-714.

KALISCH-SMITH, J., SIMMONS, D., DICKINSON, H. \& MORITZ, K. 2016. Sexual dimorphism in the formation, function and adaptation of the placenta. Placenta.

KÄLLÉN, B., FINNSTRÖM, O., LINDAM, A., NILSSON, E., NYGREN, K.-G. \& OLAUSSON, P. O. 2010. Cancer risk in children and young adults conceived by in vitro fertilization. Pediatrics, 126, 270-276.

KANIGICHERLA, D., GUMMADOVA, J., MCKENZIE, E. A., ROBERTS, S. A., HARRIS, S., NIKAM, M., POULTON, K., MCWILLIAM, L., SHORT, C. D., VENNING, M. \& BRENCHLEY, P. E. 2013. AntiPLA2R antibodies measured by ELISA predict long-term outcome in a prevalent population of patients with idiopathic membranous nephropathy. Kidney Int, 83, 940-8.

KANITZ, E., OTTEN, W., TUCHSCHERER, M., GRABNER, M., BRUSSOW, K. P., REHFELDT, C. \& METGES, C. C. 2012. High and low proteinratio carbohydrate dietary ratios during gestation alter maternal-fetal cortisol regulation in pigs. PLoS One, 7, e52748. 
KATARI, S., TURAN, N., BIBIKOVA, M., ERINLE, O., CHALIAN, R., FOSTER, M., GAUGHAN, J. P., COUTIFARIS, C. \& SAPIENZA, C. 2009. DNA methylation and gene expression differences in children conceived in vitro or in vivo. Human molecular genetics, 18, 3769-3778.

KEELY, E. J., MALCOLM, J. C., HADJIYANNAKIS, S., GABOURY, I., LOUGH, G. \& LAWSON, M. L. 2008. Prevalence of metabolic markers of insulin resistance in offspring of gestational diabetes pregnancies. Pediatric diabetes, 9, 53-59.

KIBSCHULL, M., NASSIRY, M., DUNK, C., GELLHAUS, A., QUINN, J. A., ROSSANT, J., LYE, S. J. \& WINTERHAGER, E. 2004. Connexin31-deficient trophoblast stem cells: a model to analyze the role of gap junction communication in mouse placental development. Dev Biol, 273, 63-75.

KIDDER, B. L. \& PALMER, S. 2010. Examination of transcriptional networks reveals an important role for TCFAP2C, SMARCA4, and EOMES in trophoblast stem cell maintenance. Genome Res, 20, 458-72.

KIDDER, B. L. \& PALMER, S. 2012. HDAC1 regulates pluripotency and lineage specific transcriptional networks in embryonic and trophoblast stem cells. Nucleic Acids Res, 40, 2925-39.

KLEIJKERS, S. H., EIJSSEN, L. M., COONEN, E., DERHAAG, J. G., MANTIKOU, E., JONKER, M. J., MASTENBROEK, S., REPPING, S., EVERS, J. L. \& DUMOULIN, J. C. 2015. Differences in gene expression profiles between human preimplantation embryos cultured in two different IVF culture media. Human Reproduction, 30, 2303-2311.

KOSAKA, N., SAKAMOTO, H., TERADA, M. \& OCHIYA, T. 2009. Pleiotropic function of FGF-4: its role in development and stem cells. Dev Dyn, 238, 265-76.

KRATOCHWIL, K., GALCERAN, J., TONTSCH, S., ROTH, W. \& GROSSCHEDL, R. 2002. FGF4, a direct target of LEF1 and Wnt signaling, can rescue the arrest of tooth organogenesis in Lef1-/mice. GENES \& DEVELOPMENT, 16:3173-3185.

KUBACZKA, C., SENNER, C., ARAUZO-BRAVO, M. J., SHARMA, N., KUCKENBERG, P., BECKER, A., ZIMMER, A., BRUSTLE, O., PEITZ, M., HEMBERGER, M. \& SCHORLE, H. 2014. Derivation and Maintenance of Murine Trophoblast Stem Cells under Defined Conditions. Stem Cell Reports, 2, 232-42.

KUCKENBerg, P., PEITZ, M., KUBACZKA, C., BECKER, A., EGERT, A., WARDELMANN, E., ZIMMER, A., BRUSTLE, O. \& SCHORLE, H. 2011. Lineage conversion of murine extraembryonic trophoblast stem cells to pluripotent stem cells. Mol Cell Biol, 31, 1748-56.

KUNATH, T., SABA-EL-LEIL, M. K., ALMOUSAILLEAKH, M., WRAY, J., MELOCHE, S. \& SMITH, A. 2007. FGF stimulation of the Erk1/2 signalling cascade triggers transition of pluripotent embryonic stem cells from self-renewal to lineage commitment. Development, 134, 2895902.

KUNATH, T., YAMANAKA, Y., DETMAR, J., MACPHEE, D., CANIGGIA, I., ROSSANT, J. \& JURISICOVA, A. 2014. Developmental differences in the expression of FGF receptors between human and mouse embryos. Placenta, 35, 1079-1088.

KUNIEDA, T., XIAN, M., KOBAYASHI, E., IMAMICHI, T., MORIWAKI, K. \& TOYODA, Y. 1992. Sexing of mouse preimplantation embryos by detection of $Y$ chromosome-specific sequences using polymerase chain reaction. Biology of reproduction, 46, 692-697. 
KWONG, W. Y., WILD, A. E., ROBERTS, P., WILLIS, A. C. \& FLEMING, T. P. 2000. Maternal undernutrition during the preimplantation period of rat development causes blastocyst abnormalities and programming of postnatal hypertension. Development 127, 4195-4202.

LANGLEY, S. C. \& JACKSON, A. A. 1994. Increased systolic blood pressure in adult rats induced by fetal exposure to maternal low protein diets. Clinical science, 82, 217-222.

LANNER, F. \& ROSSANT, J. 2010. The role of FGF/Erk signaling in pluripotent cells. Development, 137, 3351-3360.

LARUE, L., OHSUGI, M., HIRCHENHAIN, J. \& KEMLER, R. 1994. E-cadherin null mutant embryos fail to form a trophectoderm epithelium. Proc. Natl. Acad. Sci. USA, 91, 8263-8267.

LATOS, P. A., GONCALVES, A., OXLEY, D., MOHAMMED, H., TURRO, E. \& HEMBERGER, M. 2015. Fgf and Esrrb integrate epigenetic and transcriptional networks that regulate self-renewal of trophoblast stem cells. Nature communications, 6.

LATOS, P. A. \& HEMBERGER, M. 2016. From the stem of the placental tree: trophoblast stem cells and their progeny. Development, 143, 3650-3660.

LAZARAVICIUTE, G., KAUSER, M., BHATTACHARYA, S., HAGGARTY, P. \& BHATTACHARYA, S. 2014. A systematic review and meta-analysis of DNA methylation levels and imprinting disorders in children conceived by IVF/ICSI compared with children conceived spontaneously. Hum Reprod Update, 20, 840-52.

LEFEBVRE, L. 2012. The placental imprintome and imprinted gene function in the trophoblast glycogen cell lineage. Reprod Biomed Online, 25, 44-57.

LEON, D. A., KOUPILOVA, I., LITHELL, H. O., BERGLUND, L., MOHSEN, R., VAGERO, D., LITHELL, U.-B. \& MCKEIGUE, P. M. 1996. Failure to realise growth potential in utero and adult obesity in relation to blood pressure in 50 year old Swedish men. Bmj, 312, 401-406.

LEON, D. A., LITHELL, H. O., VÅGERÖ, D., KOUPILOVÆ, I., MOHSEN, R., BERGLUND, L., LITHELL, U.-B. \& MCKEIGUE, P. M. 1998. Reduced fetal growth rate and increased risk of death from ischaemic heart disease: cohort study of 15000 Swedish men and women born 1915-29. $B M J, 317,241-245$.

LI, J., HUANG, J., LI, J.-S., CHEN, H., HUANG, K. \& ZHENG, L. 2012. Accumulation of endoplasmic reticulum stress and lipogenesis in the liver through generational effects of high fat diets. Journal of hepatology, 56, 900-907.

LI, P., TONG, C., MEHRIAN-SHAI, R., JIA, L., WU, N., YAN, Y., MAXSON, R. E., SCHULZE, E. N., SONG, H., HSIEH, C. L., PERA, M. F. \& YING, Q. L. 2008. Germline competent embryonic stem cells derived from rat blastocysts. Cell, 135, 1299-310.

LI, Y., HE, Y., QI, L., JADDOE, V. W., FESKENS, E. J., YANG, X., MA, G. \& HU, F. B. 2010. Exposure to the Chinese famine in early life and the risk of hyperglycemia and type 2 diabetes in adulthood. Diabetes, 59, 2400-2406.

LIBRACH, C. L., WERB, Z., FITZGERALD, M. L., CHIU, K., CORWIN, N. M., ESTEVES, R. A., GROBELNY, D., GALARDY, R., DAMSKY, C. H. \& FISHER, S. J. 1991. 92-kD Type IV Collagenase Mediates Invasion of Human Cytotrophoblasts. The Journal of Cell Biology, 113, 437--449

LILLYCROP, K. \& BURDGE, G. 2015. Maternal diet as a modifier of offspring epigenetics. Journal of developmental origins of health and disease, 6, 88-95. 
LILLYCROP, K. A., PHILLIPS, E. S., TORRENS, C., HANSON, M. A., JACKSON, A. A. \& BURDGE, G. C. 2008. Feeding pregnant rats a protein-restricted diet persistently alters the methylation of specific cytosines in the hepatic PPAR $\alpha$ promoter of the offspring. British Journal of Nutrition, 100, 278-282.

LIM, A. L., NG, S., LEOW, S. C., CHOO, R., ITO, M., CHAN, Y. H., GOH, S. K., TNG, E., KWEK, K., CHONG, Y. S., GLUCKMAN, P. D. \& FERGUSON-SMITH, A. C. 2012. Epigenetic state and expression of imprinted genes in umbilical cord correlates with growth parameters in human pregnancy. J Med Genet, 49, 689-97.

LIM, D., BOWDIN, S. C., TEE, L., KIRBY, G. A., BLAIR, E., FRYER, A., LAM, W., OLEY, C., COLE, T. \& BRUETON, L. A. 2009. Clinical and molecular genetic features of Beckwith-Wiedemann syndrome associated with assisted reproductive technologies. Human reproduction, 24, 741-747.

LIN, S., LI, M., LIAN, Y., CHEN, L. \& LIU, P. 2013. No effect of embryo culture media on birthweight and length of newborns. Human Reproduction, det095.

LINDENBERG, S., SUNDBERG, K., KIMBER, S. J. \& LUNDBLAD, A. 1988. The milk oligosaccharide, lacto-N-fucopentaose $\mathrm{I}$, inhibits attachment of mouse blastocysts on endometrial monolayers. J.Reprod. Fertil., 83, 149-158.

LINZER, D. I. \& FISHER, S. J. 1999. The placenta and the prolactin family of hormones: regulation of the physiology of pregnancy. Molecular Endocrinology, 13, 837-840.

LIU, J., PUSCHECK, E. E., WANG, F., TROSTINSKAIA, A., BARISIC, D., MANIERE, G., WYGLE, D., ZHONG, W., RINGS, E. H. \& RAPPOLEE, D. A. 2004. Serine-threonine kinases and transcription factors active in signal transduction are detected at high levels of phosphorylation during mitosis in preimplantation embryos and trophoblast stem cells. Reproduction, 128, 643-54.

LOVE, J. M., KNIGHT, A. M., MCALEER, M. A. \& TODD, J. A. 1990. Towards construction of a high resolution map of the mouse genome using PCR-analysed microsatellites. Nucleic Acids Research, 18, 4123-4130.

MA, G. T., SOLOVEVA, V., TZENG, S.-J., LOWE, L. A., PFENDLER, K. C., IANNACCONE, P. M., KUEHN, M. R. \& LINZER, D. I. 2001. Nodal regulates trophoblast differentiation and placental development. Developmental biology, 236, 124-135.

MACAULEY, A., CROSS, J. C. \& WERB, Z. 1998. Reprogramming the cell cycle for endoreduplication in rodent trophoblast cells. Molecular Biology of the Cell, 9, 795- 807.

MAHER, E., BRUETON, L., BOWDIN, S., LUHARIA, A., COOPER, W., COLE, T., MACDONALD, F., SAMPSON, J., BARRATT, C. \& REIK, W. 2003. Beckwith-Wiedemann syndrome and assisted reproduction technology (ART). Journal of medical genetics, 40, 62-64.

MAIA, C. S., TEIXEIRA, V. W., TEIXEIRA, Á. A. C. \& FILHO, N. T. P. 2010. Analysis of Fetal and Placental Development in Rats after Administration of Hydroalcoholic Extract from the Root of Petiveria alliacea L. (Phytolaccaceae). Int. J. Morphol, 28(1), 165-169.

MAK, W., BAXTER, J., SILVA, J., NEWALL, A. E., OTTE, A. P. \& BROCKDORFF, N. 2002. Mitotically Stable Association of Polycomb Group Proteins Eed and Enx1 with the Inactive $X$ Chromosome in Trophoblast Stem Cells. Current Biology, 12, 1016-1020. 
MÄKINEN, S., SÖDERSTRÖM-ANTTILA, V., VAINIO, J., SUIKKARI, A.-M. \& TUURI, T. 2013. Does long in vitro culture promote large for gestational age babies? Human Reproduction, 28, 828834.

MANIPALVIRATN, S., DECHERNEY, A. \& SEGARS, J. 2009. Imprinting disorders and assisted reproductive technology. Fertility and sterility, 91, 305-315.

MARDON, G. \& PAGE, D. C. 1989. The sex-determining region of the mouse $Y$ chromosome encodes a protein with a highly acidic domain and 13 zinc fingers. Cell, 56, 765-770.

MARKET-VELKER, B. A., ZHANG, L., MAGRI, L. S., BONVISSUTO, A. C. \& MANN, M. R. 2010. Dual effects of superovulation: loss of maternal and paternal imprinted methylation in a dosedependent manner. Human molecular genetics, 19, 36-51.

MARTIN, G. R. 1981. Isolation of a pluripotent cell line from early mouse embryos cultured in medium conditioned by teratocarcinoma stem cells. Proc. Natl Acad. Sci. USA, 78, 76347638.

MAYSHAR, Y., ROM, E., CHUMAKOV, I., KRONMAN, A., YAYON, A. \& BENVENISTY, N. 2008. Fibroblast growth factor 4 and its novel splice isoform have opposing effects on the maintenance of human embryonic stem cell self-renewal. Stem Cells, 26, 767-74.

MCLAREN, A. 1970. The fate of the zona pellucida in mice. J. Embryol. exp. Morph., 23, 1-19.

MCMINN, J., WEI, M., SCHUPF, N., CUSMAI, J., JOHNSON, E. B., SMITH, A. C., WEKSBERG, R., THAKER, H. M. \& TYCKO, B. 2006. Unbalanced placental expression of imprinted genes in human intrauterine growth restriction. Placenta, 27, 540-9.

MESNER, P. W., WINTERS, T. R. \& GREEN, S. H. 1992. Nerve growth factor withdrawal-induced cell death in neuronal PC12 cells resembles that in sympathetic neurons. The Journal of cell biology, 119, 1669-1680.

MITTWOCH, U. 1993. Blastocysts prepare for the race to be male. Human reproduction, $8,1550-$ 1555.

MIYAKE, T., CAMERON, A. \& HALL, B. 1997. Variability of embryonic development among three inbred strains of mice. Growth, development, and aging: GDA, 61, 141-155.

MODLINSKI, J. A. 1970. The role of the zona pellucida in the development of mouse eggs in vivo $\mathrm{J}$. Embryol. exp. Morph, 23, 539-547.

MOTOMURA, K., INOUE, K. \& OGURA, A. 2016. Selection of accurate reference genes in mouse trophoblast stem cells for reverse transcription-quantitative polymerase chain reaction. Journal of Reproduction and Development, 62, 311-315.

NAGY, A. 2003. Manipulating the mouse embryo: a laboratory manual, Firefly Books.

NAICHE, L. A., HOLDER, N. \& LEWANDOSKI, M. 2011. FGF4 and FGF8 comprise the wavefront activity that controls somitogenesis. PNAS, 108, 4018-4023.

NAOE, H., CHIYODA, T., ISHIZAWA, J., MASUDA, K., SAYA, H. \& KUNINAKA, S. 2013. The APC/C activator $\mathrm{Cdh} 1$ regulates the $\mathrm{G} 2 / \mathrm{M}$ transition during differentiation of placental trophoblast stem cells. Biochem Biophys Res Commun, 430, 757-62.

NAVARRO, P., CHAMBERS, I., KARWACKI-NEISIUS, V., CHUREAU, C., MOREY, C., ROUGEULLE, C. \& AVNER, P. 2008. Molecular coupling of Xist regulation and pluripotency. Science, 321, 1693-1695. 
NELISSEN, E. C., DUMOULIN, J. C., DAUNAY, A., EVERS, J. L., TOST, J. \& VAN MONTFOORT, A. P. 2013. Placentas from pregnancies conceived by IVF/ICSI have a reduced DNA methylation level at the H19 and MEST differentially methylated regions. Human Reproduction, 28, 1117-1126.

NEWSOME, C. A., SHIELL, A. W., FALL, C. H. D., PHILLIPS, D. I. W., SHIER, R. \& LAW, C. M. 2003. Is birth weight related to later glucose and insulin metabolism? - a systematic review. Diabetic Medicine, 20, 339-348.

NG, R. K., DEAN, W., DAWSON, C., LUCIFERO, D., MADEJA, Z., REIK, W. \& HEMBERGER, M. 2008. Epigenetic restriction of embryonic cell lineage fate by methylation of Elf5. Nat Cell Biol, $10,1280-90$.

NISHIOKA, N., INOUE, K.-I., ADACHI, K., KIYONARI, H., OTA, M., RALSTON, A., YABUTA, N., HIRAHARA, S., STEPHENSON, R. O. \& OGONUKI, N. 2009. The Hippo Signaling Pathway Components Lats and Yap Pattern Tead4 Activity to Distinguish Mouse Trophectoderm from Inner Cell Mass. Developmental Cell, 16, 398-410.

NIWA, H., BURDON, T., CHAMBERS, I. \& 3, A. S. 1998. Self-renewal of pluripotent embryonic stem cells is mediated via activation of STAT3. Genes and Development 12, 2044-2060.

NIWA, H., TOYOOKA, Y., SHIMOSATO, D., STRUMPF, D., TAKAHASHI, K., YAGI, R. \& ROSSANT, J. 2005. Interaction between Oct3/4 and $C d \times 2$ determines trophectoderm differentiation. Cell, 123, 917-929.

NOHARA, K., WARAICH, R. S., LIU, S., FERRON, M., WAGET, A., MEYERS, M. S., KARSENTY, G., BURCELIN, R. \& MAUVAIS-JARVIS, F. 2013. Developmental androgen excess programs sympathetic tone and adipose tissue dysfunction and predisposes to a cardiometabolic syndrome in female mice. American Journal of Physiology-Endocrinology and Metabolism, 304, E1321-E1330.

OCKLEFORD, C., WHYTE, A. \& BOWYER, D. 1977. Variation in the volume of coated vesicles isolated from human placenta. Cell biology international reports, 1, 137-146.

ODA, M., TANAKA, S., YAMAZAKI, Y., OHTA, H., IWATANI, M., SUZUKI, M., OHGANE, J., HATTORI, N., YANAGIMACHI, R., WAKAYAMA, T. \& SHIOTA, K. 2009. Establishment of trophoblast stem cell lines from somatic cell nuclear-transferred embryos. Proc Natl Acad Sci U S A, $106,16293-7$.

ODENTHAL, U., HAEHN, S., TUNGGAL, P., MERKL, B., SCHOMBURG, D., FRIE, C., PAULSSON, M. \& SMYTH, N. 2004. Molecular analysis of laminin N-terminal domains mediating selfinteractions. Journal of Biological Chemistry, 279, 44504-44512.

ODOM, L. N. \& SEGARS, J. 2010. Imprinting disorders and assisted reproductive technology. Current opinion in endocrinology, diabetes, and obesity, 17, 517.

OGAWA, H., SHINDO, N., KUMAGAI, T., USAMI, Y., SHIKANAI, M., JONWN, K., FUKUDA, A., KAWAHARA, M., SOTOMARU, Y., TANAKA, S., ARIMA, T. \& KONO, T. 2009. Developmental ability of trophoblast stem cells in uniparental mouse embryos. Placenta, 30, 448-56.

OHINATA, Y. \& TSUKIYAMA, T. 2014. Establishment of Trophoblast Stem Cells under Defined Culture Conditions in Mice. 
ORASANU, B., JACKSON, K. V., HORNSTEIN, M. D. \& RACOWSKY, C. 2006. Effects of culture medium on HCG concentrations and their value in predicting successful IVF outcome. Reproductive biomedicine online, 12, 590-598.

ORNITZ, D. M., YAYON, A., FLANAGAN, J. G., SVAHN, C. M., LEVI, E. \& LEDER1, P. 1992. Heparin Is Required for Cell-Free Binding of Basic Fibroblast Growth Factor to a Soluble Receptor and for Mitogenesis in Whole Cells. Molecular And Cellular Biology, 12, 240-247.

OTTEN, W., KANITZ, E., TUCHSCHERER, M., GRÄBNER, M., NÜRNBERG, G., BELLMANN, O., HENNIG, U., REHFELDT, C. \& METGES, C. 2013. Effects of low and high protein: carbohydrate ratios in the diet of pregnant gilts on maternal cortisol concentrations and the adrenocortical and sympathoadrenal reactivity in their offspring. Journal of animal science, 91, 26802692.

OUTHWAITE, J. E., NATALE, B. V., NATALE, D. R. \& SIMMONS, D. G. 2015. Expression of aldehyde dehydrogenase family 1 , member $A 3$ in glycogen trophoblast cells of the murine placenta. Placenta, 36, 304-11.

PARK, C.-H., KIM, H.-S., LEE, S.-G. \& LEE, C.-K. 2009. Methylation status of differentially methylated regions at Igf2/H19 locus in porcine gametes and preimplantation embryos. Genomics, 93, 179-186.

PARK, J. H., STOFFERS, D. A., NICHOLLS, R. D. \& SIMMONS, R. A. 2008. Development of type 2 diabetes following intrauterine growth retardation in rats is associated with progressive epigenetic silencing of Pdx1. The Journal of clinical investigation, 118, 2316.

PERRY, V. E. A., NORMAN, S. T., OWEN, J. A., DANIEL, R. C. W. \& PHILLIPS, N. 1999. Low dietary protein during early pregnancy alters bovine placental development. Animal Reproduction Science, 55, 13-21.

PETERSON, S. E., WESTRA, J. W., REHEN, S. K., YOUNG, H., BUSHMAN, D. M., PACZKOWSKI, C. M., YUNG, Y. C., LYNCH, C. L., TRAN, H. T. \& NICKEY, K. S. 2011. Normal human pluripotent stem cell lines exhibit pervasive mosaic aneuploidy. PLoS One, 6, e23018.

PHILLIPS, R. W., FRIERSON, H. F. \& MOSKALUK, C. A. 2003. Cdx2 as a marker of epithelial intestinal differentiation in the esophagus. The American journal of surgical pathology, 27, 14421447.

PULLAR, D., TE KRONNIE, G., PEIRIS, I. D., TAVERNE, N., JEACOCK, M. K., STROBAND, H. \& SHEPHERD, D. 1990. Morphological and radiochemical evidence for the metabolism of exogenous proteins by the preimplantation sheep blastocyst. Development, 110, 539-546.

QUINN, J., KUNATH, T. \& ROSSANT, J. 2006. Mouse trophoblast stem cells. Placenta and Trophoblast. Humana Press.

RADFORD, E. J., ITO, M., SHI, H., CORISH, J. A., YAMAZAWA, K., ISGANAITIS, E., SEISENBERGER, S., HORE, T. A., REIK, W. \& ERKEK, S. 2014. In utero undernourishment perturbs the adult sperm methylome and intergenerational metabolism. Science, 345, 1255903.

RAI, A. \& CROSS, J. C. 2015. Three-dimensional cultures of trophoblast stem cells autonomously develop vascular-like spaces lined by trophoblast giant cells. Dev Biol, 398, 110-9.

RAKYAN, V. K., BLEWITT, M. E., DRUKER, R., PREIS, J. I. \& WHITELAW, E. 2002. Metastable epialleles in mammals. Trends in Genetics, 18, 348-351. 
RAMIREZ-SOLIS, R., RIVERA-PEREZ, J., WALLACE, J. D., WIMS, M., ZHENG, H. \& BRADLEY, A. 1992. Genomic DNA microextraction: a method to screen numerous samples. Analytical biochemistry, 201, 331-335.

RAMSAHOYE, B. H., BINISZKIEWICZ, D., LYKO, F., CLARK, V., BIRD, A. P. \& JAENISCH, R. 2000. Non$\mathrm{CpG}$ methylation is prevalent in embryonic stem cells and may be mediated by DNA methyltransferase 3a. Proceedings of the National Academy of Sciences, 97, 5237-5242.

RAYCHAUDHURI, N., RAYCHAUDHURI, S., THAMOTHARAN, M. \& DEVASKAR, S. U. 2008. Histone code modifications repress glucose transporter 4 expression in the intrauterine growthrestricted offspring. Journal of Biological Chemistry, 283, 13611-13626.

REBELATO, H. J., ESQUISATTO, M. A. M., MORAES, C., AMARAL, M. E. C. \& CATISTI, R. 2013. Gestational protein restriction induces alterations in placental morphology and mitochondrial function in rats during late pregnancy. Journal of molecular histology, 44, 629-637.

RICH-EDWARDS, J. W., STAMPFER, M. J., MANSON, J. E., ROSNER, B., HANKINSON, S. E., COLDITZ, G. A., WILLETT, W. C. \& HENNEKENS, C. H. 1997. Birthweight and risk of cardiovascular disease in a cohort of women followed up since 1976. BMJ, 315, 396-400.

RINAUDO, P. \& WANG, E. 2012. Fetal programming and metabolic syndrome. Annual review of physiology, 74, 107.

RIVERA, R. M., STEIN, P., WEAVER, J. R., MAGER, J., SCHULTZ, R. M. \& BARTOLOMEI, M. S. 2008. Manipulations of mouse embryos prior to implantation result in aberrant expression of imprinted genes on day 9.5 of development. Hum Mol Genet, 17, 1-14.

ROBERTS, R. M., EZASHI, T. \& DAS, P. 2004. Trophoblast gene expression: transcription factors in the specification of early trophoblast. Reprod Biol Endocrinol, 2, 47.

ROH, T.-Y., CUDDAPAH, S., CUI, K. \& ZHAO, K. 2006. The genomic landscape of histone modifications in human T cells. Proceedings of the National Academy of Sciences, 103, 15782-15787.

ROMUNDSTAD, L. B., ROMUNDSTAD, P. R., SUNDE, A., VON DÜRING, V., SKJAERVEN, R., GUNNELL, D. \& VATTEN, L. J. 2008. Effects of technology or maternal factors on perinatal outcome after assisted fertilisation: a population-based cohort study. The Lancet, 372, 737-743.

ROSARIO, F. J., JANSSON, N., KANAI, Y., PRASAD, P. D., POWELL, T. L. \& JANSSON, T. 2011. Maternal protein restriction in the rat inhibits placental insulin, mTOR, and STAT3 signaling and down-regulates placental amino acid transporters. Endocrinology, 152, 1119-29.

ROSEBOOM, T., DE ROOIJ, S. \& PAINTER, R. 2006. The Dutch famine and its long-term consequences for adult health. Early Hum Dev, 82, 485-91.

ROSEBOOM, T., PAINTER, R., DE ROOIJ, S., VAN ABEELEN, A., VEENENDAAL, M., OSMOND, C. \& BARKER, D. 2011a. Effects of famine on placental size and efficiency. Placenta, 32, 395399.

ROSEBOOM, T. J., PAINTER, R. C., DE ROOIJ, S. R., VAN ABEELEN, A. F., VEENENDAAL, M. V., OSMOND, C. \& BARKER, D. J. 2011b. Effects of famine on placental size and efficiency. Placenta, 32, 395-9. 
ROSS, M. H., ROMRELL, L. J. \& KAYE, G. I. 1995. HISTOLOGY A Text and Atlas, Maryland.

RUCHAT, S.-M., HOUDE, A.-A., VOISIN, G., ST-PIERRE, J., PERRON, P., BAILLARGEON, J.-P., GAUDET, D., HIVERT, M.-F., BRISSON, D. \& BOUCHARD, L. 2013. Gestational diabetes mellitus epigenetically affects genes predominantly involved in metabolic diseases. Epigenetics, 8, 935-943.

RUTLAND, C., LATUNDE-DADA, A., THORPE, A., PLANT, R., LANGLEY-EVANS, S. \& LEACH, L. 2007. Effect of gestational nutrition on vascular integrity in the murine placenta. Placenta, 28, 734-742.

SAITO, K., OGAWA, A., TOYOFUKU, K., HOSOI, Y., SOMA, M., IHA, M., KASUGA, K., KOJIMA, I. \& KOBAYASHI, M. 2011. Relationships between homeoprotein EGAM1C and the expression of the placental prolactin gene family in mouse placentae and trophoblast stem cells. Reproduction, 141, 259-68.

SAKAMOTO, H., MORI, M., TAIRA, M., YOSHIDA, T., MATSUKAWA, S., SHIMIZU, K., SEKIGUCHI, M., TERADA, M. \& SUGIMURA, T. 1986. Transforming gene from human stomach cancers and a noncancerous portion of stomach mucosa. Proceedings of the National Academy of Sciences, 83, 3997-4001.

SAKKA, S. D., LOUTRADIS, D., KANAKA-GANTENBEIN, C., MARGELI, A., PAPASTAMATAKI, M., PAPASSOTIRIOU, I. \& CHROUSOS, G. P. 2010. Absence of insulin resistance and low-grade inflammation despite early metabolic syndrome manifestations in children born after in vitro fertilization. Fertility and sterility, 94, 1693-1699.

SALA, M., JOH, R., SAXENA, A., BARTON, S., FRANK, D., FITZPATRICK, G., HIGGINS, M. J. \& TYCKO, B. 2004. Placental growth retardation due to loss of imprinting of Phlda2. Mech Dev, 121, 1199-210.

SANDOVICI, I., SMITH, N. H., NITERT, M. D., ACKERS-JOHNSON, M., URIBE-LEWIS, S., ITO, Y., JONES, R. H., MARQUEZ, V. E., CAIRNS, W. \& TADAYYON, M. 2011. Maternal diet and aging alter the epigenetic control of a promoter-enhancer interaction at the Hnf4a gene in rat pancreatic islets. Proceedings of the National Academy of Sciences, 108, 5449-5454.

SANTOS, J., PEREIRA, C. F., DI-GREGORIO, A., SPRUCE, T., ALDER, O., RODRIGUEZ, T., AZUARA, V., MERKENSCHLAGER, M. \& FISHER, A. G. 2010. Differences in the epigenetic and reprogramming properties of pluripotent and extra-embryonic stem cells implicate chromatin remodelling as an important early event in the developing mouse embryo. Epigenetics Chromatin, 3, 1.

SATO, H., AMAGAI, K., SHIMIZUKAWA, R. \& TAMAI, Y. 2009. Stable generation of serum-and feeder-free embryonic stem cell-derived mice with full germline-competency by using a GSK3 specific inhibitor. genesis, 47, 414-422.

SAXENA, A., FRANK, D., PANICHKUL, P., VEYVER, I. B. V. D., TYCKO, B. \& THAKER, H. 2003. The Product of the Imprinted Gene IPL Marks Human Villous Cytotrophoblast and is Lost in Complete Hydatidiform Mole. Placenta, 24, 835-842.

SCHWARZER, C., ESTEVES, T. C., ARAÚZO-BRAVO, M. J., LE GAC, S., NORDHOFF, V., SCHLATT, S. \& BOIANI, M. 2012. ART culture conditions change the probability of mouse embryo gestation through defined cellular and molecular responses. Human reproduction, des223.

SCOTT, K. A., YAMAZAKI, Y., YAMAMOTO, M., LIN, Y., MELHORN, S. J., KRAUSE, E. G., WOODS, S. C., YANAGIMACHI, R., SAKAI, R. R. \& TAMASHIRO, K. L. 2010. Glucose parameters are altered in mouse offspring produced by assisted reproductive technologies and somatic cell nuclear transfer. Biology of reproduction, 83, 220-227. 
SENNER, C. E., KRUEGER, F., OXLEY, D., ANDREWS, S. \& HEMBERGER, M. 2012. DNA methylation profiles define stem cell identity and reveal a tight embryonic-extraembryonic lineage boundary. Stem Cells, 30, 2732-45.

SHEN, M. M. 2007. Nodal signaling: developmental roles and regulation. Development, 134, 102334.

SHERR, C. J. \& ROBERTS, J. M. 2004. Living with or without cyclins and cyclin-dependent kinases. Genes \& Development, 18, 2699-2711.

SHI, X., NI, Y., ZHENG, H., CHEN, S., ZHONG, M., WU, F., XIA, R. \& LUO, Y. 2011. Abnormal methylation patterns at the IGF2/H19 imprinting control region in phenotypically normal babies conceived by assisted reproductive technologies. European Journal of Obstetrics \& Gynecology and Reproductive Biology, 158, 52-55.

SHIDA, M. M., JACKSON-GRUSBY, L. L., ROSS, S. R. \& LINZER, D. 1992. Placental-specific expression from the mouse placental lactogen II gene promoter. Proceedings of the National Academy of Sciences, 89, 3864-3868.

SIMMONS, D. G., FORTIER, A. L. \& CROSS, J. C. 2007. Diverse subtypes and developmental origins of trophoblast giant cells in the mouse placenta. Dev Biol, 304, 567-78.

SINCLAIR, K., YOUNG, L., WILMUT, I. \& MCEVOY, T. 2000. In-utero overgrowth in ruminants following embryo culture: lessons from mice and a warning to men. Human Reproduction, $15,68-86$.

SLOBODA, D. M., HOWIE, G. J., PLEASANTS, A., GLUCKMAN, P. D. \& VICKERS, M. H. 2009. Pre-and postnatal nutritional histories influence reproductive maturation and ovarian function in the rat. PloS one, 4, e6744-e6744.

SMITH, A. G., HEATH, J. K., DONALDSON, D. D., WONG, G. G., MOREAU, J., STAHL, M. \& ROGERS, D. 1988. Inhibition of pluripotential embryonic stem cell differentiation by purified polypeptides. Nature, 336, 688-690.

SONG, S., GHOSH, J., MAINIGI, M., TURAN, N., WEINERMAN, R., TRUONGCAO, M., COUTIFARIS, C. \& SAPIENZA, C. 2015. DNA methylation differences between in vitro-and in vivoconceived children are associated with ART procedures rather than infertility. Clinical epigenetics, 7, 41.

SONGYANG, Z., BALTIMORE, D., CANTLEY, L. C., KAPLAN, D. R. \& FRANKE, T. F. 1997. Interleukin 3dependent survival by the Akt protein kinase. Proceedings of the National Academy of Sciences, 94, 11345-11350.

SPRUCE, T., PERNAUTE, B., DI-GREGORIO, A., COBB, B. S., MERKENSCHLAGER, M., MANZANARES, M. \& RODRIGUEZ, T. A. 2010. An early developmental role for miRNAs in the maintenance of extraembryonic stem cells in the mouse embryo. Dev Cell, 19, 207-19.

STEIN, C. E., FALL, C. H. D., KUMARAN, K., OSMOND, C., COX, V. \& BARKER, D. J. P. 1996. Fetal growth and coronary heart disease in South India. Lancet, 348, 1269-1273.

STEWART, C. L., KASPAR, P., BRUNET, L. J., BHATT, H., GADI, I., KÖNTGEN, F. \& ABBONDANZO, S. J. 1992. Blastocyst implantation depends on maternal expression of leukaemia inhibitory factor. Nature, 359, 76-79. 
STRAKOVSKY, R. S., ZHOU, D. \& PAN, Y. X. 2010. A low-protein diet during gestation in rats activates the placental mammalian amino acid response pathway and programs the growth capacity of offspring. J Nutr, 140, 2116-20.

STRUMPF, D., MAO, C. A., YAMANAKA, Y., RALSTON, A., CHAWENGSAKSOPHAK, K., BECK, F. \& ROSSANT, J. 2005. Cdx2 is required for correct cell fate specification and differentiation of trophectoderm in the mouse blastocyst. Development, 132, 2093-102.

SUGAWARA, A., GOTO, K., SOTOMARU, Y., SOFUNI, T. \& ITO, T. 2006. Current Status of Chromosomal Abnormalities in Mouse Embryonic Stem Cell Lines Used in Japan. Comparative Medicine, 56, 31-34.

SUN, C., DENISENKO, O., SHETH, B., COX, A., LUCAS, E. S., SMYTH, N. R. \& FLEMING, T. P. 2015. Epigenetic regulation of histone modifications and Gata6 gene expression induced by maternal diet in mouse embryoid bodies in a model of developmental programming. BMC Dev Biol, 15, 3.

SUN, C., VELAZQUEZ, M. A., MARFY-SMITH, S., SHETH, B., COX, A., JOHNSTON, D. A., SMYTH, N. \& FLEMING, T. P. 2014. Mouse early extra-embryonic lineages activate compensatory endocytosis in response to poor maternal nutrition. Development, 141, 1140-50.

TAKAHASHI, Y., CARPINO, N., C.CROSS, J., TORRES, M., PARGANAS, E. \& N.IHLE, J. 2003. SOCS3 an essential regulator of LIF receptor signaling in trophoblast giant cell differentiation. The EMBO Journal, 22, 372 \pm 384 .

TAKAO, T., ASANOMA, K., TSUNEMATSU, R., KATO, K. \& WAKE, N. 2012. The maternally expressed gene Tssc3 regulates the expression of MASH2 transcription factor in mouse trophoblast stem cells through the AKT-Sp1 signaling pathway. J Biol Chem, 287, 42685-94.

TALARICO, D. \& BASILICO, C. 1991. The K-fgflhst Oncogene Induces Transformation through an Autocrine Mechanism That Requires Extracellular Stimulation of the Mitogenic Pathway. Molecular And Cellular Biology, 11, 1138-1145.

TANAKA, S., KUNATH, T., HADJANTONAKIS, A.-K., NAGY, A. \& ROSSANT, J. 1998. Promotion of Trophoblast Stem Cell Proliferation by FGF4. Science, 282, 2072-2075.

THALHAMMER, A., HANSEN, A. S., EL-SAGHEER, A. H., BROWN, T. \& SCHOFIELD, C. J. 2011. Hydroxylation of methylated $\mathrm{CpG}$ dinucleotides reverses stabilisation of DNA duplexes by cytosine 5-methylation. Chemical Communications, 47, 5325-5327.

THIEL, R., CHAHOUD, I., JÜRGENS, M. \& NEUBERT, D. 1993. Time-dependent differences in the development of somites of four different mouse strains. Teratogenesis, carcinogenesis, and mutagenesis, 13, 247-257.

THORNBURG, K., O'TIERNEY, P. \& LOUEY, S. 2010. The placenta is a programming agent for cardiovascular disease. Placenta, 31, S54-S59.

TOBI, E. W., LUMEY, L., TALENS, R. P., KREMER, D., PUTTER, H., STEIN, A. D., SLAGBOOM, P. E. \& HEIJMANS, B. T. 2009. DNA methylation differences after exposure to prenatal famine are common and timing-and sex-specific. Human molecular genetics, 18, 4046-4053.

TUNSTER, S. J., TYCKO, B. \& JOHN, R. M. 2010. The imprinted Phlda2 gene regulates extraembryonic energy stores. Mol Cell Biol, 30, 295-306.

VAN ABEELEN, A. F., DE ROOIJ, S. R., OSMOND, C., PAINTER, R. C., VEENENDAAL, M. V., BOSSUYT, P. M., ELIAS, S. G., GROBBEE, D. E., VAN DER SCHOUW, Y. T. \& BARKER, D. J. 2011. The 
sex-specific effects of famine on the association between placental size and later hypertension. Placenta, 32, 694-698.

VERGOUW, C. G., KOSTELIJK, E. H., DOEJAAREN, E., HOMPES, P. G., LAMBALK, C. B. \& SCHATS, R. 2012. The influence of the type of embryo culture medium on neonatal birthweight after single embryo transfer in IVF. Human reproduction, des252.

VERMEIDEN, J. P. \& BERNARDUS, R. E. 2013. Are imprinting disorders more prevalent after human in vitro fertilization or intracytoplasmic sperm injection? Fertility and sterility, 99, 642-651.

VISTICA, D. T., SKEHAN, P., SCUDIERO, D., MONKS, A., PITTMAN, A. \& BOYD, M. R. 1991. Tetrazolium-based assays for cellular viability: a critical examination of selected parameters affecting formazan production. Cancer research, 51, 2515-2520.

WAAL, E. D., VROOMAN, L. A., FISCHER, E., ORD, T., MAINIGI, M. A., COUTIFARIS, C., SCHULTZ, R. M. \& BARTOLOMEI, M. S. 2015. The cumulative effect of assisted reproduction procedures on placental development and epigenetic perturbations in a mouse model Hum Mol Genet.

WANG, Y. A., SULLIVAN, E. A., BLACK, D., DEAN, J., BRYANT, J. \& CHAPMAN, M. 2005. Preterm birth and low birth weight after assisted reproductive technology-related pregnancy in Australia between 1996 and 2000. Fertility and sterility, 83, 1650-1658.

WATKINS, A. J., LUCAS, E. S., MARFY-SMITH, S., BATES, N., KIMBER, S. J. \& FLEMING, T. P. 2015. Maternal nutrition modifies trophoblast giant cell phenotype and fetal growth in mice. Reproduction, 149, 563-75.

WATKINS, A. J., LUCAS, E. S., TORRENS, C., CLEAL, J. K., GREEN, L., OSMOND, C., ECKERT, J. J., GRAY, W. P., HANSON, M. A. \& FLEMING, T. P. 2010. Maternal low-protein diet during mouse pre-implantation development induces vascular dysfunction and altered reninangiotensin-system homeostasis in the offspring. Br J Nutr, 103, 1762-70.

WATKINS, A. J., PLATT, D., PAPENBROCK, T., WILKINS, A., ECKERT, J. J., KWONG, W. Y., OSMOND, C., HANSON, M. \& FLEMING, T. P. 2007. Mouse embryo culture induces changes in postnatal phenotype including raised systolic blood pressure. Proc Natl Acad Sci U S A, 104, 5449-54.

WATKINS, A. J., URSELL, E., PANTON, R., PAPENBROCK, T., HOLLIS, L., CUNNINGHAM, C., WILKINS, A., PERRY, V. H., SHETH, B., KWONG, W. Y., ECKERT, J. J., WILD, A. E., HANSON, M. A., OSMOND, C. \& FLEMING, T. P. 2008a. Adaptive responses by mouse early embryos to maternal diet protect fetal growth but predispose to adult onset disease. Biol Reprod, 78, 299-306.

WATKINS, A. J., WILKINS, A., CUNNINGHAM, C., PERRY, V. H., SEET, M. J., OSMOND, C., ECKERT, J. J., TORRENS, C., CAGAMPANG, F. R., CLEAL, J., GRAY, W. P., HANSON, M. A. \& FLEMING, T. P. 2008b. Low protein diet fed exclusively during mouse oocyte maturation leads to behavioural and cardiovascular abnormalities in offspring. J Physiol, 586, 2231-44.

WATSON, A. 2004. Molecular regulation of blastocyst formation. Animal Reproduction Science, 82-83, 583-592.

WATSON, A. J., NATALE, D. R. \& BARCROFT, L. C. 2004. Molecular regulation of blastocyst formation. Anim Reprod Sci, 82-83, 583-92. 
WEN, F., TYNAN, J. A., CECENA, G., WILLIAMS, R., MUNERA, J., MAVROTHALASSITIS, G. \& OSHIMA, R. G. 2007. Ets2 is required for trophoblast stem cell self-renewal. Dev Biol, 312, 284-99.

WILCOX, A. J., BAIRD, D. D. \& WEINBERG, C. R. 1999. Time of implantation of the conceptus and loss of pregnancy. The new england journal of medicine, 340, 1796-1799.

WILLIAMS, R. L., HILTON, D. J., PEASE, S., WILLSON, T. A., STEWART, C. L., GEARING, D. P., WAGNER, E. F., METCALF, D., NICOLA, N. A. \& GOUGH, N. M. 1988. Myeloid leukaemia inhibitory factor maintains the developmental potential of embryonic stem cells. Nature, 336, 684-687.

WINSLOW, T. 2001. In: IMPLANTATION, M. E. O. T. (ed.) http://stemcells.nih.gov/StaticResources/info/scireport/images/figurea3.jpg

XIE, Y., WANG, Y., SUN, T., WANG, F., TROSTINSKAIA, A., PUSCHECK, E. \& RAPPOLEE, D. A. 2005. Six post-implantation lethal knockouts of genes for lipophilic MAPK pathway proteins are expressed in preimplantation mouse embryos and trophoblast stem cells. Mol Reprod Dev, $71,1-11$.

YAN, X., HUANG, Y., ZHAO, J.-X., ROGERS, C. J., ZHU, M.-J., FORD, S. P., NATHANIELSZ, P. W. \& DU, M. 2013. Maternal obesity downregulates microRNA let-7g expression, a possible mechanism for enhanced adipogenesis during ovine fetal skeletal muscle development. International Journal of Obesity, 37, 568-575.

YANG, W., KLAMAN, L. D., CHEN, B., ARAKI, T., HARADA, H., THOMAS, S. M., GEORGE, E. L. \& NEEL, B. G. 2006. An Shp2/SFK/Ras/Erk signaling pathway controls trophoblast stem cell survival. Dev Cell, 10, 317-27.

YING, Q. L., WRAY, J., NICHOLS, J., BATLLE-MORERA, L., DOBLE, B., WOODGETT, J., COHEN, P. \& SMITH, A. 2008. The ground state of embryonic stem cell self-renewal. Nature, 453, 51923.

YOUNG, L. E., SINCLAIR, K. D. \& WILMUT, I. 1998. Large offspring syndrome in cattle and sheep. Reviews of reproduction, 3, 155-163.

ZAKRZEWSKA, M., WIEDLOCHA, A., SZLACHCIC, A., KROWARSCH, D., OTLEWSKI, J. \& OLSNES, S. 2009. Increased protein stability of FGF1 can compensate for its reduced affinity for heparin. Journal of Biological Chemistry, 284, 25388-25403.

ZERNICKA-GOETZ, M. 2005. Cleavage pattern and emerging asymmetry of the mouse embryo. Nature Reviews Molecular Cell Biology, 6, 919-928.

ZHENG, G., MARINO, M., ZHAO, J. \& MCCLUSKEY, R. T. 1998. Megalin (gp330): a putative endocytic receptor for thyroglobulin (Tg). Endocrinology, 139, 1462-1465.

ZHONG, W., SUN, T., WANG, Q. T., WANG, Y., XIE, Y., JOHNSON, A., LEACH, R., PUSCHECK, E. E. \& RAPPOLEE, D. A. 2004. SAPKgamma/JNK1 and SAPKalpha/JNK2 mRNA transcripts are expressed in early gestation human placenta and mouse eggs, preimplantation embryos, and trophoblast stem cells. Fertil Steril, 82 Suppl 3, 1140-8.

ZHOU, D. \& PAN, Y.-X. 2011. Gestational low protein diet selectively induces the amino acid response pathway target genes in the liver of offspring rats through transcription factor binding and histone modifications. Biochimica et Biophysica Acta (BBA)-Gene Regulatory Mechanisms, 1809, 549-556. 
ZHU, G., FEI, T., LI, Z., YAN, X. \& CHEN, Y. G. 2015. Activin Regulates Self-renewal and Differentiation of Trophoblast Stem Cells by Down-regulating the X Chromosome Gene Bcor. J Biol Chem, 290, 22019-29.

ZVETKOVA, I., APEDAILE, A., RAMSAHOYE, B., MERMOUD, J. E., CROMPTON, L. A., JOHN, R., FEIL, R. \& BROCKDORFF, N. 2005. Global hypomethylation of the genome in XX embryonic stem cells. Nature genetics, 37, 1274-1279.

ZYBINA, E. V. \& ZYBINA, T. G. 1996. Polytene chromosomes in mammalian cells. Int Rev Cytol, 165, 53-119. 